TE WHARE WĀNANGA O TE ÜPOKO O TE IKA A MĀUI

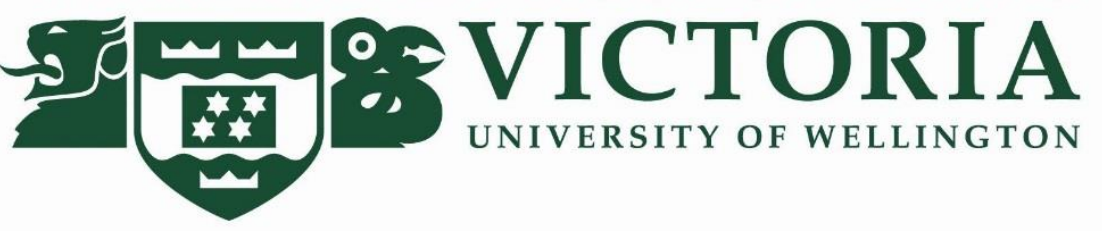

\title{
Pleistocene cyclostratigraphy on the continental rise and abyssal plain of the western Ross Sea, Antarctica.
}

\author{
by
}

Olga Borisovna Albot

\author{
A thesis \\ submitted to Victoria University of Wellington \\ in partial fulfilment of the requirements for the degree of \\ Master of Science \\ in Geology
}

Victoria University of Wellington

Wellington, New Zealand

2016 



\begin{abstract}
This thesis investigates glacimarine sedimentation processes operating on the continental margin of the western Ross Sea during the Pleistocene ( $2.5 \mathrm{Ma})$. This time period is characterised by a major global cooling step at $\sim 0.8 \mathrm{Ma}$, although several proposed episodes of major marine-based Antarctic Ice Sheet (AIS) retreat in warm interglacial periods are inferred to have occurred after this time. Constraining the timing and magnitude of past marine-based AIS retreat events in the Ross Sea through this time will improve our understanding of the forcing mechanisms and thresholds that drive marine-based ice sheet retreat. Identifying such mechanisms and thresholds is crucial for assisting predictive models of potential ice sheet collapse in a future world with rapidly rising atmospheric carbon dioxide $\left(\mathrm{CO}_{2}\right)$ concentrations.
\end{abstract}

Six sedimentary cores forming a north-to-south transect from the continental rise to the abyssal plain of the western Ross Sea were examined in order to identify potential sedimentary signatures of past marine-based ice sheet variability and associated oceanographic change. A lithofacies scheme and stratigraphic framework were developed, which allowed the identification of shifting sedimentary processes through time. The sediments are interpreted to have been deposited primarily under the influence of bottom currents, most likely from changing rates of dense Antarctic Bottom Water (AABW) formation over glacial-interglacial cycles. Two dominant lithofacies (laminated and bioturbated) are recognised in the Pleistocene contourite sequences. Laminated facies alongside reduced ice-rafted debris (IRD) fluxes and reduced biological productivity are interpreted to represent expanded ice sheet and sea ice margins during glacial conditions, which acted to restrict surface water ventilation resulting in less oxygenated bottom waters. Conversely, laminated facies alongside reduced IRD fluxes and increased productivity are inferred to represent a reduction of ice shelf and sea ice cover resulting in enhanced AABW formation and sediment delivery. In general, it is interpreted that bioturbated facies in combination with enhanced productivity are common during interglacial conditions, with peaks in IRD associated with ice sheet retreat events leading into interglacial conditions. However, the relationships between laminated and bioturbated facies vary between sites, and facies at most sites generally alternate on timescales exceeding that of individual glacial-interglacial cycles $(<100$ kyr). Nonetheless, there are clear baseline shifts in the facies distributions through time across the sites, and it is inferred these represent step-like shifts in the ice sheet volume and sea ice processes on the continental shelf and above the study sites during the Pleistocene. 
This thesis also assesses and compares three independent methodologies of obtaining IRD mass accumulation rates (MARs). The three methodologies include counting clasts $>2 \mathrm{~mm}$ in $\mathrm{x}$-ray images, the sieved weight percentage of the medium-to-coarse sand fraction ( $250 \mu \mathrm{m}-2 \mathrm{~mm}$ ), and volumetric estimates of the $>125 \mu \mathrm{m}$ sand fraction using a laser particle sizer. The $x$-ray and sieve methods produced comparable results, while the volumetric estimate, although showing comparable long-term trends, produces a lesser correlation to the other two methods.

Spectral analysis of the IRD content and the magnetic susceptibility data series reveals that during the Early Pleistocene (2.5-1.2 Ma) ice discharge into the western Ross Sea was paced by the 41 kyr and 100 kyr cycles of obliquity and eccentricity, respectively. The Mid-Pleistocene Transition (MPT; 1.2-0.8 Ma) was characterised by a switch to a higher-frequency, lower-amplitude IRD flux during a long-term period of high power in eccentricity, obliquity and precession ( $23 \mathrm{kyr}$ ) observed in the orbital solutions, suggesting a relatively linear response to orbital forcing at this time. The colder climate state of the Late Pleistocene (0.8-0.01 Ma) is characterised by IRD fluctuations modulated primarily by the 100 kyr eccentricity forcing that became dominant by 400 ka. In the western Ross Sea, IRD fluxes show a clear response to the orbital pacing of glacialinterglacial cycles, but are equivocal in identifying the magnitude of ice sheet loss or growth through glacial-interglacial cycles. 


\section{Acknowledgements}

I would like to thank many people who have helped me during this work. First and foremost, a huge thank you to my supervisors Rob McKay and Gavin Dunbar for all your support and guidance throughout this project. I feel very lucky to have got a chance to travel to Antarctica and Korea to conduct research, and thoroughly enjoyed the experience. Thank you also to Kyu-Cheul Yoo, Jae II Lee, Min Kyung and Sunghan Kim from the Korea Polar Research Institute, and Richard Levy from GNS, this project would not have been possible without your contribution.

A big thank you to Jane Chewings for all the help with my laboratory work and Peppe Cortese for providing helpful tips and expertise regarding map making. Thank you especially to Juliet Sefton and Georgia Grant for running my stable isotope samples.

I would like to acknowledge the Rutherford Discovery Fellowship for granting Rob McKay funding for this project and Victoria University of Wellington for granting me the Victoria Graduate and the Victoria Master's by thesis scholarships.

I am very grateful to my family and friends for supporting me during all my years as a student, even when I was a hermit and didn't leave my room for weeks. Many thanks to Anya, Christoph, Bryn, Agustin and Vanisha for their thorough editing of my thesis. Most of all, thank you Hubert for your unwavering love and support (and proof reading, helping with everything computerrelated... the list goes on). Thank you to all the SGEES and ARC staff who have supported me during my time as an undergraduate and postgraduate student at Victoria University. 


\section{Table of Contents}

CHAPTER 1: INTRODUCTION 1

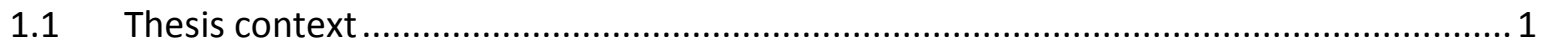

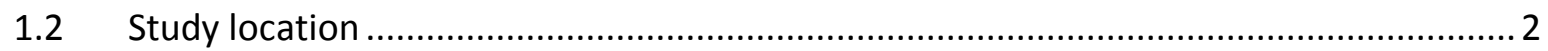

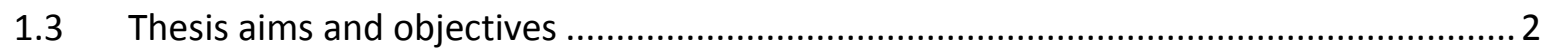

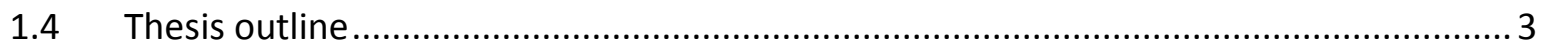

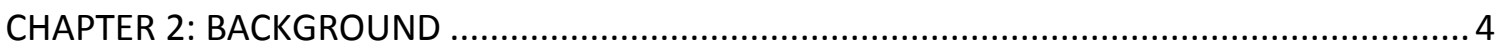

2.1 Antarctic Ice Sheet history from proximal and far-field sedimentary records and climate models

2.1.1 Cenozoic cooling and initiation of Antarctic Ice Sheets ...................................... 5

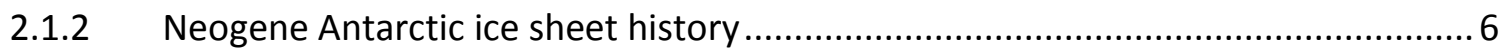

2.1.3 Plio-Pleistocene cooling and the onset of Northern Hemisphere glaciation ........... 7

2.1.4 Present-day change and future response of the WAIS to global change.

2.2 External and internal drivers of climate change: Orbital cycles and the global carbon cycle. .10

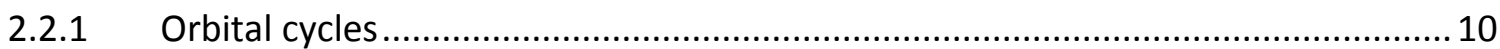

2.2.2 Internal drivers of climate change: The global carbon cycle ................................ 11

2.3 Depositional processes and depositional facies models in continental

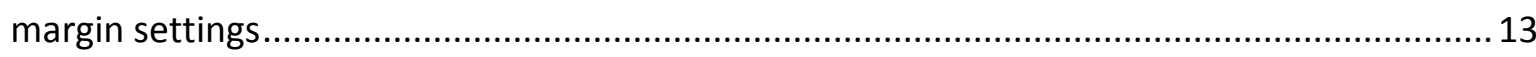

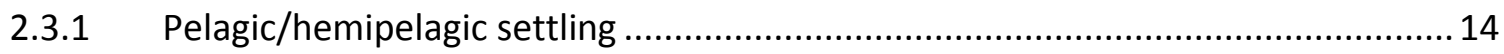

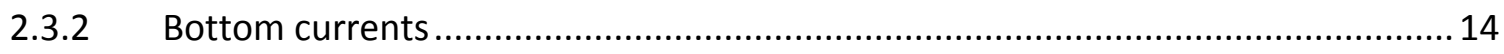

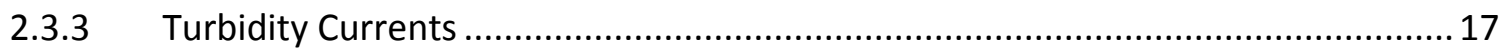

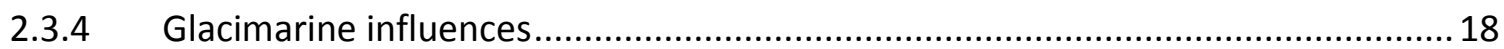

2.3.5 Previous work on the Antarctic continental margin ............................................ 19

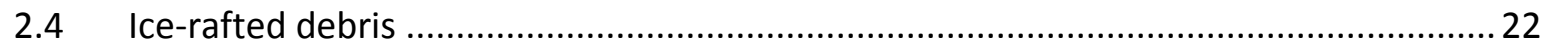

2.4.1 The use of ice-rafted debris as proxy for dynamic ice sheet discharge in the Northern Hemisphere 
2.4.2 Antarctic ice-rafted debris records and paleoenvironmental implications

2.4.3 Physical controls on ice-rafted debris deposition .................................................. 23

2.4.4 Issues with the interpretations of ice-rafted debris records ...............................23

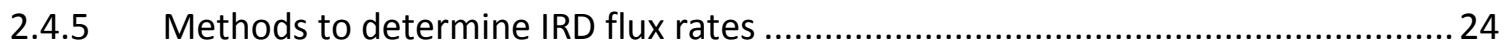

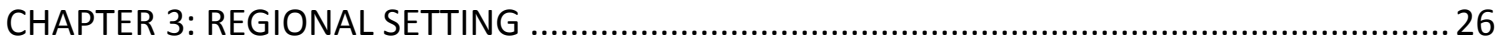

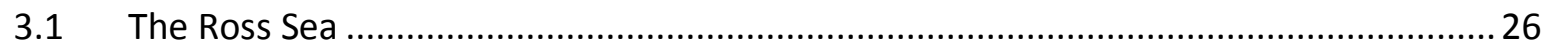

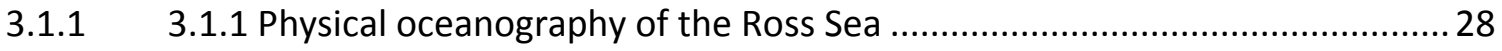

3.1.2 Oceanographic changes in the Ross Sea during the observational period (1958 to present)...

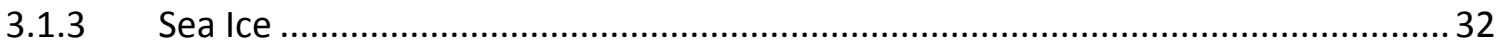

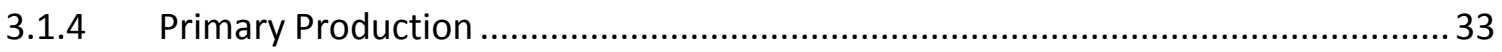

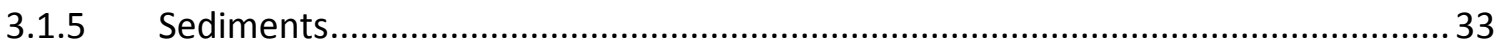

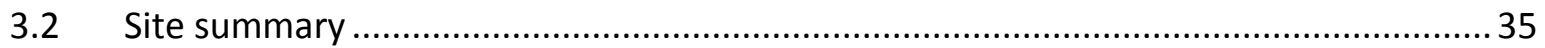

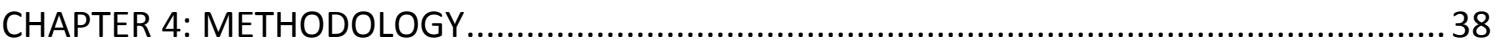

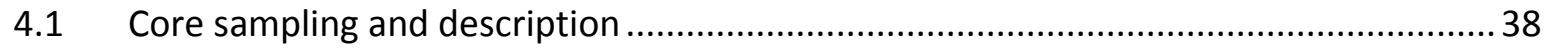

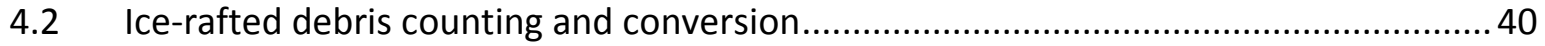

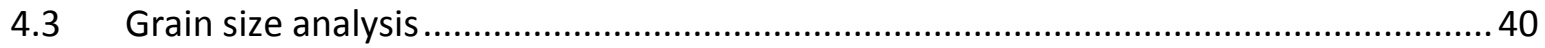

4.3.1 Ice-rafted debris determined by weight percentages ......................................... 40

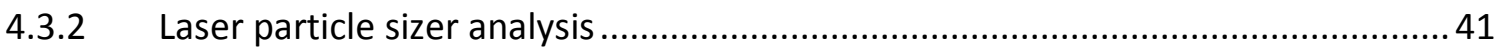

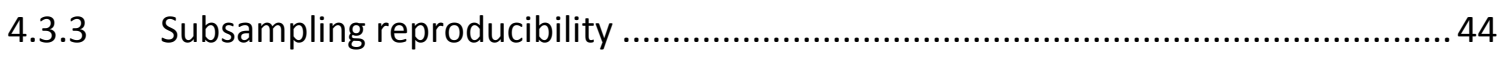

4.4 Scanning Electron Microscope imaging of the biogenic component .............................51

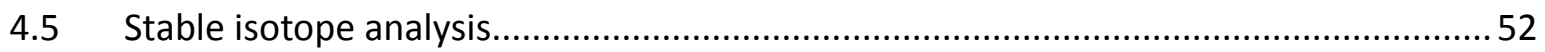

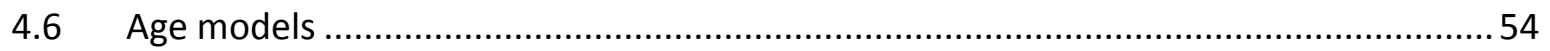

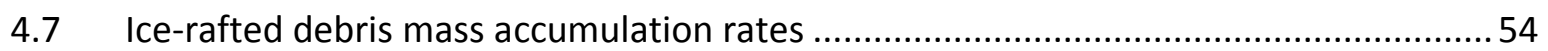

4.7.1 Ice-rafted debris mass accumulation rates for the $250 \mu \mathrm{m}-2 \mathrm{~mm}$ fraction. ...........54

4.7.2 Ice-rafted debris mass accumulation rates using $>125 \mu \mathrm{m}$ from bulk particle size analysis. 


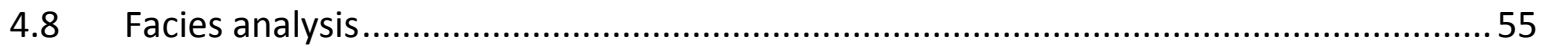

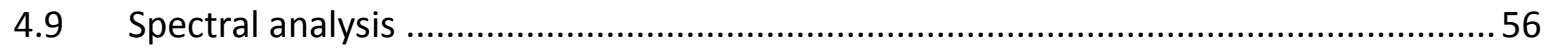

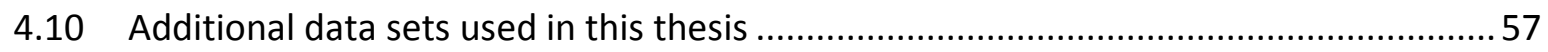

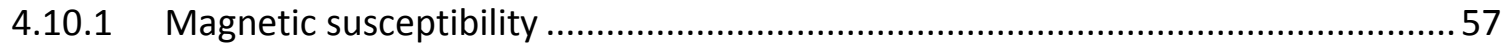

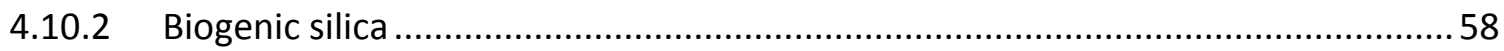

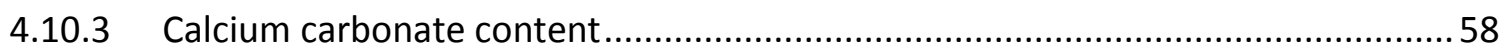

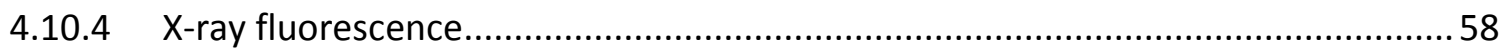

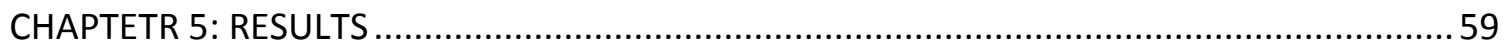

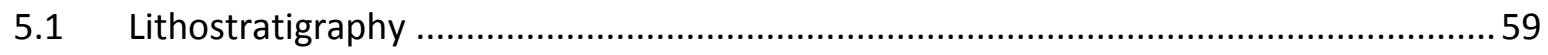

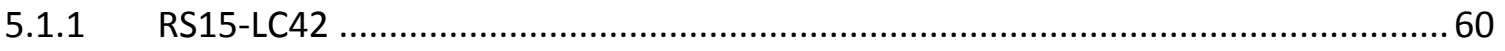

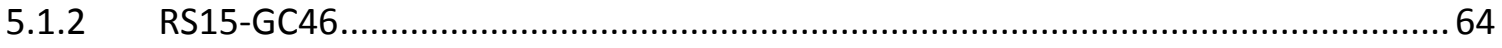

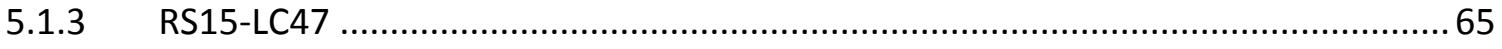

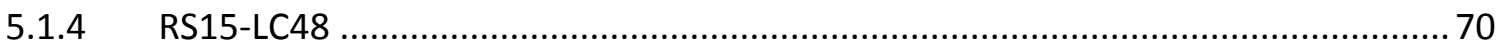

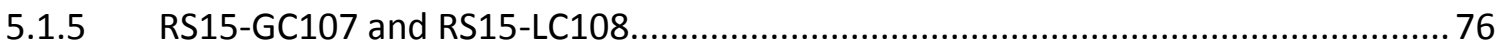

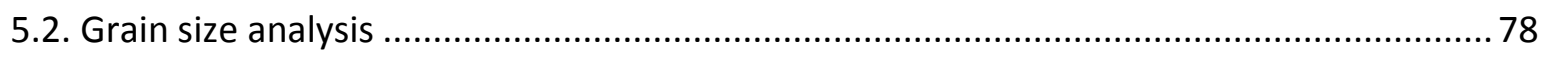

5.2.1 Grain size frequency distributions of the non-gravel fraction ............................. 78

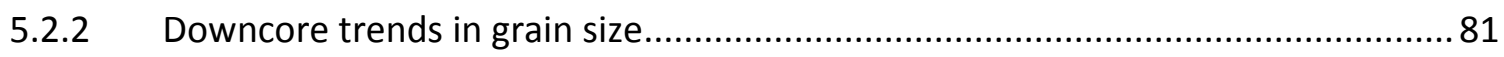

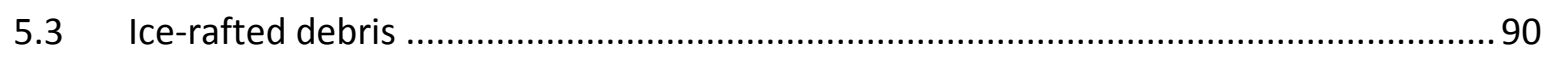

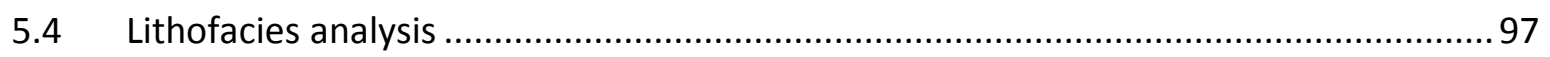

5.4.1 Lithofacies descriptions and preliminary interpretations................................. 98

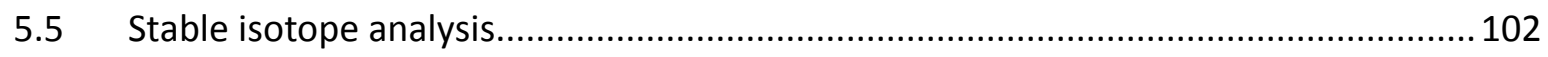

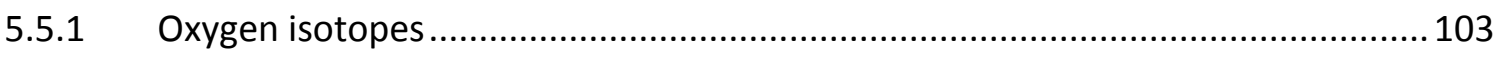

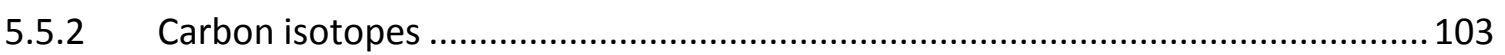

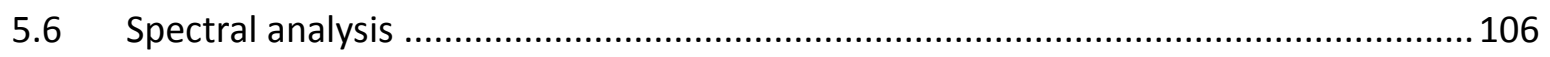

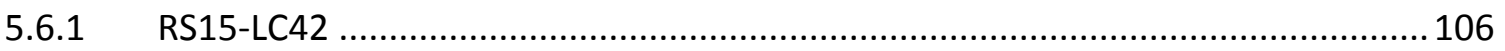

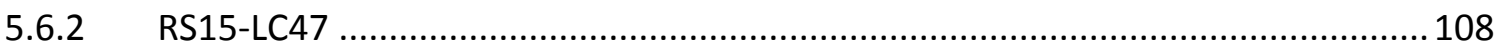

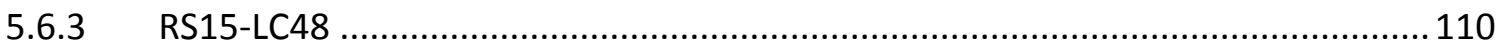




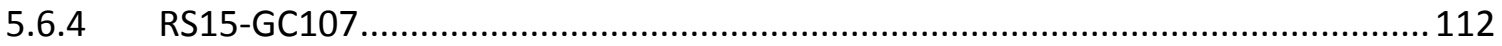

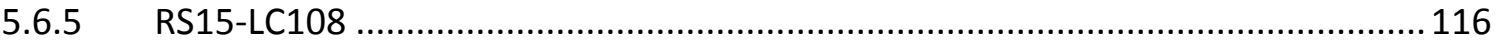

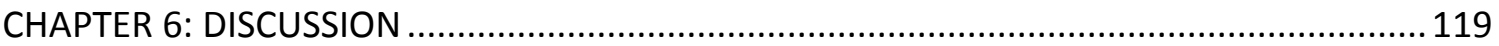

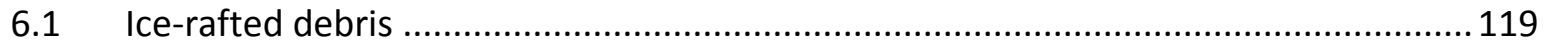

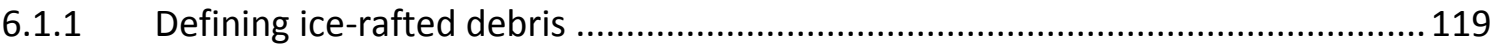

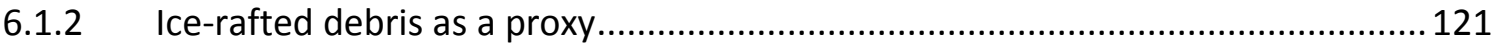

6.1.3 Ice-rafted debris mass accumulation rates versus lag deposits .........................123

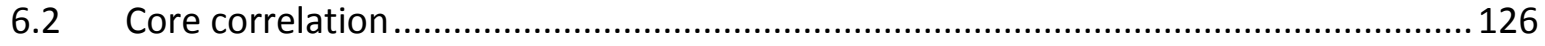

6.3 Environmental interpretation of stable isotopes ...................................................131

6.3.1 Foraminifera $\delta^{18} \mathrm{O}$ and paleotemperature estimates ......................................134

6.3.2 Foraminifera $\delta^{13} \mathrm{C}$ and paleoproductivity proxies............................................

6.4 Depositional patterns and associated climate changes during the Quaternary ..........138

6.4.1 Pre-Mid Pleistocene Transition (2.5-1.2 Ma) .................................................. 138

6.4.2 The Mid-Pleistocene Transition (1.2-0.8 Ma) ................................................ 140

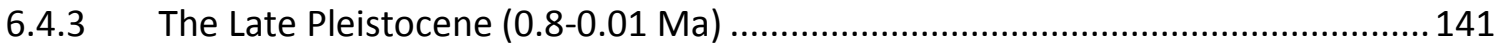

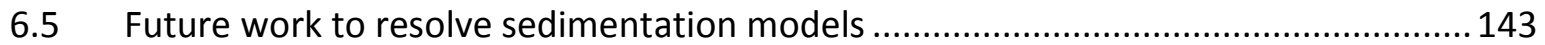

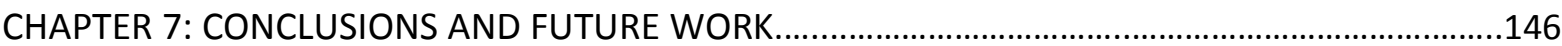

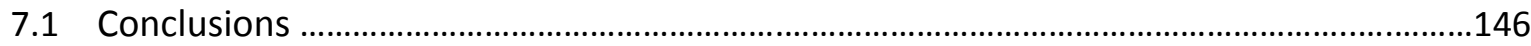

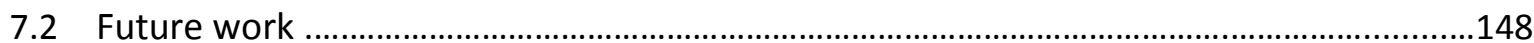

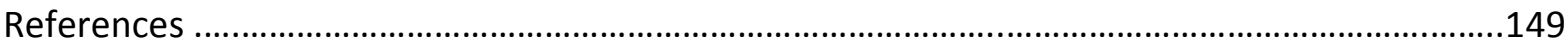

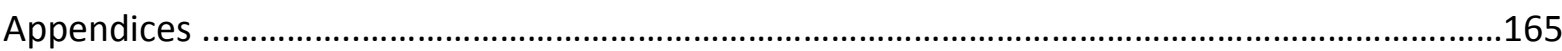




\section{List of Figures}

Figure 2.1: Reconstruction of Cenozoic climate.

Figure 2.2: Illustrated cross-section (B-B') through the WAIS.

Figure 2.3: Schematic diagram illustrating the orbital cycles of eccentricity, obliquity and axial precession. 11

Figure 2.4: Schematic diagram of the ocean's biological pump.

Figure 2.5: Conceptual diagram illustrating the three main sedimentary depositional processes operating in the deep sea and the facies models of the respective depositional models. .13

Figure 2.6: Facies model for contourite sequences. 16

Figure 2.7: Variations on the standard contourite facies models.

Figure 3.1: Map of the Antarctic continent and detailed bathymetry of the Ross Sea continental margin.

Figure 3.2: Seismic line IT91A88 showing contourite drifts at site RS15-LC42 .28

Figure 3.3: Map of the Ross Sea continental shelf highlighting major circulation features and conditions observed during the past 50 years.

Figure 3.4: Global thermohaline circulation highlighting AABW formation at its southern limb.

Figure 3.5: Hypothesised intensification of Antarctic Slope Current leading to an alternative mode of deep ocean ventilation during the next century.

Figure 3.6: 3D map of the Ross Sea continental margin showing the major bathymetric features and oceanic circulation. 36

Figure 3.7: Map of modern iceberg tracks, summer net primary productivity and summer SSTs.

Figure 4.1: Classification schemes for fine-grained terrigenous clastic sediments and poorly sorted terrigenous clastic sediments containing gravel.

Figure 4.2: X-ray image (RS15-LC42, $188.5-218.5 \mathrm{cmbsf}$ ) with selected IRD clasts $>2 \mathrm{~mm}$ in diameter.

Figure 4.3: Images of untreated, $0.2 \mathrm{M} \mathrm{NaOH}$ treated, and $1 \mathrm{M} \mathrm{NaOH}$ treated subsamples for cores RS15-LC42 and RS15-LC48.

Figure 4.4: Grain size curves for three representative samples from core RS15-LC48 that were treated with $0.2 \mathrm{M} \mathrm{NaOH}$ and $1 \mathrm{M} \mathrm{NaOH}$ solutions. 
Figure 4.5: Grain size curves of four IRD-rich and laminated samples that were subsampled from RS15-LC42 and RS15-LC48 and measured three times on an LPSA.

Figure 4.6: Grain size curves of four IRD-free samples that were subsampled from RS15-LC42 and RS15-LC48, and measured three times on an LPSA. 46

Figure 4.7: Grain size curves of the normalised clay and silt (mud) fractions of two IRD-rich samples from RS15-LC48.

Figure 4.8: Comparison of the mud content of the original (Subsample 1) and repeat (Subsample

2) measurements on an LPSA for RS15-LC42 and RS15-LC48.

Figure 4.9: Comparison of the IRD component of sediments of the original (Subsample 1) and repeat (Subsample 2) measurements on an LPSA for RS15-LC42 and RS15-LC48.

Figure 4.10: Comparison of the clay\%, silt\% and sand\% for RS15-LC48 and RS15-LC42 as measured by the sedigraph at KOPRI versus LPSA measurements at VUW with a clay cut-off at $8 \mu \mathrm{m} . . . . . . .50$

Figure 4.12: SEM images of $1 \mathrm{M} \mathrm{NaOH}$ treatment and $0.2 \mathrm{M} \mathrm{NaOH}$ treatments. .............................51

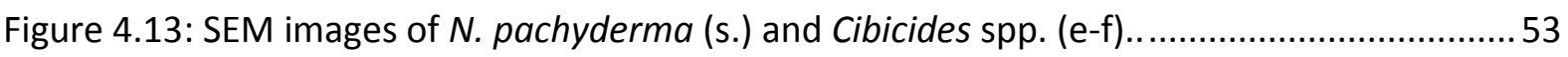

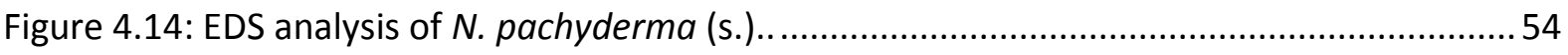

Figure 5.1: Representative x-ray images and photographs of RS15-LC42 unit 1. .......................61

Figure 5.2: Representative x-ray images and photographs of RS15-LC42 unit 2. .......................62

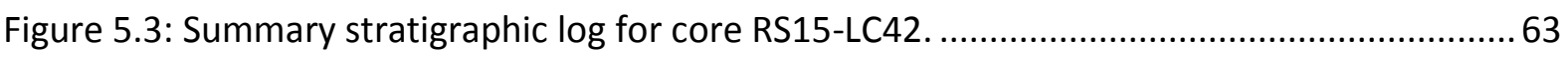

Figure 5.4: Representative x-ray images and photographs of RS15-GC46 unit 1.........................64

Figure 5.5: Summary stratigraphic log for core RS15-GC46................................................... 65

Figure 5.6: Representative x-ray image and photograph of RS15-LC47 unit 1............................66

Figure 5.7: Representative x-ray image and photograph of RS15-LC47 unit 2 2............................67

Figure 5.8: Representative x-ray images and photographs of RS15-LC47 unit 3. .......................68

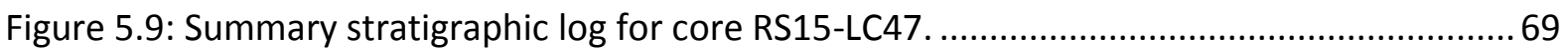

Figure 5.10: Representative x-ray images and photographs of RS15-LC48 unit 1. .........................71

Figure 5.11: Representative x-ray image and photograph of RS15-LC48 unit 2. ............................72

Figure 5.12: Representative x-ray images and photographs of RS15-LC48 unit 3. ........................73

Figure 5.13: Summarised stratigraphic log for core RS15-LC48. ............................................. 76

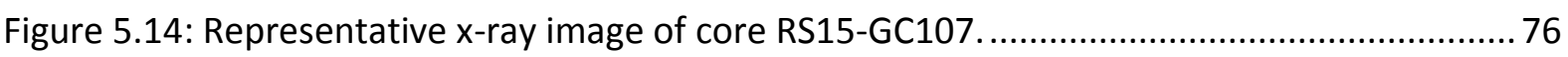

Figure 5.15 Representative $x$-ray images of core RS15-LC108:. ................................................. 77

Figure 5.16: Depth distribution of the gravel count for core RS15-GC107................................. 77

Figure 5.17: Depth distribution of the gravel count for core RS15-LC108. ................................. 78 
Figure 5.18: Grain size distributions for cores RS15-LC42 and RS15-LC48 .............................. 80

Figure 5.19: Depth distribution of the physical properties in core RS15-LC42 ........................... 83

Figure 5.20: Least square regression analysis of sand\% versus mean grain size and sorting for core RS15-LC42. .84

Figure 5.21: Depth distribution of the physical properties in core RS15-GC46. .85

Figure 5.22: Least square regression analysis of sand\% versus mean grain size and sorting, and silt\% versus mean grain size for core RS15-GC46. 86

Figure 5.23: Depth distribution of the physical properties in core RS15-LC47. .87

Figure 5.24: Least square regression analysis of sand\% versus mean grain size and sorting, and silt\% versus sorting for core RS15-LC47. .88

Figure 5.25: Depth distribution of the physical proprties in core RS15-LC48. .89

Figure 5.26: Least square regression analysis of sand\% versus mean grain size and sorting for core RS15-LC48. .90

Figure 5.27: Least square regression analyses of sorting versus gravel counts for cores RS15-LC42, RS15-GC46, RS15-LC-47, and RS15-LC48.

Figure 5.28: IRD MARs determined by LPSA and sieve measurements versus sorting for cores RS15-LC42 and RS15-LC48.

Figure 5.29: Cross correlation plots with the least square regression model for core RS15-LC42 of IRD MARs estimated from sieve and LPSA analysis versus gravel counts. .95 Figure 5.30: Cross correlation plots with the least square regression model for core RS15-LC48 of IRD MARs estimated from sieve and LPSA analysis versus gravel counts. 96 Figure 5.31: Ternary diagrams for RS15-LC42, RS15-GC46, RS15-LC47 and RS15-LC48 displaying textural variability between bioturbated and laminated lithofacies. .98 Figure 5.32: Photograph, $x$-ray image, and grain size frequency distributions of laminated lithofacies in cores RS15-LC48 and RS15-LC42. 100 Figure 5.33: Photograph, x-ray image, and grain size frequency distributions of bioturbated lithofacies in cores RS15-LC48 and RS15-LC42. 101 Figure 5.34: Photograph, $x$-ray image, and grain size frequency distributions of bioturbated lithofacies in cores RS15-LC48 and RS15-LC42. 102

Figure 5.35: Spectral analyses results for core RS15-LC42.. 107

Figure 5.36: Spectral analyses results for core RS15-LC47. 109

Figure 5.37: Spectral analyses results for core RS15-LC48. 111

Figure 5.38: Spectral analyses results for core RS15-GC107. 114 
Figure 5.39: ASM results for core RS15-GC107.

Figure 5.40: Spectral analyses results for core RS15-LC108

Figure 5.41: ASM results for core RS15-LC108

Figure 6.1: RS15-LC48 and RS15-LC42 IRD MARs $(250 \mu \mathrm{m}-2 \mathrm{~mm})$ compared to bulk sorting of terrigenous material.

Figure 6.2: RS15-LC48 and RS15-LC42 IRD MARs (>125 $\mu \mathrm{m})$ compared to sorting of the $<125 \mu \mathrm{m}$ grain size fraction. 125

Figure 6.3: Core-to-core correlation of the physical and geochemical properties of sediments.

Figure 6.4: Spectral analyses and depth-time series for cores RS15-LC48, RS15-LC108 and PS58/254 from the Amundsen Sea.

Figure 6.5: Stable isotope results and paleoproductivity proxies for cores RS15-LC42 and RS15LC48.

Figure 6.6: Schematic diagram illustrating the interpreted interglacial and glacial climate stages influence on sedimentation at the study sites. 145

\section{List of Tables}

Table 2.1: Continental slope and rise lithofacies characteristics, glacimarine sedimentary processes and associated climate regime on the Antarctic continental margin. .21

Table 4.1: Location and details of the retrieved sediment cores. .39

Table 5.1: Summary of the identified lithofacies, their sedimentary structures and preliminary interpretations.

Table 5.2: N. pachyderma (s.) and Cibicides spp. $\delta^{18} \mathrm{O}$ and $\delta^{13} \mathrm{C}$ results for cores RS15-LC42 and RS15-LC48. 105

Table 6.1: Sand\% vs mud\% as measured by the LPSA vs sedigraph for depth intervals showing significantly smaller IRD MARs calculated from sieve analysis.

Table 6.2: Comparison of IRD MARs for depth intervals showing significantly smaller IRD MARs calculated from sieve analysis.

Table 6.3: $N$. pachyderma (s.) $\delta^{18} \mathrm{O}$ and paleotemperature estimates using the equation of Shackleton (1974) 


\section{Abbreviation Index}

\section{Text Abbreviations}

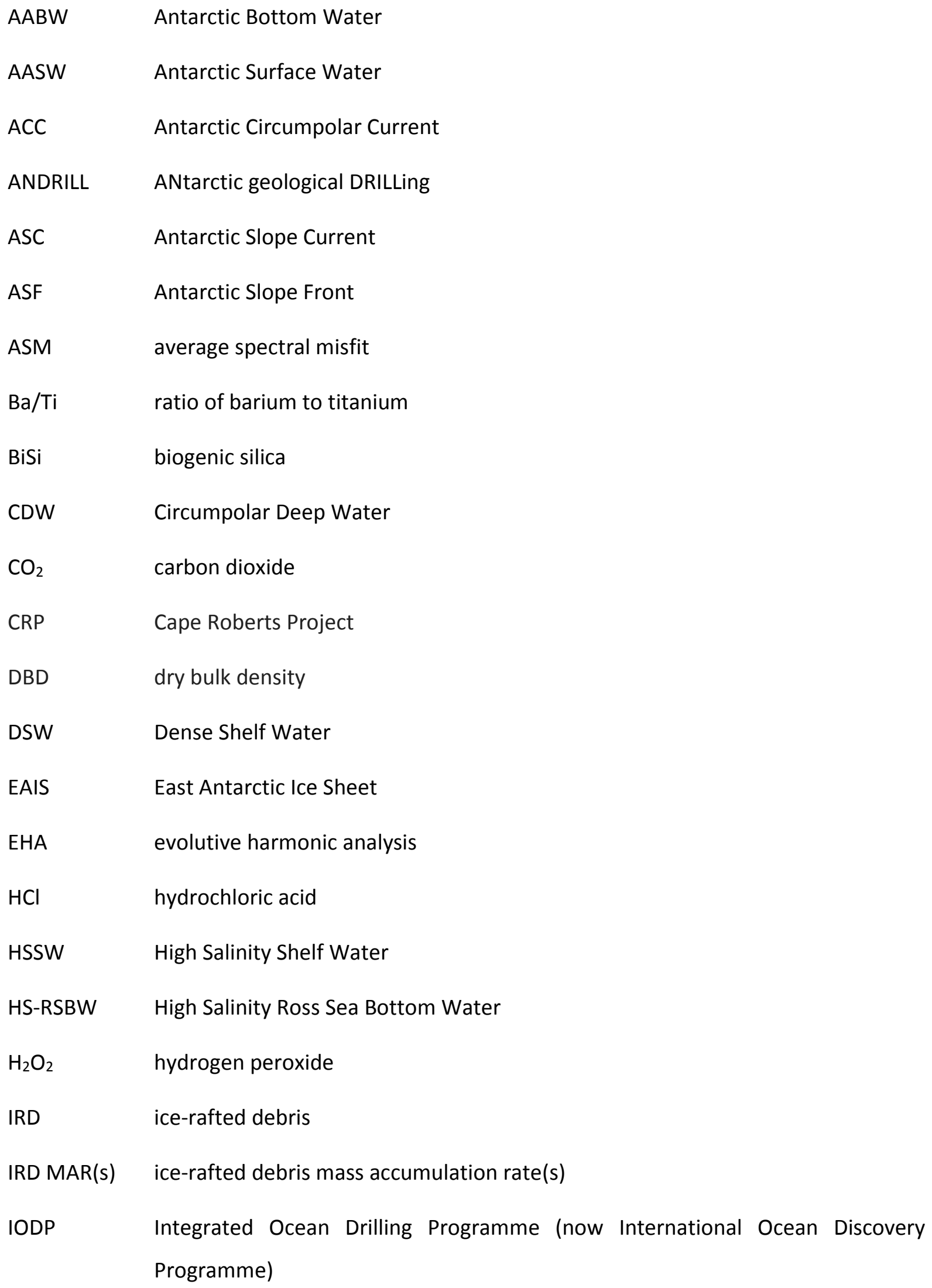




\begin{tabular}{|c|c|}
\hline ISW & Ice Shelf Water \\
\hline KOPRI & Korea Polar Research Institute \\
\hline LDI & long chain diol index \\
\hline LGM & Last Glacial Maximum \\
\hline LS-RSBW & Low Salinity Ross Sea Bottom Water \\
\hline LPSA & laser particle sizer analyser \\
\hline LSR & linear sedimentation rate \\
\hline $\operatorname{MAR}(s)$ & mass accumulation rate(s) \\
\hline MCDW & Modified Circumpolar Deep Water \\
\hline $\mathrm{Mg} / \mathrm{Ca}$ & ratio of magnesium to calcium \\
\hline MIS & Marine Isotope Stage \\
\hline MTM & Multi-Taper Method \\
\hline NADW & North Atlantic Deep Water \\
\hline $\mathrm{NaOH}$ & sodium hydroxide \\
\hline RIS & Ross Ice Shelf \\
\hline $\mathrm{SST}(\mathrm{s})$ & sea surface temperature(s) \\
\hline VUW & Victoria University of Wellington \\
\hline WAIS & West Antarctic Ice Sheet \\
\hline XRF & X-ray fluorescence \\
\hline $\mathrm{TEX}_{86}$ & tetraether lipid-based paleothermometer \\
\hline$\delta^{13} \mathrm{C}$ & ratio of carbon-13 to carbon-12 \\
\hline$\delta^{18} \mathrm{O}$ & ratio of oxygen-18 to oxygen-16 \\
\hline CS\% & percentage of medium-to-coarse sand \\
\hline
\end{tabular}

\section{Units of Measurement}




\begin{tabular}{|c|c|}
\hline${ }^{\circ} \mathrm{C}$ & $\begin{array}{l}\text { degrees Celsius; unit of temperature, the freezing point of } \\
\text { atmosphere is } 0^{\circ} \mathrm{C}=-273.15^{\circ} \mathrm{K}\end{array}$ \\
\hline $\mathrm{cm}$ & centimeter; unit of length, equivalent to one hundredth of a meter \\
\hline cmbsf & centimetres below sea floor \\
\hline $\mathrm{cm} / \mathrm{kyr}$ & centimeter per thousand years \\
\hline $\mathrm{cms}^{-1}$ & centimeters per second \\
\hline g & gram; unit of mass, equivalent to one thousandth of a kilogram \\
\hline $\mathrm{g} / \mathrm{cm}^{2} / \mathrm{kyr}$ & grams per centimeter squared per thousand year \\
\hline $\mathrm{g} / \mathrm{cm}^{3}$ & grams per centimeter cubed \\
\hline $\mathrm{ka} / \mathrm{kyr}$ & thousands of years before present/thousand years (duration) \\
\hline $\mathrm{km}$ & kilometer; unit of length, equivalent to one thousand meters \\
\hline $\mathrm{km}^{2}$ & kilometers squared; measure of surface area \\
\hline kV & kilovolt \\
\hline $\mathrm{m}$ & meter; base in the International System of Units (SI) units of length \\
\hline $\mathrm{m} / \mathrm{myr}$ & meters per millions years \\
\hline M & molar concentration defined as $\mathrm{mol} / \mathrm{L}$ \\
\hline $\mathrm{Ma} / \mathrm{myr}$ & millions of years before present/millions of years (duration) \\
\hline mbsf & meters below sea floor \\
\hline $\mathrm{mL}$ & milliliter; unit of volume, equivalent to one cubic centimeter \\
\hline $\mathrm{mm}$ & millimeter; unit of length, equivalent to one thousandth of a meter \\
\hline $\mathrm{ms}^{-1}$ & meters per second \\
\hline rpm & revolutions per minute \\
\hline$\mu \mathrm{m}$ & micron; unit of length, equivalent to one millionth of a meter \\
\hline$\mu \mathrm{A}$ & microampere \\
\hline
\end{tabular}




\section{CHAPTER 1: INTRODUCTION}

\subsection{Thesis context}

The West Antarctic Ice Sheet (WAIS) is largely grounded below sea level on an overdeepened continental shelf bathymetry (see 2.1.4) and is believed to be susceptible to marine ice sheet instability processes, both in the past and the future (Thomas and Bentley, 1978; Mercer, 1978). For example, over the past two decades, thinning of buttressing ice shelves has resulted in the retreat of the grounding line of the WAIS in the Amundsen Sea region (Pritchard et al., 2009; Joughin et al., 2014; Rignot et al., 2014). Ice shelf thinning in this region has been attributed to basal melting resulting from incursions of relatively warm Circumpolar Deep Water (CDW) onto the Antarctic continental shelves (Jacobs et al., 2011). West of the Amundsen Sea, surface waters in the Ross Sea have experienced significant freshening, partially as a consequence of increased meltwater input from the Amundsen Sea, and this is proposed to have resulted in a decrease of AABW formation over the past 50 years (Jacobs et al., 2002; Rintoul, 2007).

Paleoclimate reconstructions based on marine sediments and coupled ice sheet/ice shelf models suggest that the Ross Ice Shelf (RIS) and the WAIS collapsed during the Middle Pliocene and Early Pleistocene Epochs, when global temperatures and sea levels were higher than present and atmospheric $\mathrm{CO}_{2}$ concentrations were $\sim 400$ ppm (Naish et al., 2009; Pollard and DeConto, 2009). Collapse of the WAIS during the Late Pleistocene has also been proposed from far-field sea level records (Kopp et al., 2009), but direct evidence of this from Antarctica remains equivocal (Scherer et al., 1998; Mckay et al., 2012b). With present day $\mathrm{CO}_{2}$ concentrations already exceeding $\sim 400$ ppm and increasing air temperatures over Antarctica $\left(\sim 3^{\circ} \mathrm{C}\right.$ by 2100 ; Bracegirdle and Stephenson, 2012), understanding past ice sheet instability under a range of climate scenarios, particularly its vulnerability to ocean-induced melting, is critical for predicting the response of the WAIS in a warming climate.

Sedimentary records around the Antarctic continental margin enable a direct examination of past ice sheet behavior, but sediment records on the continental shelf are often glacially eroded and thus discontinuous in time (Wise, 2000; McKay et al., 2016a). However, sediment sequences on the continental rise, provide a less direct, but more complete record of paleoceanographic response to changes in regional ice sheet dynamics. Thus, well-dated high-resolution records of paleoceanographic change are key to understanding both oceanic drivers of marine ice sheet retreat, and the oceanographic response to ice sheet variability through time. Such data will 
provide context for the recently observed changes and provide critical constraints for atmosphere-ocean-ice sheet interactions for numerical modelling of future projections.

IRD records provide direct physical evidence of iceberg calving events along the marine margins of ice sheets, which are related to the release of ice from fast-flowing outlet glaciers and ice streams (Depoorter et al., 2013). Consequently, numerous studies on Antarctic continental margin sediments have employed IRD records as proxies of ice sheet stability (e.g., Williams et al., 2010; Passchier, 2011; Patterson et al., 2014). This thesis aims to critically assess three key methods used to quantify IRD. This follows a recent series of studies on the Wilkes Land IRD records for sites U1361 (Patterson et al., 2014) and U1359 (Hansen et al., 2015). The two publications were conflicting in regards to the orbital pacing of ice sheets, and raise questions over the use of different methodologies to determine IRD. As these studies used two different methods to derive the IRD content, weight percentage of medium-to-coarse sand ( $250 \mu \mathrm{m}-2 \mathrm{~mm}$ ) (Patterson et al., 2014) and volume percentage of the $>125 \mu \mathrm{m}$ grain size fraction measured on a laser particle sizer analyser (LPSA; Hansen et al., 2015), the reproducibility of both methods is tested in this thesis, alongside a third method of counting $>2 \mathrm{~mm}$ particles on $\mathrm{x}$-radiographs from the core face (e.g., Weber et al., 2014).

\subsection{Study location}

Four gravity cores from the mid-to-lower continental rise (RS15-LC42, RS15-GC46, RS15-LC47, RS15-LC48), and two gravity cores from the abyssal plain (RS15-GC107 and RS15-LC108) were retrieved from the western Ross Sea (Figure 3.1) during the austral summer of 2014/15 by the Korea Polar Research Institute (KOPRI) Icebreaker R/V ARAON as part of cruise RS15. Previous seismic work has shown the presence of thick wavy sediment deposits on the continental rise of the Central Basin, indicating preservation of thick contourite drifts under the Antarctic Slope Current (ASC; Figure 3.2; McKay et al., 2016b). These sites are thus in an ideal location to assess WAIS response to oceanographic changes, as they are not subject to glacial erosion, yet are proximal enough to record a direct signal of ice sheet dynamics. The sites on the mid-to-lower continental rise are also directly influenced by upwelling of CDW, and outflow of newly formed AABW.

\subsection{Thesis aims and objectives}

The overarching aim of this thesis is to assess if coherent patterns of sedimentation can be identified through Pleistocene glacial-interglacial cycles at the continental margin of the western 
Ross Sea. In this context, a preliminary offshore depositional model is developed, but additional proxies are required to fully develop this model and its associated ice sheet history. To achieve this aim, several objectives are outlined below:

1) Investigate differences and uncertainties between various methods used to obtain IRD records.

2) Define relationships between IRD, sediment core lithofacies, physical and geochemical properties of sediments to assess environmental change.

3) Conduct time-series analysis on the IRD and physical properties of these cores to assess if orbitally-paced oceanographic and glacial processes are influencing sedimentation on the continental margin of the western Ross Sea throughout the Pleistocene.

The preliminary lithofacies scheme, depositional models and cyclostratigraphy developed in this thesis will assist in identifying which depositional settings on this part of the Antarctic continental margin are best suited for deeper geological drilling during the upcoming IODP Expedition 374 to the Ross Sea, which aims to recover a history of ocean-ice sheet interactions over the past 20 million years.

\subsection{Thesis outline}

This thesis comprises seven chapters. Chapter 1 outlines the context and motivation behind this study, its aims and objectives. Chapter 2 is a comprehensive literature review of the climate history of Antarctica, with emphasis placed on the Pliocene-Pleistocene, and high-latitude continental margin sedimentation. Chapter 3 provides a detailed overview of the regional setting. Chapter 4 outlines the methodology employed to assess the sedimentation processes operating on the continental margin of the western Ross Sea. The results of grain size, IRD, and facies analyses are detailed in Chapter 5. Chapter 6 discusses the interpretation of these results in the context of sedimentation processes and depositional environments under oceanographic and glacial influences. This chapter also provides preliminary sedimentation models for the continental margin of the western Ross Sea for the Pleistocene. Chapter 7 outlines the main conclusions and synthesis of this study. 


\section{CHAPTER 2: BACKGROUND}

The slope to rise of the Ross Sea continental margin is a poorly-explored area where sedimentary processes and depositional systems are poorly constrained. Sedimentation at the continental margin of the Ross Sea sector of Antarctica is likely to be heavily influenced by both ice and oceanographic depositional processes. This chapter provides a literature review of the climate history of Antarctica, with a focus on the evolution of the marine-based WAIS, in the context of broader global change during the Pliocene and Pleistocene epochs. It also reviews the relevant depositional models for continental margins from Antarctica and other regions globally.

2.1 Antarctic Ice Sheet history from proximal and far-field sedimentary records and climate models

Deciphering the history of the AIS(s) is a difficult task because geological evidence in proximal marine records is often lacking as a consequence of erosion during repeated advances of the ice sheet, and more distal deep sea records are often ambiguous (Wise, 2000; McKay et al., 2016a). Consequently, much of our direct knowledge of AIS behaviour comes from the analyses of marine sediments uplifted and preserved on the Antarctic continental margin, the surrounding Southern Ocean, and far-field sites. This knowledge is derived from the following sources: 1) sedimentary (e.g., deposition of IRD; Weber et al., 2014), geochemical (e.g., biogenic components such as biogenic silica (BiSi) and calcium carbonate $\left(\mathrm{CaCO}_{3}\right.$; Grützner et al., 2005) and biological (e.g., marine microfossils such as diatoms and foraminifera; Scherer et al., 1998) properties of sediments; 2 ) oxygen isotope $\left(\delta^{18} \mathrm{O}\right)$ composition of planktonic and benthic foraminifera in deep sea sediments (Cramer et al., 2011); and 3) far-field sea level records (Miller et al., 2005).

Oxygen isotopes and far-field sea level records provide continuous estimates of global ice volume change through much of the Cenozoic, as ice sheets preferentially sequester ${ }^{16} \mathrm{O}$ over ${ }^{18} \mathrm{O}$, thus enriching the oceans in ${ }^{18} \mathrm{O}$ relative to ${ }^{16} \mathrm{O}$ as they grow (Emiliani, 1966; Ravelo and Hillaire-Marcel, 2007). Foraminiferal $\delta^{18} \mathrm{O}$ reflects changes in $\delta^{18} \mathrm{O}$ of seawater (and thus ice volume) in their calcite tests, providing one measure of ice sheet change over time (Chappell and Shackleton, 1986; Zachos et al., 2001). However, $\delta^{18} \mathrm{O}$ in foraminifera is also influenced by water temperature, with heavier $\delta^{18} \mathrm{O}$ values reflecting cooler temperatures. Lesser non-temperature and ice volume effects on foraminiferal $\delta^{18} \mathrm{O}$ are also apparent. These include the balance of evaporation to precipitation in determining the $\delta^{18} \mathrm{O}$ of surface waters (the 'salinity effect'), carbonate ion $\left(\mathrm{CO}_{3}{ }^{2-}\right.$ ) concentrations, the $\mathrm{pH}$ of the ambient seawater and biological "vital effects" (Chappell and Shackleton, 1986; Spero et al., 1997; Elderfield et al., 2002). Furthermore, $\delta^{18} \mathrm{O}$ records represent 
a globally integrated ice volume signature and additional evidence is necessary to differentiate between phases of Antarctic and Arctic ice sheet growth and decay.

\subsubsection{Cenozoic cooling and initiation of Antarctic Ice Sheets}

The Cenozoic Era is characterised by a global cooling trend, with the Earth transitioning from a 'greenhouse' world with warm conditions and essentially ice-free poles to an 'icehouse' world with cold conditions and ice-covered poles (Figure 2.1; Zachos et al., 2001; 2008; Mudelsee et al., 2014). High-resolution foraminifera $\delta^{18} \mathrm{O}$ records show an abrupt $\sim 1.5 \%$ increase, attributed to cooling of deep ocean temperatures by $4^{\circ} \mathrm{C}$ and growth of the first continental-sized AIS at the Eocene/Oligocene boundary 34 Ma (Zachos et al., 2001; Coxall et al., 2005; Liu et al., 2009). This is supported by an IRD record from Prydz Bay, East Antarctica, and glacial deposits in the western Ross Sea and Wilkes Land, which provide direct evidence of continental ice sheet expansion during the Early Oligocene (Barrett, 1989; Hambrey et al., 1991; Escutia et al., 2011; Galeotti et al., 2016). It is hypothesised that the inception of the AIS resulted from continental drift and subsequent opening of Southern Ocean gateways, and/or declining atmospheric $\mathrm{CO}_{2}$ concentrations crossing key cooling and ice sheet growth thresholds in combination with Earth's response to periodic changes in orbital forcing parameters (Shackleton and Kennett, 1975; DeConto and Pollard, 2003; Coxall et al., 2005).

Analyses of proximal sedimentary records (Naish et al., 2001; Barrett, 2009; Galeotti et al., 2016), high-resolution deep sea $\delta^{18} \mathrm{O}$ records (Pälike et al., 2006) and numerical models (DeConto et al., 2008) indicate that these early AISs were highly dynamic in response to insolation forcing, driving global sea level changes until the Middle Miocene ( 14 Ma; Miller et al., 2005). 


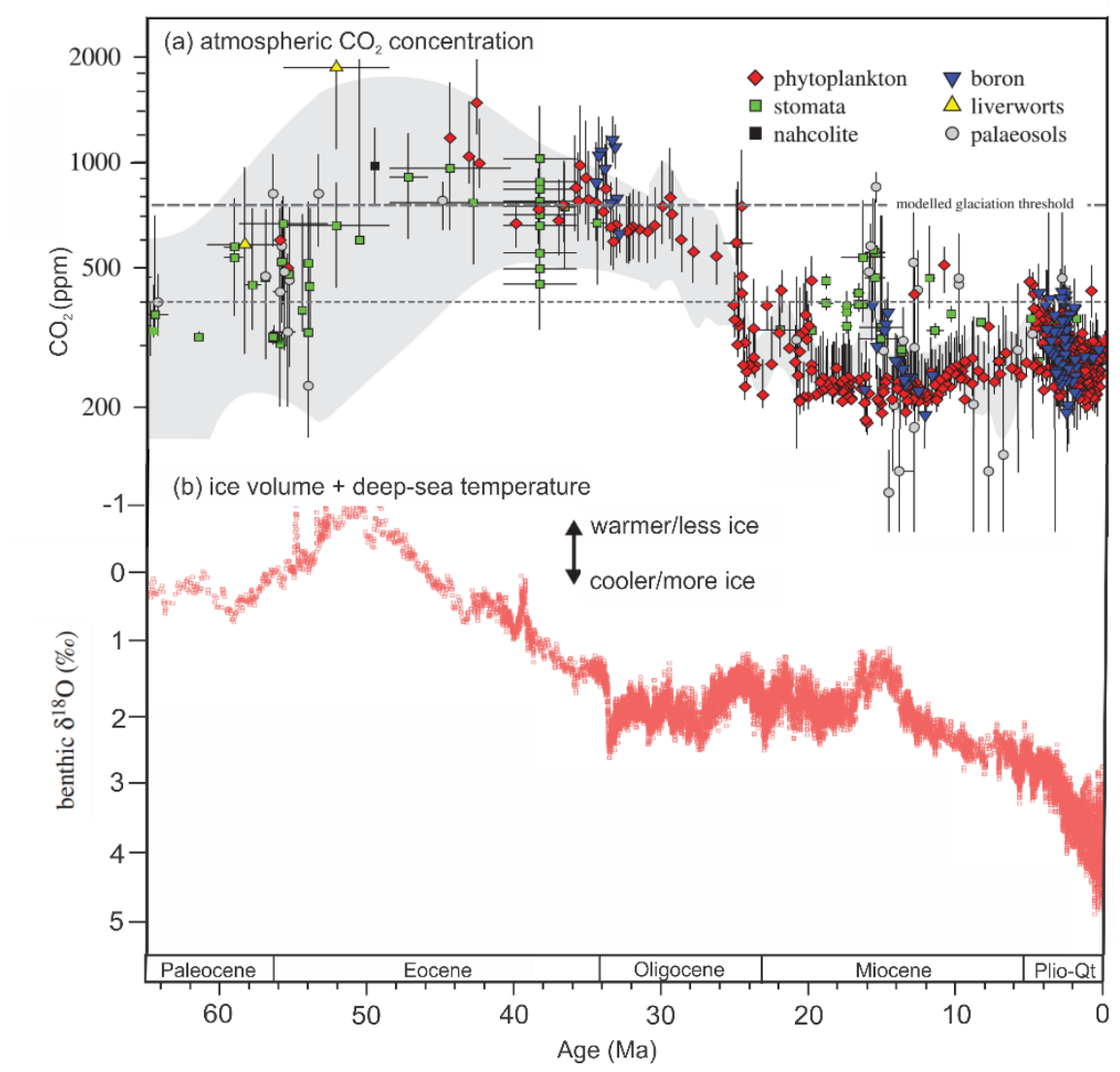

Figure 2.1: Reconstruction of Cenozoic climate from a compilation of (a) atmospheric $\mathrm{CO}_{2}$ proxies; and (b) composite deep ocean benthic $\delta^{18} \mathrm{O}$ record of global ice volume and deep ocean temperature. Figure modified from McKay et al. (2016a).

\subsubsection{Neogene Antarctic Ice Sheet history}

The Middle Miocene is marked by a $\sim 1.2 \%$ increase in benthic $\delta^{18} \mathrm{O}$, interpreted as a $7^{\circ} \mathrm{C}$ cooling of deep ocean waters, and a decrease of $\mathrm{CO}_{2}$ levels below 400 ppm (Shackleton and Kennett, 1975; Zhang et al., 2013). The stability of the East Antarctic Ice Sheet (EAIS), since $14 \mathrm{Ma}$, has long been debated (e.g., Barrett, 2013), but there is now general consensus that the central regions of EAIS have remained relatively stable since 14 Ma (Webb et al., 1984; Sugden et al., 1993), although its marine-based margins may have fluctuated in their extent since this time (Cook et al., 2013; Levy et al., 2016). While paleomagnetic and seismic stratigraphy shows there has been a terrestrial ice sheet in the West Antarctic since the Oligocene (Allis et al., 1975; Sorlien et al., 2007), uncertainty remains over the exact timing of the onset of marine-based ice sheets in West Antarctica. An increase in turbidite activity in the abyssal plain of the Weddell Sea during the Late Miocene is inferred to represent the development of the marine-based ice sheet in the West Antarctic (Kennett and Barker, 1990), and future planned drilling by International Ocean Discovery Programme (IODP) expeditions on the continental shelf, slope and rise of the Ross Sea (the study area of this thesis) will test this hypothesis. 
A sediment record retrieved beneath the McMurdo Ice Shelf (ANDRILL Project; AND-1B drill core) demonstrates that the marine-based WAIS oscillated at orbitally-paced frequencies during the Pliocene ( 5.3-2.6 Ma), with diatom ooze deposition indicative of seasonally open water occurring beneath regions of the Ross Sea now covered by an ice shelf (Naish et al., 2009). Comparisons to far-field sea level records and ice sheet modelling studies inferred these periods to represent the collapse of the marine-based WAIS when average global temperatures were $2-3^{\circ} \mathrm{C}$ warmer, and atmospheric $\mathrm{CO}_{2}$ levels were $\sim 400$ ppm (Naish et al., 2009; Pollard and DeConto, 2009; Miller et al., 2005; 2012). Provenance studies and IRD records from recent drilling on the Wilkes Land margin suggest there was also retreat of some marine-based sectors of the EAIS during the Early to Middle Pliocene (Cook et al., 2013; Patterson et al., 2014), which may have contributed to higher global sea levels, with far-field sea level records indicating $22 \pm 10 \mathrm{~m}$ higher than present (Miller et al., 2012; Rohling et al., 2014).

\subsubsection{Plio-Pleistocene cooling and the onset of Northern Hemisphere glaciation}

Sedimentological, geochemical and micropaleontologic analyses of the AND-1B drill core provide evidence of marine based ice sheet advance during glacial periods of the Late Pliocene ( $<3.5 \mathrm{Ma}$; McKay et al, 2009), and major expansion of sea ice and surface water cooling during interglacials in the Ross Sea (McKay et al., 2012a). The global cooling at this time (Figure 2.1) is hypothesised to have driven changes in surface and deep water circulation, altering the heat transport between the world's ocean basins and ultimately helped trigger the onset of major glaciation in the Northern Hemisphere (McKay et al., 2012a). Magnesium/Calcium (Mg/Ca) temperature reconstructions from benthic foraminifera in the deep Pacific and Atlantic oceans support this hypothesis, providing evidence of more efficient heat transport between the Atlantic and Pacific abyssal oceans (Woodard et al., 2014). Although ephemeral ice caps may have been present in the Northern Hemisphere since the Eocene (Tripati et al., 2008), the establishment of major continental Northern Hemisphere ice sheets is reflected as cyclic pulses of IRD in both the Atlantic and North Pacific since 2.7 Ma (Jansen et al., 2000; Kleiven et al., 2002).

Diatom oozes representing open sea sedimentation in the AND-1B drill core were deposited until the Early to Middle Pleistocene, indicating at least partial collapse of the marine-based ice sheets in West Antarctica. The youngest diatom deposit occurs during Marine Isotope Stage (MIS) 31-27 (1.08-1; McKay et al., 2012b). Scherer et al. (2008) documented a $\mathrm{CaCO}_{3}$-rich unit in the nearby Cape Roberts Project drill core (CRP-1), also during MIS 31. This unit lacks sea ice diatoms suggesting sea surface temperature(s) (SSTs) in the western Ross Sea were $3-5^{\circ} \mathrm{C}$ warmer than 
present. Sedimentological and micropaleontologic evidence from Prydz Bay (Villa et al., 2008), the Antarctic Peninsula (Vautravers and Hillenbrand, 2008), and the Southern Ocean (Scherer et al., 2008; Maiorano et al., 2009) indicate that a warming event at this time extended around the Antarctic continent.

The MPT (1.2-0.8 Ma) is a period during which the dominant periodicity of global glacialinterglacial cycles changed from 41 kyr (obliquity) to 100 kyr (eccentricity) (Mudelsee and Schulz, 1997). In AND-1B, most interglacials following the MPT are characterised by ice shelf deposition rather than open water, suggesting a period of major cooling relative to the Early Pleistocene (McKay et al., 2012b). Elderfield et al. (2012) used Mg/Ca-based estimates of ocean temperature to extract the ice volume component from a deep SW Pacific core (ODP 1123) $\delta^{18}$ O benthic isotope record. They proposed that the apparent shift in orbital forcing during the MPT was driven by the major change in AIS volume, also noted in the ANDRILL record. The MPT is also associated with enhanced biological productivity and increased sea ice cover in the Subantarctic Zone $\left(46^{\circ} \mathrm{S}\right.$ $60^{\circ} \mathrm{S}$ ) of the Southern Ocean, which may have acted as positive feedback mechanisms to the Late Pleistocene intensification of glacial cycles (Kemp et al., 2010; Martinez-Garcia et al., 2011; Lear et al., 2016).

Sediments in the AND-1B record also indicate that during the Late Pleistocene (past $~ 800 \mathrm{kyr}$ ) the WAIS has oscillated between subglacial (i.e., advanced ice sheet) and ice shelf (i.e., retreated ice sheet) environments at least seven times, implying a sensitivity of the ice sheet to orbitallyinfluenced surface temperature, oceanic temperature and sea level changes, although the relative importance of these is poorly constrained (McKay et al., 2012b). The series of Late Pleistocene 'super-interglacials', most notably MIS 5e (130-118 ka) and MIS 11 (425-374 ka), which were characterised by warmer than present climates and higher sea levels (Droxler et al., 2003), are therefore of critical interest as these may be representative of widespread deglaciation of the WAIS.

Marine diatoms and beryllium-10 concentrations from sediments recovered from under the Whillans ice stream that drains West Antarctica indicate open water conditions occurred under now-grounded regions of the WAIS in the past 1.3 Ma (Scherer et al. 1998). Scherer et al. (1998) inferred MIS 5e and MIS 11 to be the most likely candidates for this collapse but could not constrain the timing to these periods. In contrast, Hillenbrand et al. (2009) cited evidence of reduced deposition of IRD and increased SSTs and biological productivity from a sediment core on the continental rise of the Amundsen Sea to argue that a single, extended warm period 
between MIS 15-MIS 13 (621-478 ka) was the most likely period for a WAIS collapse. However, direct evidence for this remains equivocal and further geological evidence is required to constrain the magnitude of the WAIS contribution to sea level during the Late Pleistocene.

\subsubsection{Present-day change and future response of the WAIS to global change}

Mercer (1978) suggested that the stability of the WAIS is in part dependent on the presence of ice shelves that restrain the flow of ice inland of the grounded ice sheet ("buttressing"). He argued their removal could cause a complete loss of the WAIS due to the reverse slope gradient (i.e., deepening towards the center of the ice sheet rather than towards the seaward margin of the continental shelf) of the continental shelves in the West Antarctic. Models indicate runaway events occur once all ice sheet retreat is triggered as a consequence of an increasing flux of ice across a grounding line, and the ice sheet retreats into increasingly deeper marine basins - a process referred to as marine ice sheet instability (Thomas and Bentley, 1978; Alley et al., 2015;

Figure 2.2).

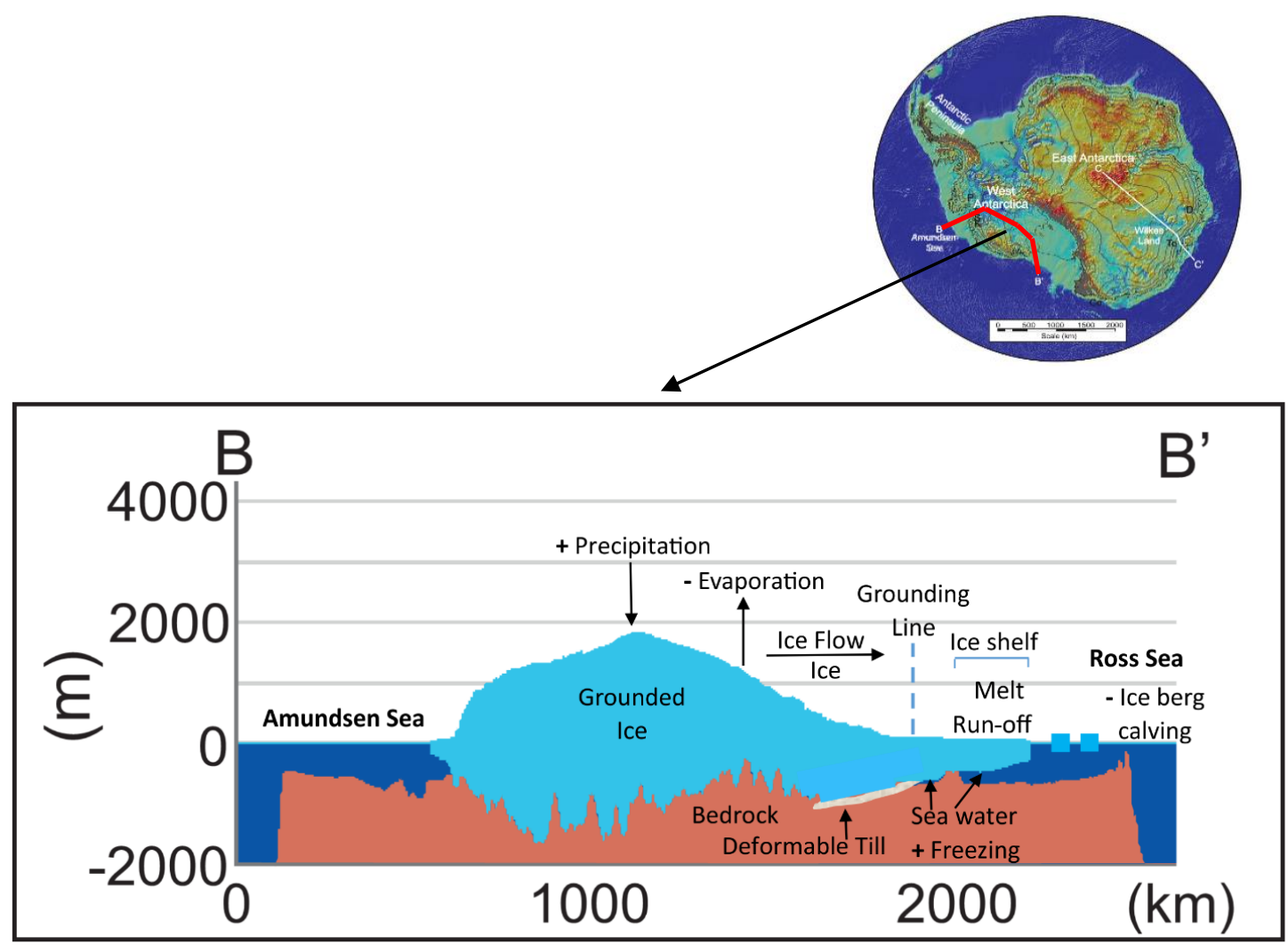

Figure 2.2: Illustrated cross-section (B-B') through the WAIS (red line on the Antarctic continent). The cross section shows a flowing ice stream, an ice shelf and its grounding line. Note the reverseslope bed on which the ice rests. Plus and minus symbols indicate ice gain and loss processes, respectively. Figure modified from IPCC (2013). 
Recent satellite observations show significant thinning of ice shelves and accelerated flow of outlet glaciers in the Amundsen and Ross Sea sectors of the WAIS over the past two decades (Payne et al., 2004; Shepherd et al., 2004; Pritchard et al., 2012; Rignot et al., 2014; Paolo et al., 2015). Two main mechanisms have been proposed to explain the accelerated retreat, including:

1) Increased atmospheric warming, which initiates surface melt and the growth of crevasses by hydrofracturing, whereby water's greater density relative to ice overpressurises a water-filled crevasse, causing it to fracture and may act to accelerate ice shelf thinning (Scambos et al., 2000; Vaughan et al., 2003);

2) Ocean-forced sub-ice shelf melting due to increased heat flux on the continental shelf via incursions of warm CDW. This increased heat flux is transported into ice shelf cavities, promoting ice shelf thinning. This accelerates the flow of inland glaciers that feed the ice shelf to the ocean (Jacobs et al., 2011; Pritchard et al., 2012; Steig et al., 2012; Wåhlin et al., 2013; Dutrieux et al., 2014).

Both of these processes would lead to reduced buttressing of the grounded inland ice and accelerate the flow of inland glaciers that feed the ice shelf to the ocean. Current ice sheet models predict that a continuation of sustained warming and increased ocean-ice sheet interaction will drive future WAIS loss, with top end projections estimating 0.6-3 $\mathrm{m}$ of sea level equivalent by the year 2300 (Golledge et al., 2015; DeConto and Pollard, 2016). Improved understanding of ice sheet behaviour to atmospheric and oceanographic forcing during warm interglacials of the Pleistocene is critical for providing boundary conditions in order to reduce uncertainties in these projections in ice sheet models, which are tuned to match past data-based reconstructions of sea level and ice sheet loss.

2.2 External and internal drivers of climate change: Orbital cycles and the global carbon cycle

\subsubsection{Orbital cycles}

The oscillations between glacials and interglacials are triggered by changes in the Earth's orbit, which are the first order control on the amount and distribution of solar insolation that reaches the Earth's surface (Figure 2.3) (Hays et al., 1976). Eccentricity is a measure of the circularity of the orbit, and varies from nearly circular to an extreme ellipse at periods of 95 (E1) 124 (E2) and 405 (E3) kyr (Laskar et al., 2004). It has a strong impact on seasonality, as a more elliptical orbit results in greater seasonal variation than a circular orbit (Ruddiman, 2001). Obliquity defines 
the tilt of Earth's axis of rotation which varies from $24.5^{\circ}$ to $22.2^{\circ}$ at periods of $\sim 53(\mathrm{O} 1)$ and $\sim 41$ (O2) kyr (Laskar et al., 2004). Increased (decreased) tilt angles expose the Polar Regions to more (less) solar radiation, which strongly affects the pole to equator temperature gradient and thus, the strength of seasons (Ruddiman, 2001). Precession refers to (1) the wobble of the Earth's axis of rotation and (2) the rotation of the elliptical orbit of the Earth, which combined vary at periods of $\sim 23$ (P1) and $\sim 19$ (P2) kyr with an average period of $\sim 21$ kyr (Laskar et al., 2004). Precession changes the orientation of hemispheres relative to the sun and exerts control on the duration and intensity of the seasons. Changes in eccentricity moderate the effect of precession by amplifying or suppressing the intensity of the seasons (Ruddiman, 2001).

As Northern Hemisphere ice sheets are land-based (i.e., not grounded below sea level and buttressed by ice shelves), traditional Milankovitch theory suggests that large ice sheets will accumulate during periods of low high-latitude Northern Hemisphere summer insolation when summer melt is reduced (Milankovitch, 1941; Ruddiman, 2001). However, the orbital response of ice sheets is more complex in the Antarctic where mass balance of the marine-based ice is largely regulated by oceanic temperature (Patterson et al., 2014).

Numerous climate forcings and feedbacks, including variations in atmospheric $\mathrm{CO}_{2}$ concentrations and temperatures, and their impact on the global ocean dynamics, act to amplify the relatively small changes in the Earth's energy balance in response to Milankovitch cycles, and thus control the growth and decay of ice sheets (Denton et al., 2010; Sigman et al., 2010).

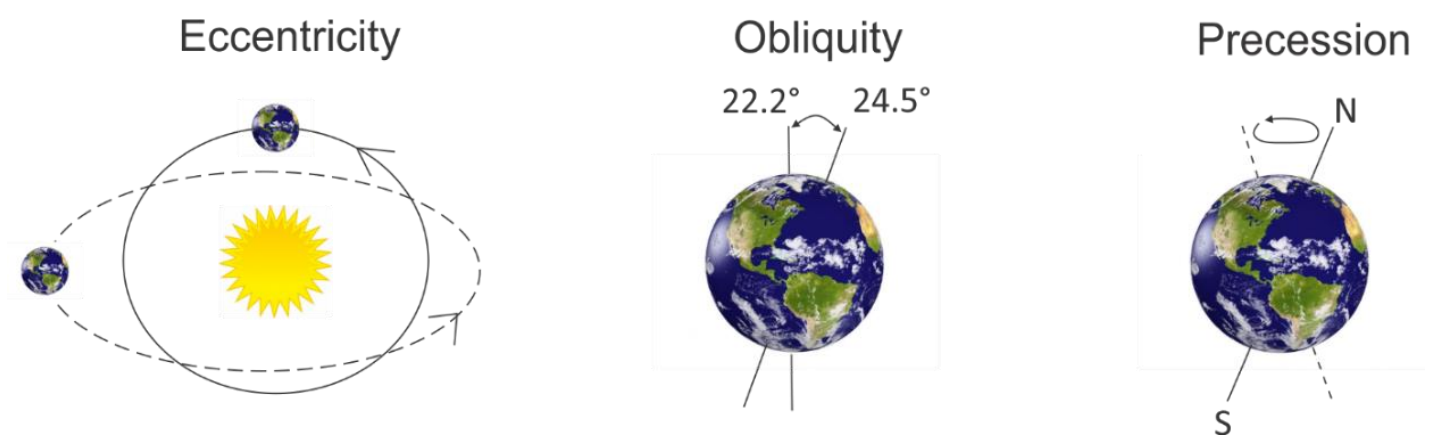

Figure 2.3: Schematic diagram illustrating the orbital cycles of eccentricity, obliquity and axial precession. Figure redrawn from Zachos et al. (2001).

\subsubsection{Internal drivers of climate change: The global carbon cycle}

The Southern Ocean has been identified as a key region for modulating glacial-interglacial atmospheric $\mathrm{CO}_{2}$. It may act as a source or sink for atmospheric $\mathrm{CO}_{2}$ depending on the balance between upwelling of nutrients and release of deeply sequestered $\mathrm{CO}_{2}$ to the atmosphere, and drawdown of atmospheric $\mathrm{CO}_{2}$ though phytoplankton production (i.e., the 'biological pump'). The 
biological pump involves sequestration of atmospheric $\mathrm{CO}_{2}$ through photosynthesis of phytoplankton in the surface ocean, and sinking and regeneration of their organic remains to inorganic forms of carbon and nutrients at depth (Figure 2.4; Sarmiento, 1984; Sigman et al., 2010). Several mechanisms have been proposed by which the Southern Ocean $\mathrm{CO}_{2}$ outgassing may have been reduced, contributing to glaciation, including:

1) Reduced exchange of Southern Ocean surface waters with the deep ocean due to changes in ocean structure (e.g., stratification leading to reduced Antarctic overturning) and circulation (shallower ventilation of North Atlantic waters resulting in isolation of deep Southern Ocean waters) (Toggweiler, 1999; Sigman et al., 2010);

2) Increased sea ice cover provided a barrier to $\mathrm{CO}_{2}$ release (Stephens and Keeling, 2000);

3) Enhanced phytoplankton productivity, particularly in the Subantarctic Zone, increased $\mathrm{CO}_{2}$ storage in the deep ocean (Martin, 1990; Jaccard et al., 2013).

Thus, high resolution records of sea ice extent in the high-latitude Southern Ocean remain key to understanding the drivers of atmospheric $\mathrm{CO}_{2}$ variations in the Plio-Pleistocene and its role in the major Pliocene to Pleistocene climate shifts (e.g., MPT and the onset of Northern Hemisphere glaciation).

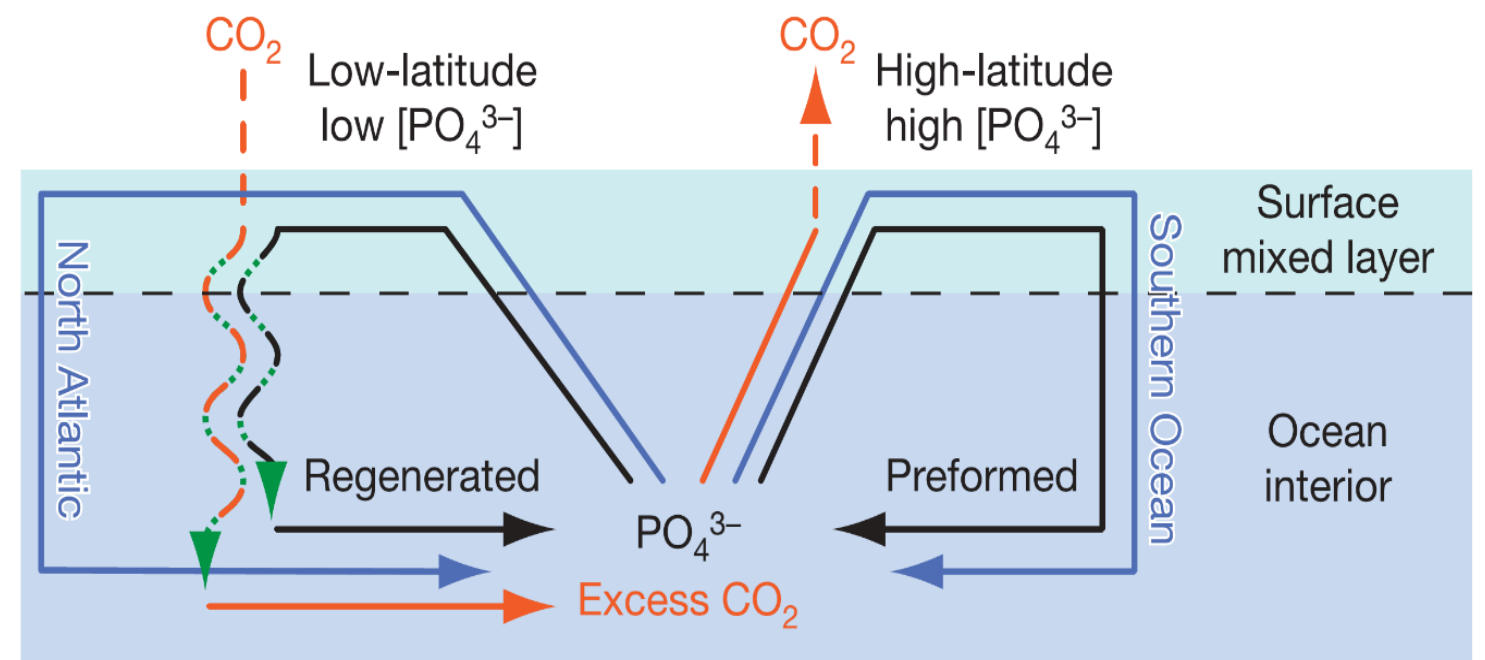

Figure 2.4: Schematic diagram of the ocean's biological pump. Blue, black, and orange lines depict the movement of water, nutrients (phosphate, $\mathrm{PO}_{4}{ }^{3-}$ ), and $\mathrm{CO}_{2}$, respectively. Solid, wavy, and dashed lines represent transport by water flow, sinking organic matter, and air-sea exchange, respectively. $\mathrm{CO}_{2}$ is sequestered to the deep ocean from low-latitude, low nutrient surface regions where complete biological assimilation of the major macronutrients nitrate and phosphate results in bacterial regeneration of organic matter and subsequently release of nutrients and excess $\mathrm{CO}_{2}$ from bacterial respiration. The resulting nutrient- and $\mathrm{CO}_{2}$-rich surface waters in the North Atlantic sink to become dense bottom waters that ultimately upwell in the Southern Ocean. The $\mathrm{CO}_{2}$ sequestered by the regenerated nutrient loop is released back to the atmosphere. In contrast, the waters in the Southern Ocean descend with most of the nutrients remaining unused (=preformed nutrients). Figure from Sigman et al. (2010). 


\subsection{Depositional processes and depositional facies models in continental margin settings}

The main depositional processes that operate in Antarctic continental margin settings represent a continuum between pelagic/hemipelagic settling, bottom currents, and turbidity currents, all of which are superimposed by subglacial and glacimarine influences (Figure 2.5; Stow and Piper, 1984; Rebesco et al., 2014). Facies models are idealised sequences of distinct sedimentary structures, textures and compositions that enable interpretation of sediments deposited by a particular sedimentary process, and thus provide a tool to reconstruct past depositional environments (Stow and Piper, 1984; Stow, 1985).
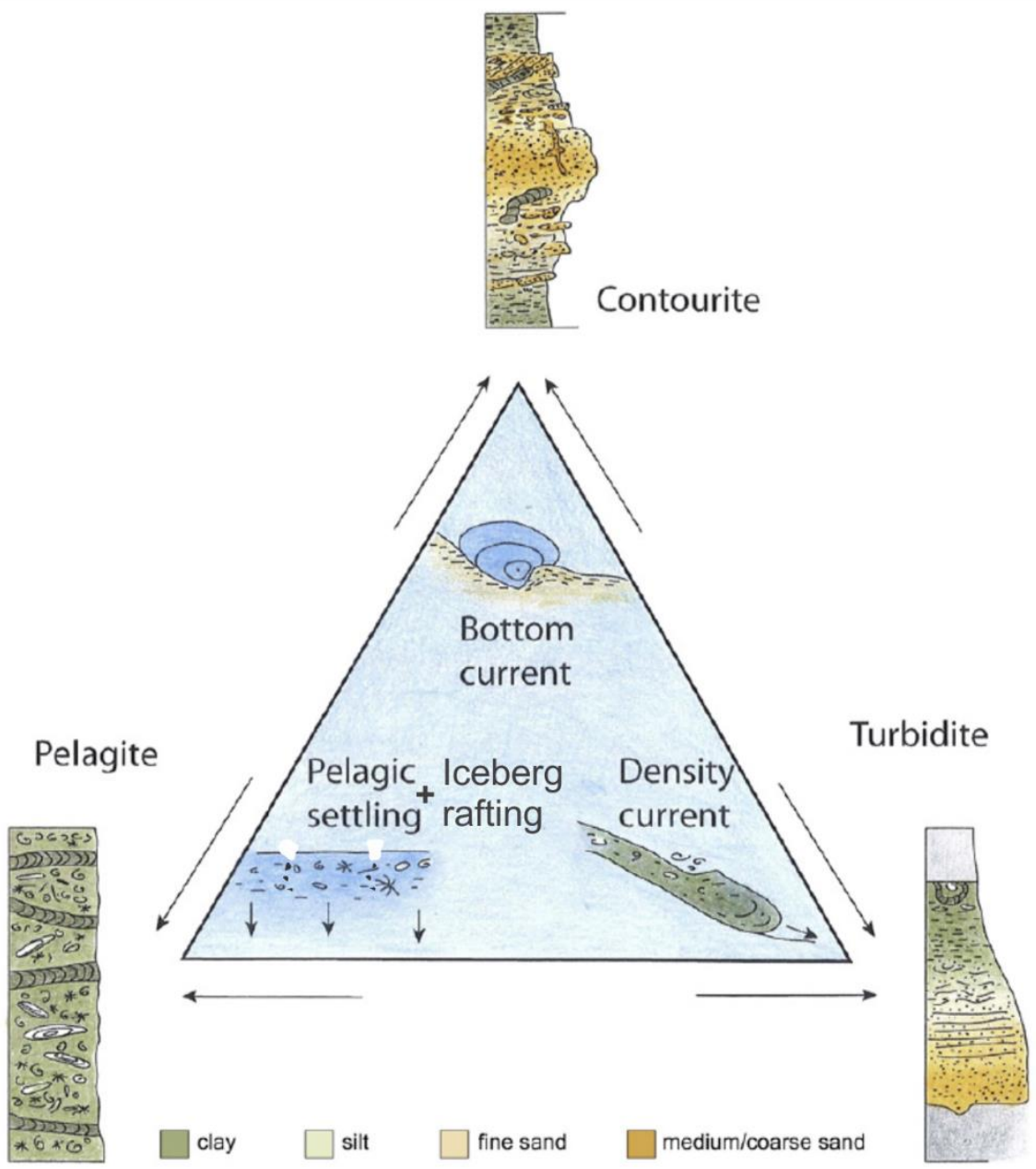

Figure 2.5: Conceptual diagram illustrating the three main sedimentary depositional processes operating in the deep sea (within triangle) and the facies models of the respective depositional models. Figure modified from Rebesco et al. (2014). 


\subsubsection{Pelagic/hemipelagic settling}

The slow settling of pelagic particles through the water column largely involves the tests of calcareous (coccolithophores and foraminifera) and siliceous (radiolarians and diatoms) planktonic organisms and their associated organic matter, although minor amounts of benthic material (e.g., sponge spicules and benthic foraminifera) and terrigenous sediment may also be present. Much of this material settles as flocs and faecal pellets $\left(10^{-2}-10^{-3} \mathrm{~ms}^{-1}\right)$. During settling the material may undergo dissolution of calcareous and siliceous components and oxidation of organic matter (Stow and Piper, 1984; Stow, 1985). Terrigenous input (hemipelagic), such as silts and clays, very fine-grained quartz, volcanic dust and IRD, is derived from a combination of aeolian, glacial (ice-rafting), volcanic, or coastal-shelf mechanisms, which introduce suspended plumes and dispersed particles to the open ocean. Hemipelagic sediments are characteristic of continental margin settings where there is an abundant supply of terrigenous material.

Hemipelagites and pelagites are deposits resulting from hemipelagic and pelagic processes, and under well-oxygenated bottom water conditions show a complete absence of primary sedimentary structures and are highly bioturbated. When bottom waters become low in oxygen or completely anoxic, bioturbation is reduced or absent and weak to well-developed parallel laminations are preserved, although these show no evidence for current controlled deposition (Stow and Piper, 1984). Stow and Piper (1984) identify the following primary distinguishing features of pelagites and hemipelagites:

1) Continuous bioturbation (except in anoxic basins where laminae are preserved) with evidence for low rates of sedimentation;

2) Absence of primary sedimentary structures and current-controlled deposition;

3) A mainly uniform composition within any one succession, that may show a regular cyclicity related to climatic or other controls.

Thus, pelagite/hemipelagite lithological characteristics are evidence for low-energy, lowsedimentation rates environments with no current-control during deposition (Stow and Piper, 1984; Stow and Tabrez, 1998).

\subsubsection{Bottom currents}

Different types of bottom currents may occur on the shelf, slope and basinal environments, including alongslope, contour or boundary currents, as well as persistent downslope currents (Stow and Piper, 1984; Rebesco et al., 2014). Following the criteria set out by Rebesco et al. 
(2014), in this thesis the terms "bottom current deposit" or "contourite" are used to describe sediments deposited by bottom currents, rather than contour currents sensu stricto.

The mean flow speed of bottom contour currents globally is $10-30 \mathrm{cms}^{-1}$, but can exceed $100 \mathrm{cms}^{-}$ ${ }^{1}$ when the flow is constrained though narrow gateways and against the western margins of basins (due to the Coriolis force induced by the Earth's spin), or where the slope is especially steep (Stow et al., 2002; Shangmugan, 2008). These currents may transport a substantial amount of fine (<2$12 \mu \mathrm{m}$ ) material and particulate organic matter in suspension. In turn this material forms a thick layer of suspended material above the ocean floor called the nepheloid layer, and affects sediment on the seafloor by generating processes such as winnowing of fine-grained sediments and large-scale erosion and deposition (Stow and Piper, 1984; Stow, 1985; Shangmugan, 2008).

Well-established facies models highlight three primary characteristics diagnostic of contourites (Stow and Piper, 1984; Stow and Faugeres, 2008 and references therein):

1) Continuous bioturbation (except under anoxic conditions) that has kept pace with deposition, but with some relic of current-controlled structures. This contrasts with hemipelagites, which display no current-induced structures, and fine-grained turbidites where bioturbation is commonly found in the uppermost part of the bed and sedimentary structures are well preserved;

2) Irregular vertical variation of facies types and grain size with superimposing fining-upward and coarsening-upward units, but no regular structural sequence. Conversely, turbidites are composed of fining upward units;

3) Compositional, textural or other features that indicate a combined in situ and exotic origin.

However, some distinctly laminated sandy deposits may also represent contourites where traction structures (e.g., cross bedding, flaser bedding, lenticular bedding) are abundant due to the action of bottom currents on the ocean floor (Vianna et al., 1998; Hüneke and Stow, 2008; Shanmugam, 2008; 2012). In addition, research on the Antarctic continental margin has revealed contourites deposited across bathymetric contours, which is thought to be the result of interacting downslope and acrossslope depositional processes (Michels et al., 2001; Rebesco et al., 2002). This is particularly significant in areas of dense bottom water production (e.g., Ross Sea) where density-driven downslope bottom currents are responsible for contourite deposition (McKay et al., 2016b). 
The grain size of contourites can vary from clay to gravel and the composition may be terrigenous siliciclastic, volcanic, biogenic (calcareous or siliceous) or mixed (Stow and Piper, 1984; Shanmugam, 2008; Stow and Faugeres, 2008; Faugeres and Mulder, 2011). Figure 2.6 shows an idealised facies model for contourites, which has been reproduced from several continental margins, although partial sequences (Figure 2.7) have also been reported (Faugeres et al., 1984; Gonthier et al., 1984; Viana and Faugeres, 1998; Øvrebø et al., 2006; Stow et al., 2002; 2013). This facies model demonstrates a coarsening-up and fining-up cycle which, in theory, represents two shifts in the strength of the bottom contour current: from weak to strong and vice versa (Stow et al., 2002; Huneke and Stow, 2008). Stow et al. (2002) suggest that the stacked sequence represents cyclic variations in the driving mechanism, such as orbitally-paced cyclical changes in climate regulating bottom current strength (e.g., Somoza et al., 1997; Llave et al., 2006). Contourite deposits are thus of crucial importance for understanding past changes in deep paleocirculation and its links to Pleistocene glacial cycles.

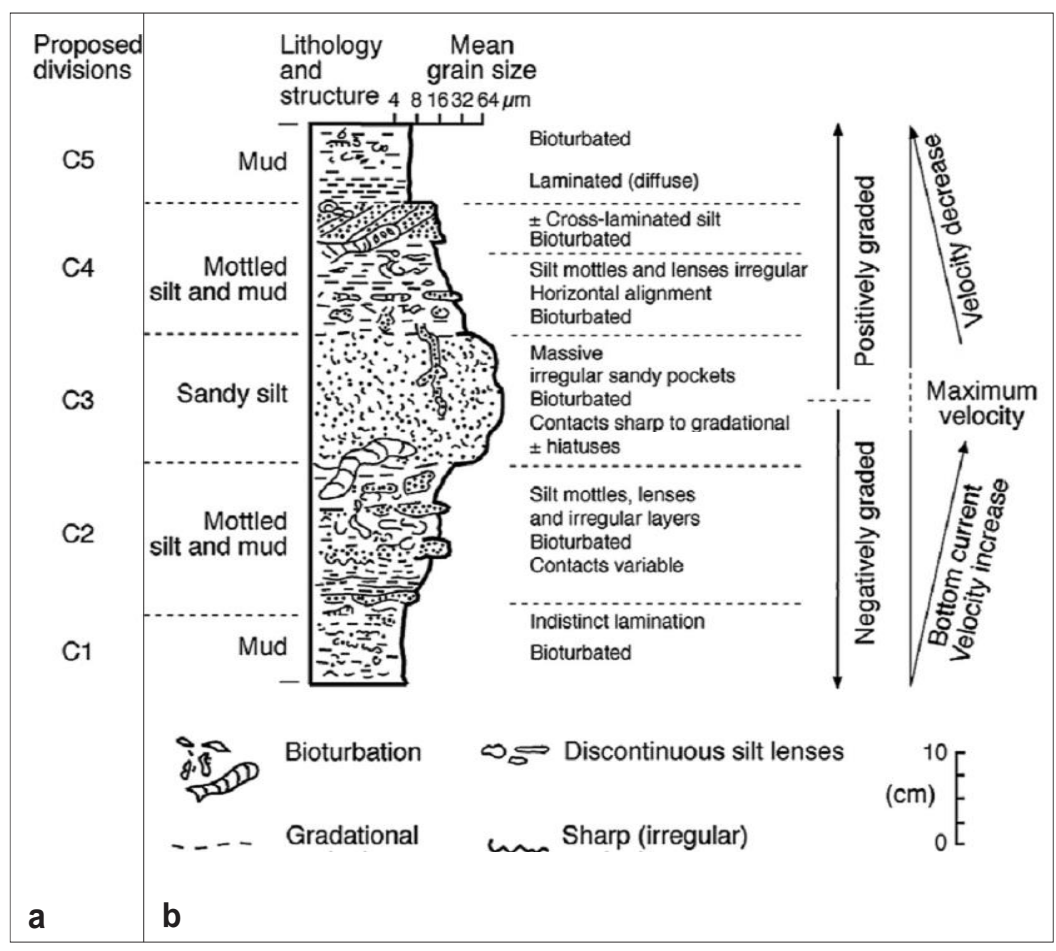

Figure 2.6: a) Facies model for contourite sequence with five internal divisions (C1-C5) proposed by Stow et al. (2002). b) Standard facies model of contourite sequence showing grain size variation through mud-silt-sand, linked to variation in contour-current velocity (Faugeres et al., 1984; Gonthier et al., 1984). Figure modified from Stow et al. (2002). 


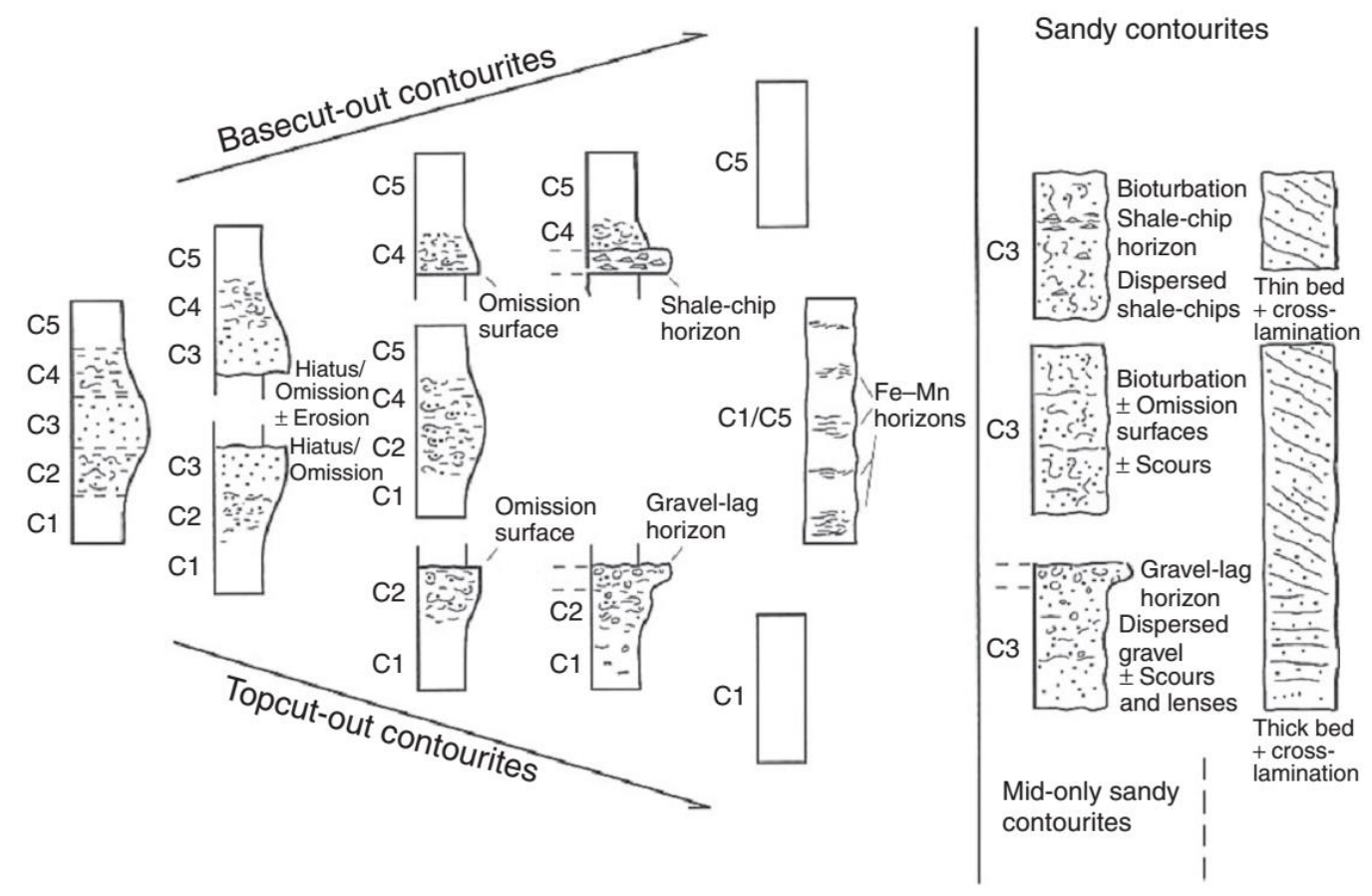

Figure 2.7: Variations on the standard contourite facies models showing the range of contourite facies, sequences and partial sequences commonly encountered in contourite successions (Stow and Faugéres, 2008).

\subsubsection{Turbidity Currents}

Turbidity currents develop from both slumps and debris flows mixing with seawater, or from sediment suspensions on the seafloor caused by storms or melt-out from glaciers, where the sediment is supported by fluid turbulence. Types of flow include high density ( $>10 \%$ sediment by weight) and low density ( $<1 \%$ sediment by weight) currents, which may travel for distances up to several thousands of kilometres. Deposition can be by grain flow, fluidised- or liquefied-flow mechanisms and by sediment fallout from suspension (Middleton and Hampton, 1973; Lowe, 1982; Middleton, 1993; Shanmugam, 1997).

Turbidites are direct deposits of turbidity currents and are most commonly found across the lower continental rise and in submarine-fan settings (Bouma, 1962; Middleton and Hampton, 1973). Stow and Piper (1984) identify several distinct turbidite facies models, consisting of silt, mud, biogenic and disorganised turbidites. Fine-grained turbidites are commonly identified as mudstones with very thin $\mathrm{mm}$-scale laminae to thick $\mathrm{cm}$-scale beds that are a result of resedimentation events. Stow and Piper (1984) introduced diagnostic criteria that can be used to distinguish turbidites from other facies that they may resemble, which include: 
1) A regular vertical sequence of sedimentary structures commonly associated with positive grading;

2) The presence of sedimentary structures indicating rapid deposition, with bioturbation restricted to the tops of beds;

3) Compositional, textural or other features which point to an exotic origin in their depositional environment.

Each of these idealised turbidite sequences can be interpreted to be the product of a single turbidity current that deposited progressively finer grades of sediment and produced different sedimentary structures as the speed and carrying power of the flow decreased. An idealised turbidite deposit should therefore encompass a progression of an up-sequence succession from graded laminated turbidite mud, graded turbidite mud, and ungraded turbidite mud to pelagite/hemipelagite (Shanmugan, 1997). However, the turbidite sequence is rarely preserved in its entirety due to the combined effects of erosion and depositional locations (e.g., channel levee and fan systems, etc) in the deep sea. Thus, complete turbidite sequences are virtually nonexistent in either modern or ancient deposits, and most deposits are dominated by partial sequences, and may be top-absent, base-absent, or mid-absent (Shanmugam, 1997).

\subsubsection{Glacimarine influences}

In high northern latitudes, the discharge of subglacial meltwater results in turbid surface-plumes (Hesse et al., 1997; Donda et al., 2007). These meltwater plumes deliver glacially-derived detritus and en route eroded material to more distal parts of the continental slope and rise of glacimarine margins, although their deposition is limited to tens of kilometers from the ice margin (Hesse et al., 1997; Donda et al., 2007; Lucchi and Rebesco, 2007). The deposition of turbid surface-plumes results in sedimentary sequences referred to as plumites (Hesse et al., 1997). Hesse et al. (1997) describe plumite sedimentary sequences on the Labrador slope, Greenland, that consist of 1 to 2$\mathrm{cm}$-thick alternations of fine sandy silt/coarse silt layers that are interlayered with finer-grained, laminated and bioturbated clayey silt and silty clay. In the Antarctic, Lucchi and Rebesco (2007) determined $\mathrm{mm}$-thick faintly laminated silty layers with sharp, non-erosive bases to represent pulsing events of weak turbid flows on the Antarctic Peninsula margin. However, subglacial meltwater plumes appear to be minor process in the Ross Embayment, where a lack of terrigenous fine-grained sediment during glacial minima is inferred to represent limited amounts of subglacial meltwater (Domack et al., 1999; McKay et al., 2008; 2009). Here, mass gravity flows (e.g., debris and turbidity flows) near an ice sheet grounding zone play a key role in delivering 
sediment to the shelf edge and the distal parts of the continental slope and rise (Anderson, 1999). This is evident in seismic profiles from the Ross Sea continental shelf, where Mid-Pliocene and younger strata are characterised by aggradation till sheets that result from reworking of older Miocene strata, and most Pleistocene sedimentation is concentrated at the outer shelf edge (Alonso et al., 1992; Brancolini et al., 1995). This sediment delivery process is most apparent in the central Ross Sea, where a large trough fan ( $2 \mathrm{~km}$ thick) has formed through past periods of grounded WAIS advances to the shelf edge (Brancolini et al., 1995).

The range of processes that deposit and rework sediments on the sea floor are closely interrelated, and thus facies distributions across the continental slope and rise are also closely interrelated (Stow and Piper, 1984). For example, bottom contour currents have been found to be very influential in shaping the Antarctic continental margin. Here, contourites are commonly interbedded with turbidites, which are deposited when glacial meltwater plumes or mass gravity flows transport sediments to the shelf edge. Further slumping and down-slope gravity flows then deliver the terrigenous material to the lower continental slope, rise and abyssal plain where bottom currents control the geometry and morphology of the deposit (Escuita et al., 2002; 2003; 2005; Lucchi et al., 2002; Donda et al., 2007; Lucchi and Rebesco, 2007; Caburlotto et al., 2010).

\subsubsection{Previous work on the Antarctic continental margin}

Previous work on Antarctic continental slope to rise sedimentary sequences has largely focused on the Antarctic Peninsula (Pudsey and Camerlenghi, 1998; Pudsey, 2000; Lucchi et al., 2002; Hepp et al., 2006; Lucchi and Rebesco, 2007; Cowan et al., 2008; Escutia et al., 2009), Wilkes Land (Escutia et al., 2002; 2003; 2005; Caburlotto et al., 2010), Prydz Bay (Escutia et al., 2009) and Weddell Sea (Gilbert et al., 1998; Camerlenghi et al., 2001; Michels et al., 2001) margins. These researchers propose that glacial periods are characterised by high sediment supply regimes dominated by mass gravity flows (e.g., debris and turbidity flows) triggered by the advance of the grounded ice sheet to the continental shelf edge. This ice advance causes reduced biogenic and IRD supply due to increased extent and duration of seasonal sea ice cover. Conversely, interglacial periods are characterised by increased biogenic productivity and IRD supply, resulting from retreating ice sheets and decreased sea ice cover. However, it is important to note that the proposed depositional models are likely to be region specific depending on the sediment delivery mechanisms to the continental shelf edge (e.g., streaming versus stagnant ice sheet flow), as well as overlying changes in water masses, biological productivity, sea ice and iceberg pathways. Table 1 summarises lithofacies characteristics, depositional processes and their associated climate 
regimes based on previous work carried out on Antarctic continental margin sedimentary sequences. Note this table is highly generalised and because of the large spatial variability in ice sheet, sea ice and oceanographic processes around Antarctica, a specific facies model should be developed for any newly- or under-studied regions of the Antarctic margin.

Table 2.1: Continental slope and rise lithofacies characteristics, glacimarine sedimentary processes and associated climate regime on the Antarctic continental margin (Pudsey and Camerlengi, 1998; Pudsey, 2000; Lucchi et al., 2002; Escutia et al., 2002; 2003; 2005; Busetti et al., 2003; Hepp et al., 2006; Lucchi and Rebesco, 2007; Cowan et al., 2008; Caburlotto et al., 2010; Golledge et al., 2012). 


\begin{tabular}{|c|c|c|}
\hline Lithofacies characteristics & $\begin{array}{l}\text { Inferred sedimentary processes operating on continental slope } \\
\text { and rise }\end{array}$ & Climate regime \\
\hline $\begin{array}{l}\text { Massive, strongly bioturbated, IRD } \\
\text { abundant, diatomaceous mud. }\end{array}$ & $\begin{array}{l}\text { Dominated by hemipelagic and pelagic settling from nepheloid } \\
\text { layer derived from turbid plumes (glacial meltwater), and other } \\
\text { suspended sediment matter (from winnowed sea floor sediment } \\
\text { or the fine-grained component of mass flows). } \\
\text { Ice-rafting and aeolian deposition contribution. } \\
\text { Pervasive bioturbation and high biogenic content suggests low } \\
\text { terrigenous sediment supply. }\end{array}$ & Interglacial \\
\hline $\begin{array}{l}\text { Terrigenous, structureless mud with } \\
\text { sparse IRD and minor bioturbation, low } \\
\text { biogenic content, sharp boundaries } \\
\text { separate IRD abundant muds above } \\
\text { and laminated muds below. }\end{array}$ & $\begin{array}{l}\text { Grounded ice sheet advances to continental shelf edge. } \\
\text { Enhanced dynamic ice sheet flow and increased terrigenous } \\
\text { supply from sediment-laden plumes and mass flow processes near } \\
\text { the shelf edge. } \\
\text { Extended sea ice cover restricts biogenic productivity } \\
\text { (except in polynyas). } \\
\text { Ice-rafting may decrease (if ice shelves present) or increase (in } \\
\text { areas of highly dynamic ice sheet flow). }\end{array}$ & $\begin{array}{l}\text { Interglacial to Glacial } \\
\text { Transition }\end{array}$ \\
\hline $\begin{array}{l}\text { Hemipelagic laminated to massive mud } \\
\text { with sparse IRD, low biogenic content, } \\
\text { rare bioturbation. Note high spatial } \\
\text { variablity around the continental } \\
\text { margin. } \\
\text { *turbidite facies } \\
\text { upwards fining sandy/silty mud, sharp } \\
\text { to irregular bases, presence of } \\
\text { ripple/cross lamination, no IRD, no } \\
\text { bioturbation } \\
\text { *contourite facies } \\
\text { well defined laminated/cross laminated } \\
\text { silty/sandy mud, presence of IRD layers, } \\
\text { bioturbated in areas of dense bottom } \\
\text { water production. } \\
\text { *plumite facies } \\
\text { laminated coarse- and fine-grained } \\
\text { deposits of sands and muds with sharp, } \\
\text { non-erosive bases. }\end{array}$ & $\begin{array}{l}\text { High terrigenous supply to shelf break by subglacial transport, with } \\
\text { the formation of trough mouth fans at the mouth of large glacial } \\
\text { troughs in large embayments (Weddell Sea, Prydz Bay and Ross } \\
\text { Sea). } \\
\text { Extended sea ice cover restricts biogenic productivity (except in } \\
\text { polynyas). } \\
\text { Downslope gravity flow processes. } \\
\text { Traction currents from dense water production, with polynyas } \\
\text { forming at the shelf break (Weddell Sea). } \\
\text { Hemipelagic and pelagic settling from nepheloid layer derived } \\
\text { from turbid plumes (glacial meltwater in lower latitudes e.g., } \\
\text { Antarctic Peninsula) and other suspended sediment matter (from } \\
\text { winnowed sea floor sediment or the fine-grained component of } \\
\text { mass flows). }\end{array}$ & Glacial \\
\hline $\begin{array}{l}\text { Hemipelagic, structureless mud with } \\
\text { closely spaced IRD layers, mud laminae } \\
\text { are less frequent (obscured by } \\
\text { bioturbation), and IRD peaks are } \\
\text { common. }\end{array}$ & $\begin{array}{l}\text { Ice sheet retreats from continental shelf edge. } \\
\text { Iceberg calving events are more frequent due to dynamic ice } \\
\text { discharge and marine ice sheet instablity. } \\
\text { Decreased terrigenous supply by subglacial transport to shelf edge } \\
\text { (sediment is sequestered on the reverse slope continental } \\
\text { shelves). } \\
\text { Increased glacial meltwater discharge and surface water } \\
\text { stratification. } \\
\text { Decreasing sea ice cover and increased biogenic productivity. }\end{array}$ & $\begin{array}{l}\text { Glacial to Interglacial } \\
\text { Transition }\end{array}$ \\
\hline
\end{tabular}




\subsection{Ice-rafted debris}

2.4.1 The use of ice-rafted debris as proxy for dynamic ice sheet discharge in the Northern Hemisphere

Records of IRD are commonly believed to represent the flux of melting icebergs calving off inland glaciers that flow out to the ocean, and thus reflect changes in the mass balance of ice sheets (Jansen et al., 2000; Kanfoush et al., 2000). This was first recognised in north Atlantic sediments, where prominent layers of concentrated IRD, termed Heinrich events, were identified in north Atlantic sediment cores (Heinrich, 1988). Subsequent studies have demonstrated that these layers were dominated by material sourced from the Hudson Bay region, the main drainage basin for the Laurentide Ice Sheet (LIS), and were deposited in centuries or less (Bond et al., 1992; Andrews et al., 1994; McManus et al., 1998). The leading hypothesis is that Heinrich events were triggered by ice shelf collapses from subsurface oceanic warming, resulting in a surge of the LIS in Hudson Bay, which released large quantities of debris-rich icebergs into the north Atlantic (Hulbe et al. 2004; Flückiger et al., 2006; Marcott et al., 2011; Li and Piper, 2015).

The substantial retreat or collapse of the LIS during Heinrich events may be analogous to the proposed collapse of the WAIS as a result of a disintegration of the RIS, driven by increased oceanic heat flux (Joughin et al., 2012; Pritchard et al., 2012; Golledge et al., 2015). Because the AISs lose $\sim 50-80 \%$ of their mass by iceberg calving from outlet glaciers and ice streams (Depoorter et al., 2013), IRD records from the Antarctic continental margin are frequently used as proxies of ice sheet stability (e.g., Hillenbrand et al., 2009; Williams et al., 2010; Patterson et al., 2014).

\subsubsection{Antarctic ice-rafted debris records and paleoenvironmental implications}

Studies from Prydz Bay and the Wilkes Land continental margin of Antarctica reveal that the timing of major IRD pulses throughout the Miocene, Pliocene and Early Pleistocene is paced by orbital cyclicity, indicating that the volume of the AIS also fluctuates on this timescale (Williams and Handwerger, 2005; Williams et al., 2010; Patterson et al., 2014; Hansen et al., 2015). Mid-toLate Pleistocene studies of Antarctic continental margin IRD records display glacial to interglacial cyclicity, with peaks occurring during deglaciation and interglacials (Lucchi et al., 2002; Escutia et al., 2003). Millennial-scale pulses of IRD to the Scotia Sea during the last deglaciation (20-9 kyr) have been interpreted to represent episodes of Antarctic marine ice sheet instability on suborbital timescales, indicating that IRD records have the potential to provide high-resolution archives of dynamic ice sheet discharge in the geological past (Weber et al., 2014). 


\subsubsection{Physical controls on ice-rafted debris deposition}

The debris content of icebergs is determined by several factors, including the basal thermal regime, subglacial hydrology, and the topography and composition of the subglacial bed (Death et al., 2006). For example, glaciers and ice streams in a warmer glacial thermal regime produce abundant sand and silt-sized rock flour by means of glacial erosion of primary bedrock. In colder glacial thermal regimes, which are associated with ice shelves and cold-based and polythermal glaciers, the erosion of large rock fragments to silt-sized particles is reduced, and the debris deposited contains significantly more sand and gravel by volume, although the total volume of generated basal debris is less (Evans and Pudsey, 2002). However, this is unlikely to be the case in West Antarctica, where the majority of the ice sheet advance overrides and reworks preexisting glacial muddy tills and glacimarine muds in Late Cenozoic sedimentary basins that are several kilometres thick, and thus sand and gravel eroded directly from bedrock are comparatively rare (Tulaczyk et al., 1998). Additionally, the base of a large ice shelf, such as the RIS, is commonly debris free, as the majority of basal debris is melted out close to the grounding line. As a result, large iceberg calving events from such ice shelves may deliver little or no IRD to the ocean (Anderson, 1999).

IRD deposition is also determined by the availability of calving icebergs, and thus the glacier flow speed and calving rate, which further influence iceberg production and size. Rapid iceberg discharge occurs where ice sheets and glaciers are in contact with the ocean and grounded below sea level (Bassis and Jacobs, 2013). Other controls such as coastal morphology, sea ice extent, SSTs and current directions exert a strong influence on iceberg survival, residence time, and the spatial distribution of icebergs (Gilbert, 1990; Jansen et al., 2000; Teitleret al., 2010). However, IRD records may also reflect regional processes controlled by the ice sheet response to glacialinterglacial variability, such as current winnowing and changes in sedimentation rates, rather than regional-scale episodes of increased/decreased iceberg calving (Cofaigh and Dowdeswell, 2001).

\subsubsection{Issues with the interpretations of ice-rafted debris records}

Given the controls on IRD deposition discussed above, there are long standing debates regarding what IRD flux actually represents in terms of ice sheet stability, and the methodology used to derive IRD records. Clark and Pisias (2000) state that IRD layers derived from the AIS should show high sediment fluxes that span a short interval of time and cover a large area, as evidenced by Heinrich layers. Furthermore, the interpretation that IRD layers represent ice sheet instability is dependent on a number of assumptions: 1) IRD is delivered through fallout from icebergs rather 
than sea ice; 2 ) an increase in IRD is representative of an increased iceberg flux as opposed to a greater amount of debris incorporated at the base of the ice sheet from which icebergs are calved off; 3) the amount of IRD is the same in all icebergs, thus there is a correlation between IRD concentration and iceberg flux (Clark and Pisias, 2000). In reality, the amount of IRD deposited is dependent on the number and size of icebergs passing over the site, the proximity to the calving glaciers, the type of glacier it has calved from, drift paths relating to ocean currents changing through time, and the variability of sea ice and SSTs (see above) - all of which vary greatly with local climatic and glacial regimes (Gilbert, 1990; Powell and Domack, 1995). Considerable research is required to fully understand the IRD record around Antarctica and its relationship to past ice sheet dynamics. Therefore, IRD records in ice-proximal Antarctic continental margin settings are inferred to capture a local signal of ice sheet and sea ice-SST dynamics on the adjacent continental shelf, and their exact interpretation is dependent upon the framework provided by other related proxy records (Kanfoush et al., 2002; Teitler et al., 2010; Rashid et al., 2012).

\subsubsection{Methods to determine IRD flux rates}

Numerous methods have been used to determine the IRD content in sediment cores. The most frequently used methods include: 1) counting IRD particles in the $150 \mu \mathrm{m}-2 \mathrm{~mm}$ size fraction under the microscope where IRD particles are quartz, feldspars, mafic minerals and metamorphic lithic fragments with sharp, angular surfaces (Kanfoush et al., 2000; 2002; Murphy et al., 2002); 2) the weight percentages of the $250 \mu \mathrm{m}-2 \mathrm{~mm}$ size fraction as an IRD parameter (Krissek, 1995; Patterson et al., 2014); and 3) visually counting particles $>2 \mathrm{~mm}$ from the x-radiographs of the sediment core (Grobe, 1987; Weber et al., 2014). The cut-off point at 150 or $250 \mu \mathrm{m}$ eliminates the finer material transported within sea ice $(63-150 \mu \mathrm{m})$, and by other processes such as wind and resuspension by bottom currents (<63 $\mu \mathrm{m}$; Andrews, 2000). Recently, Passchier (2011) and Hansen et al. (2015) introduced a new methodology, where bulk sample is measured on an LPSA with a size range of $0.02-2000 \mu \mathrm{m}$, and the volume percentage of $>125 \mu \mathrm{m}$ is taken to represent the IRD content.

All individual methods have uncertainties. For example, when using weight-percentages and LPSA volume percentages, a single large dropstone in an IRD-poor interval would bias the results (Grobe, 1987). However, the bias would be more strongly pronounced in the case of the LPSA due to the smaller sampling size of $<0.15 \mathrm{~g}$ versus $\sim 15-20 \mathrm{~g}$ of sample used to obtain weight percentages. On the contrary, a higher proportion of larger IRD grains is required to obtain a significant result for the weight percentage. Visually counting grains, on $x$-radiographs or under 
the microscope, is considered a more reliable method but can be subject to operator-induced uncertainties (Grobe, 1987). 


\section{CHAPTER 3: REGIONAL SETTING}

\subsection{The Ross Sea}

The Ross Sea embayment and its associated basins (Eastern Basin, Central Basin and Victoria Land Basin) formed as a result of extensional stresses generated during the breakup of Gondwanaland (Anderson, 1999). The Ross Sea lies between the Transantarctic Mountains of Victoria Land in the west and Marie Byrd Land in the east $\left(150^{\circ} \mathrm{W}\right.$ to $163^{\circ} \mathrm{E}$; Figure 3.1$)$. To the south of the Ross Sea lies the RIS, the largest ice shelf in the world covering almost half of the continental shelf, and exerting a significant control on the regional ocean circulation (Orsi et al., 1999; Jacobs, 2004; Whitworth and Orsi, 2006; Orsi and Wiederwohl, 2009). Seaward of the RIS, the continental shelf deepens toward the continent and has an average depth of approximately $500 \mathrm{~m}$ (Davey, 2004). Numerous troughs trending northeast-southwest traverse the shelf and extend to the shelf break, and were carved by expanded ice streams during past advances of the marine-based ice sheet to the shelf edge during glacial periods (Figure 3.1; Anderson et al., 2014).

North of the shelf break, the upper continental slope (average gradient of $5^{\circ}$ ) is characterised by numerous gullies, which form a system of downslope trending, sinuous channels (Davey and Jacobs, 2007). The network of channels merges at the base of the gentle lower slope (average gradient of $1.5^{\circ}$ ) and develops into major canyons that continue down the continental rise (Vanney et al., 1981; Davey and Jacobs, 2007). These channels and canyons facilitate the downslope transport of sediment and act as conduits for the outflow of newly formed bottom waters. West of the Iselin Bank, the submarine canyons are more numerous and the continental rise is narrow (100 km wide) and highly irregular due to a mid-oceanic ridge topography that extends to $72^{\circ} \mathrm{S}$. East of the Iselin Bank, the continental rise is characterised by a large prograding fan formed by mass transport processes associated with the subglacial delivery of sediment to the shelf edge (De Santis et al., 1999). The troughs and associated intervening banks on the continental shelf focus sediment delivery on the upper continental slope, which then along with dense water masses enters into the continental slope channel system and the canyon network extending down the continental rise (Vanney et al., 1981; Davey and Jacobs, 2007; Smith et al., 2012a). There is also significant interplay between downslope and geostrophic (alongslope) currents, most notably the westward flowing ASC. Seismic profiles from the region show mounded and wavy sediment deposits, which indicate the contourite drifts are forming from reworked mass transport deposits beneath this current (Figure 3.2; McKay et al., 2016b). 


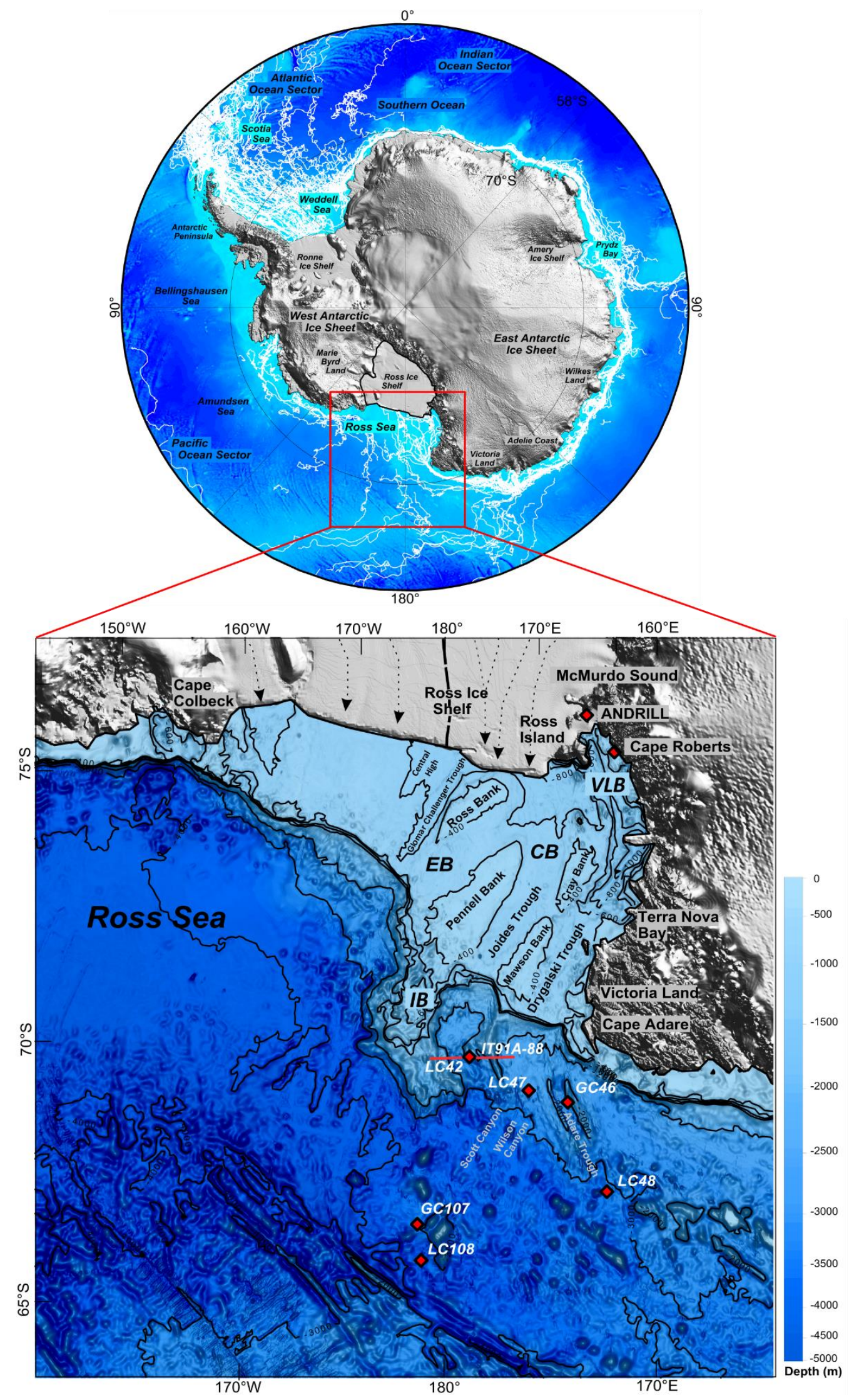


Figure 3.1: Map of the Antarctic continent and detailed bathymetry of the Ross Sea continental margin (inset depicted by red box). White lines around the Antarctic continents depict modern iceberg tracks (1999-2009; http://www.scp.byu.edu/data/iceberg/database1/). Inset map of the Ross Sea shows detailed bathymetry of the region with a contour interval of $200 \mathrm{~m}$, the locations of Eastern Basin (EB), Central Basin (CB), Victoria Land Basin (VLB), Iselin Bank (IB), the study sites (red diamonds), the location of a seismic line through site RS15-L42 (red line) and modern ice flow lines (black arrows) and divide between the WAIS and EAIS (black dashed line; Barrett, 1999). Bathymetry and topography are based on the ETOPO1 global relief model (https://www.ngdc.noaa.gov/mgg/global/).

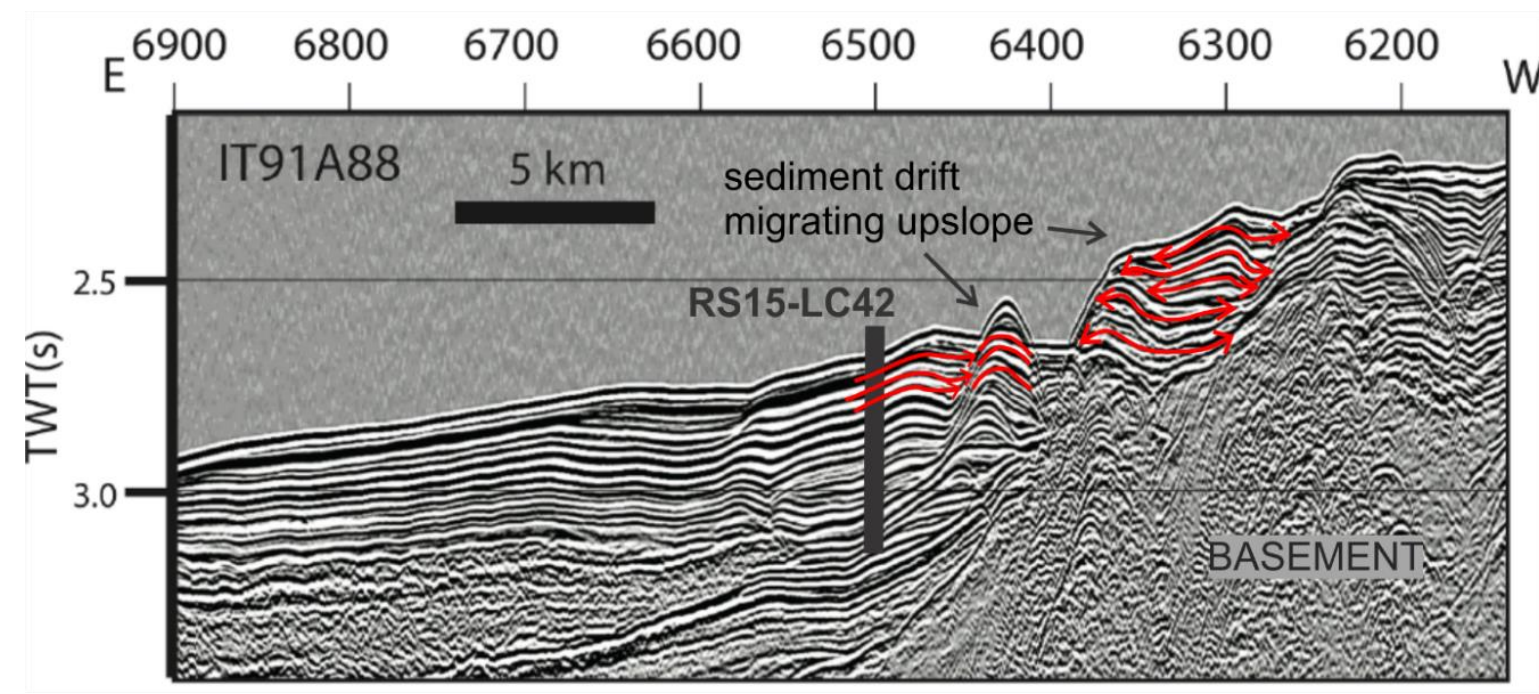

Figure 3.2: Seismic line IT91A88 showing contourite drifts at site RS15-LC42. Chaotic reflectors at 3.2 to 3.5 TWT(s) between shotpoints 6900 and 6600 are mass transport deposits that have subsequently been reworked by alongslope currents to form mounded drift deposits. Red arrows depict the sediment drift migrating upslope. Figure modified from McKay et al. (2016b).

\subsubsection{Physical oceanography of the Ross Sea}

Ocean circulation in the Ross Sea north of the continental shelf is dominated by the clockwise rotation of the Ross Sea gyre, which is driven by the westerly winds of the Antarctic Circumpolar Current (ACC) at its northern limb, and easterly winds at its southern limb. The Ross Sea gyre draws a relatively warm oceanic water mass, CDW, from the bypassing ACC. CDW originates in the North Atlantic as North Atlantic Deep Water (NADW) and as a result is low in oxygen, high in nutrients, and has relatively high temperatures $\left(>2^{\circ} \mathrm{C}\right)$ compared to overlying and underlying water masses. CDW cools as it is transported within the Gyre $\left(\sim 1.5^{\circ} \mathrm{C}\right.$ in the Ross Sea region) and mixes with shelf and surface waters as it moves onto the continental shelf to become modified CDW (MCDW; Orsi and Wiederwohl, 2009). Input of MCDW onto the shelf is critical to the regional sea-ice cycle and basal melt rate of the RIS (Smith et al., 2012a), as well as primary productivity in the Ross Sea (Arrigo et al., 2008), as it is the primary oceanic source of heat and nutrients. 
Unlike the Amundsen and Bellingshausen Seas, where the tight ACC flow across the continental slope allows for the relatively uninterrupted presence of CDW on the inner shelf, a sharp subsurface front (Antarctic Slope Front; ASF) separates cold fresh Antarctic Surface Waters (AASW) from underlying MCDW. AASW is the result of continental meltwater derived from sea ice/ice shelf melt and precipitation (Smith et al., 2012a). The ASF is focussed on the upper continental slope, and is maintained by the westward-flowing ASC, which combines with the AASW water mass to act as a hydrographic barrier limiting the transfer of MCDW onto the Ross Sea continental shelf (Smith et al., 2012b). The ASC also carries a layer of cold and fresh AASW from the Amundsen Sea into the Ross Sea (AASW; Whitworth et al., 1998).

Sea ice and polynyas are important controls on Ross Sea water mass formation. Polynyas are generated in winter due to strong offshore katabatic winds that lead to the offshore movement of sea ice. Polynyas expand during spring and summer as sea ice formation in the polynya is outpaced by melting and advection (Arrigo and van Dijken, 2004). In the Ross Sea there are three persistent polynyas: the Ross Sea polynya, the largest Antarctic coastal polynya that forms adjacent the RIS to the east of Ross Island, and two smaller polynyas that form in Terra Nova Bay and McMurdo Sound (Martin et al., 2007). The persistence of strong katabatic winds over the polynyas during winter results in continual freezing of ocean water and export of sea ice. The combination of cooling MCDW and increased salinity due to brine rejection during sea ice formation produces dense, High Salinity Shelf Water (HSSW; $<-1.9^{\circ} \mathrm{C},>34.6 \mathrm{~g} / \mathrm{kg}$ ) in the western Ross Sea (Orsi and Wiederwohl, 2009; Smith et al., 2012b). In the central and eastern Ross Sea, slightly less dense, Low Salinity Shelf Water (LSSW; $<1.8^{\circ} \mathrm{C}, 34.4-34.6 \mathrm{~g} / \mathrm{kg}$ ) is produced due to progressive basal melting of glacial ice by inflows of warm MCDW onto the continental shelf (Orsi and Wiederwohl, 2009; Smith et al., 2012b).

The shelf waters mix with cold, fresh ASW and warm, salty MCDW at the ASF to form AABW, the dominant abyssal water mass in the world ocean (Whitworth et al., 1998; Orsi and Wiederwohl, 2009). Mixing of the parent water masses and export of the resultant AABW to adjacent ocean basins is facilitated by strong tidal currents along the continental slope (Whitworth and Orsi, 2006; Muench et al., 2009; Padman et al., 2009). The newly formed bottom water is transferred from the Ross Sea continental shelf via cascading gravity currents down the channel network, through the Drygalski, Joides and Glomar Challenger troughs and Hilary, Scott and Wilson canyons into the abyssal ocean (Gordon et al., 2004; 2009; Davey and Jacobs, 2007). The major ocean circulation features over the Ross Sea continental shelf are summarised in Figure 3.3. 
The western Ross Sea is estimated to produce $\sim 20 \%$ of AABW that primarily enters the SE Pacific Basin (Jacobs, 2004), with Weddell Sea and the Wilkes Land margin including the Adelie Coast contributing $~ 50 \%$ and $30 \%$ primarily to the Indian Ocean, respectively (Rintoul, 1998). The subsequent export of AABW to world oceans contributes to the net cooling and ventilation of the deep ocean. Thus, AABW production and its variability in the western Ross Sea is an important aspect of the global thermohaline circulation, which plays a central role in climate variability by transporting heat, salt, carbon and nutrients around the globe (Figure 3.4; Orsi et al., 2001; 2002; Marshall and Speer, 2012).
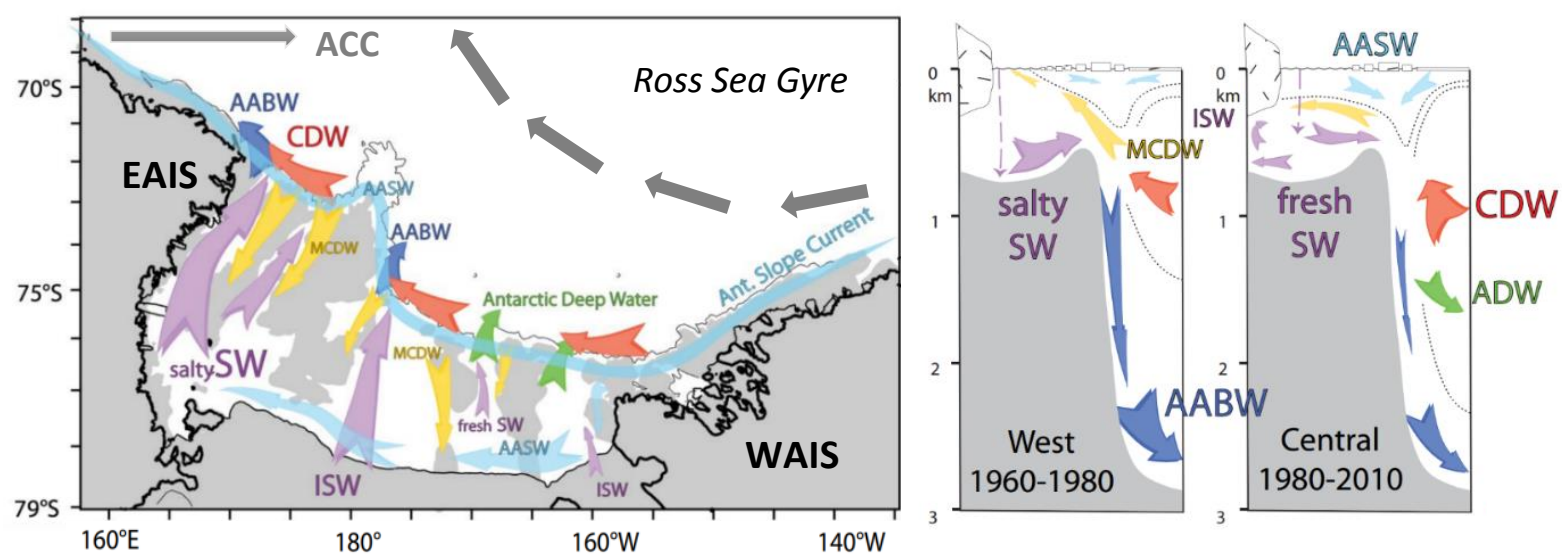

Figure 3.3: Map of the Ross Sea continental shelf highlighting major circulation features and conditions observed during the past 50 years. Size of arrow indicates relative strength of flow. Antarctic Surface Water: AASW (light blue); Ice Shelf Water: ISW (purple); Modified Circumpolar Deep Water; MCDW (orange), Circumpolar Deep Water: CDW (red); Antarctic Deep Water (green); Antarctic Bottom Water: AABW (dark blue); Antarctic Circumpolar Current: ACC (grey); East Antarctic Ice Sheet: EAIS; West Antarctic Ice Sheet: WAIS. Figure modified from Smith et al. (2012a). 


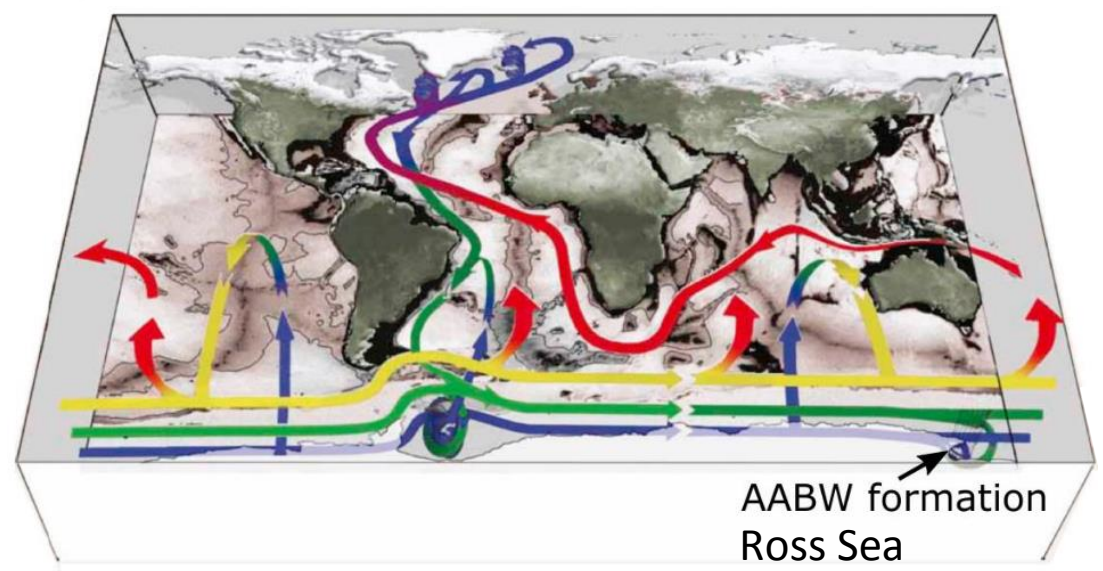

Figure 3.4: Global thermohaline circulation highlighting AABW formation at its southern limb. Cold water: blue and green arrows. Warm water: red and yellow arrows. Figure modified from Marshall and Speer, (2012).

3.1.2 Oceanographic changes in the Ross Sea during the observational period (1958 to present)

A number of studies outline evidence for widespread freshening of Ross Sea-derived AABW from 1958-2008 (Jacobs et al., 2002; Jacobs and Giulivi, 2010). The principal cause for these changes has been attributed to the cryosphere connection between intensification and southward shift of the zonal polar winds (i.e., subpolar westerlies and polar easterlies) and the location and intensity of the ocean fronts and currents (Thompson and Solomon, 2002; Russell et al., 2006). Such changes have been proposed to strengthen the ASC (Kida, 2011), which controls the frequency and strength of CDW (or MCDW when mixing with AASW has occurred) intrusions onto the Ross Sea continental shelf, thus leading to melting of marine-based ice and increased meltwater input (Jacobs et al., 2011; Pritchard et al., 2012), with significant consequences for the stability of the WAIS and the global thermohaline circulation (Smith et al., 2012a;b). 

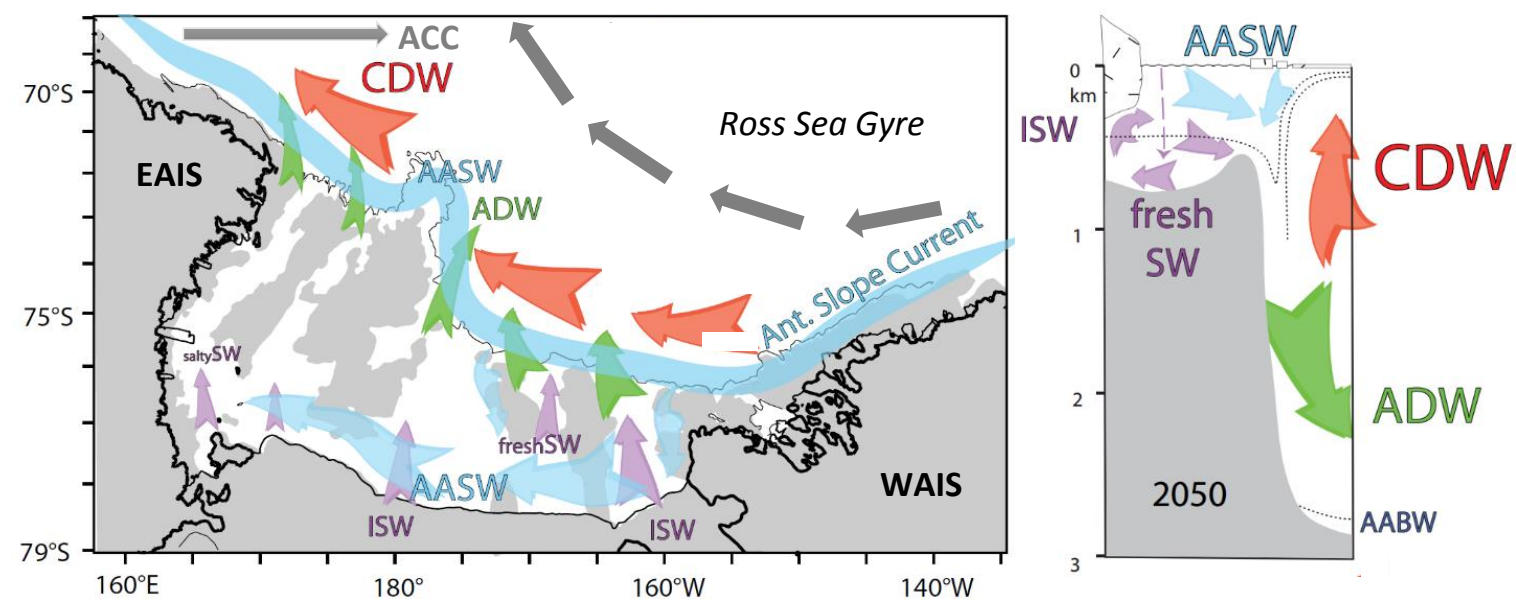

Figure 3.5: Hypothesised intensification of the ASC leading to an alternative mode of deep ocean ventilation during the next century. Size of arrow indicates relative strength of flow. Antarctic Surface Water: AASW (light blue); Ice Shelf Water: ISW (purple); Circumpolar Deep Water: CDW (red); Antarctic Deep Water: ADW (green); Antarctic Bottom Water: AABW (dark blue); Antarctic Circumpolar Current: ACC (grey). Figure modified from Smith et al. (2012a).

\subsubsection{Sea Ice}

At present, Antarctic sea ice extends out to $\sim 60^{\circ} \mathrm{S}$ in the Pacific, and $\sim 55^{\circ} \mathrm{S}$ in the Atlantic and Indian Oceans, with the average extent varying from a minimum of $3.5 \times 10^{6} \mathrm{~km}^{2}$ in February to a maximum of $18 \times 10^{6} \mathrm{~km}^{2}$ in September (Gloersen et al., 1992; Comiso et al., 2011). Sea ice formation is controlled by seasonal variations in SST $\left(<1.86^{\circ} \mathrm{C}\right.$ for sea ice formation), salinity and surface wind speed, which advects sea ice away from the site of formation (Ackley \& Sullivan, 1994; Pezza et al., 2012). The seasonal growth and decay of Antarctic sea ice regulates the exchange of heat and gases between the ocean and atmosphere, affects the formation of bottom waters, ocean stratification, and primary productivity in the ocean, and influences atmospheric circulation on a global scale (Gersonde and Zielinski, 2000; Pezza et al., 2012).

At glacial-interglacial timescales, Antarctic sea ice affects the global surface albedo, as well as the ventilation of $\mathrm{CO}_{2}$ from deep waters in the Southern Ocean. Combined, these changes act as a positive feedback that greatly amplifies the response of the climate system to orbital variations (Gersonde and Zielinski, 2000; Stephens and Keeling, 2000). Increased aeolian deposition of iron (Fe) in the Subantarctic Zone $\left(46^{\circ} \mathrm{S}-60^{\circ} \mathrm{S}\right)$ during glacial periods further contributes to this positive feedback by increasing primary productivity and hence the biological sequestration of $\mathrm{CO}_{2}$ (Martin, 1990; Stephens and Keeling, 2000). Thus, Antarctic sea ice is a first order control on regulating variations in the past climate of the planet. 


\subsubsection{Primary Production}

Sea ice dynamics are one of the principal controls on primary production in the Southern Ocean with the resulting impact on upper-ocean stratification affecting the availability of light and nutrients essential for phytoplankton (Arrigo et al., 1998; Arrigo and van Dijken, 2004). The Southern Ocean is rich in macronutrients such as nitrate $\left(\mathrm{NO}_{3}{ }^{-}\right)$, phosphate $\left(\mathrm{PO}_{4}{ }^{3-}\right)$ and silicate $\left(\mathrm{SiO}_{4}{ }^{4-}\right)$, but is characterised by relatively low rates of primary production due to low concentrations of micronutrients such as Fe, which phytoplankton utilise in order to synthesise chlorophyll, and thus photosynthesise (Martin, 1990; Arrigo et al., 1998). An increase in atmospheric supply of Fe by dust transport off the exposed continental shelves during glacial periods is hypothesised to have stimulated marine productivity in high nutrient regions like the Southern Ocean (Martin et al., 1990; Martinez-Garcia et al., 2011). At present, regions of high productivity in the Southern Ocean include: 1) zones of micronutrient upwelling such as the Antarctic Polar Front; 2) marginal ice zones on the Antarctic continental shelf where atmospherically-derived dust in sea ice melt, iceberg calving, meltwater plumes, sediment resuspension and upwelling of nutrient-rich MCDW provide additional sources of Fe; and 3) Antarctic coastal polynyas, which due to the year-round open waters are the first marine coastal systems to receive increased solar insolation and meltwater stratification (Prézelin et al., 2000; Arrigo and van Dijken, 2004; Arrigo et al., 2008).

The Ross Sea is the most productive sector of the Southern Ocean, with rates of primary production often exceeding $2 \mathrm{~g} \mathrm{C} \mathrm{m}^{-2} \mathrm{~d}^{-1}$ (Arrigo et al., 2000). The western Ross Sea is subject to an increased flux of BiSi due to diatom growth occurring in highly-stratified waters on the continental shelf that are formed by coastal sea ice melt, although $65 \%$ of the silica produced by diatoms dissolves within the upper $50 \mathrm{~m}$ of the water column, yielding a mean silica production rate of $7.4 \times 10^{-3} \mathrm{~g} \mathrm{~cm}^{-2} \mathrm{y}^{-1}$ (DeMaster et al., 1992). Advective transport of siliceous material by west- and south-ward flowing marine currents also contributes to higher BiSi fluxes in the western Ross Sea, such that BiSi content in surface sediments on the continental shelf ranges from $~ 2 \%$ (by weight) in the eastern and central Ross Sea to $\sim 41 \%$ in the southwestern Ross Sea (Dunbar et al., 1985; Ledford-Hoffman et al., 1986).

\subsubsection{Sediments}

Surface sediments in the Ross Sea are the product of biological (i.e., primary production) and terrigenous (i.e., land-derived) inputs. Consequently, the sediments comprise of highly variable mixtures of siliceous mud and ooze, calcareous shell material, unsorted IRD, and terrigenous silts 
and clays that are entrained by currents at the base of ice streams and the grounding line of the WAIS (Anderson et al., 1984; Dunbar et al., 1985). The distribution of these sediments reflects the relative influence of ocean circulation, biological processes and the morphology of the continental margin (Dunbar et al., 1985; Anderson, 1999).

\section{Continental shelf}

On the continental shelf, glacial sediments (e.g., diamictons which are composed of poorly sorted mixtures of gravel, sand and mud) are overlain by a Holocene cover of hemipelagic and pelagic material (Anderson et al., 1980; Domack et al., 1999). Generally, muddy sediment is present in the deeper parts of the continental shelf $(>300 \mathrm{~m})$, reflecting quiescent bottom conditions. In contrast, sands and gravels are common in shallower portions of the shelf $(<300 \mathrm{~m})$, reflecting the action of wave- and wind-driven bottom currents that are effective at sorting sediment to depths of up to 300 m (Chriss and Frakes, 1972; Anderson et al., 1984). Grounding of large outlet glaciers during past glacial periods has deepened the inner shelf (Anderson et al., 1984). As a result, finegrained sediments including terrigenous silts and fine sands, siliceous mud composed of diatom frustules and sponge spicules, and unsorted IRD are present in the glacially scoured troughs and basins of the inner continental shelf.

\section{Continental slope and rise}

The shelf break to upper continental slope is blanketed by bioclastic rippled sands and gravel lags (Anderson et al., 1984; Anderson, 1999). This reflects sorting and winnowing by geostrophic currents impinging on the upper slope (Chriss and Frakes, 1972; Anderson et al., 1984; Anderson, 1999). The winnowed sediments, including fine-grained biogenic material, are transported north to the abyssal ocean and south into the deep basins of the shelf, where quiescent bottom conditions allow the sediment to settle out from suspension (Dunbar et al., 1985; Anderson, 1999). Gravel lags and rippled sands are also found in the channel system of the western part of the continental slope, consistent with strong currents that funnel the newly formed bottom water to the abyssal ocean (Anderson, 1999). In contrast, sediments on the lower slope and continental rise, with the exception of sediment gravity flows, comprise of mud and laminated mud, characteristic of weak bottom currents (Anderson, 1999).

\section{Sediment dispersal mechanisms}

Gravity sediment flows (e.g., debris and turbidity flows) play a significant role in regulating sediment dispersal on the Ross Sea continental margin, and in the delivery of terrigenous and 
reworked biogenic material to the abyssal environment. Sediment gravity flows can be initiated at shallow depths on the continental shelf due to the irregular, glacially scoured topography. On the steeper continental slope and rise, gravity flows may occur due to large volume of accumulated eroded material being delivered to the continental shelf edge by repeated grounding of the WAIS (Anderson, 1999; Domack et al., 1999). This is most apparent in the Eastern Basin, where the continental slope to rise is characterised by a large Plio-Pleistocene prograding fan consisting of mass transport deposits (Brancolini et al., 1995). Other deposits are common along the flanks of troughs adjacent to banks (e.g., the flanks of the Pennell and Mawson banks) and in the canyon network of the western slope and rise (Anderson, 1999).

\subsection{Site summary}

Sites RS15-LC42, RS15-GC46, RS15-LC47 and RS15-LC48 form a transect along the upper to lower continental rise of the Ross Sea continental margin, and are $\sim 302 \mathrm{~km}, \sim 128 \mathrm{~km}, \sim 184 \mathrm{~km}$ and $\sim 275 \mathrm{~km}$ offshore Cape Adare, respectively. RS15-LC42 is the shallowest site (2084 m water depth) and lies on the flanks of the Hallet Ridge directly down-path of Joides Trough. The deeper sites RS15-LC46 (2434 m water depth) and RS15-LC47 (2417 m water depth) are located within the Adare Trough, and on a channel-levee complex bounded by the Scott and Wilson Canyons, respectively. RS15-LC48 is the deepest site $(3207 \mathrm{~m})$ and lies $100 \mathrm{~km}$ down-path of the Adare Trough. Cores RS15-GC107 (3050 m water depth) and RS15-LC108 (3690 m water depth) are located on the abyssal plain, $\sim 280 \mathrm{~km}$ and $\sim 340 \mathrm{~km}$ north from Iselin Bank. Figure 3.6 illustrates the site locations in relation to the Ross Sea continental margin bathymetric features and water mass circulation.

Presently, sea ice covers the core sites 9-10 months of the year, while open marine conditions persist during the Austral summer from January to March, although the more proximal sites (e.g., RS15-LC42) may be subject to increased duration of summer sea ice cover. Sea ice advances rapidly from March, reaching its maximum extent between July and September to $64^{\circ} \mathrm{S}$ north of Cape Adare, then retreats slowly during spring melting attaining its minimum extent in February to $72^{\circ} \mathrm{S}$ south of Cape Adare (Figure 3.7a). The average summer SST at the sites is $\sim 0^{\circ} \mathrm{C}$ (Figure 3.7b). The core sites lie directly in the path of ice bergs calving from the Amundsen Sea embayment and the RIS (Figures 3.1 and 3.7a) and are located in a relatively low productivity area several hundred kilometers north of the large Ross Sea polynya and the smaller McMurdo Sound and Terra Nova Bay polynyas (Figure 3.7c). The core sites along the continental rise are 
particularly exposed to eddies of CDW, inflows of MCDW and outflow of newly formed AABW, and are subject to both downslope and along currents as summarised in Figure 3.6.

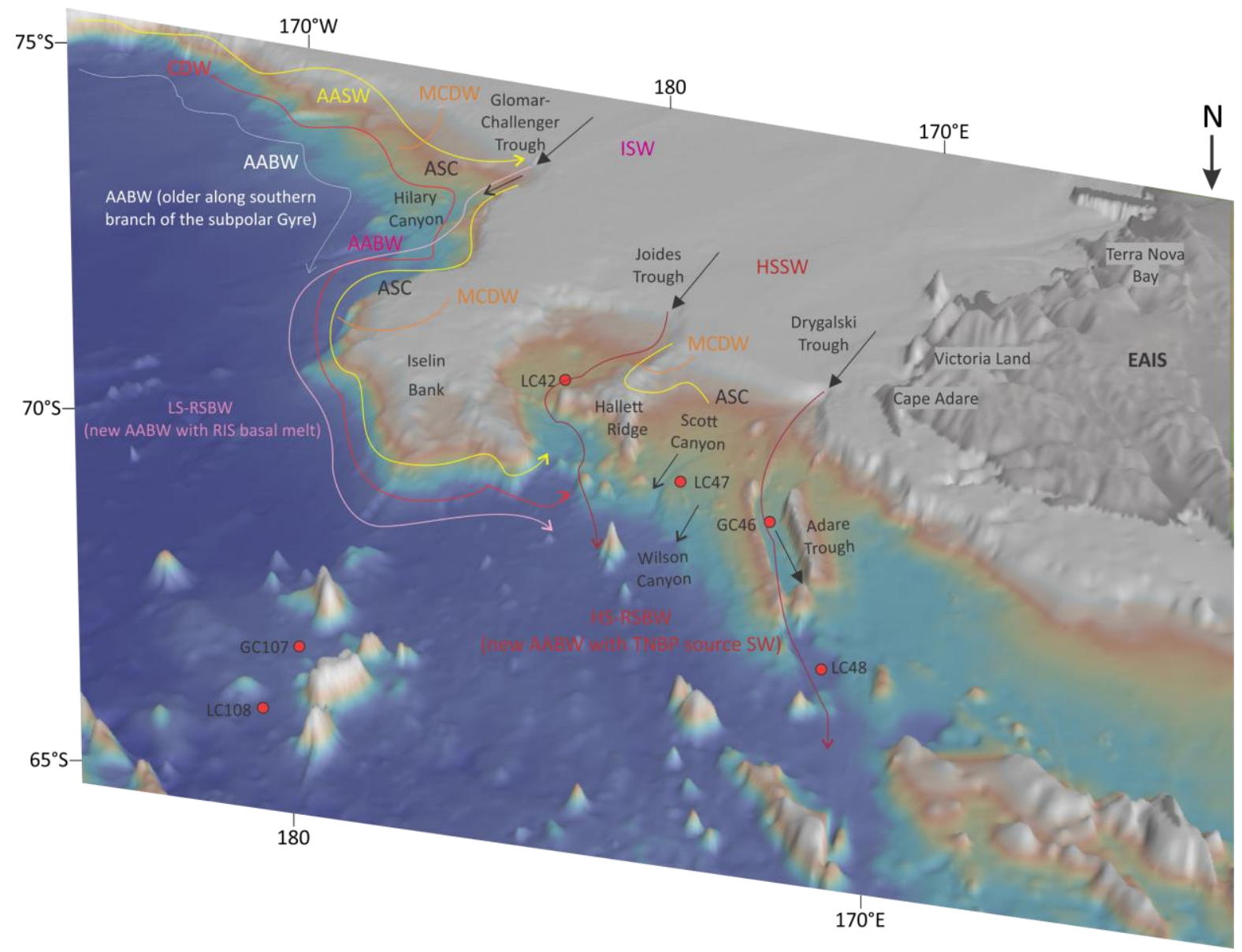

Figure 3.6: 3D map of the Ross Sea continental margin. The map illustrates the main water mass flows (coloured arrows), the location of troughs and canyons (black arrows) and the study locations (red circles). Antarctic Surface Water: AASW (yellow); Antarctic Bottom Water: AABW (white and pink); Circumpolar Deep Water: CDW (red); Modified Circumpolar Deep Water: MCDW (orange); High Salinity Shelf Water: HSSW (dark red); Ice Shelf Water: ISW (dark pink); Low Salinity Ross Sea Bottom Water: LS-RSBW (light pink); High Salinity Ross Sea Bottom Water: HS-RSBW (dark red); Antarctic Slope Current: ASC (black). Figure re-drawn from McKay et al. (2016b). 

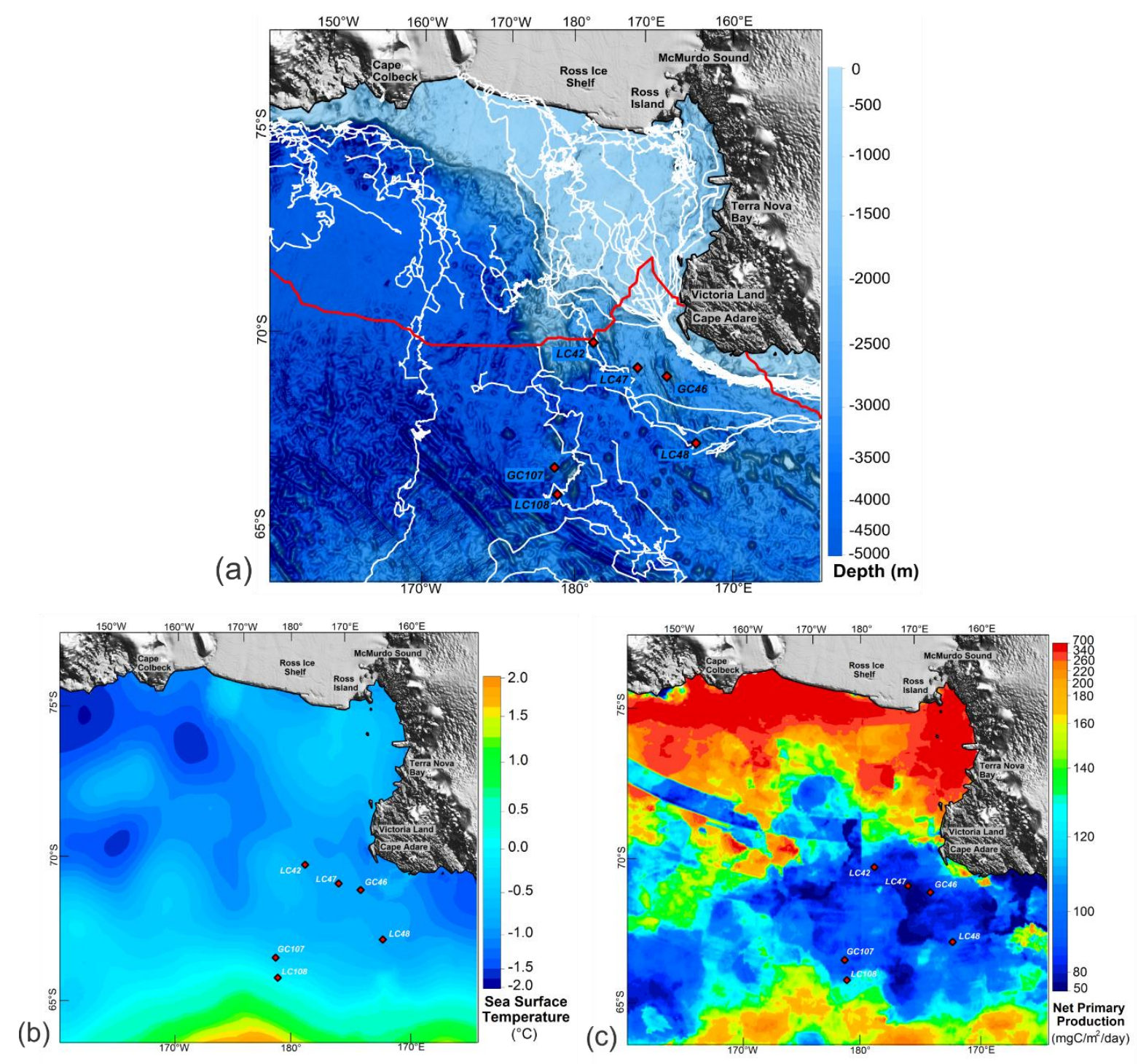

Figure 3.7: Maps of (a) modern ice berg tracks (white lines; 1999-2009); http://www.scp.byu.edu/data/iceberg/database1/) and the median summer sea ice extent (red line; 1979-present; http://nsidc.org/data/seaice_index/archives.html), (b) Summer SSTs (January-March, 1955-2012; https://www.nodc.noaa.gov/OC5/woa13/), and (c) Summer net primary productivity (20022015; http://www.science.oregonstate.edu/ocean.productivity/index.php). Red diamonds denote study locations. 


\section{CHAPTER 4: METHODOLOGY}

\subsection{Core sampling and description}

Sediment gravity cores (11 cm diameter) RS15-LC42, RS15-GC46, RS15-LC47, and RS15-LC48 were retrieved during the austral summer of $2014 / 15$ by the KOPRI Icebreaker R/V ARAON during cruise RS15 (Table 4.1). The cores were split and visual core descriptions were undertaken in August 2015 at KOPRI (Incheon, Republic of Korea). The working halves of the cores were visually described and sampled by KOPRI staff and New Zealand researchers. These descriptions were subsequently modified for this thesis following quantitative grain size analysis and classified according to the clastic lithology scheme of Mazzulo and Graham (1988) for fine-grained sediments, and Moncrieff's (1989) classification scheme for poorly sorted terrigenous clastic sediments containing gravel (>2 mm) (Figure 4.1). This approach is designed to allow for a more direct comparison of these results to geological drill cores collected by ANDRILL (Krissek et al., 2007), and IODP Expedition 318 to Wilkes Land (Escutia et al., 2011) and the upcoming IODP Expedition 374 to the Ross Sea (McKay et al., 2016b).

1-cm-thick, 8-cm-wide and 30-cm-long slabs from the center of each split core section were cut out, placed on plastic plates and imaged using an x-radiograph system (carried out by KOPRI technical staff). Discrete samples for geochemical and grain size analysis were collected from cores RS15-LC42 and RS15-LC48 following the x-ray slab sampling.

Sediment gravity cores RS15-GC107 and RS15-LC108 were collected during the following austral summer of $2015 / 16$, and have only been initially described by KOPRI scientists. They are included in this thesis to assess if preliminary non-destructive datasets (point magnetic susceptibility, $\mathrm{x}$-ray image analysis) can be used to identify the same sedimentary patterns identified in the better characterised cores, and provide a preliminary age model based on cyclostratigraphy. Consequently, the results, and in particular the age model inferences from these cores, are preliminary and need to be verified by additional data - most notably paleomagnetic chronological constraints. 
Table 4.1: Location and details of the retrieved sediment cores.

\begin{tabular}{llllll}
\hline Core ID & Latitude & Longitude & $\begin{array}{c}\text { Water } \\
\text { Depth }(\mathrm{m})\end{array}$ & $\begin{array}{c}\text { Total } \\
\text { length }(\mathrm{cm})\end{array}$ & $\begin{array}{c}\text { Number of } \\
\text { sections }\end{array}$ \\
\hline RS15-LC42 & $71^{\circ} 49.3969 \mathrm{~S}$ & $178^{\circ} 34.7602 \mathrm{E}$ & 2084 & 1175 & 9 \\
RS15-GC46 & $70^{\circ} 36.1129 \mathrm{~S}$ & $172^{\circ} 53.5816 \mathrm{E}$ & 2434 & 666 & 5 \\
RS15-LC47 & $70^{\circ} 50.7003 \mathrm{~S}$ & $175^{\circ} 04.1603 \mathrm{E}$ & 2417 & 1375.5 & 10 \\
RS15-LC48 & $68^{\circ} 53.9289 \mathrm{~S}$ & $171^{\circ} 09.5914 \mathrm{E}$ & 3207 & 1471 & 11 \\
RS15-GC107 & $68^{\circ} 04.0741 \mathrm{~S}$ & $178^{\circ} 37.9066 \mathrm{~W}$ & 3050 & 858 & - \\
RS15-LC108 & $67^{\circ} 29.6139 \mathrm{~S}$ & $178^{\circ} 45.1185 \mathrm{~W}$ & 3690 & 1740 & - \\
\hline
\end{tabular}

(a)

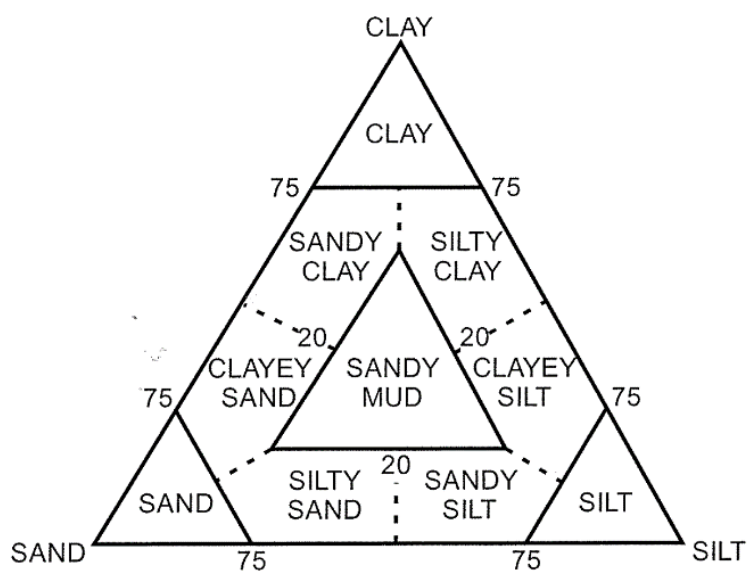

\begin{tabular}{|c|c|c|c|c|c|c|}
\hline & \multicolumn{6}{|c|}{ PERCENT GRAVEL $(>2 \mathrm{~mm})$ IN WHOLE ROCK ESTIMATED FROM CORE } \\
\hline $0-$ & & Trace $(<1 \%)$ & $1-5 \%$ & $5-30 \%$ & $30-80 \%$ & $>80 \%$ \\
\hline $0-$ & \multirow{4}{*}{$\begin{array}{l}\text { FINE-GRAINED } \\
\text { SEDIMENTS }\end{array}$} & $\begin{array}{l}\text { MUDSTONE with } \\
\text { dispersed clasts }\end{array}$ & $\begin{array}{l}\text { MUDSTONE with } \\
\text { common clasts }\end{array}$ & $\begin{array}{l}\text { MUDSTONE with } \\
\text { abundant clasts }\end{array}$ & \begin{tabular}{|c|} 
Muddy \\
CONGLOMERATE / \\
BRECCIA
\end{tabular} & \multirow{4}{*}{$\begin{array}{c}\text { CONGLOMERATE } \\
\text { BRECCIA }\end{array}$} \\
\hline 䇏 & & $\begin{array}{c}\text { Sandy MUDSTONE } \\
\text { with dispersed } \\
\text { clasts }\end{array}$ & $\begin{array}{l}\text { Clast-poor muddy } \\
\text { DIAMICTITE }\end{array}$ & $\begin{array}{l}\text { Clast-rich muddy } \\
\text { DIAMICTITE }\end{array}$ & $\begin{array}{c}\text { Sandy muddy } \\
\text { CONGLOMERATE / } \\
\text { BRECCIA }\end{array}$ & \\
\hline$\sum_{\breve{u}}^{0}$ & & $\begin{array}{c}\text { Muddy } \\
\text { SANDSTONE with } \\
\text { dispersed clasts }\end{array}$ & $\begin{array}{l}\text { Clast-poor sandy } \\
\text { DIAMICTITE }\end{array}$ & $\begin{array}{l}\text { Clast-rich sandy } \\
\text { DIAMICTITE }\end{array}$ & $\begin{array}{c}\text { Muddy sandy } \\
\text { CONGLOMERATE / } \\
\text { BRECCIA }\end{array}$ & \\
\hline & & $\begin{array}{l}\text { SANDSTONE with } \\
\text { dispersed clasts }\end{array}$ & $\begin{array}{l}\text { SANDSTONE with } \\
\text { common clasts }\end{array}$ & $\begin{array}{l}\text { SANDSTONE with } \\
\text { abundant clasts }\end{array}$ & $\begin{array}{c}\text { Sandy } \\
\text { CONGLOMERATE / } \\
\text { BRECCIA }\end{array}$ & \\
\hline
\end{tabular}

Figure 4.1: Classification schemes for (a) fine-grained terrigenous clastic sediments (after Mazzulo and Graham, 1988) and (b) poorly sorted terrigenous clastic sediments containing gravel (after Moncrieff, 1989). 


\subsection{Ice-rafted debris counting and conversion}

Sedimentary grains $>2 \mathrm{~mm}$ in diameter were identified manually in $\mathrm{x}$-ray images and their stratigraphic depth recorded using a custom-made script in Matlab (Figure 4.2). The occurrence of grains $>2 \mathrm{~mm}$ was then summed in $5 \mathrm{~cm}$ depth increments. This methodology is consistent with previous ship-based investigations of Antarctic continental margin sediments, with the abundance of material $>2 \mathrm{~mm}$ considered a reliable indicator of the content of IRD (e.g., Grobe, 1987; Weber et al., 2014). Two repeat counts were carried out for each core to reduce operator error (note for peer-review publication, these counts should ideally be conducted by separate operators). The final IRD count data is an average of the two IRD count runs. IRD counts for individual cores are available in Appendix B.

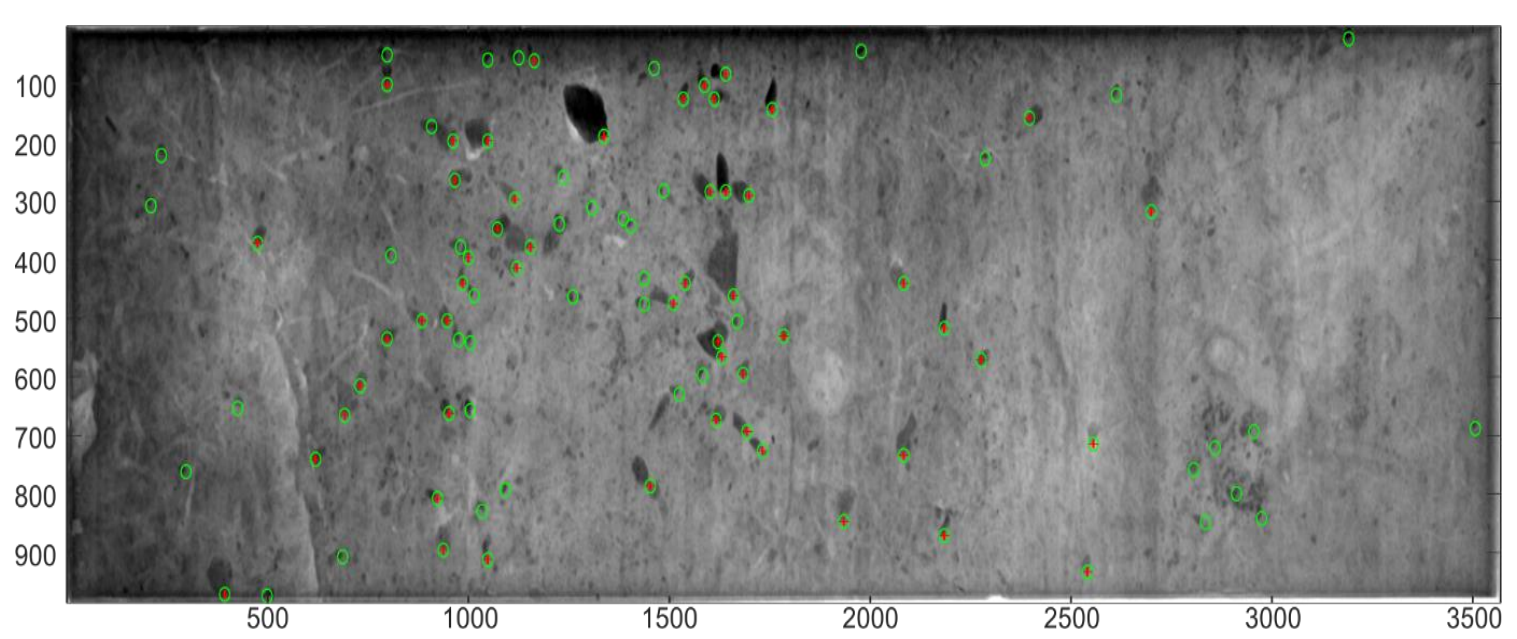

Figure 4.2: X-ray image (RS15-LC42, $188.5-218.5 \mathrm{cmbsf}$ ) with selected IRD clasts $>2 \mathrm{~mm}$ in diameter (green circle with red cross denoting the lower corner of the grain) and selected clasts that are below $2 \mathrm{~mm}$ in diameter (green circle). Note, all visible grains are selected and the matlab script identifies those exceeding $2 \mathrm{~mm}$ in diameter.

\subsection{Grain size analysis}

RS15-LC48 was sampled approximately every $20 \mathrm{~cm}$ (total of 74 samples), and RS15-LC42 was sampled at a higher resolution, approximately every $10 \mathrm{~cm}$ (total of 121 samples) for grain size analysis.

\subsubsection{Ice-rafted debris determined by weight percentages}

Approximately $15 \mathrm{~cm}^{3}$ of dry sample (oven dried at $50^{\circ} \mathrm{C}$ for 24 hours) were initially weighed and then wet sieved at $250 \mu \mathrm{m}$. The $<250 \mu \mathrm{m}$ fraction was left to settle, the residual water was then siphoned off and the samples were oven dried at $50^{\circ} \mathrm{C}$ and weighed. The $>250 \mu \mathrm{m}$ fraction was oven dried at $50{ }^{\circ} \mathrm{C}$ overnight and then dry sieved at 250-355 $\mu \mathrm{m}$ and $355 \mu \mathrm{m}-2 \mathrm{~mm}$. 
The 250-355 $\mu \mathrm{m}$ and $355 \mu \mathrm{m}-2 \mathrm{~mm}$ size fractions for each sample were visually checked under a stereo microscope for biogenic components, including $\mathrm{BiSi}$ and $\mathrm{CaCO}_{3}$. If present, the foraminifera Neogloboquadrina pachyderma (sinistral) and Cibicides spp. were hand-picked from this material with a brush and stored for later analysis.

After foraminifera were extracted, the $250-355 \mu \mathrm{m}$ and $355 \mu \mathrm{m}-2 \mathrm{~mm}$ size fractions were combined and submersed in $\sim 20 \mathrm{~mL}$ of $10 \%$ hydrochloric acid $(\mathrm{HCl})$ for approximately two hours to dissolve any remaining $\mathrm{CaCO}_{3}$. The remaining $\mathrm{HCl}$ and reaction product was subsequently removed from the subsamples by adding Milli-Q water to the samples and centrifuging them three times for ten minutes each at $4700 \mathrm{rpm}$.

Next, BiSi was removed by adding $20 \mathrm{~mL}$ of $1 \mathrm{M}$ sodium hydroxide $(\mathrm{NaOH})$ for a 72 -hour period. The samples were heated in a water bath to $70^{\circ} \mathrm{C}$ and occasionally stirred (Lewis and McConchie, 1994). The samples were subsequently washed in Milli-Q water and centrifuged three times for ten minutes each at $4700 \mathrm{rpm}$. The washed samples were then oven dried at $50^{\circ} \mathrm{C}$ overnight and final weights recorded.

Hydrogen peroxide $\left(\mathrm{H}_{2} \mathrm{O}_{2}\right)$ treatment to dissolve organic matter was not deemed necessary for this analysis as organic matter is bound to the clay-rich fraction $(<4 \mu \mathrm{m})$ of the sediment and does not influence the weight of the sand fraction $(63 \mu \mathrm{m}-1 \mathrm{~mm}$ ) (Lewis and McConchie, 1994).

\subsubsection{Laser particle sizer analysis}

In order to characterise the sedimentation trends for RS15-LC42 and RS15-LC48, the grain size distribution of a small subsample of the bulk sample was carried out. Approximately $2 \mathrm{~g}$ of bulk sample were treated with $10 \% \mathrm{HCl}$ (as described above). Organic matter was removed next by adding $20 \mathrm{~mL}$ of $27 \%$ hydrogen peroxide $\left(\mathrm{H}_{2} \mathrm{O}_{2}\right)$ to the bulk samples for a 72 -hour period, heating them in a water bath at $70^{\circ} \mathrm{C}$ and stirring them occasionally (Lewis and McConchie, 1994). The samples were subsequently washed in Milli-Q water and centrifuged three times for ten minutes each at $4700 \mathrm{rpm}$ to remove the remaining $\mathrm{H}_{2} \mathrm{O}_{2}$ and reaction product.

A key aspect of this work is to test for methodological uncertainties regarding the dissolution of $\mathrm{BiSi}$, which is a common component of Antarctic margin sediments and may have a significant influence on the grain size distribution. This material needs to be removed in order to quantify IRD MARs using LPSA methods (e.g., Passchier, 2011). Seven samples were randomly selected from RS15-LC42, and subsampled three times. The first set of subsamples was used as a control 
and remained untreated, while the second set of subsamples was treated with $\sim 20 \mathrm{~mL} 0.2 \mathrm{M} \mathrm{NaOH}$ solution, following the methodology of Passchier (2011). The third set of subsamples was treated with $1 \mathrm{M} \mathrm{NaOH}$ (as described above), as a more aggressive treatment for the removal of BiSi.

Smear slides of the untreated, and $0.2 \mathrm{M} \mathrm{NaOH}$ and $1 \mathrm{M} \mathrm{NaOH}$ treated samples were examined under a binocular microscope. All samples treated with $0.2 \mathrm{M} \mathrm{NaOH}$ showed evidence of common sponge spicule fragments and partially dissolved diatoms, and thus the $0.2 \mathrm{M} \mathrm{NaOH}$ treatment was deemed inadequate for dissolving the BiSi fraction of the sediment. Smear slides of the $1 \mathrm{M}$ $\mathrm{NaOH}$ treatment showed almost complete dissolution of BiSi with rare instances of wispy "spines" and fragments from diatom remains (Figure 4.3).

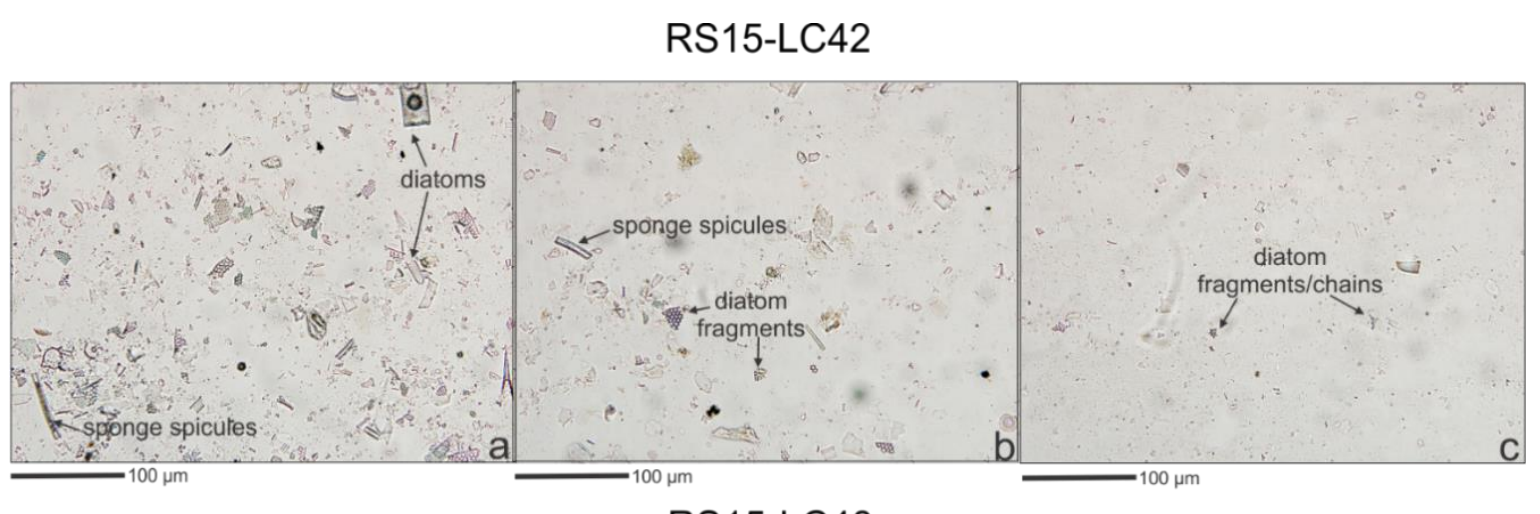

RS15-LC48

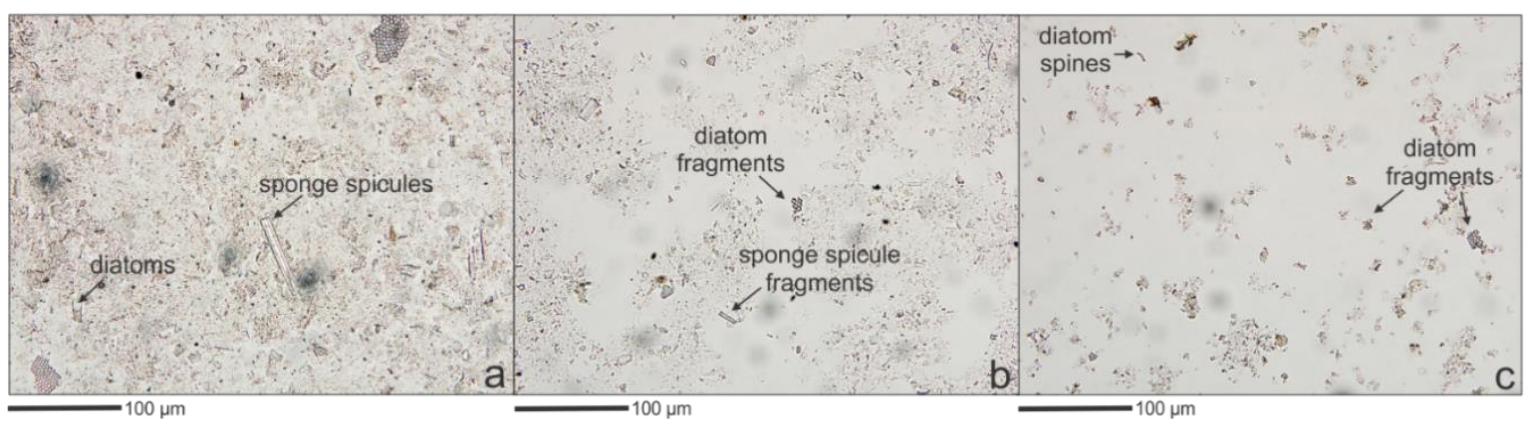

Figure 4.3: Images of two representative samples (0-2 cmbsf from RS15-LC42 and 217-219 cmbsf from RS15-LC48) showing (a) untreated, (b) $0.2 \mathrm{M} \mathrm{NaOH}$ treated, and (c) $1 \mathrm{M} \mathrm{NaOH}$ treated subsamples for cores RS15-LC42 and RS15-LC48. The degree of dissolution is significantly greater for the subsamples treated with $1 \mathrm{M} \mathrm{NaOH}$ solution, rather than the $0.2 \mathrm{M} \mathrm{NaOH}$ solution. Smear slides were imaged with CX31-P Olympus microscope (40x).

To compare the grain size distributions of the $0.2 \mathrm{M} \mathrm{NaOH}$ and $1 \mathrm{M} \mathrm{NaOH}$ treatments, three samples were randomly selected from RS15-LC48 and subsampled three times. The first subsample was left as a control and had no $\mathrm{NaOH}$ treatment, while the remaining two subsamples were treated with $0.2 \mathrm{M} \mathrm{NaOH}$ and $1 \mathrm{M} \mathrm{NaOH}$, respectively, as described above. The samples were then freeze-dried before being analysed on a Beckman Coulter LS 13320 LPSA (with the aqueous liquid module). Two of the samples treated with $0.2 \mathrm{M} \mathrm{NaOH}$ solution have a similar grain size 
frequency distributions to that of $1 \mathrm{M} \mathrm{NaOH}$ treatment, suggesting complete dissolution of $\mathrm{BiSi}$ (Figure 4.4). The majority of BiSi dissolved with a $0.2 \mathrm{M}$ and $1 \mathrm{M} \mathrm{NaOH}$ treatment occurred in the fine-grained $(<63 \mu \mathrm{m})$ fraction, which is consistent with noted grain size frequency of BiSi particles in Antarctic drift sediments (e.g., Warner and Domack, 2002). However, the results of sample 217$219 \mathrm{cmbsf}$ indicate that some biogenic-rich sediments may need a stronger treatment. The initial results presented in Figure 4.4 also suggest BiSi percentage alone may not be a reliable estimate for the type of treatment required as some genera of diatoms and radiolaria are more susceptible to dissolution than others (Ryves et al., 2001). Visual examination of smear slides of the control samples reveals $<20 \%$ of $\mathrm{BiSi}$ content. BiSi measurements provided by KOPRI confirm that the BiSi content ranges between $10-17 \%$ in these samples, thus highlighting the need to consider robustness of different types of silica.
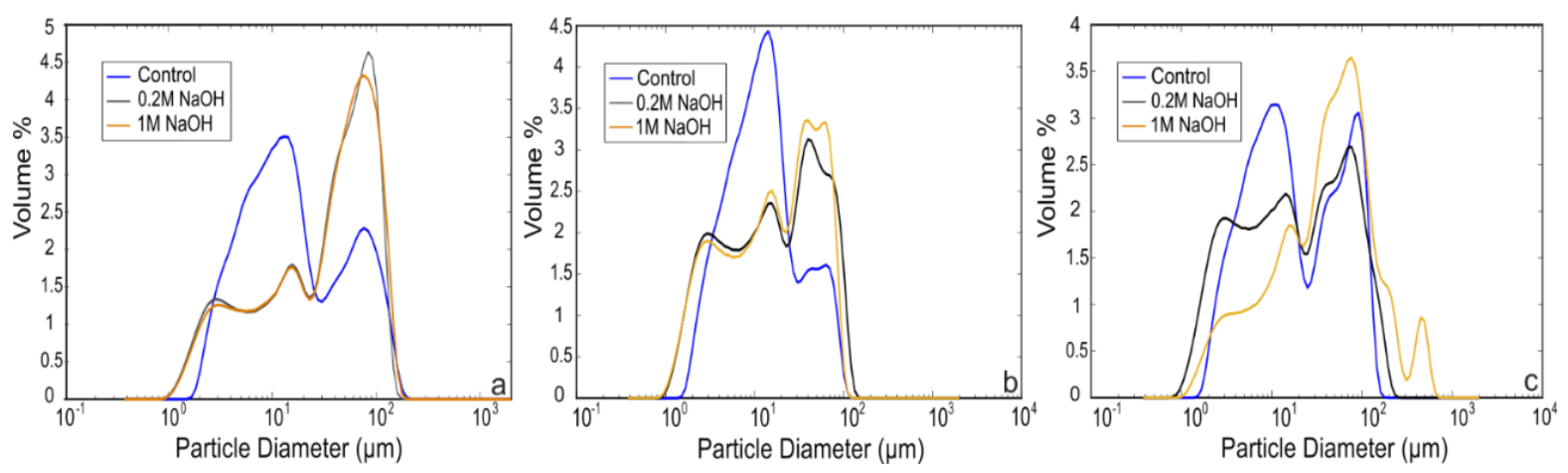

Figure 4.4: Grain size curves for three representative samples from core RS15-LC48 (a) 15-17 cmbsf (b) $126-128 \mathrm{cmbsf}$ and (c) $217-219 \mathrm{cmbsf}$ that were treated with $0.2 \mathrm{M} \mathrm{NaOH}$ and $1 \mathrm{M} \mathrm{NaOH}$ solutions. BiSi content of all samples is $<20 \%$.

Based on the above results, a $0.2 \mathrm{M} \mathrm{NaOH}$ was deemed to be insufficient to dissolve the majority of the $\mathrm{BiSi}$, and a $1 \mathrm{M} \mathrm{NaOH}$ treatment was applied to the rest of the samples for RS15-LC42 and RS15-LC48. The samples were subsequently washed in Milli-Q water and centrifuged three times for ten minutes each at $4700 \mathrm{rpm}$ to remove any remaining $\mathrm{NaOH}$ and reaction product.

Before being analysed on the LPSA, the samples were subsampled ( $0.15 \mathrm{~g}$ to $0.9 \mathrm{~g}$ dependent on the mud content) to obtain an optimal obscuration ( $6 \%$ to $14 \%$ ) of the laser beam. The cone-andquartering-method was used for the subsampling (Lewis and McConchie, 1994). This technique involves mixing and evenly dividing the sample into smaller quantities, which ensures representative subsampling for the entire range of grain sizes. The subsamples were then dispersed in $\sim 50 \mathrm{~mL}$ of $0.5 \mathrm{~g} / \mathrm{L}$ calgon $\left(\mathrm{Na}_{6} \mathrm{P}_{6} \mathrm{O}_{18}\right)$ and stirred in an ultrasonic bath for a minimum of 20 minutes. The samples were then analysed on the LPSA for 60 seconds. Prior to analysis the samples were stirred by hand to keep sediment in suspension due to the susceptibility of grains 
$<10 \mu \mathrm{m}$ to clump due to any remaining organic/biogenic content (McCave et al., 1995). To obtain the proper obscuration, the chamber was drained prior to sample analysis so that it was not necessary to drain the sample to achieve the required obscuration in the case of high obscuration values, which may potentially result in preferential removal of the coarser fraction of the sediment (Bianchi et al., 1999). The laser was re-aligned and the background measured before every sample, and the unit was automatically rinsed for 2 minutes before and 3 minutes after each run. The offset was measured every 30 minutes. The measurements were converted to grain size using the QuartzNatural.rf780d optical model, which assumes all material has a refractive index of quartz suspended in water. Glass bead informal standards (250, 68 and $24 \mu \mathrm{m}$ modal sizes) were run at the beginning and end of every day to check the accuracy and precision of the machine.

\subsubsection{Subsampling reproducibility}

In order to check the precision of the subsampling technique and the reproducibility of the results, 26 repeat samples for RS15-42 and 16 repeat samples for RS15-48 were run, where each sample was subsampled and measured three times. Samples with a large proportion of material $>125 \mu \mathrm{m}$ (attributed to IRD) in size, as well as samples selected from sediment containing $\mathrm{mm}$-scale alternating sandy silt and silt laminae, showed poor reproducibility (Figure 4.5). Samples with no IRD content and no $\mathrm{mm}$-scale laminae all showed good reproducibility (Figure 4.6), suggesting that a lack of sample homogeneity is the main cause of poor reproducibility. To test whether the IRD content of the samples was affecting the reproducibility, the $<63 \mu \mathrm{m}$ fraction was normalised to $100 \%$. All samples showed a strong correlation ( $R=>0.96$ in all cases; Figure 4.7 ), indicating good reproducibility of the clay and silt (mud) fractions.

Figure 4.8 shows a comparison between the mud content of the original measurements and repeat samples. Least square regression analysis displays strong correlations of $R^{2}=0.90$ for RS15LC42 and $R^{2}=0.89$ for RS15-LC48, which provide confidence in the precision of the subsampling and reproducibility of the results. However, least square regression of the IRD component (volume \% >125 $\mu \mathrm{m}$ of the LPSA measurements; Passchier, 2011) of the original measurements and repeat samples displays a moderate correlation with $\mathrm{R}^{2}=0.52$ and $\mathrm{R}^{2}=0.46$ for RS15-LC42 and RS15-LC48, respectively (Figure 4.9). In addition, to ensure the reproducibility and internal consistency of the instrument all of the samples were measured three times. Figures 4.5 and 4.6 show consistency in the precision and reproducibility of the instrument. 

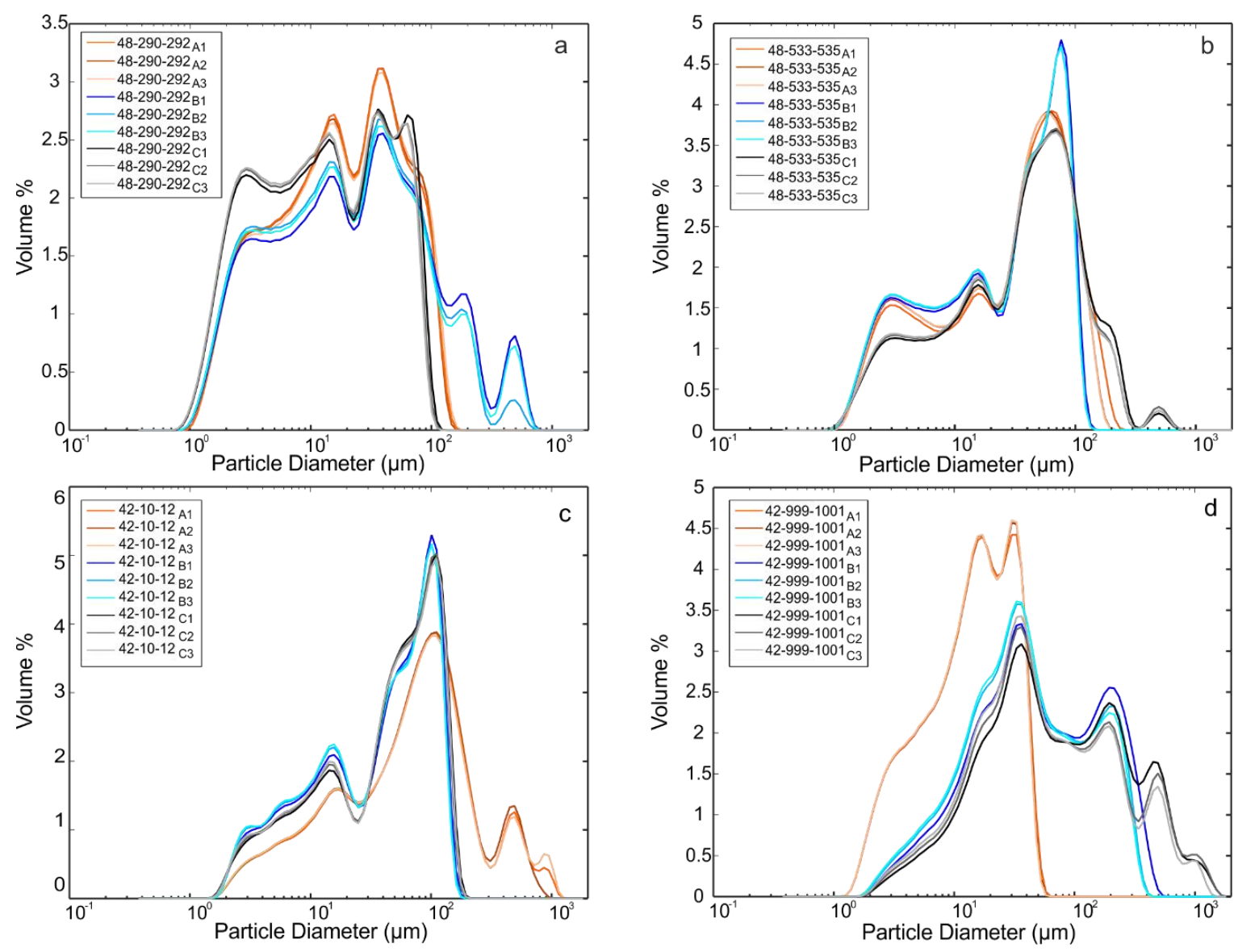

Figure 4.5: Grain size curves of four representative samples (cmbsf) that were subsampled and measured three times. (a) and (b) Grain size curves of two IRD-rich samples from RS15-LC48. (c) Grain size curve of an IRD-rich sample from RS15-LC42. (d) Grain size curve of a mm-laminated sample from RS15-LC42. 

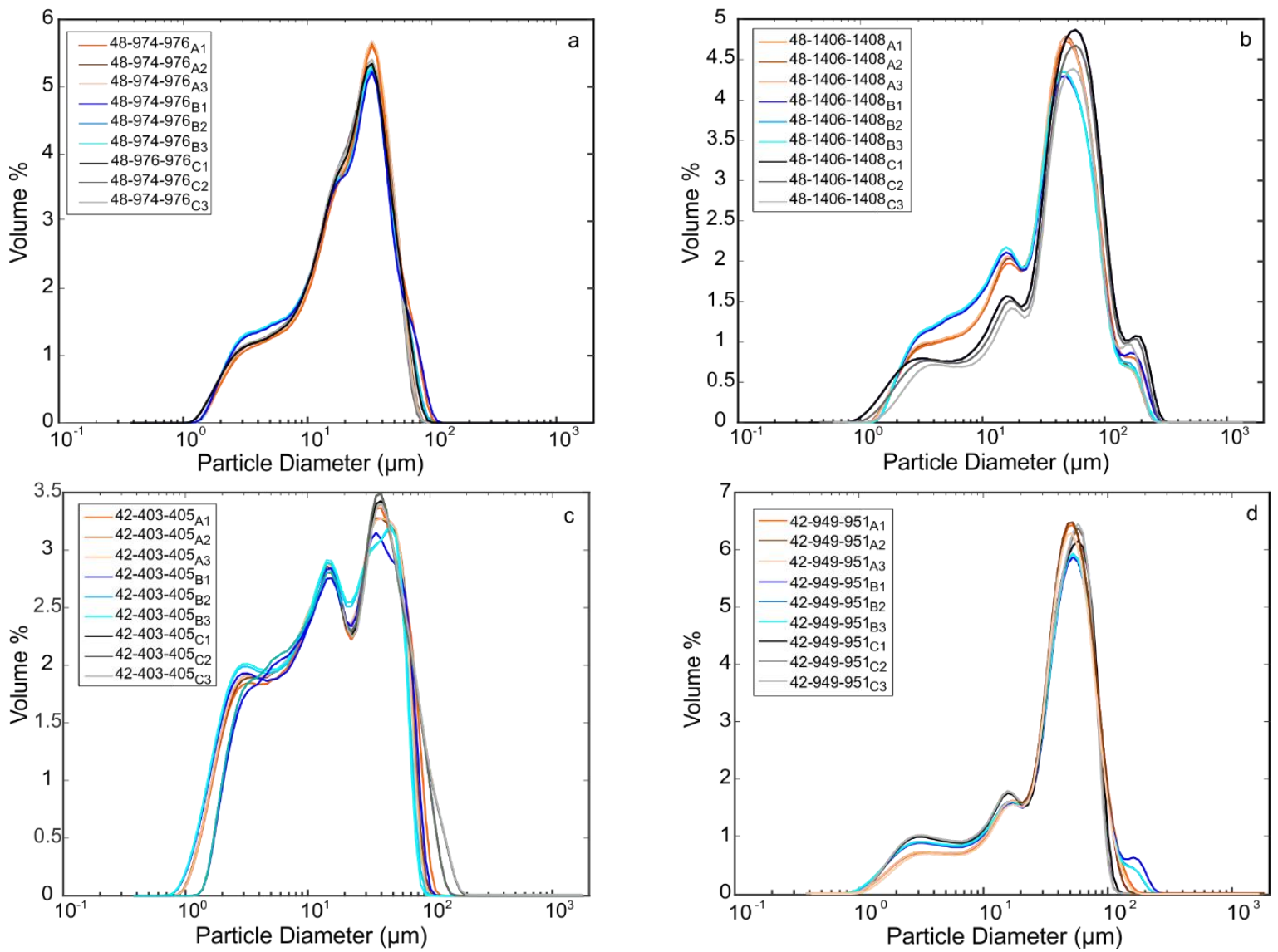

Figure 4.6: Grain size curves of four representative samples (cmbsf) that were subsampled and measured three times. (a) and (b) Grain size curves of two IRD-free samples from RS15-LC48. (c) and (d) Grain size curve of IRD-free samples from RS15-LC42.
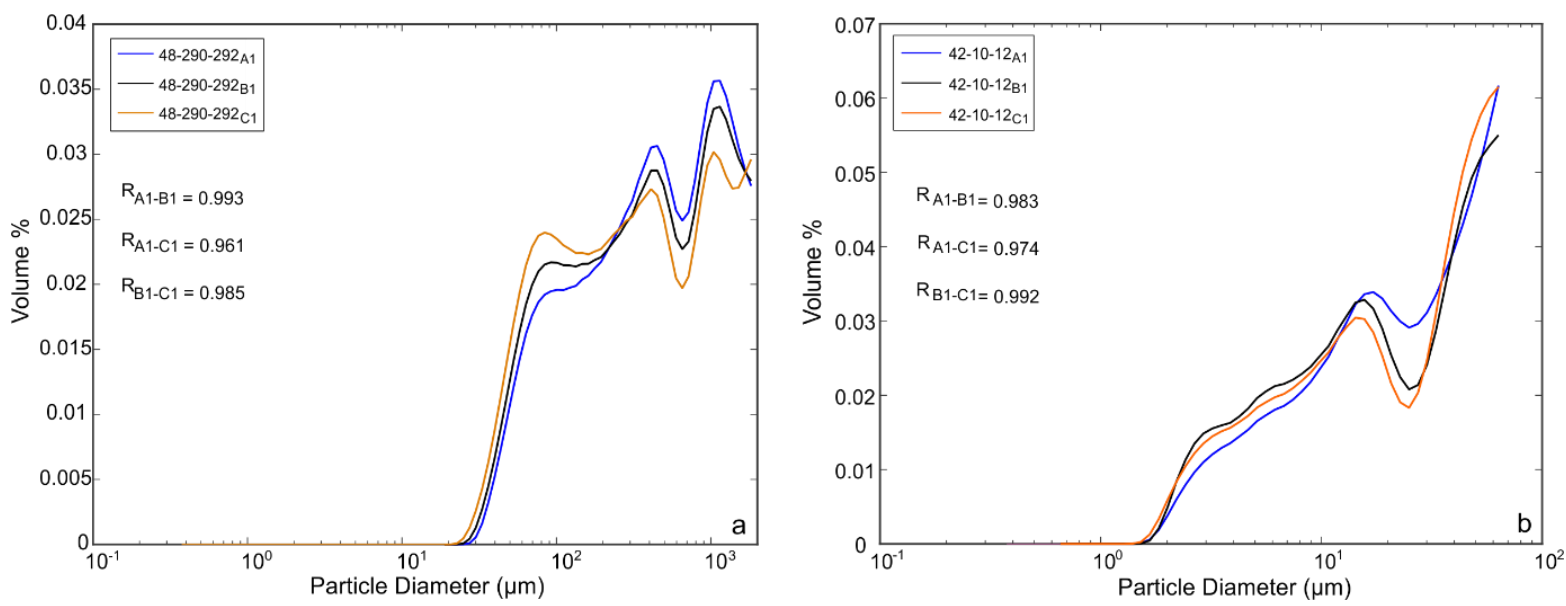

Figure 4.7: Grain size curves of the normalised clay and silt (mud) fractions of two IRD-rich samples from (a) RS15-LC48 (290-292 cmbsf) and (b) RS15-LC42 (10-12 cmbsf). 

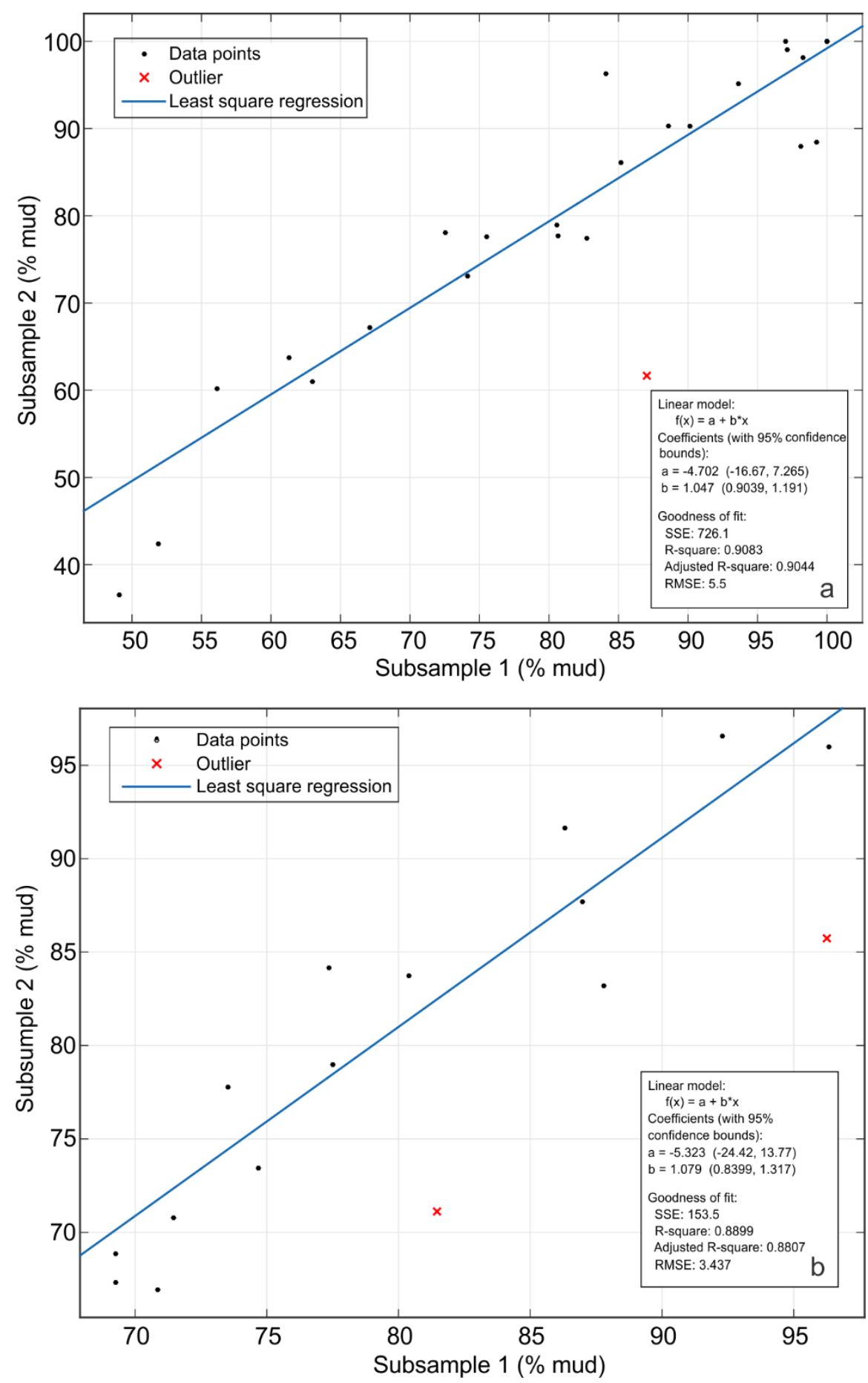

Figure 4.8: Comparison of the mud content of the original (Subsample 1) and repeat (Subsample 2) measurements for (a) RS15-LC42 and (b) RS15LC48. The least square regression of mud\% shows a high reproducibility with $R^{2}$ values of 0.90 and 0.89 for RS15-LC42 and RS15-LC48, respectively. 

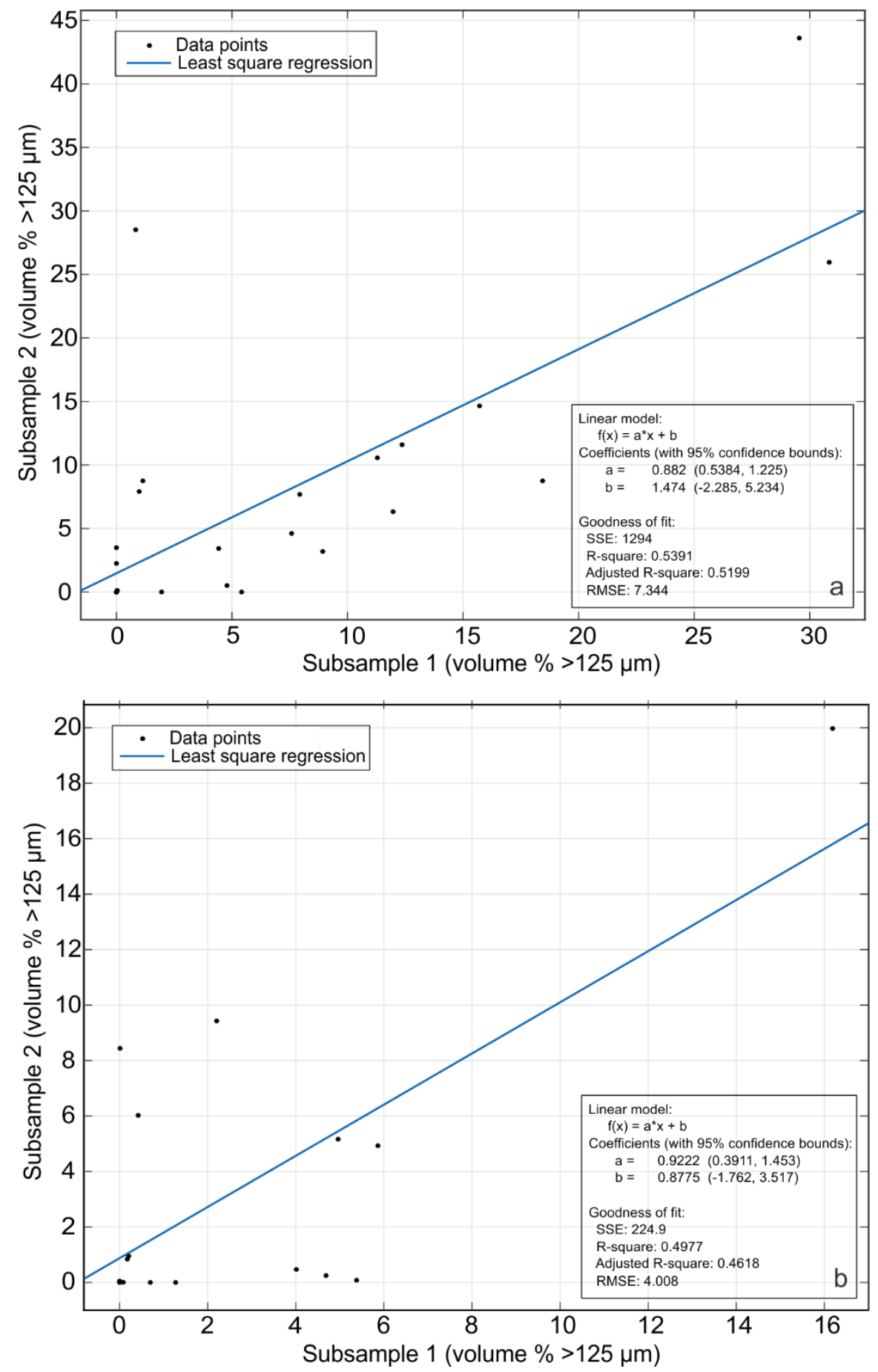

Figure 4.9: Comparison of the IRD component of sediments of the original (Subsample 1) and repeat (Subsample 2) measurements for (a) RS15-LC42 and (b) RS15-LC48. The least square regression of volume $\%>125 \mu \mathrm{m}$ LPSA measurements shows a moderate reproducibility with $R^{2}$ values of 0.52 and 0.46 for RS15-LC42 and RS15-LC48, respectively. 
An additional consideration is that the aqueous liquid module in the LPSA does not accurately record the clay fraction $(<4 \mu \mathrm{m})$ of the sediment due to the platey shape of clay particles (Konert and Vanderberghe, 1997). Instead, it is a measurement of their largest surface area rather than volume $\%$. Particles that are measured with a mean diameter of $2 \mu \mathrm{m}$ by settling (sedigraph) or volume (coulter counter) methods may therefore be measured by an LPSA as having a diameter of $8 \mu \mathrm{m}$ (Konert and Vanderberghe, 1997). This results in particles being recorded as having the same volume as coarser grains, thus biasing the size distribution of clays and fine silts. Consequently, the results may be misleading in terms of depositional models and interpretations should be reviewed carefully (McCave et al., 1995; McCave and Hall, 2006). This is apparent from the comparison of the LPSA (measured at VUW) and sedigraph data (measured at KOPRI) for RS15-LC42 and RS15-LC-48 (Figure 4.10).

To assess this, the raw LPSA frequency distributions were examined with clay being defined as a cut-off of $4 \mu \mathrm{m}$ and $8 \mu \mathrm{m}$ (Udden, 1914; Wentworth, 1922; Konert and Vanderberghe, 1997). However, these data clearly show the tendency of LPSAs to underestimate the clay fraction of the sediment, even when a correction is applied by assuming the clay fraction includes all particles up to $8 \mu \mathrm{m}$ in diameter as measured by the LPSA outputs (c.f. Konert and Vanderberghe, 1997; Figure 4.10). Despite the apparent underestimation of the clay content, no significant differences in downcore trends of clay were observed, regardless of what boundary is used to define the clay fraction as measured by LPSA (Figure 4.11). Therefore, the cut-off point of $4 \mu \mathrm{m}$ for clay is assigned for LPSA data in this thesis, but caution is warranted when comparing between sedigraph and LPSA data. The data were statistically analysed using the GRADISTAT programme (Blott and Pye, 2001). Grain size data and statistics for individual samples are provided in Appendix C. 

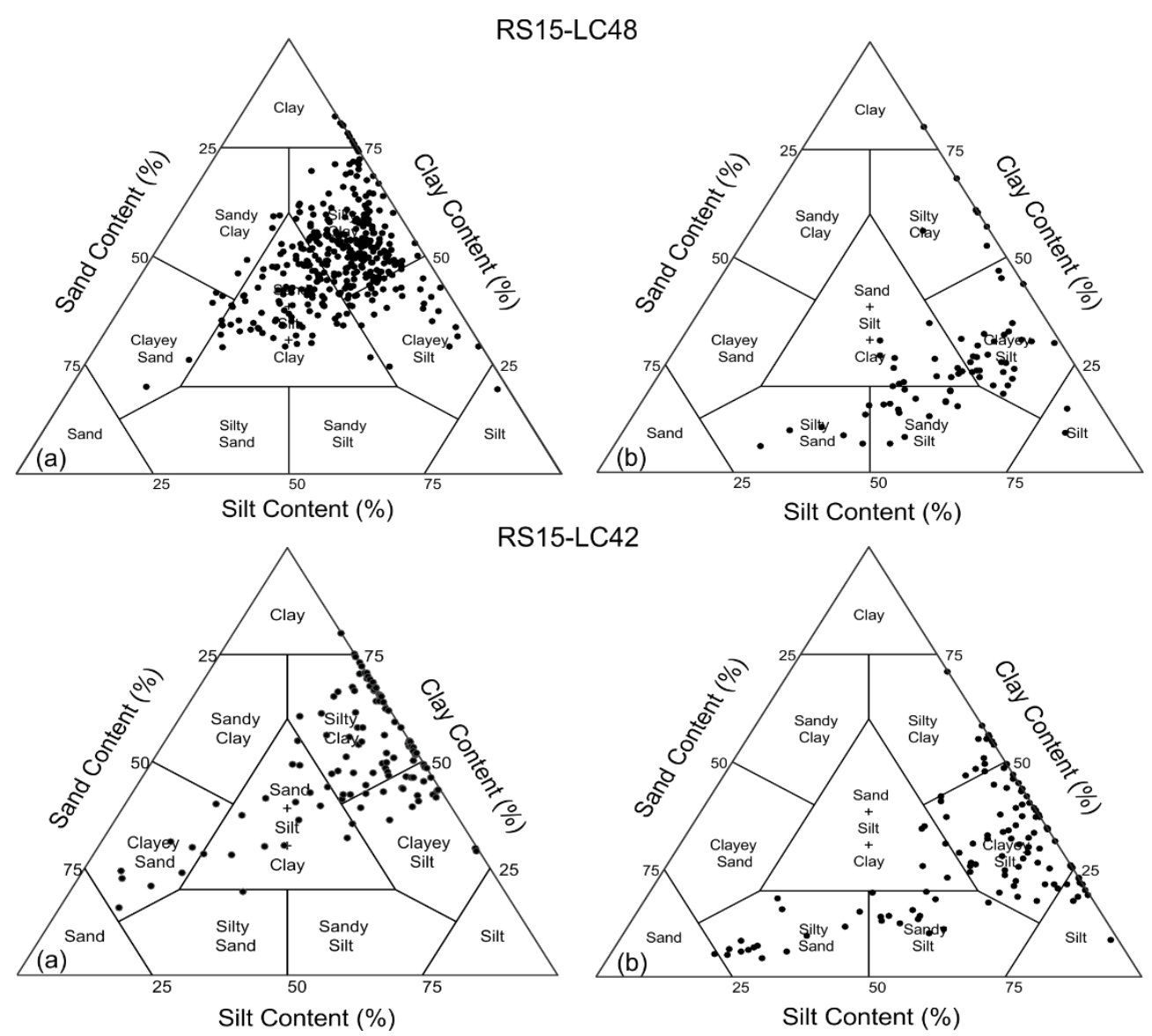

Figure 4.10: Comparison of the clay\%, silt\% and sand\% for RS15LC-48 and RS15-LC42 as measured by (a) the sedigraph at KOPRI versus (b) LPSA measurements at VUW with a clay cut-off at $8 \mu \mathrm{m}$.
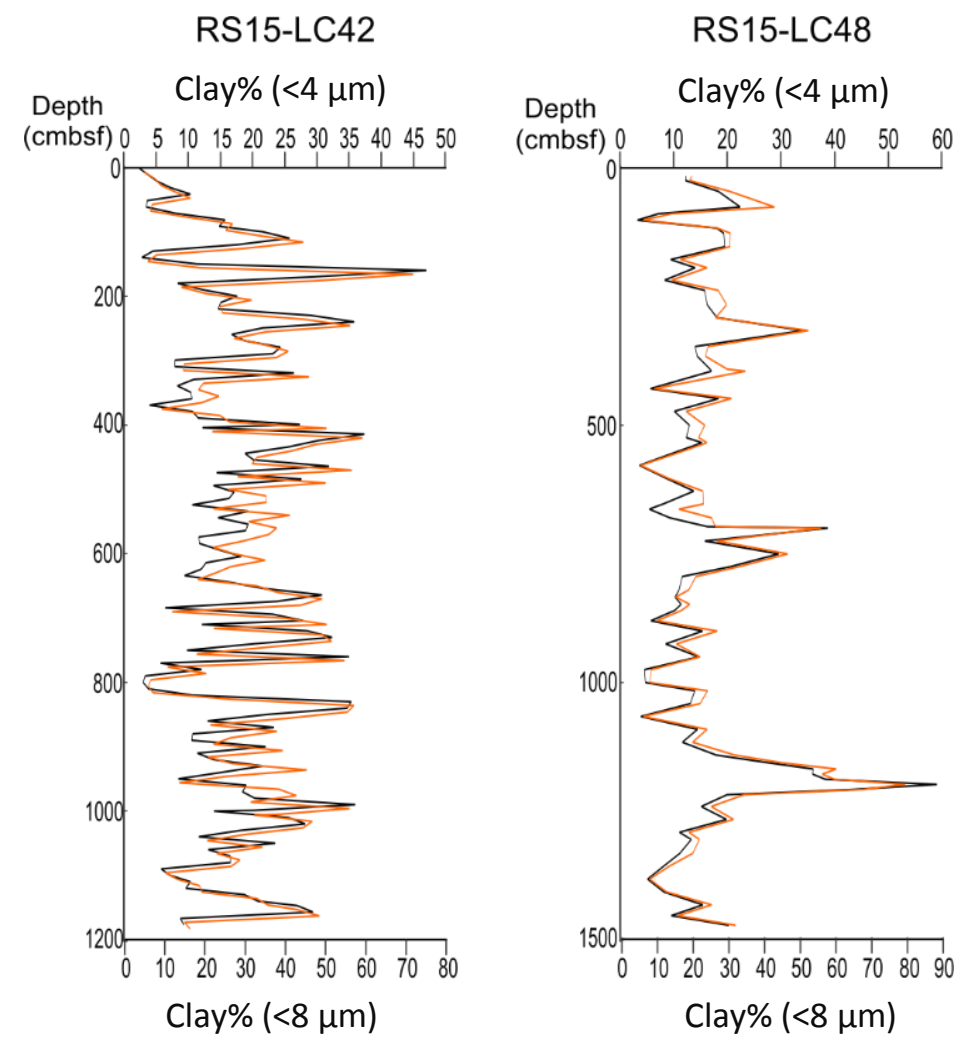

Figure 4.11: Clay percent (clay\%) with a cut-off of $4 \mu \mathrm{m}$ (black line) and $8 \mu \mathrm{m}$ (orange line) for cores RS15-LC42 and RS15-LC48. No significant trends in the grain size distributions are observed between the $4 \mu \mathrm{m}$ and $8 \mu \mathrm{m}$ cut-off points. 


\subsection{Scanning Electron Microscope imaging of the biogenic component}

Scanning Electron Microscope (SEM) imaging was performed to examine the preservation state of foraminifera recovered in the core. Foraminifera were placed onto a carbon tape covered SEM stub with a dry hairbrush and coated in platinum. SEM images were taken using either a JEOL SEM-6610LA or a 6500F SEM. SEM imaging using a 6500F SEM was also carried out on the RS15LC48 samples treated with $0.2 \mathrm{M} \mathrm{NaOH}$ and $1 \mathrm{M} \mathrm{NaOH}$ solutions in order to compare the relative effectiveness of each solution for dissolving the BiSi fraction of the sediment. For these samples, carbon tape was attached to an SEM stub, with a silicon wafer placed on top. A pipette was used to place a drop of sediment diluted in Milli-Q water onto a stub. Stubs were then dried under a heat lamp before being platinum and carbon coated. These images show significantly increased dissolution of diatoms with only rare fragments of diatoms observed in the $1 \mathrm{M} \mathrm{NaOH}$-treated samples (also see 4.3.2), but with whole diatoms still present in the $0.2 \mathrm{M} \mathrm{NaOH}$ treated samples (Figure 4.12).

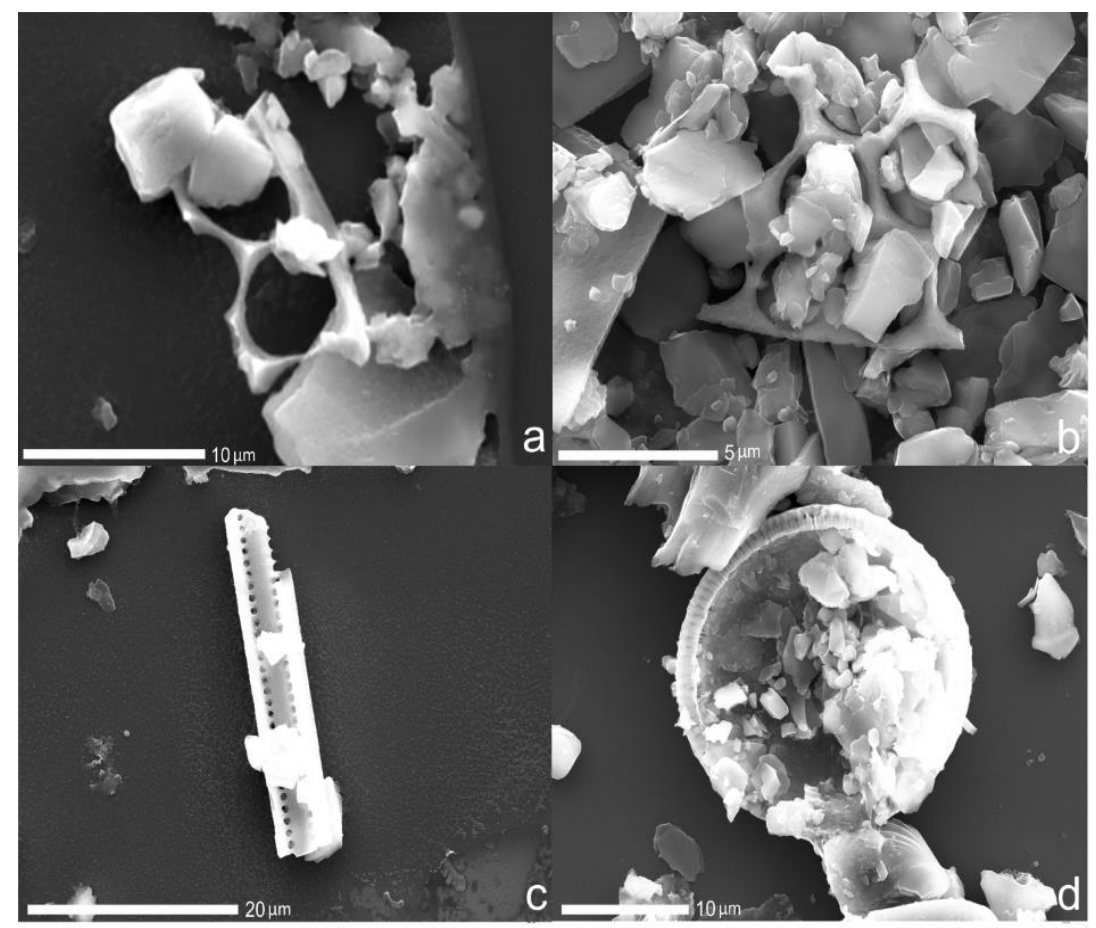

Figure 4.12: SEM images of (a) and (b) $1 \mathrm{M} \mathrm{NaOH}$ treatment and (c) and (d) $0.2 \mathrm{M} \mathrm{NaOH}$ treatment. $1 \mathrm{M} \mathrm{NaOH}$ treatment shows almost complete dissolution of diatoms with very rare diatom fragment $<10 \mu \mathrm{m}$ in size, while $0.2 \mathrm{M} \mathrm{NaOH}$ treatment shows the remains of more intact diatoms exceeding $10 \mu \mathrm{m}$ in size. 


\subsection{Stable isotope analysis}

The planktonic foraminifer N. pachyderma (s.) and benthic Cibicides spp. were picked from the 250-355 $\mu \mathrm{m}$ size fraction to reduce size-related isotope ratio variability (e.g., Elderfield et al., 2002). Specimens which showed minimal diagenetic alteration under binocular microscope examination, such as overgrowths and infillings, were chosen. Care was taken to select the same morphotype of $N$. pachyderma (s.) from each sample to reduce morphotype-related isotope ratio variability ( $a$ and $c$ in Figure 4.13; Bauch et al., 2003). No other foraminifera species were present in sufficient quantity for stable isotope analysis.

Picked foraminiferal samples were rinsed in Milli-Q water three times to remove any fine fraction contamination and material in the tests, such as coccolith and diatom remains, or diagenetic alteration products. The water was then siphoned off with a pipette and the foraminifera allowed to dry at room temperature. The foraminifera were not sonicated to aid cleaning as several test runs showed sonicating for as short as one second resulted in complete disintegration of the tests. Two to five specimens from samples with sufficient numbers were selected for SEM analysis. The images of $N$. pachyderma (s.) reveal the presence of spines and internal pores indicating relatively well preserved original structure and no secondary $\mathrm{CaCO}_{3}$ precipitation (Figure 4.13a;b). However, minor dissolution effects are evident along the primary organic membrane, the proportion of the test with the highest magnesium (Mg) content (Figure 4.13d). Surface contaminants, most likely pyrite and/or calcite cubes and diatom material adhered to the surface, and several specimens show chamber infilling (with no pores evident) (Figure 4.13c). Energy Dispersive Spectroscopy (EDS) analysis confirms the surface contaminants and chamber infillings are BiSi and detrital elements (potassium and aluminium), and shows no evidence of secondary $\mathrm{CaCO}_{3}$ precipitation within the aperture (Figure 4.14).

The images of Cibicides spp. show well preserved original structure, although a few specimens appear to be slightly fragmented. Care was taken to avoid such specimens by picking the final sample sets under a SZX12 Olympus microscope (1.2x objective lens with the highest magnification of $108 \mathrm{x}$ ) to inspect the preservation state, and check for the presence of secondary cements and internal contamination of the foraminifera. After inspection, oxygen and carbon isotopes of 28 samples of $N$. pachyderma (s.) and 2 samples of Cibicides spp. from RS15-LC42, and 6 samples N. pachyderma (s.) and Cibicides spp. from RS15-LC48 were measured on a Finnigan MAT252 mass spectrometer coupled to a Kiel IV carbonate device by colleagues at Stanford University. Reproducibility of the NBS-19 standard was $0.03 \%$ for $\delta^{18} \mathrm{O}$ and $0.04 \%$ or $\delta^{13} \mathrm{C}$. 
Standard errors (i.e., standard error on the average difference: calculated from the standard deviation divided by the square root of the number of measurements) are reported for $\delta^{18} \mathrm{O}$ and $\delta^{13} \mathrm{C}$ measurements. Data are reported in standard delta notation as the per mil (\%o) difference from the Vienna Pee Dee Belemnite (VPDB) standard.

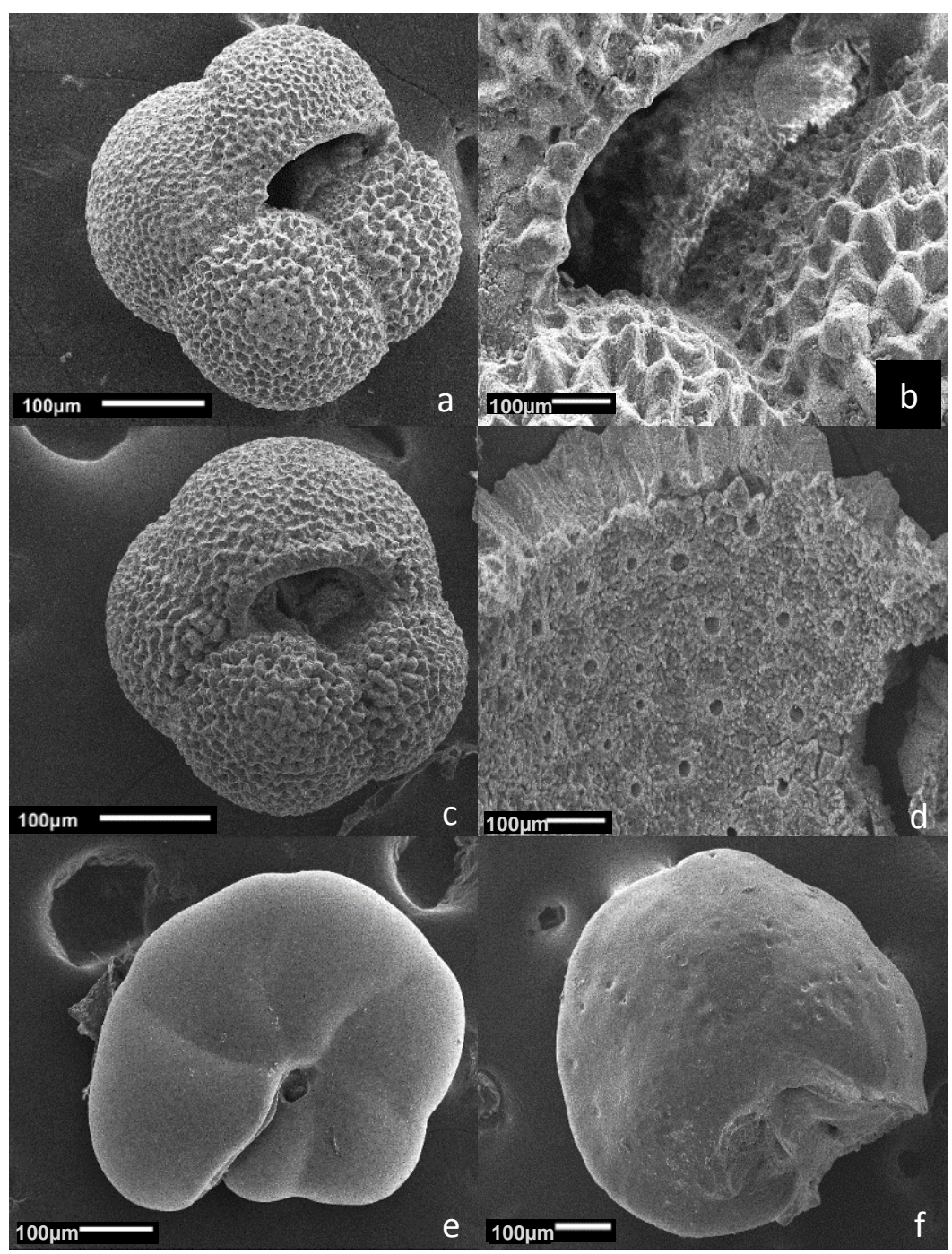

Figure 4.13: SEM images of N. pachyderma (s.) (a-d) and Cibicides spp. (e-f). (a) and (b) show the presence of spines and original pores indicating relatively well preserved original structure. (c) shows infilling of the aperture and (d) reveals minor dissolution of the inner chamber wall and along the primary organic membrane. (e) well preserved specimen of Cibicides spp. (f) slightly fragmented specimen of Cibicides spp. 


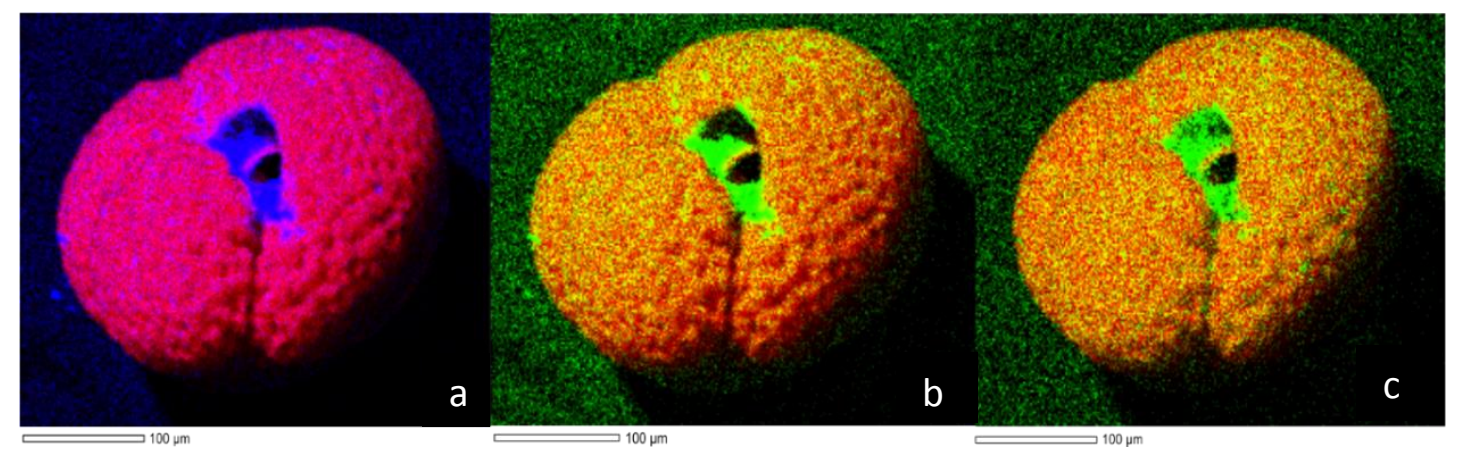

Figure 4.14: EDS analysis of N. pachyderma (s.) (sample from RS15-LC42). Red shading in (a), (b), and (c) depicts calcium distribution, while blue shading in (a) denotes silica distributions and green shading in (b) and (c) depicts aluminium and potassium distributions, respectively. Black shading represents data blanks due to beam orientation during analysis.

\subsection{Age models}

This thesis uses age models based on paleomagnetic reversal stratigraphy for cores RS15-LC42, RS15-LC47 and RS15-LC48 (see Appendix D). Paleomagnetic analysis was carried out on U-channel samples by Christian Ohneiser, at the Otago Paleomagnetic Research Facility. The preliminary cyclostratigraphic results in this thesis and future biostratigraphic work will help to further constrain the age-depth relationship. Preliminary age models for cores RS15-GC46, RS15-GC107 and RS15-LC108 were developed by correlating the magnetic susceptibility records (provided by KOPRI) between these cores, to those with an established paleomagnetic timescale (e.g., RS15LC42, RS15-LC47 and RS15-LC48). Consequently, all the age models in this thesis must be treated as preliminary and subject to future refinement.

\subsection{Ice-rafted debris mass accumulation rates}

\subsubsection{Ice-rafted debris mass accumulation rates for the $250 \mu \mathrm{m}-2 \mathrm{~mm}$ fraction.}

The fraction of medium-to-coarse sand $(250 \mu \mathrm{m}-2 \mathrm{~mm})$ has been widely used to characterise the IRD fraction of the sediments in previous Arctic and Antarctic studies (Krissek, 1995; St John and Krissek, 1999; St John, 2008; Patterson et al., 2014). After chemical treatment and sieving (see 4.3.2), each sample was visually examined under a binocular microscope to check for volcanic ash, clay aggregates, and diagenetic minerals, the presence of which would result in an overestimation of the detrital $250 \mu \mathrm{m}-2 \mathrm{~mm}$ fraction. No fresh volcanic glass or diagenetic minerals were observed, and rare samples with clay aggregates were further disaggregated in Milli- $Q$ water, resieved and re-checked under the binocular microscope. The MAR of the medium-to-coarse sand was then estimated using the following equation:

IRD MAR $=C S \% \times D B D \times L S R$ 
Where the IRD MAR is the mass accumulation rate $\left(\mathrm{g} / \mathrm{cm}^{2} / \mathrm{kyr}\right), \mathrm{CS} \%$ is the medium-to-coarse sand weight percent, DBD is the dry-bulk density $\left(\mathrm{g} / \mathrm{cm}^{3}\right)$ calculated according to the methodology of Dadey et al. (1992), and LSR is the interval average linear sedimentation rate (cm/kyr) calculated using the paleomagnetic age-depth models. Following Patterson et al. (2014), this is a slight modification of the equation derived by Krissek (1995), who conducted a correction using a visual estimate for the detrital vs biogenic component of the CS\%. As this study chemically removes this component, this correction is not required. Individual variables and data used for this calculation are provided in Appendix E.

4.7.2 Ice-rafted debris mass accumulation rates using $>125 \mu \mathrm{m}$ from bulk particle size analysis

The percentage of material $>125 \mu \mathrm{m}$ in the bulk sample as measured on the LPSA has also been proposed as an independent measure of the IRD content of the sediments in previous Antarctic studies (Passchier, 2011). The samples were treated with $10 \% \mathrm{HCl}, 27 \% \mathrm{H}_{2} \mathrm{O}_{2}$ and $1 \mathrm{M} \mathrm{NaOH}$ solution to remove biogenic components in order to obtain the terrigenous fraction, and measured on the Beckman Coulter LS 13320 LPSA (see 4.3.2). IRD MAR was calculated according the methodology of Passchier (2011) with the following equation:

IRD MAR $=\% I R D \times T E R R \times D B D \times L S R$

Where the IRD MAR is the mass accumulation rate $\left(\mathrm{g} / \mathrm{cm}^{2} / \mathrm{kyr}\right), \%$ IRD is the volume $\%>125 \mu \mathrm{m}$ of the LPSA measurements, TERR is the terrigenous fraction calculated by difference i.e., as 1 minus the $\mathrm{CaCO}_{3}$ fraction minus the BiSi fraction (see below), DBD is the dry-bulk density $\left(\mathrm{g} / \mathrm{cm}^{3}\right.$ ) calculated according to the methodology of Dadey et al. (1992), and LSR is the interval average linear sedimentation rate $(\mathrm{cm} / \mathrm{kyr})$ calculated using the paleomagnetic age-depth models. The biogenic carbonate (to the nearest whole percentage value) and BiSi content (to the nearest whole percentage value) were calculated for each measurement by using the nearest discrete samples for percent $\mathrm{CaCO}_{3}$ and percent BiSi provided by KOPRI. Individual variables and data used for this calculation are provided in Appendix E.

\subsection{Facies analysis}

Following previous Antarctic studies (e.g., Naish et al., 2008; McKay et al., 2009), preliminary lithofacies for cores RS15-42, RS15-46, RS15-47 and RS15-48 are defined based on identification of common characteristics of the lithology, thickness and contact of beds, sedimentary texture and structures, IRD abundance, fossil content and bioturbation. 


\subsection{Spectral analysis}

Spectral analysis was conducted on the gravel count (5 $\mathrm{cm}$ spacing) and magnetic susceptibility records (a proxy of grain size variation through time; $1 \mathrm{~cm}$ spacing) of cores RS15-LC42, RS15LC47, RS15-LC48, RS15-GC107 and RS15-LC108 using the astrochron package in the computer programme $R$, in order to evaluate orbital frequencies in the data sets (Meyers, 2014). Based on the preliminary age models and sample spacing, the temporal resolution is $\sim 1-5 \mathrm{kyr}$ for the magnetic susceptibility records and $\sim 5-25 \mathrm{kyr}$ for gravel count data series. The methodology presented here follows Meyers et al. (2012), who also utilised records where the resolution of the independent age control was coarser than that of the orbital periods. Thus, the results of this study are an independent assessment of the initial age models, which are subject to future refinement.

Prior to spectral analysis, the gravel count data series were interpolated to $5 \mathrm{~cm}$ intervals and any linear trends were removed. The magnetic susceptibility data sets had outliers removed in the $5^{\text {th }}$ and $95^{\text {th }}$ percentiles, as spurious peaks caused by measurement of lone large clasts (e.g., IRD) and cracks in the core enhance red noise in the data, thereby reducing the significance of potential orbital signals (Weedon, 2003). Linear trends were removed next, and the data sets were interpolated to $2 \mathrm{~cm}$ intervals.

The Multi-Taper Method (MTM), which incorporates the red noise estimation of Mann and Lees (1996) was used to identify significant frequencies in the depth domain of the data (Ghil et al., 2002). This method allows for the detection of harmonic (regular periodicity) and significant narrowband, 'quasi-oscillatory' (irregular periodicity) signals, while providing a robust estimate of the background noise (Ghil et al., 2002). Spectral peaks are identified as statistically significant in the MTM power spectrum based on rejecting the null hypothesis $\left(H_{0}\right)$ of a robust red noise background, AR(1) modelling of median smoothing, at a confidence level of $90 \%$ (Mann and Lees, 1996), and surpassing the $90 \%$ confidence level requirements in the MTM harmonic FischerSnedecor (F) test (Ghil et al., 2002; Weedon, 2003).

Potential orbital signals are evaluated by utilising the preliminary age models (see 4.6), with the assumption of a constant sedimentation rate between age-depth tie points. This assumption is an obvious oversimplification, as sedimentation rates are likely to vary down-core due to sediment compaction and shifting sedimentary response to external forcings. Shifting sedimentation rates could result in broader, smaller spectral peaks, or higher frequency spectral peaks that are 
indistinguishable from the background noise, despite being still influenced by periodic forcings (Weedon, 2003).

Next, evolutionary harmonic analysis (EHA) was conducted to investigate the spatial bedding of frequencies and hence the stability of sedimentation, as pronounced changes in sedimentation rates could alias potential orbital signals (Weedon, 2003; Meyers et al., 2012). The EHA was conducted using window sizes of $2,2.5$ and $3 \mathrm{~m}$ in steps of 0.05 to $0.1 \mathrm{~m}$. To enhance the clarity of the signal, the results were normalised and padded with zeroes to 1000 points.

Average spectral misfit (ASM) analysis is performed on the entire gravel count and magnetic susceptibility data series for cores RS15-GC107 and RS15-LC108 in order to evaluate the potential astronomical signals independent of the established preliminary age models. ASM calculates the alignment (i.e., tunes) between measured spectral peaks (frequencies) in a stratigraphic record and a set of orbital period targets across a possible set of constant sedimentation rates to identify the most plausible sedimentation rate, which has to surpass the critical significance level of $0.5 \%$ and therefore reject the null hypothesis (Meyers et al., 2012). The orbital period targets were identified by applying the MTM to existing theoretical astronomical models of Laskar et al. (2004) and Laskar et al. (2011) for the Pleistocene Epoch. The sedimentation rates derived from ASM analyses for cores RS15-GC107 and RS15-LC108 were used to calibrate the spectra and determine relative 'floating' timescales.

\subsection{Additional data sets used in this thesis}

A large volume of data was collected during the standard core characterisation procedures undertaken by the KOPRI scientific program. The magnetic susceptibility data sets are used for all sedimentary cores investigated in this study, $\mathrm{BiSi}$ and $\mathrm{CaCO}_{3}$ data sets are used for cores RS15LC42 and RS15-LC48, and x-ray fluorescence (XRF) measurements are also utilised for core RS15LC48. As these are supporting datasets in the context of this thesis, only brief measurement details are provided below.

\subsubsection{Magnetic susceptibility}

Magnetic susceptibility (point count) of the sediments was measured at $1 \mathrm{~cm}$ intervals using a Bartington MS2 susceptibility meter. 


\subsubsection{Biogenic silica}

BiSi was determined by Continuous Flow Analyzer (SKALAR SANplus Analyzer) with a wet-alkaline extraction method modified from Mortlock and Froelich (1989). Biogenic opal was measured at 5 $\mathrm{cm}$ intervals for core RS15-LC42 and at $4 \mathrm{~cm}$ intervals for core RS15-LC48. BiSi MARs were calculated by multiplying the bulk MARs $(L S R \times D B D)$ by the fractional concentration of BiSi.

\subsubsection{Calcium carbonate content}

$\mathrm{CaCO}_{3}$ content of sediments was analysed using a $\mathrm{CM} 5015 \mathrm{UIC} \mathrm{CO}_{2}$ coulometer by measuring the $\mathrm{CO}_{2}$ gas generated by the reaction of $20 \mathrm{mg}$ powdered samples with $10 \% \mathrm{HCl}$ at $50^{\circ} \mathrm{C}$ for 10 minutes (Heath et al., 1977). Measurements were taken every $5 \mathrm{~cm}$ for RS15-LC42 and every 4 $\mathrm{cm}$ for RS15-LC48. $\mathrm{CaCO}_{3}$ MARs were calculated by multiplying the bulk MARs (LSR $\times$ DBD) by the fractional concentration of $\mathrm{CaCO}_{3}$.

\subsubsection{X-ray fluorescence}

The core sections were scanned using an ITRAX linescan. Scans were conducted at $30 \mathrm{kV}, 30 \mu \mathrm{A}$, and at $2 \mathrm{~mm}$ intervals with 10 second contact times. All XRF data presented in this study are normalised (i.e., to the total counts at that point in the core), which is common practice to minimise any reduced XRF signals due to coarser lithologies, rough surfaces and porosity changes (Weltje and Tjallingii, 2008). 


\section{CHAPTER 5: RESULTS}

\subsection{Lithostratigraphy}

Summary stratigraphy descriptions are provided in this chapter for cores RS15-LC42, RS15-GC46, RS15-LC47 and RS15-LC48, with summary logs shown in Figures 5.3, 5.5, 5.9 and 5.13. High resolution stratigraphic logs with lithological descriptions are provided in Appendix A. These are based on visual core descriptions made on the core by myself at KOPRI using ANDRILL-based lithological classification schemes (detailed in the methods) to allow for comparison to previous continental margin drill cores (e.g., ANDRILL and IODP Expedition 374). These have been supplemented and modified through the detailed analysis of $x$-ray images, and quantitative grain size measurements. Initial visual descriptions were also made by KOPRI scientists using a standardized KOPRI-based classification scheme (Dr Kyu-Chuel Yoo and Dr. Jae II Lee). Thus, the descriptions in this thesis are a combined integration of these various descriptions and quantitative grain size and $\mathrm{x}$-ray datasets.

Cores RS15-LC107 and RS15-LC108 do not currently have a detailed descriptive dataset and the descriptions in this thesis are preliminary. For these cores, variations in IRD are assessed from $\mathrm{x}$ ray image analysis alone. Preliminary stratigraphic logs are shown in Figure 5.16 and 5.17.

Lithological units are assigned on the basis of common characteristics in the lithostratigraphy. Detailed provenance and compositional analysis of the cores is outside the scope of this thesis, although preliminary summaries are provided for cores RS15-LC42 and RS15-LC48 based on visual examination of smear slides and the $250 \mu \mathrm{m}-2 \mathrm{~mm}$ grain size fraction of sediments for biogenic versus terrigenous components, in combination with BiSi data (provided by KOPRI). 


\subsubsection{RS15-LC42}

Unit 1 (0-155 cmbsf)

Unit 1 is a clast-rich muddy to sandy diamictite that consists of gradational interbeds of fine-tomedium sand, sandy silt and rare silt. The fine sand beds are $<30 \mathrm{~cm}$ thick, dark brownish-grey, and bioturbated with rare $\mathrm{mm}$-scale faint laminations. Clasts are abundant, ranging from granules to pebbles grade, and occasionally occur in concentrated layers. Sandy silt beds are $<25 \mathrm{~cm}$ thick, greenish-grey, and bioturbated with abundant clasts. Sparse to moderate bioturbation is persistent throughout. Basal contacts of beds are gradational over 1-2 cm and bioturbated over several $\mathrm{cm}$, except at the base of the unit which has a sharp wavy, but sparsely bioturbated basal contact.

Unit $2(155-315 \mathrm{cmbsf})$

This unit consists of interbeds of muddy diamictite interbedded with laminated and bioturbated silt. The interbeds contain gradational (over 1-2 cm) and bioturbated contacts (over several $\mathrm{cm}$ ). The olive-brown, clast-rich diamictites are up to $40 \mathrm{~cm}$ in thickness, and display moderate to abundant bioturbation, although planar-laminae may be present, but are discontinuous and weakly-defined. Silt beds are greenish-grey and generally $<35 \mathrm{~cm}$ in thickness and contain sparse (to absent) clasts, although some moderate to abundantly bioturbated intervals contain common to abundant clasts, while laminated intervals are characterised by absent to rare clasts. Planarlaminae are rare in bioturbated silt intervals and are weakly-defined, discontinuous and wavy. Laminated silts are characterised by intervals with packages of well-defined $\mathrm{mm}$-scale clayey silt/coarse silt planar- and cross-laminae that are parallel, even to wavy in nature and have sharp upper and lower contacts. The bases of the laminae may contain scour features (Figure 5.1a). Between 155 and $175 \mathrm{cmbsf}$ there is an interval of non-bioturbated, clast-free silt with welldefined mm-scale planar-laminae that are wavy, with sharp upper and lower contacts (Figure 5.1b). This interval also contains thin ( $<1.5 \mathrm{~cm}$ thick) intervals of cross-laminae with sharp wavy lower and upper contacts that are parallel and discontinuous in nature and are characterised by planar-laminae grading into cross-laminae and alongtop erosional sets (Figure 5.1c). Laminae show no obvious evidence for grading. The unit has a sharp wavy and strongly bioturbated basal contact. 


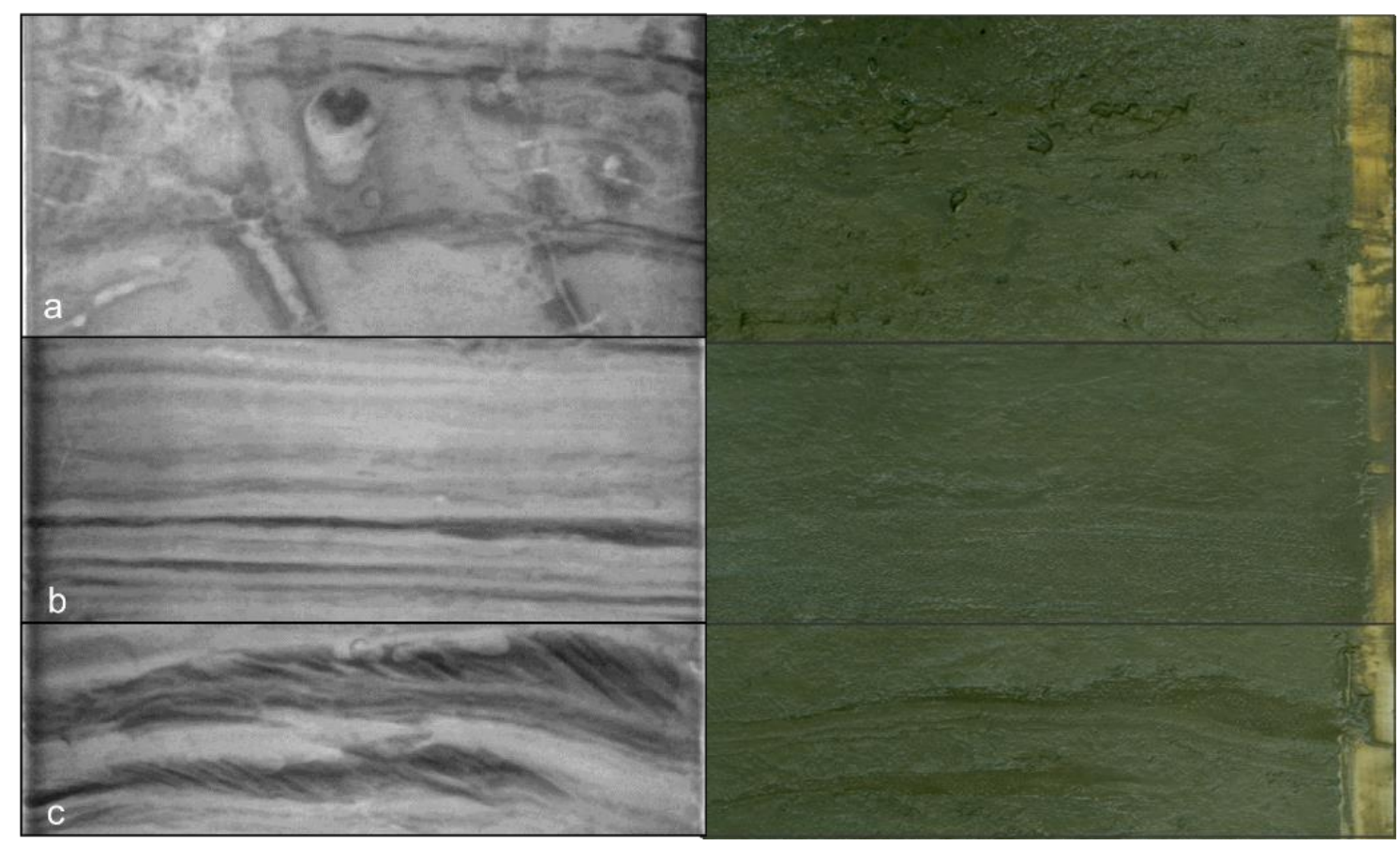

Figure 5.1: Representative x-ray images (left) and photographs (right) of (a) weakly-defined mm-scale laminae between 150 and $155 \mathrm{cmbf}$, laminae are bioturbated with scour features, (b) well-defined planar lamine between 170 and $175 \mathrm{cmbsf}$, and (c) planar laminae grading into cross-laminae with alongtop erosional sets between 165 and 169 cmbsf.

\section{Unit 3 (315-1178 cmbsf)}

Unit 3 consists of interbeds of laminated silt to sandy silt with a general lack of clasts and bioturbated silts and muddy to sandy diamictites with common to abundant clasts. The laminated silt and sandy silt intervals are structurally and texturally identical to the interval between 155 and $175 \mathrm{cmbsf}$ in unit 2 (described above), but are up to $220 \mathrm{~cm}$ in thickness with rare $\mathrm{cm}$-scale laminae and rare clasts. There are also occasional normal and reverse faults present with $\mathrm{mm}$ - to $\mathrm{cm}$-scale offsets, which are more pervasive between 880 and $1030 \mathrm{cmbsf}$, and soft sediment deformation features, particularly at the base of laminae (Figure 5.2a and 5.2b). Beds of greenishgrey silt with uncommon-to-moderate bioturbation and common to abundant clasts are up to 20 $\mathrm{cm}$ in thickness. Greyish-brown muddy diamictites and yellow-brown sandy diamictites contain common to abundant clasts, are moderately bioturbated and are up to $25 \mathrm{~cm}$ in thickness. These are faintly laminated in places with the laminae showing identical characteristics to the faintly laminated intervals of unit 2 (described above). Basal contacts of beds are gradational over 1-2 $\mathrm{cm}$ or sharp wavy, and commonly bioturbated. 


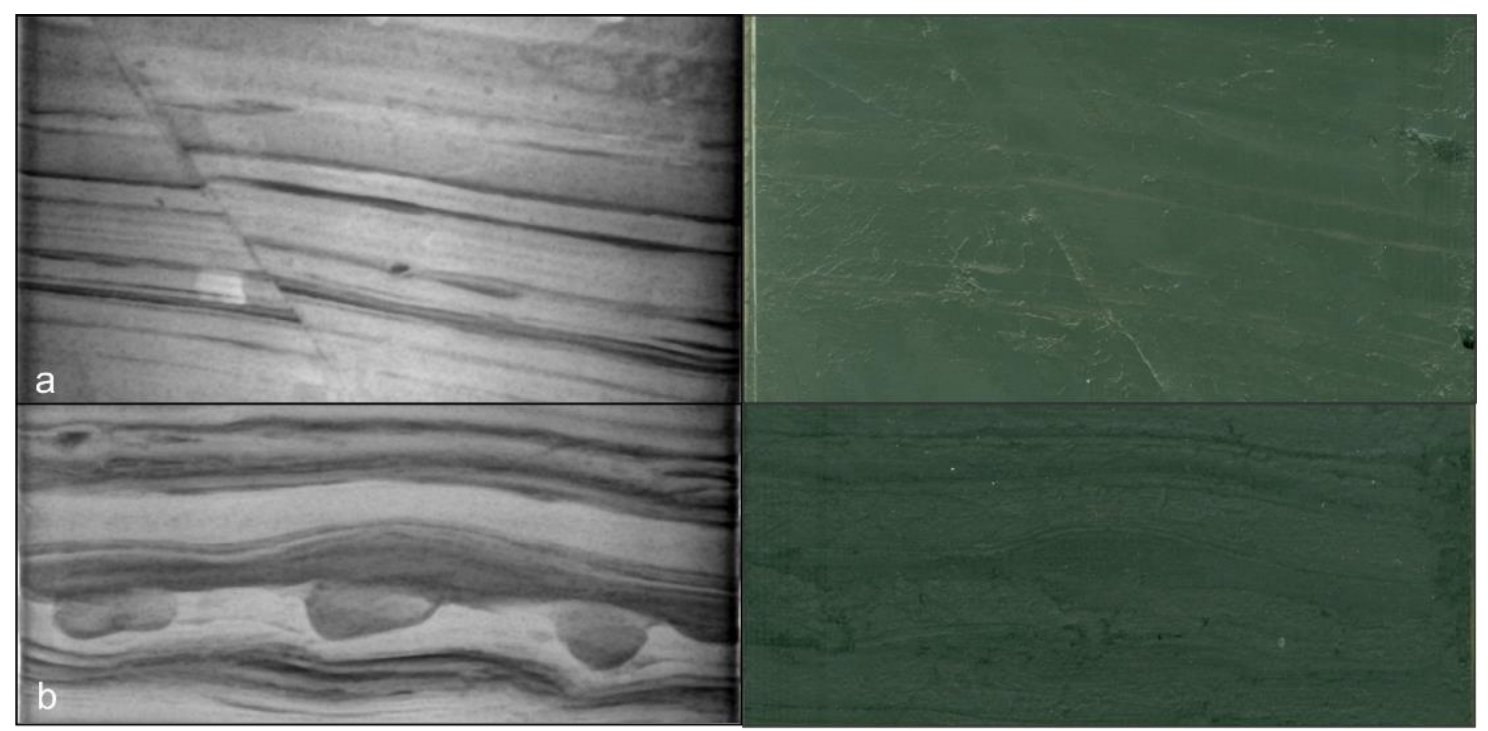

Figure 5.2: Representative x-ray images (left) and photographs (right) of (a) well-defined planar laminae offset by a reverse fault between 540 and $545 \mathrm{cmbsf}$, and (b) soft sediment deformation features at the base of planar/wavy laminae between 870 and $875 \mathrm{cmbsf}$.

\section{Clast lithologies}

Clasts sizes range from granule to pebble grade, are sub-angular to angular in shape, and striated/facetted clasts are present. Pebble lithologies are varied and include granite, gneiss, basalt, argillite, greywacke and large mineral grains including feldspars and quartz.

\section{Biogenic content}

Visual analysis of smear slides in combination with BiSi data indicate a low diatom content throughout the core $(<20 \%)$, with only a few bioturbated silt and sandy silt beds having a slightly higher diatom content (20-30\%). Foraminifera bearing beds are common, and include benthic species Cibicides spp, Uvigerina spp., Lagena spp., and Dentalina spp., and planktonic species $N$. pachyderma (s.) Ostracods, radiolarians and sponge spicules are also present, and range from trace to common amounts. 


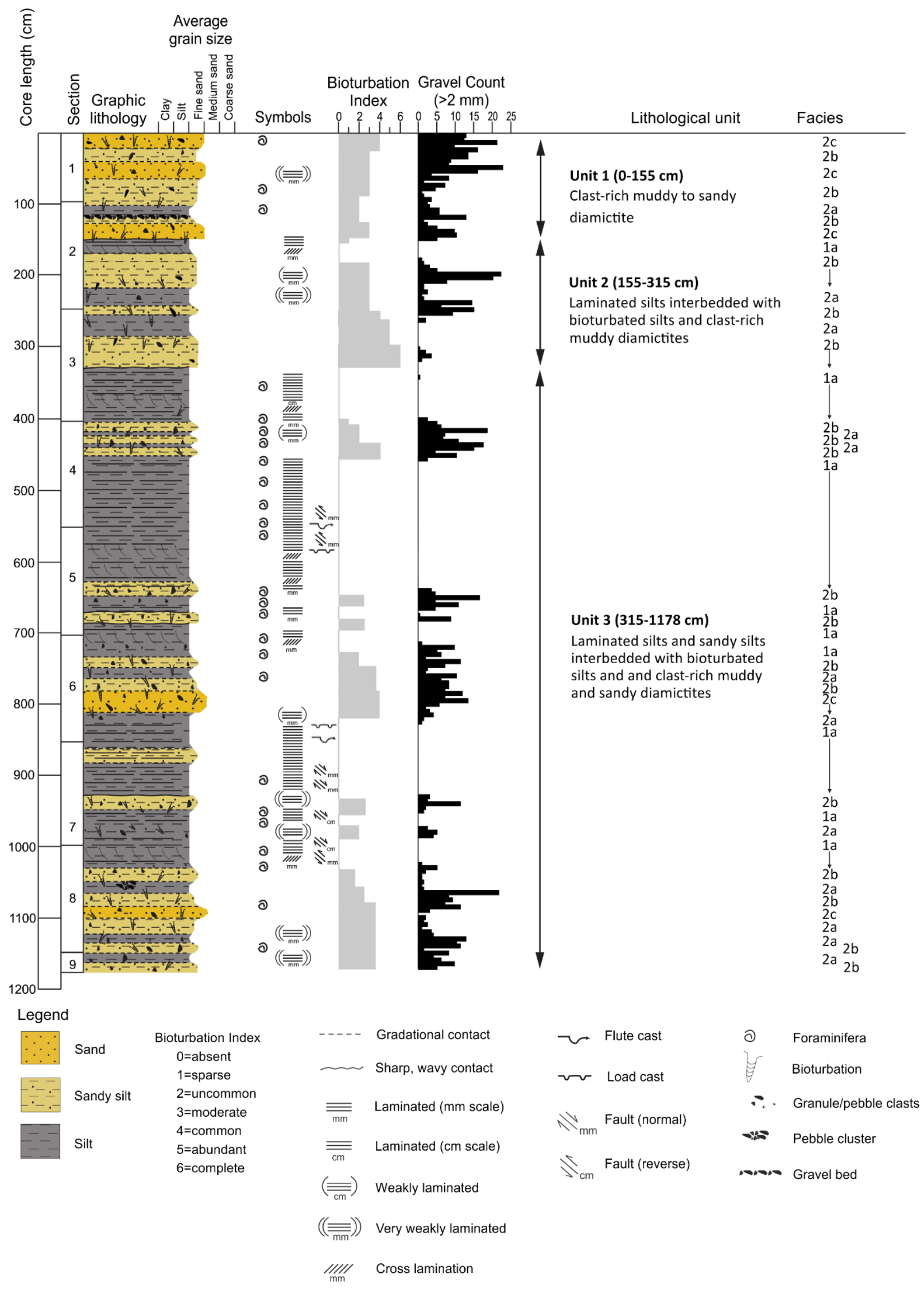

Figure 5.3: Summary stratigraphic log for core RS15-LC42. Refer to Table 5.1 for facies definitions. 


\subsubsection{RS15-GC46}

Unit $1(0-660 \mathrm{cmbsf})$

Unit 1 consists of bioturbated silt characterised by gradational variations between silty clay and clayey silt. Silty clay beds are olive grey and are up to $50 \mathrm{~cm}$ in thickness, while clayey silt beds are dark grey and are up to $30 \mathrm{~cm}$ in thickness. Contacts are gradational over several $\mathrm{cm}$. Bioturbation is moderate to abundant throughout, and clasts vary from absent to common, although they occasionally occur in concentrated layers or clusters. Between 350 and $415 \mathrm{cmbsf}$, and 600 and $615 \mathrm{cmbsf}$ there are intervals of $\mathrm{mm}$-scale faintly laminated silt with uncommon bioturbation and absent to sparse clasts. Laminae are characterised by packages of $\mathrm{mm}$-scale fine to coarse silt that are planar, parallel and are even- to wavy in nature with sharp upper and lower contacts, but are generally wispy and discontinuous, so that silt mottles and lenses are more common rather than continuous laminae (Figure 5.4a). A soft-sediment deformation or loading feature is present between 155 and $158 \mathrm{cmbsf}$ (Figure 5.4b). Two $1 \mathrm{~cm}$ thick black organic layers occur at 580 and $585 \mathrm{cmbsf}$. A single bed of clast-rich muddy diamictite is present between 510 and $520 \mathrm{cmbsf}$ that is brownish-grey and moderately bioturbated with abundant clasts and weakly-defined $\mathrm{mm}$-scale planar-laminae. The basal contact of this bed is gradational over $2 \mathrm{~cm}$ and moderately bioturbated. There were no calcareous fossils noted in the core. The basal contact of the unit is gradational over $2 \mathrm{~cm}$ and moderately bioturbated over several $\mathrm{cm}$.

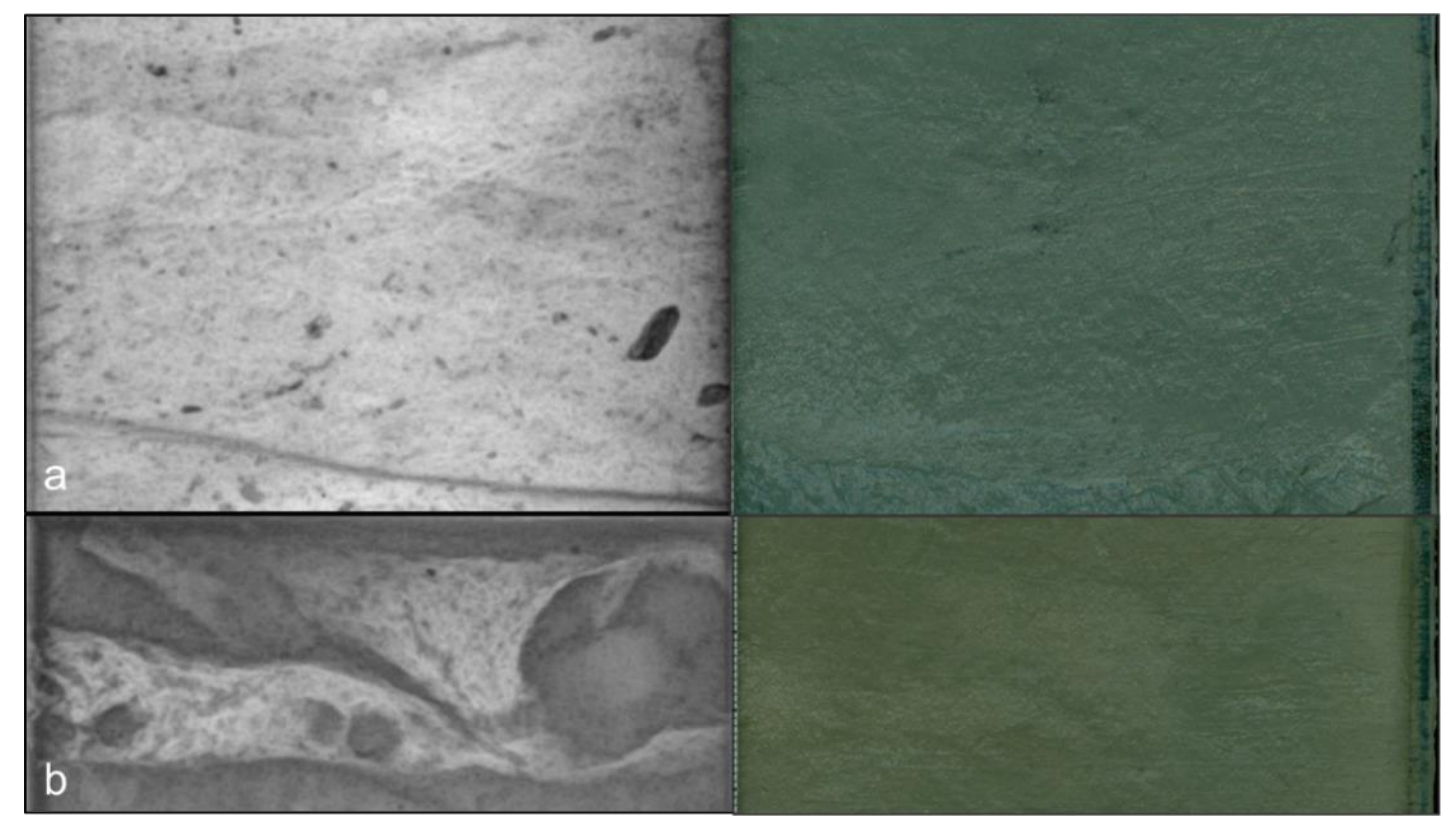

Figure 5.4: Representative x-ray images (left) and photographs (right) of (a) mm-scale faintlylaminated silt between 406 and $411 \mathrm{cmbsf}$, and (b) soft sediment deformation between 155 and 158 cmbsf. 


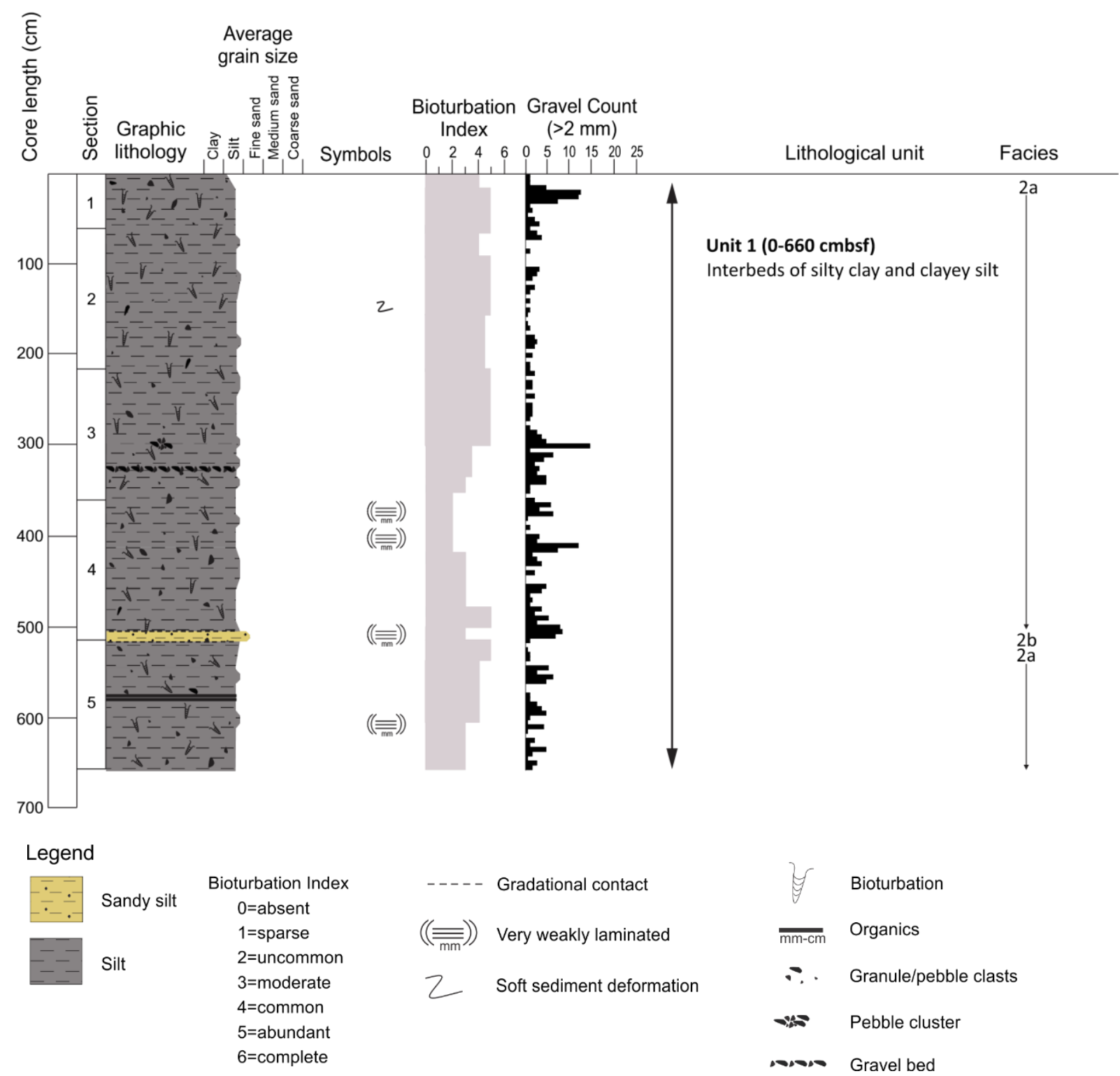

Figure 5.5: Summary stratigraphic log for core RS15-GC46. Refer to Table 5.1 for facies definitions.

\subsubsection{RS15-LC47}

\section{Unit $1(0-740 \mathrm{cmbsf})$}

Unit 1 consists of interbeds of silt with sparse to abundant clasts and clast-rich muddy diamictites. Silt beds are olive- to greenish-grey, moderately to strongly bioturbated with rare mm-scale faint laminations, and are up to $180 \mathrm{~cm}$ in thickness. Laminated intervals are characterised by packages of $\mathrm{mm}$-scale fine to coarse silt planar-laminations that are even to wavy and parallel in nature, and are generally weakly-defined and discontinuous so that silt mottles and lenses, rather than continuous laminae, are common. Occasional clasts and common bioturbation occur throughout the laminated sections (Figure 5.6). Muddy diamictites are dark grey with abundant clasts and are moderately to abundantly bioturbated, and up to $20 \mathrm{~cm}$ in thickness. Black organic-rich layers are 
present between 436 and $438 \mathrm{cmbsf}$ and 457 and $459 \mathrm{cmbsf}$. The top half of the unit is characterised by abundant clasts, while the bottom half of the unit is characterised by scarce to common clasts. Clasts range from granules to pebbles grade, and are occasionally concentrated into layers and clusters. Basal contacts of beds are gradational over 1-2 cm or sharp wavy and bioturbated over several $\mathrm{cm}$. The unit has a gradational, bioturbated basal contact over $1-2 \mathrm{~cm}$.

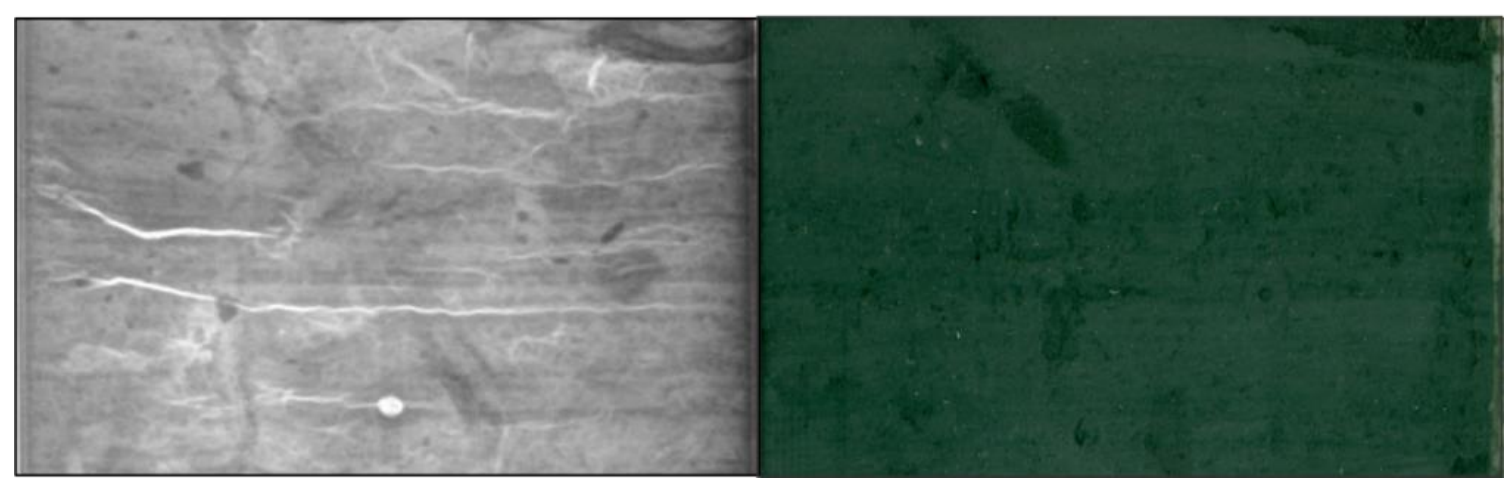

Figure 5.6: Representative x-ray image (left) and photograph (right) of faintly laminated silt between 555 and $560 \mathrm{cmbsf}$. Laminae are weakly-defined, discontinuous, bioturbated and contain occasional clasts.

\section{Unit $2(740-1010 \mathrm{cmbsf})$}

This unit is comprised of interbeds of silt, sandy silt and silty sand with well-defined $\mathrm{mm}$-scale laminations. Bioturbation and clasts are sparse to absent throughout the entire unit, although rare laminated silt intervals with sparse clasts and sparse bioturbation are present. Silt beds are olive grey with well-defined $\mathrm{mm}$-scale planar- and cross-laminae, and are up to $150 \mathrm{~cm}$ in thickness. Sandy silt beds are dark grey with well-defined mm-scale planar-and cross- laminae, and up to $20 \mathrm{~cm}$ in thickness. A $10 \mathrm{~cm}$ thick, mm-scale planar- and cross-laminated, weaklybioturbated brownish-grey silty sand bed is present between 1000 and $1010 \mathrm{cmbsf}$. Laminae are defined by discrete packages of $\mathrm{mm}$-scale planar- and cross-laminae of fine/coarse silt and coarse silt/fine sand with sharp upper and lower contacts. Intervals with $\mathrm{mm}$-scale planar-laminae are generally well-defined, are even to wavy and parallel in nature, and are mostly continuous but with rare intervals of discontinuous wispy laminae (Figure 5.7). Normal and reverse faults with $\mathrm{mm}$-scale offsets are common. Intervals with $\mathrm{mm}$-scale cross-laminae are less frequent, are between 1 and $3 \mathrm{~cm}$ in thickness and characterised by erosional sets along their top (Figure 5.7). Laminae show no evidence for internal grading. Basal contacts of beds are gradational over 1$2 \mathrm{~cm}$ or sharp wavy. The unit has a sharp wavy lower contact. 


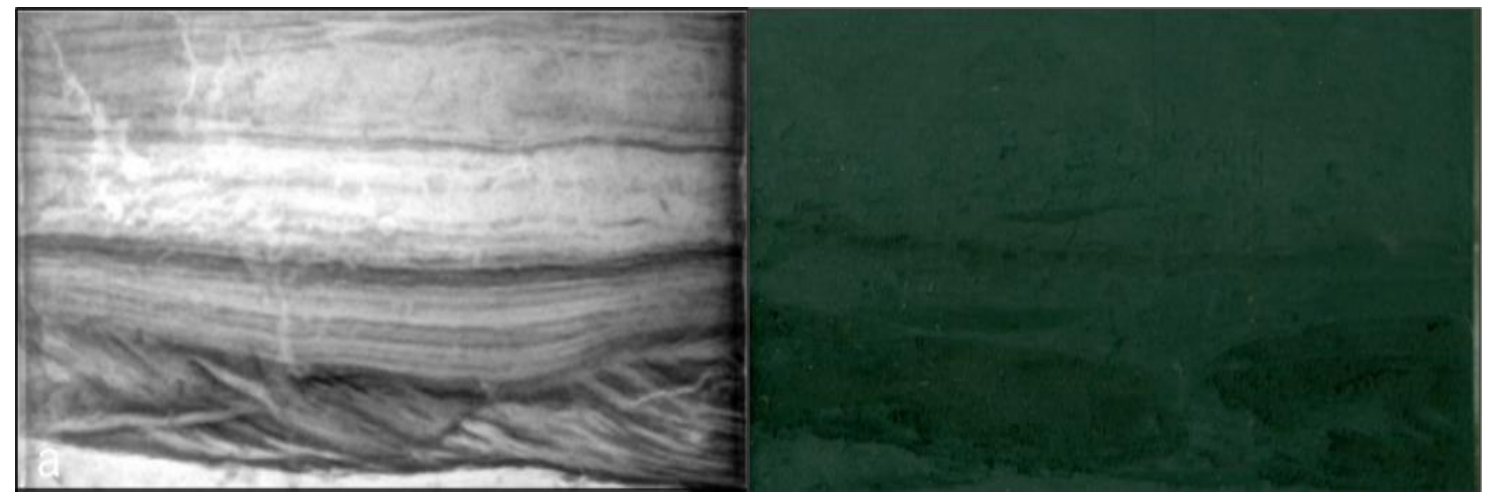

Figure 5.7: Representative x-ray images (left) and photographs (right) of well-defined planar-and cross-laminae between 770 and 775 cmbsf.

\section{Unit $3(1010-1375.5 \mathrm{cmbsf})$}

Unit 3 comprises interbeds of silty clay and clayey silt. The beds are olive- to greenish-grey, moderately to commonly bioturbated with scarce to common clasts. Intervals with faint mm-scale planar-laminae are rare and identical in structure to those of unit 1 (described above), but include normal faults with mm-scale offsets (Figure 5.8a). The silt interval between 1275 and $1325 \mathrm{cmbsf}$ is sparsely bioturbated and clast-poor with well-defined $\mathrm{mm}$-scale planar fine/coarse silt laminations. These are similar to the discontinuous, wispy planar-laminae observed in unit 2, but display mm-scale offsets due to numerous normal and reverse faults (Figure 5.8b). An interval of inclined laminae $\left(\sim 20^{\circ} \mathrm{dip}\right)$ is also present between 1062 and $1070 \mathrm{cmbsf}$. There is no evidence for calcareous fossils in the core. Basal contacts of units are gradational over $1-2 \mathrm{~cm}$ and bioturbated over several $\mathrm{cm}$. 


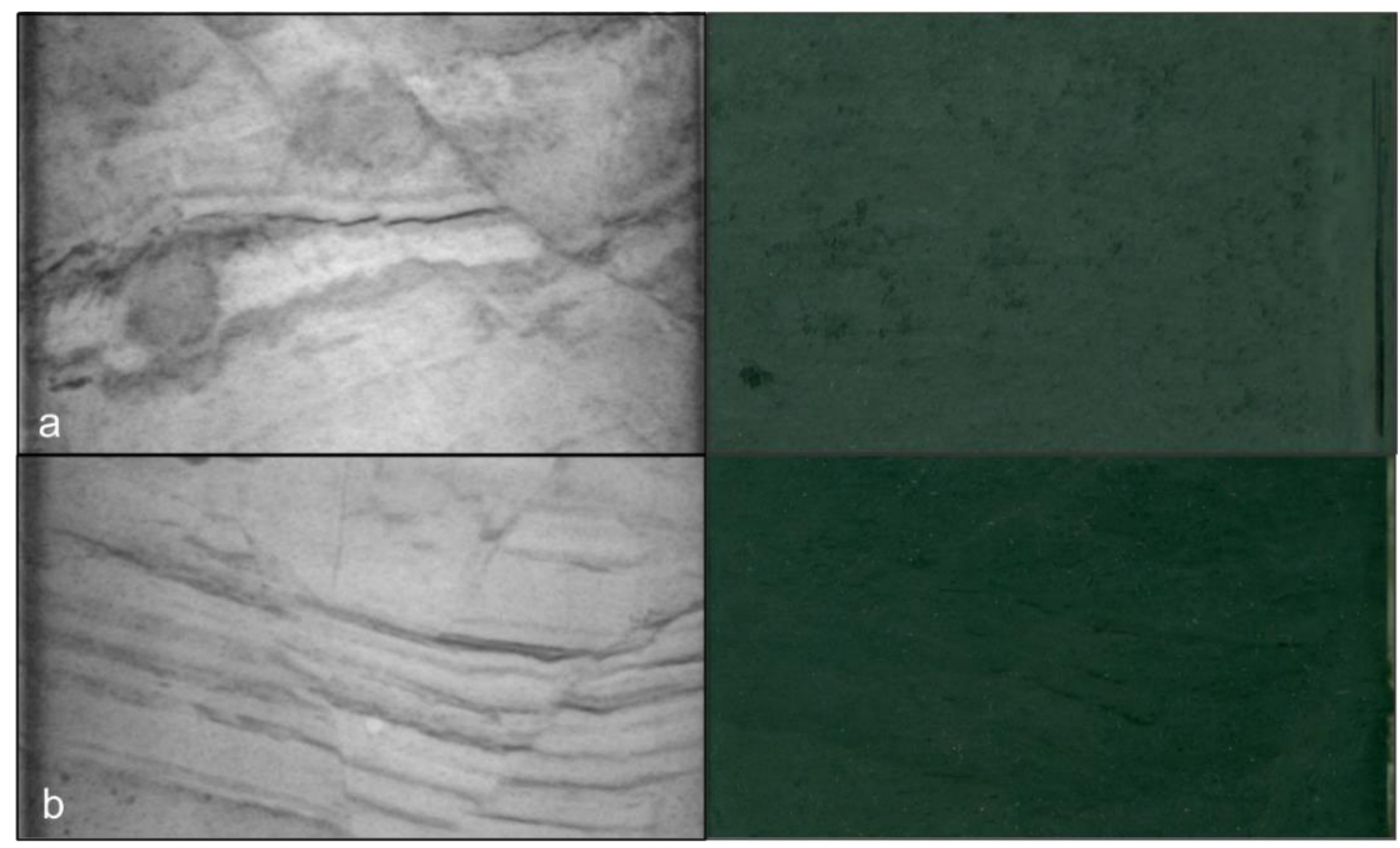

Figure 5.8: Representative x-ray images (left) and photographs (right) of (a) weakly-defined mmscale laminae between 1345 and $1350 \mathrm{cmbsf}$, laminae are weakly bioturbated and offset by normal faults, and (b) well-defined, faulted mm-scale laminae between 1290 and $1294 \mathrm{cmbsf}$. 


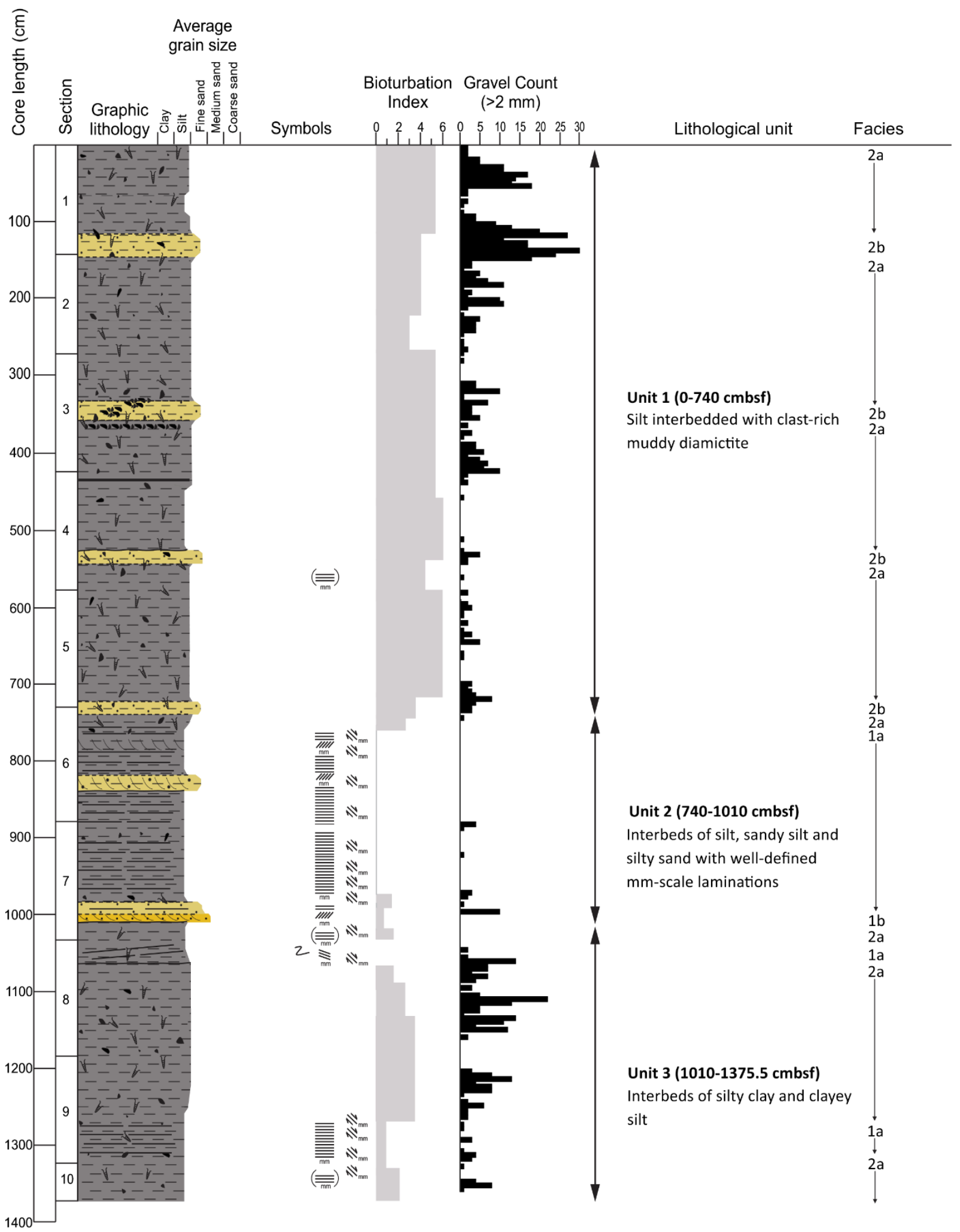

Continued on next page 


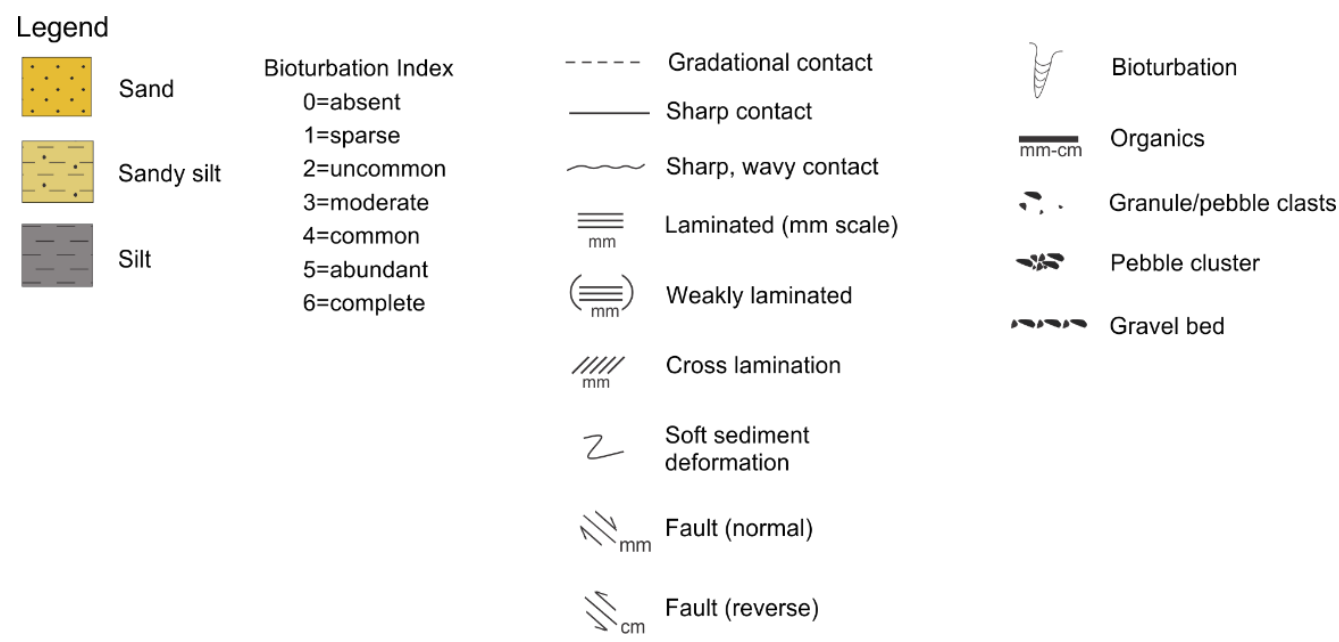

Figure 5.9: Summary stratigraphic log for core RS15-LC47. Refer to Table 5.1 for facies definitions.

\subsubsection{RS15-LC48}

Unit 1 (0-240 cmbsf)

Unit 1 comprises gradational interbeds of clast-rich muddy diamictite, bioturbated silt with common to abundant clasts and laminated silt with absent to sparse clasts. Muddy diamictite beds are $<110 \mathrm{~cm}$ in thickness, greyish-brown, and moderately to strongly bioturbated with abundant clasts. Silt beds are $<40 \mathrm{~cm}$ in thickness, greenish-grey, and moderately bioturbated with $\mathrm{mm}$-scale faint laminations and common to abundant clasts. Laminated intervals are characterised by packages of $\mathrm{mm}$-scale planar- and cross-laminae of clayey silt/coarse silt, which vary from even to wavy, are parallel, but often discontinuous and weakly-defined with common silt mottles and lenses. The laminae in this unit are also disrupted by $\mathrm{cm}$-scale burrows and $\mathrm{cm}$ scale scour features (Figure 5.10a). A silt bed with sparse bioturbation and well-defined $\mathrm{mm}$-scale planar- and cross-laminae occurs between 90 and $100 \mathrm{cmbsf}$. The planar-laminae vary from even to wavy, are parallel and continuous, and have sharp upper and lower contacts. Cross-laminae are less frequent and occur in beds up to $1 \mathrm{~cm}$ in thickness, are parallel and continuous, and characterised by planar-laminae grading into cross-laminae and unidirectional bundled lenses (Figure 5.10b). Laminae show no evidence for grading. Basal contacts of beds are gradational and bioturbated over several $\mathrm{cm}$ or sharp wavy. The lower contact of the unit is gradational and bioturbated over several $\mathrm{cm}$. 


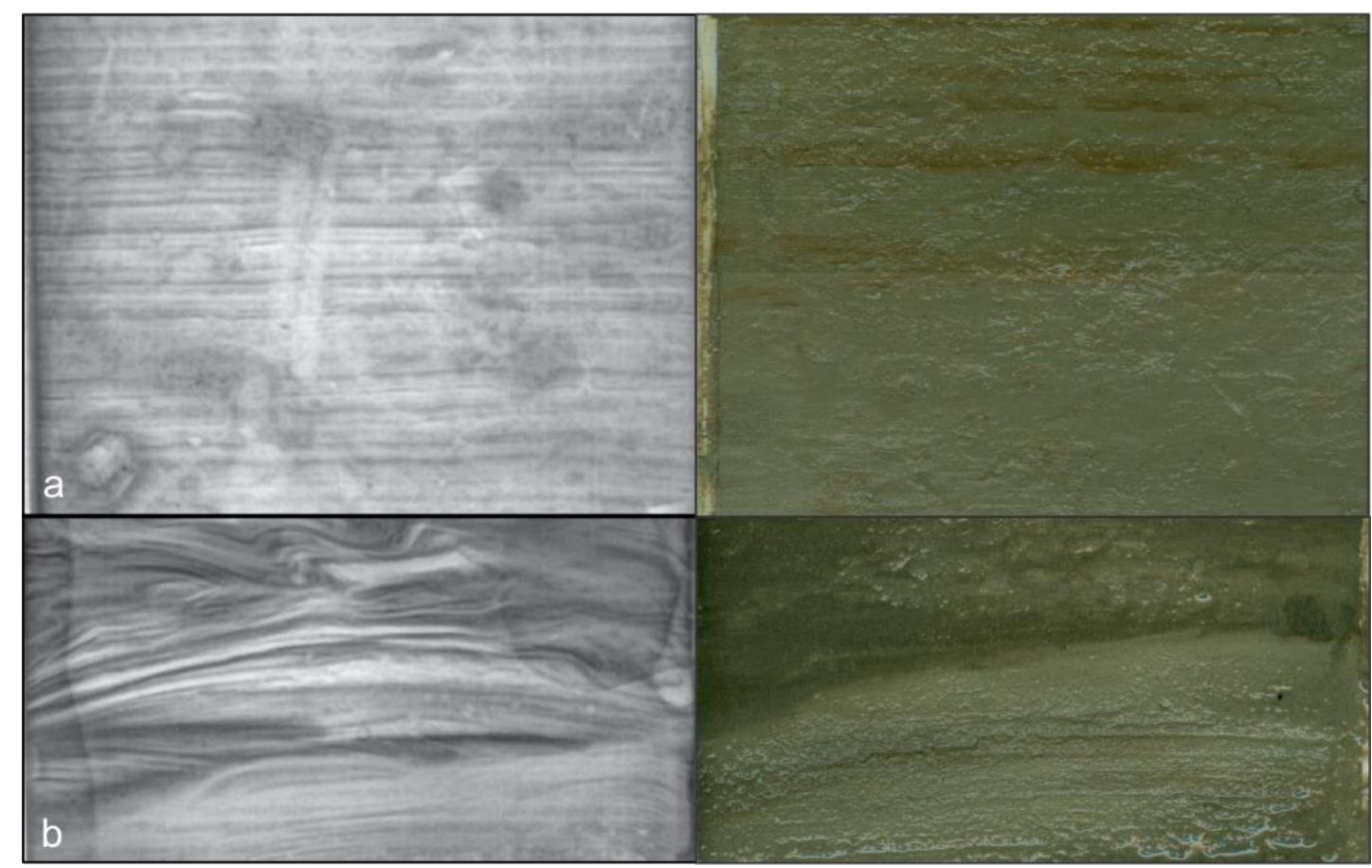

Figure 5.10: Representative x-ray images (left) and photographs (right) of (a) a weakly laminated silt bed between 70 and $80 \mathrm{cmbsf}$, laminae are bioturbated and show scour features, and (b) well-defined planar- and cross-laminae between 95 and $100 \mathrm{cmbsf}$.

\section{Unit 2 (240-944 cmbsf)}

Unit 2 consists of faintly laminated silt interbedded with muddy and sandy diamictites. Silt beds are $<30 \mathrm{~cm}$ thick, grey-brownish with uncommon to common bioturbation, faint $\mathrm{mm}$-scale laminae and common to abundant clasts. The laminae in this unit are structurally and texturally identical to the laminae described in unit 1 with $\mathrm{cm}$-burrows and scour features, but are also cut by rare normal faults with $\mathrm{mm}$-to-cm-scale offsets (Figure 5.11). Muddy diamictites are $<80 \mathrm{~cm}$ thick, greyish-brown, with moderate to abundant bioturbation and common to abundant clasts. These are occasionally interbedded with yellowish-brown sandy diamictites up to $20 \mathrm{~cm}$ thick, with moderate to abundant bioturbation and common to abundant clasts. Clasts are abundant throughout the unit and range from granules to pebbles grade, and occasionally occur in concentrated layers and clusters. Bioturbation is pervasive throughout the entire unit. Basal contacts of beds are gradational and bioturbated over several $\mathrm{cm}$, with the exception of a sharp wavy, bioturbated contact at 285 cmbsf. The lower contact of the unit is gradational and bioturbated over $2 \mathrm{~cm}$. 


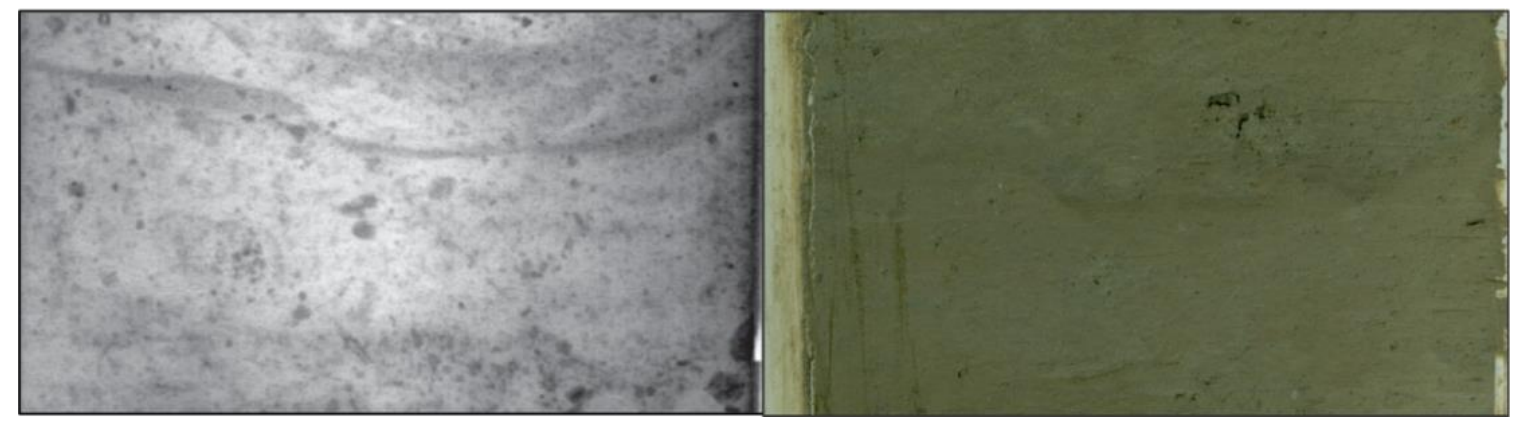

Figure 5.11: Representative x-ray image (left) and photograph (right) of faint mm-scale laminations offset by a normal fault between 680 and $685 \mathrm{cmbsf}$.

Unit $3(944-1220 \mathrm{cmbf})$

Unit 3 comprises of interbeds of silt with well-defined $\mathrm{mm}$-scale laminations and clast-rich muddy and sandy diamictites. Silt beds are up to $55 \mathrm{~cm}$ thick, greenish-grey, and sparsely bioturbated in places with absent to scarce clasts. However, a concentrated layer of gravel (i.e., gravel lag) is observed at $1220 \mathrm{cmbsf}$ (Figure 5.12c). Laminated intervals are structurally and texturally identical to those between 90 and $100 \mathrm{cmbsf}$ in unit 1 (see above), but are much thicker (up to 55 $\mathrm{cm}$ ) and more prevalent throughout the unit. The laminae in this unit are also characterised by more frequent scour features at the bases. These are commonly wavy and contain soft sediment compressional features. Numerous normal and reverse faulting with mm-to-cm-scale offsets are also present, particularly between 1185 and 1215 cmbsf (Figure 5.12a). Mm-scale cross-laminae in this unit are also less frequent and occur in beds up to $1 \mathrm{~cm}$ in thickness, but differ from those of unit 1 as they are discontinuous and show grading from parallel planar-laminae (Figure 5.12b). Muddy and sandy diamictites are up to $50 \mathrm{~cm}$ and $15 \mathrm{~cm}$ in thickness, respectively, and are identical to those described in unit 2, but lack abundant bioturbation (although the massive structure could be due to pervasive bioturbation) and show rare faint $\mathrm{mm}$-scale laminations. Basal contacts of beds are gradational and bioturbated over several $\mathrm{cm}$, with the exception of a sharp sparsely bioturbated contact at $985 \mathrm{cmbsf}$. The lower contact of the unit is sharp and wavy. 


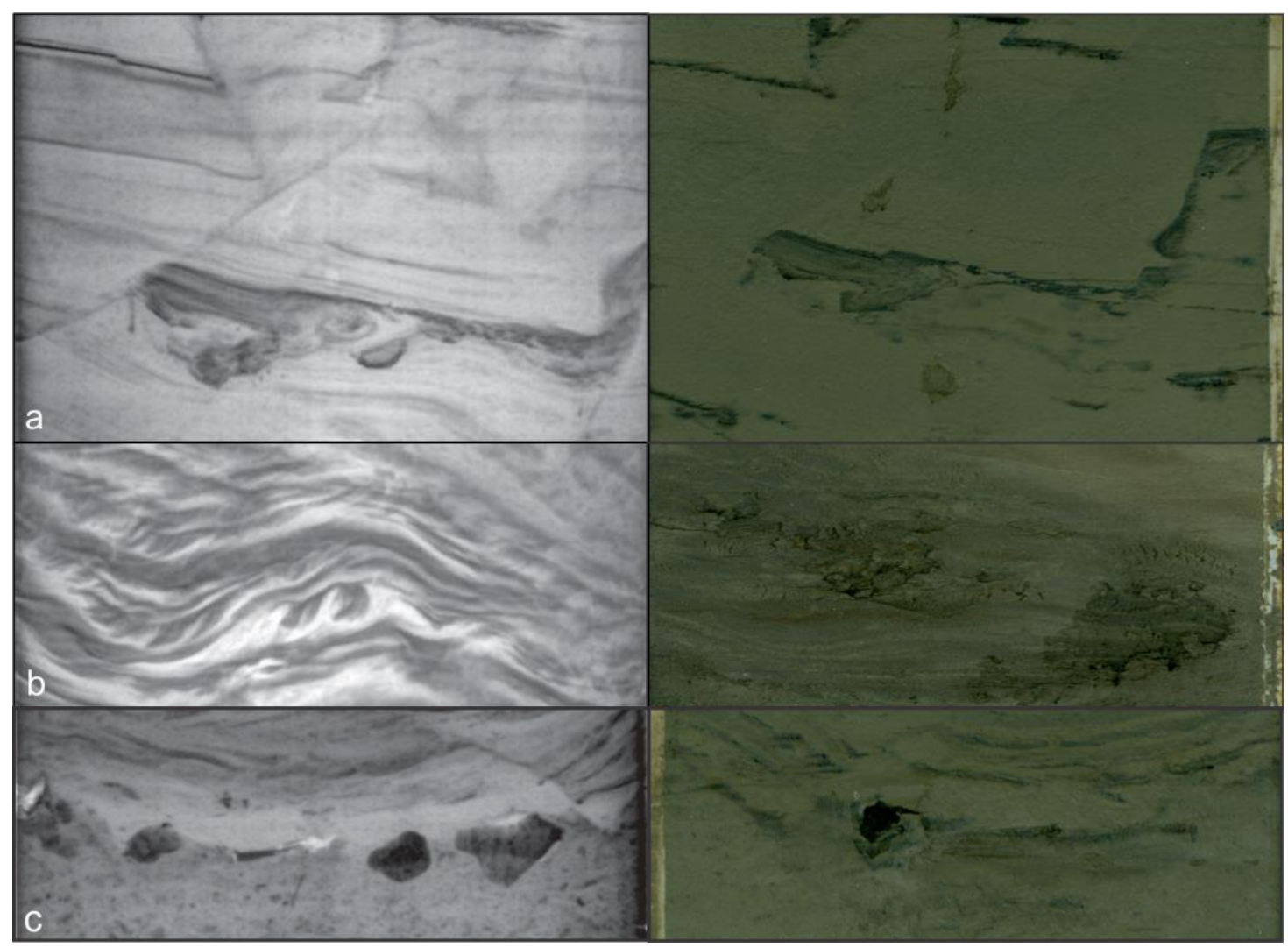

Figure 5.12: Representative x-ray images (left) and photographs (right) of (a) laminae offset by reverse faulting and soft sediment deformation compressional features at the base of laminae between 1195 and 1205 cmbsf, (b) discontinuous planar-laminae grading into cross-laminae between 980 and $985 \mathrm{cmbsf}$, and (c) gravel lag at $1220 \mathrm{cmbsf}$.

\section{Unit 4 (1220-1472 cmbsf)}

This unit consists of clast-rich, muddy diamictites with moderate to abundant bioturbation interbedded with weakly laminated silt with uncommon to moderate bioturbation and common to abundant clasts. Muddy diamictites are up to $180 \mathrm{~cm}$ thick, and are identical to those described in units 1, 2 and 3, with rare $\mathrm{mm}$-scale faint laminations and a $2 \mathrm{~cm}$ thick black organic layer at $1260 \mathrm{cmbsf}$. Silt beds are up to $20 \mathrm{~cm}$ in thickness with faint $\mathrm{mm}$-scale planar-laminae, identical to those described in unit 1 , but appear more irregularly aligned. Bioturbation is pervasive throughout and clast content varies from common to abundant throughout the unit. Basal contacts of the interbeds are gradational and bioturbated over several $\mathrm{cm}$.

\section{Clast lithologies}

Clasts sizes range from granule to pebble grade, are sub-angular to angular in shape, and striated/facetted clasts are present. Pebble lithologies are varied throughout and include granite, gneiss, basalt, argillite, greywacke and large mineral grains including feldspars and quartz. 


\section{Biogenic content}

Visual analysis of smear slides in combination with BiSi data indicate a low diatom content throughout the entire core $(<20 \%)$. Foraminifera-rich beds are common in unit 1 and are rare throughout the rest of the core, and include benthic species Cibicides spp., Uvigerina spp., Lagena spp., and Dentalina spp., and planktonic species N. pachyderma (s.). Ostracods, radiolarians and sponge spicules are also present, and range from trace to common amounts. 

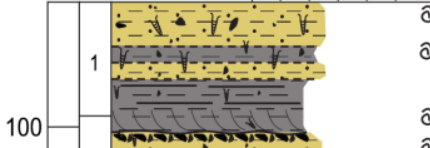

2
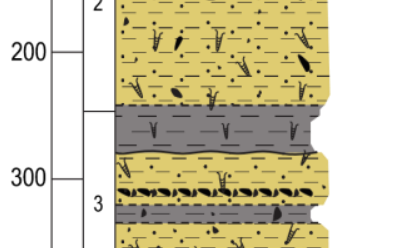

400

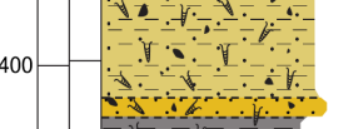

$4 \leq-4$

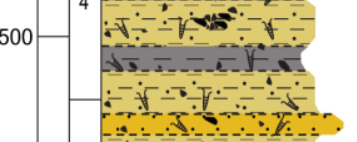

600
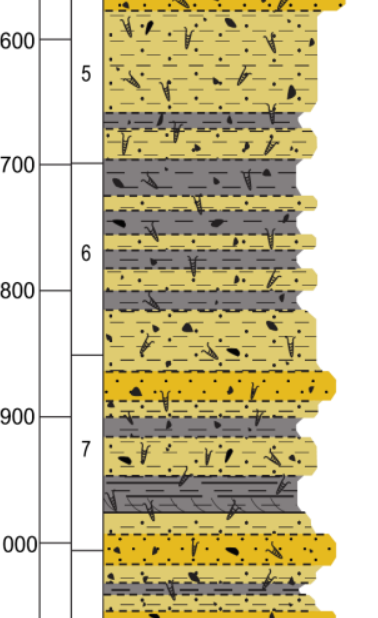

8 i -1

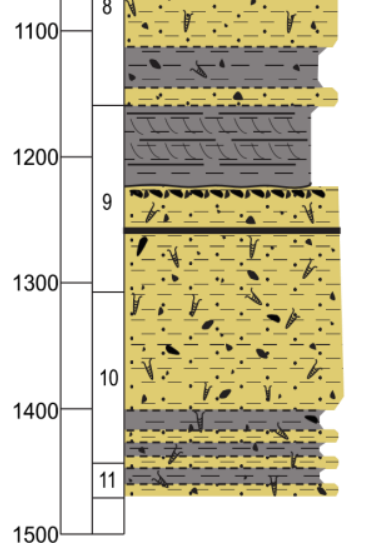

a

a

a

(

$((\equiv))$

a ((三)) ה

$((\equiv))$
$(\equiv)$
$((\equiv))$
$((\equiv))$

$((\equiv))$
$(\equiv)$
$((\equiv))$
$((\equiv))$

$($ (三)

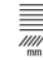

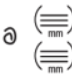

((三)

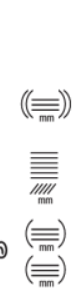

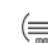

2

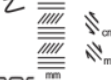

$((\equiv)$

$((\overline{(\equiv)})$

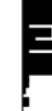

글

를

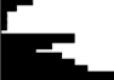

2

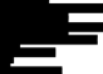

를

吾

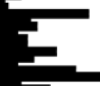

厂

크

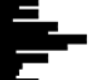

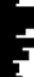

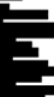

(1)

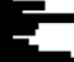

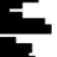

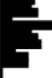

E

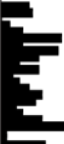

ra

1
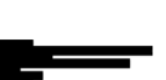

-

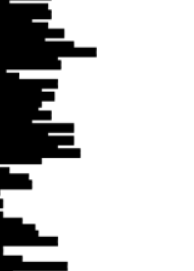

Lithological unit

Facies

Clast-rich muddy diamictites

interbedded with silt

\section{Unit 2 (240-944 cm)}

Weakly laminated silt interbedded

with clast-rich muddy and sandy

diamictites

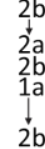

$2 \mathrm{~b}$
$2 \mathrm{a}$
$2 \mathrm{~b}$
$1 \mathrm{a}$
$2 \mathrm{~b}$

Unit 3 (944-1220 cm)

Laminated silt interbedded with

clast-rich muddy and sandy

diamictites

Clast-rich muddy diamictites

interbedded with weakly laminated silt 
Legend

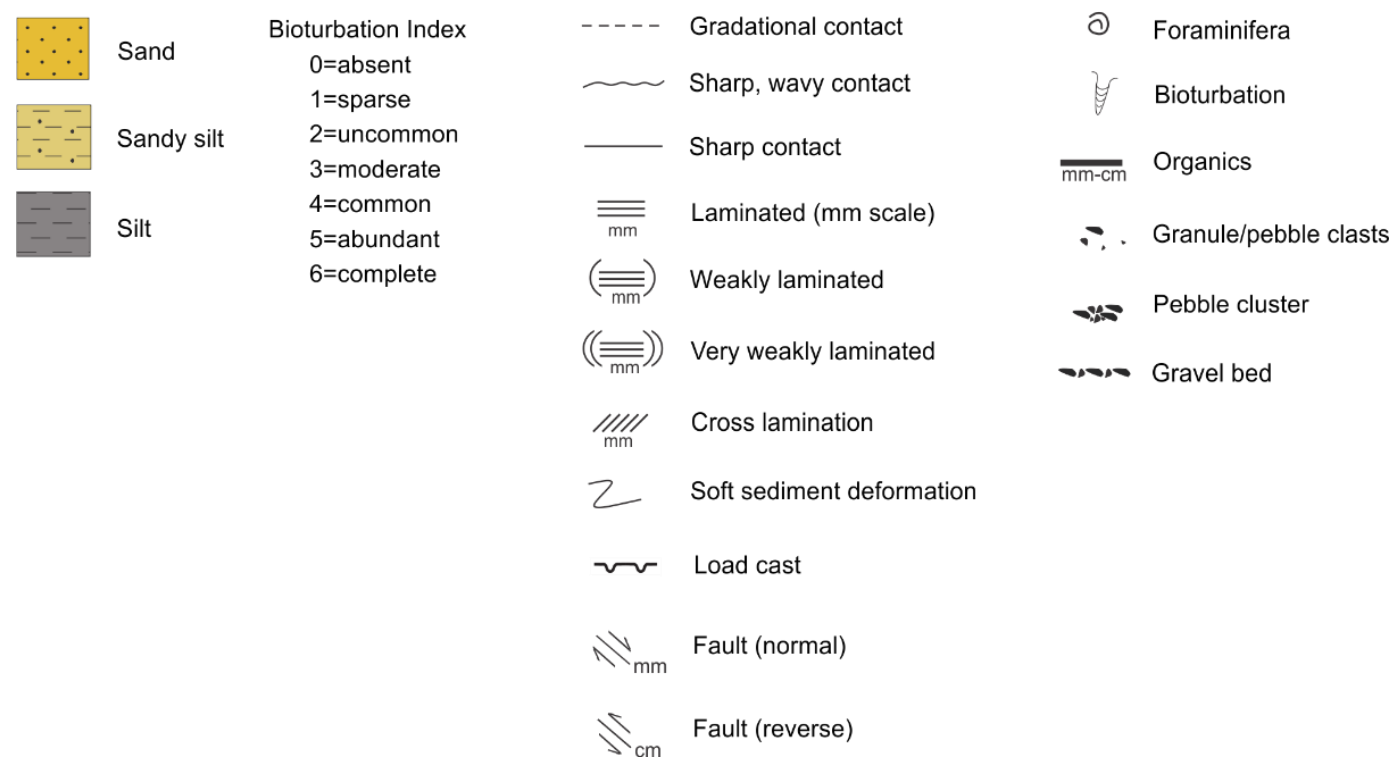

Figure 5.13: Summarised stratigraphic log for core RS15-LC48. Refer to Table 5.1 for facies definitions.

\subsubsection{RS15-GC107 and RS15-LC108}

Analysis of $\mathrm{x}$-ray images for core RS15-GC107 suggests a monotonous lithology with common to complete bioturbation and abundant clasts, which occasionally occur in concentrated layers (Figure 5.14), throughout the entire record. X-ray images of core RS15-LC108 also demonstrate a monotonous lithology, with abundant to complete bioturbation and common to abundant clasts occasionally concentrated into layers (Figure 5.15a). However, an interval with well-defined mm-scale planar laminae, identical to those described in RS15-LC48, is present between 568 and $571 \mathrm{cmbsf}$, and rare, faintly laminated intervals ( $<20 \mathrm{~cm}$ in thickness) with uncommon to moderate bioturbation and common clasts are also common between 800 and $1650 \mathrm{cmbsf}$ (Figure 5.15b).

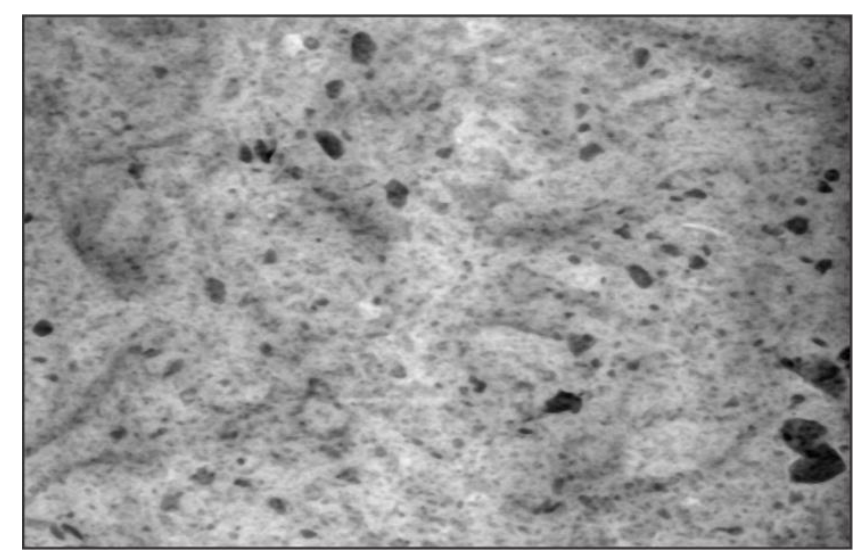

Figure 5.14: Representative x-ray image of an abundantly bioturbated interval with abundant clasts between 40 and $45 \mathrm{cmbsf}$ in core RS15-GC107. 


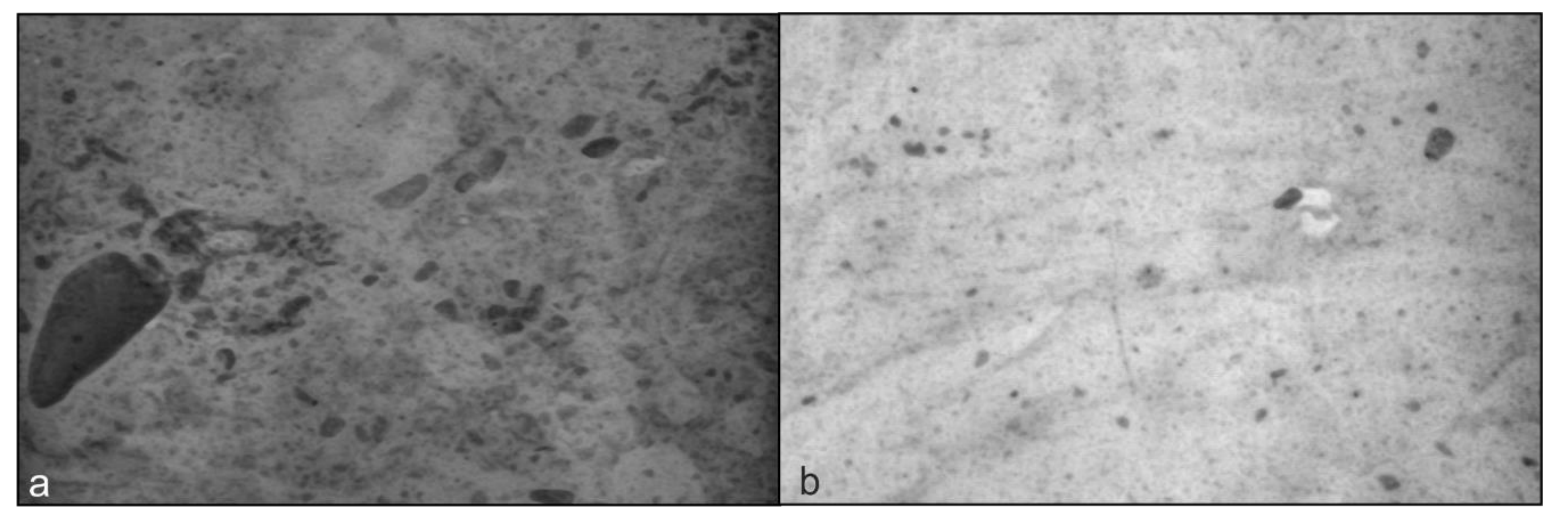

Figure 5.15: Representative x-ray images of (a) commonly bioturbated and clast-rich interval between 195 and $190 \mathrm{cmbsf}$ and (b) faintly laminated interval with uncommon bioturbation and common clasts between 1235 and $1240 \mathrm{cmbsf}$ in core RS15-LC108.
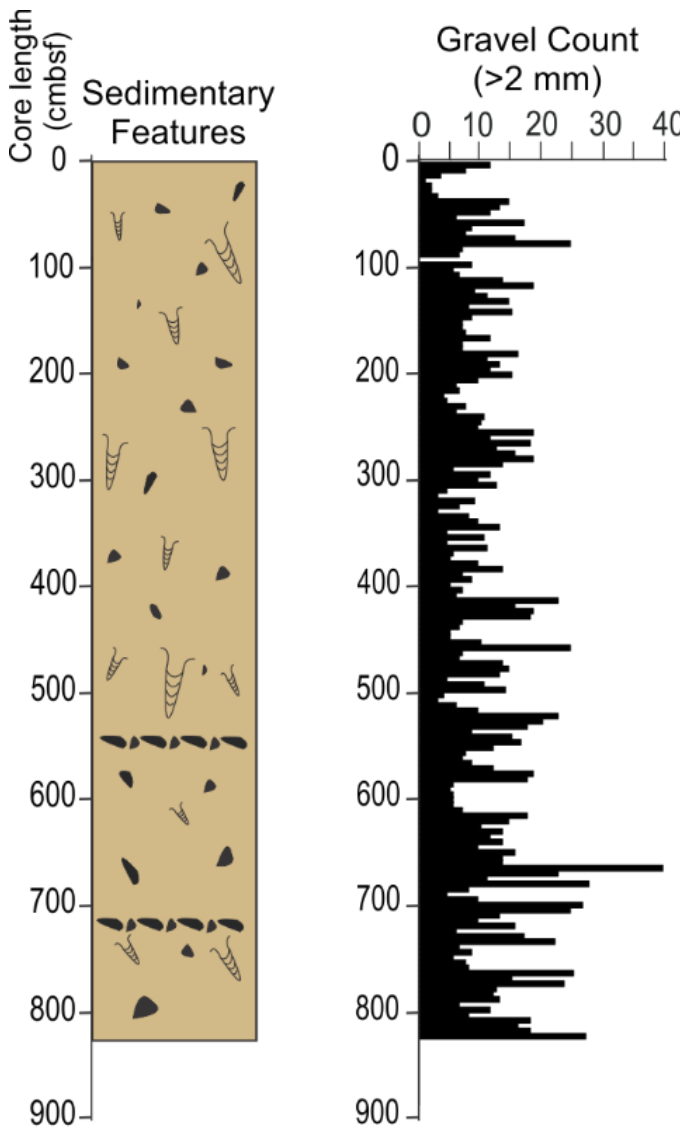

Legend

\section{$\therefore$ Clasts \& Bioturbation œD Gravel bed}

Figure 5.16: Depth distribution of the gravel count for core RS15-GC107. 

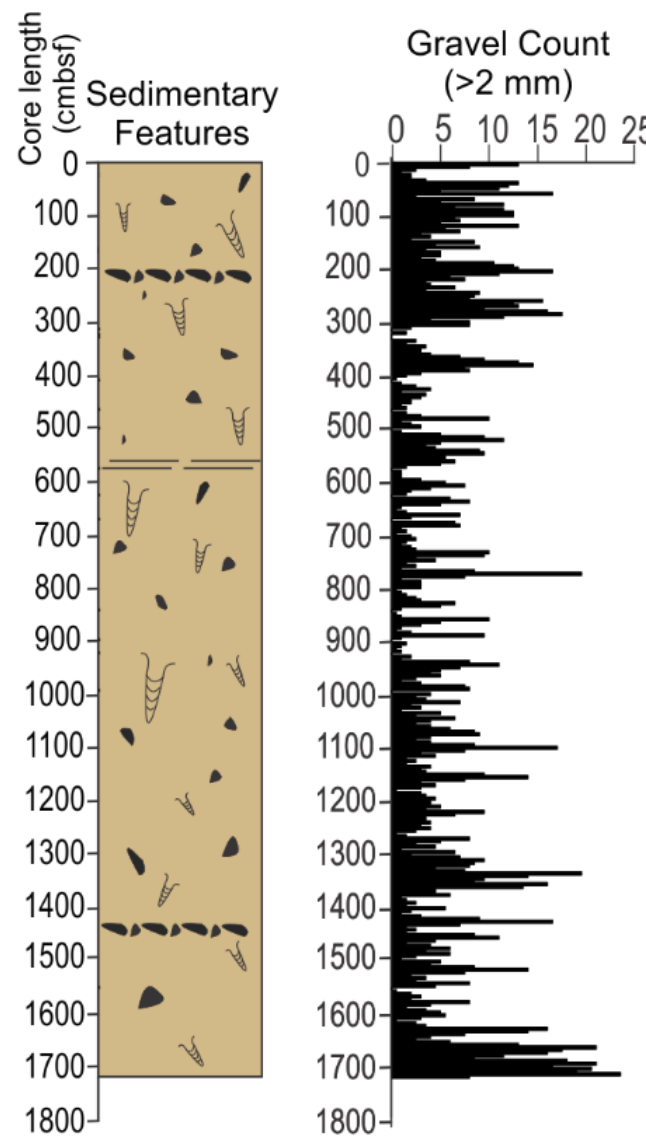

Legend

\section{$\therefore$ Clasts \& Bioturbation}

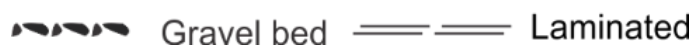

Figure 5.17: Depth distribution of the gravel count for core RS15-LC108.

\subsection{Grain size analysis}

\subsubsection{Grain size frequency distributions of the non-gravel fraction}

LPSA grain size frequency distributions for the $<2 \mathrm{~mm}$ grain size fraction are provided for cores RS15-LC42 and RS15-LC48. To assist with sediment descriptions the non-gravel fraction of each sample was classified on the basis of its sand/silt/clay ratio according to the ternary sediment classification scheme of Mazzulo et al., (1988). Clayey silts and silts display bimodal distributions and are poorly to very-poorly sorted, with modes in the clay, and medium-to-coarse silt ranges (Figure 5.18). The distributions for sandy silt are polymodal and poorly to very-poorly sorted, but with a dominant mode in the coarse silt to fine sand range. However, silty sands contain only a single mode in the fine sand range (centered on $\sim 125 \mu \mathrm{m}$ ) and have a much smaller fine-grained tail, and increased sorting relative to the silt lithologies, with some samples classified as 
moderately sorted (Figure 5.18). All lithologies display occasional peaks in the fine to coarse sand fractions. Sample by sample statistics are available in Appendix C. 

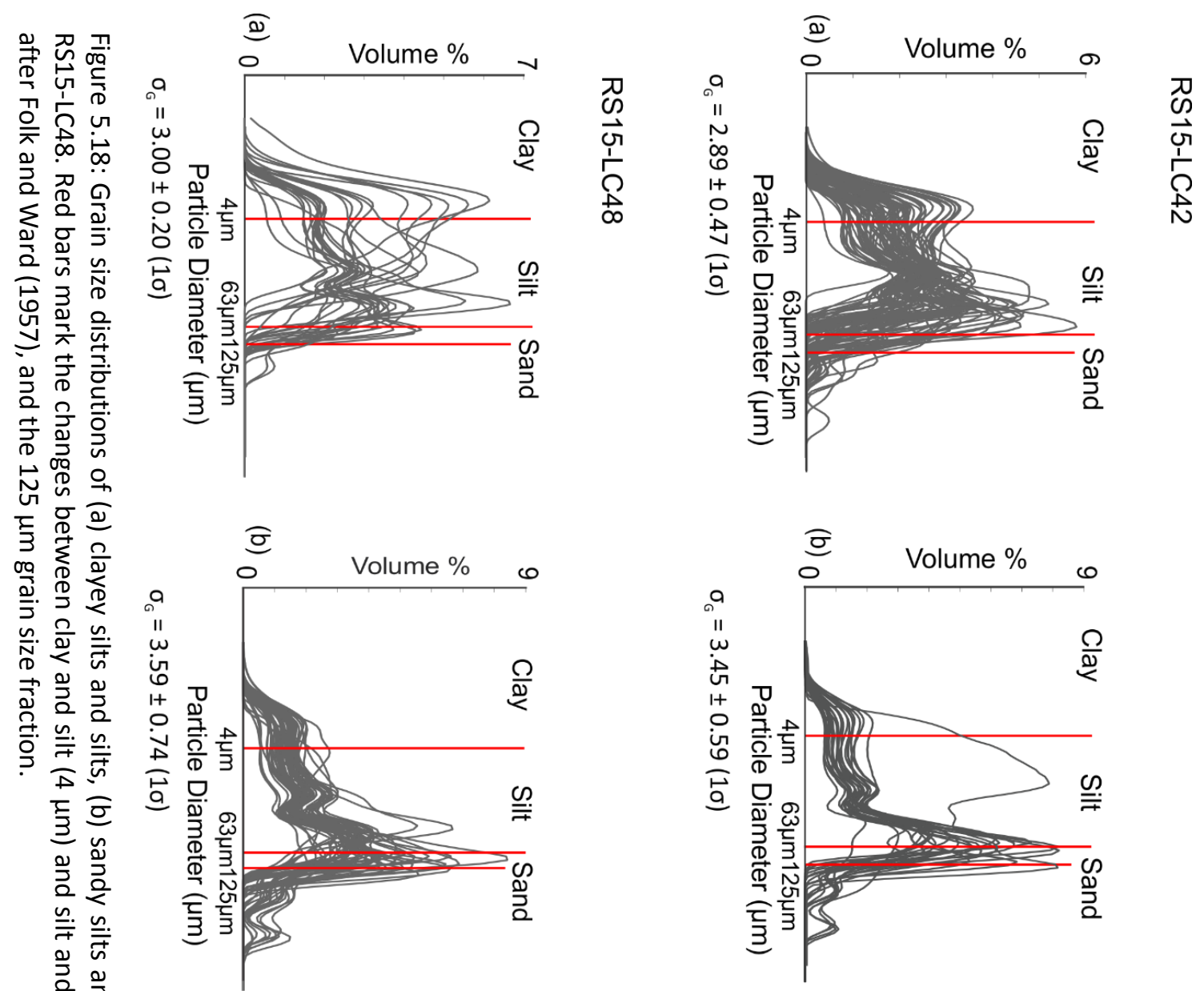

ํํㄹ

㐫
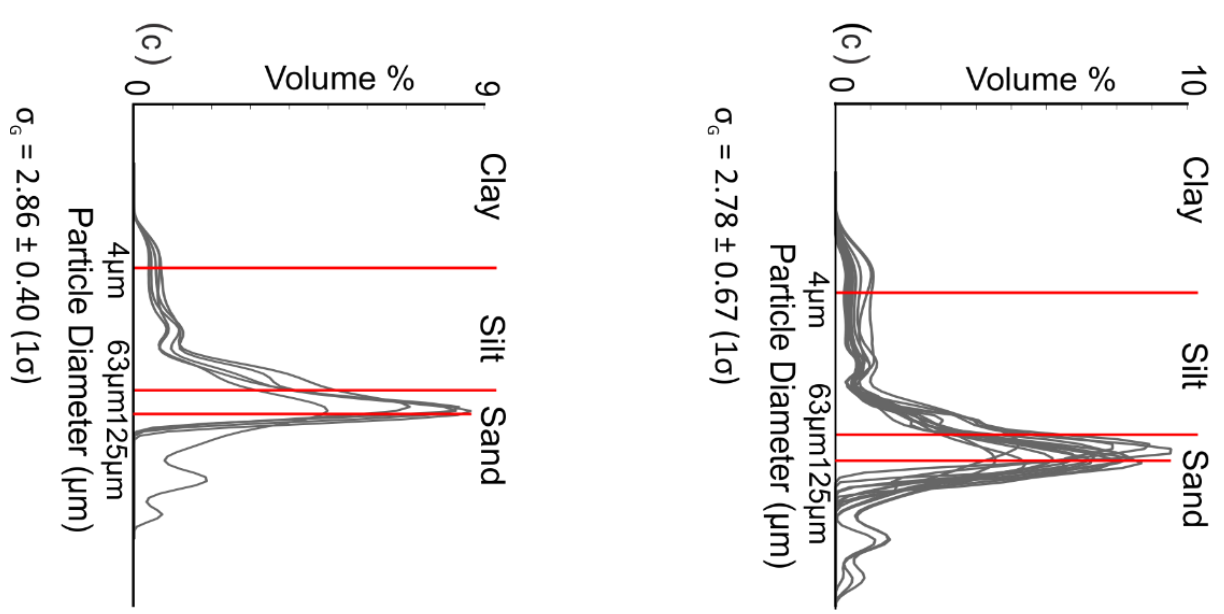


\subsubsection{Downcore trends in grain size}

Primary shifts in downcore trends for RS15-LC42, RS15-GC46, RS15-LC47 and RS15-LC48 are identified by examining clay percent (clay\%), silt percent (silt\%), sand percent (sand\%), mean grain size and sorting. LPSA grain size results are provided for cores RS15-LC42 and RS15-LC48, while sedigraph grain size data (provided by KOPRI) are reported for cores RS15-GC46 and RS15-LC47.

RS15-LC42: Three distinct intervals are identified in the grain size record based on the mud $(<63 \mu \mathrm{m})$ and sand $(63 \mu \mathrm{m}-1 \mathrm{~mm})$ content of the record (Figure 5.19). The first interval between 0 and $315 \mathrm{cmbsf}$ corresponds to units 1 and 2, and shows beds where the percentage of sand commonly exceeds $20 \%$. A second interval between 315 and $760 \mathrm{cmbsf}$ shows a significant decline in sand content, with beds rarely exceeding $20 \%$. Below $760 \mathrm{cmbsf}$ sand content is highly variable, and although overall sand percent is low $(<10 \%)$, increases in sand percent (up to $75 \%$ ) occur in intervals between 760 and $830 \mathrm{cmbsf}$ and 1030 and $1177 \mathrm{cmbsf}$. The variations observed in the mean grain size positively correlate with changes in sand\%. Linear regression analysis of sand\% versus mean grain size shows a very strong correlation with an $\mathrm{R}^{2}$ value of 0.9 (Figure 5.20a). However, sorting demonstrates no relationship with sand\%, although some samples with increased sand\% are correlated with increased (better) sorting (Figure 5.20b). Sand\% and silt\% show inverse trends, whereby increased sand\% is reflected by decreased silt\% and vice versa (Figure 5.19).

RS15-GC46: The grain size record for core RS15-GC46 shows consistently low sand\% (<10\%), with the exception of one excursion to $19 \%$ at $510 \mathrm{cmbsf}$ (Figure 5.21). The variations observed in the mean grain size and sorting are correlated with variations in sand\%, whereby decreasing sand\% is reflected in a decreased mean and increased sand\% correlates with poorer sorting. However, silt\% shows the strongest positive covariance with mean grain size, with increased silt\% correlated with increased mean grain size. Linear regression analyses of sand\% versus mean grain size, silt\% versus mean grain size, and sand\% versus sorting show moderate to strong correlations with $\mathrm{R}^{2}$ values of $0.44,0.67$ and 0.58 , respectively (Figure 5.22a;b;c). Clay\% and silt\% show inverse trends, whereby increased silt\% is reflected by decreased clay\% and vice versa.

RS15-LC47: Similar to core RS15-GC46, the grain size record for core RS15-LC47 shows consistently low sand\% $(<10 \%)$, but with five thin $(<20 \mathrm{~cm})$ beds distributed throughout the core with sand\% peaks $>10 \%$ occurring at 120-135, 340-350, 540-550, 720-730, and 990-1010 cmbsf (Figure 5.23). However, sand content is higher in the upper $450 \mathrm{~cm}$ of the core. The trends observed in the mean grain size and sorting are correlated with sand\%, whereby decreasing sand\% results in a 
decreased mean, and increased sand\% results in poorer sorting. However, sorting also displays a moderate correlation with silt\%, with poorer sorting reflected by increased silt\%. Linear regression analyses of sand\% versus mean grain size, sand\% versus sorting, and silt\% versus sorting show moderate to strong correlations with $R^{2}$ values of $0.81,0.62$ and 0.46 , respectively (Figure 5.24a;b;c).

RS15-LC48: The grain size record for core RS15-LC48 shows continuous large fluctuations between low sand\% (0-20\%) and high sand\% (30-69\%) throughout the entire record (Figure 5.25). The cyclic variations observed in the mean grain size are positively correlated with variations in sand\%. Similar to core RS15-LC42, sorting demonstrates no relationship, but few samples with increased sand\% are correlated with increased (better) sorting (Figure 5.26b). Linear regression analysis of sand\% versus mean grain size shows a very strong correlation with $R^{2}$ values of 0.84 (Figure 5.26a). In all cores, the majority of grain size distributions fall within the poorly to very poorly sorted category of Folk and Ward (1957), but some moderately sorted samples are present in core RS15-LC42 (see Appendix C). 


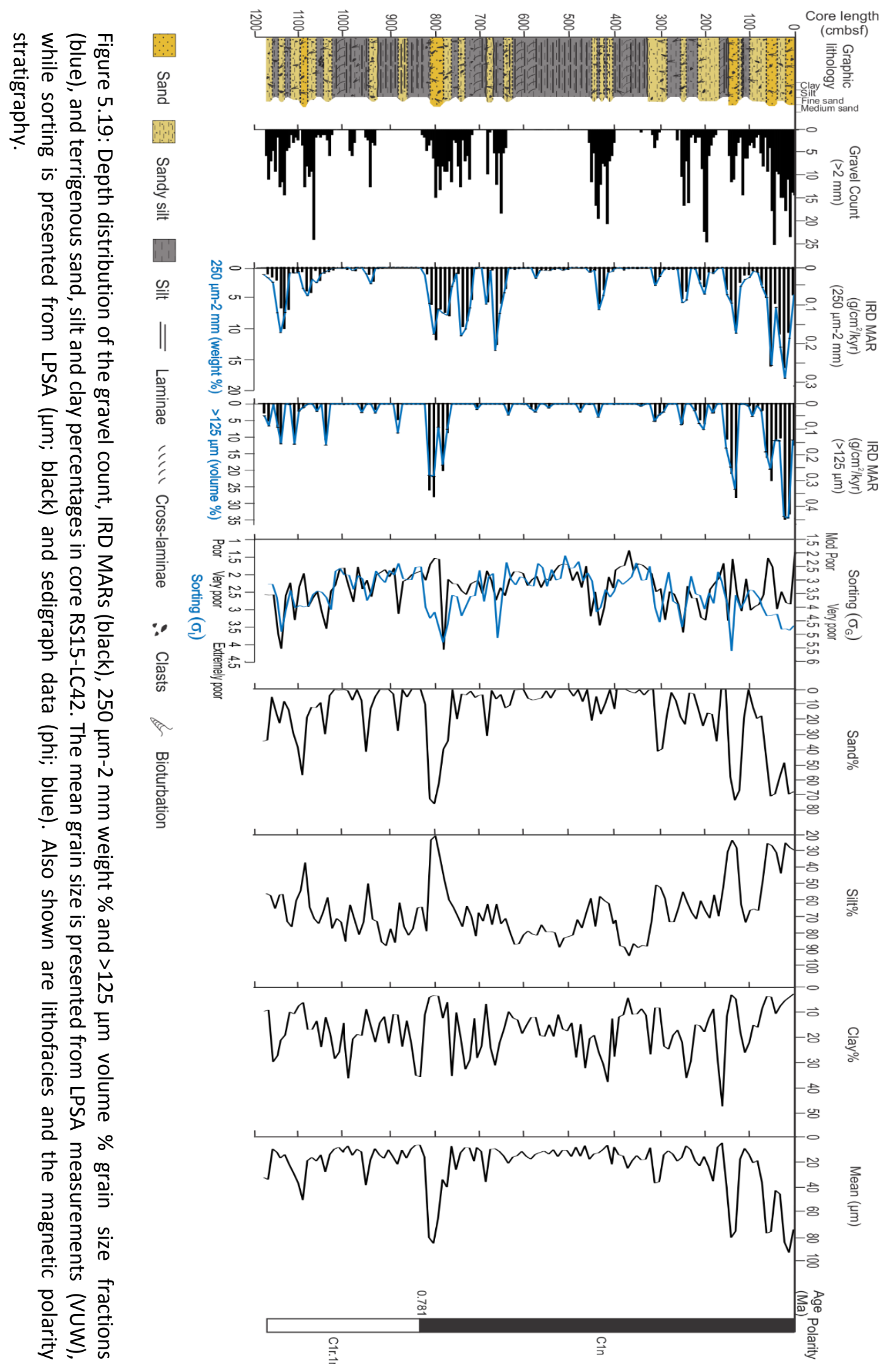



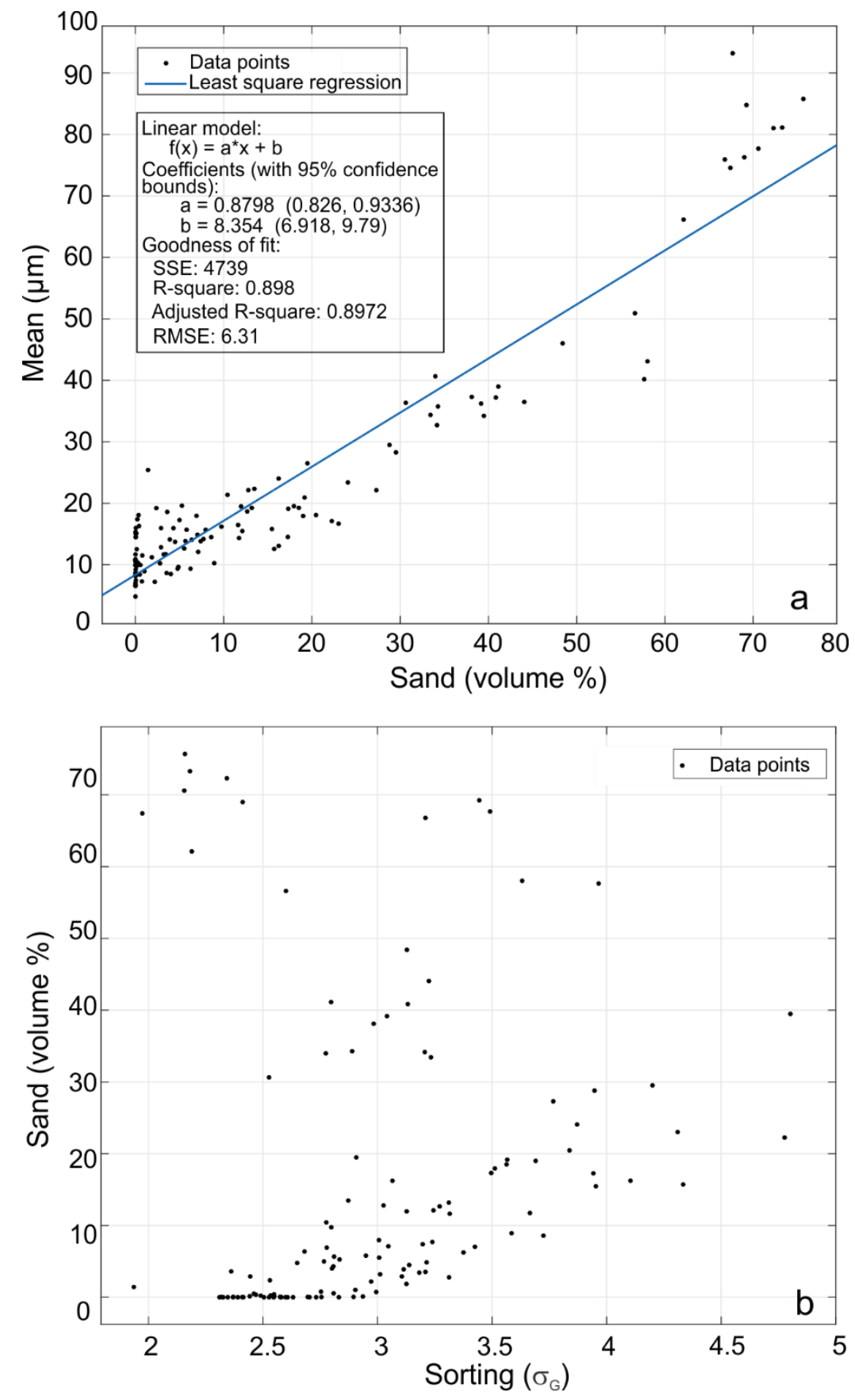

Figure 5.20: RS15-LC42 linear regression analysis. (a) Least square regression analysis of sand\% versus mean grain size shows a very strong correlation with an $R^{2}$ value of 0.90 . (b) Sorting versus sand\% shows no relationship. 


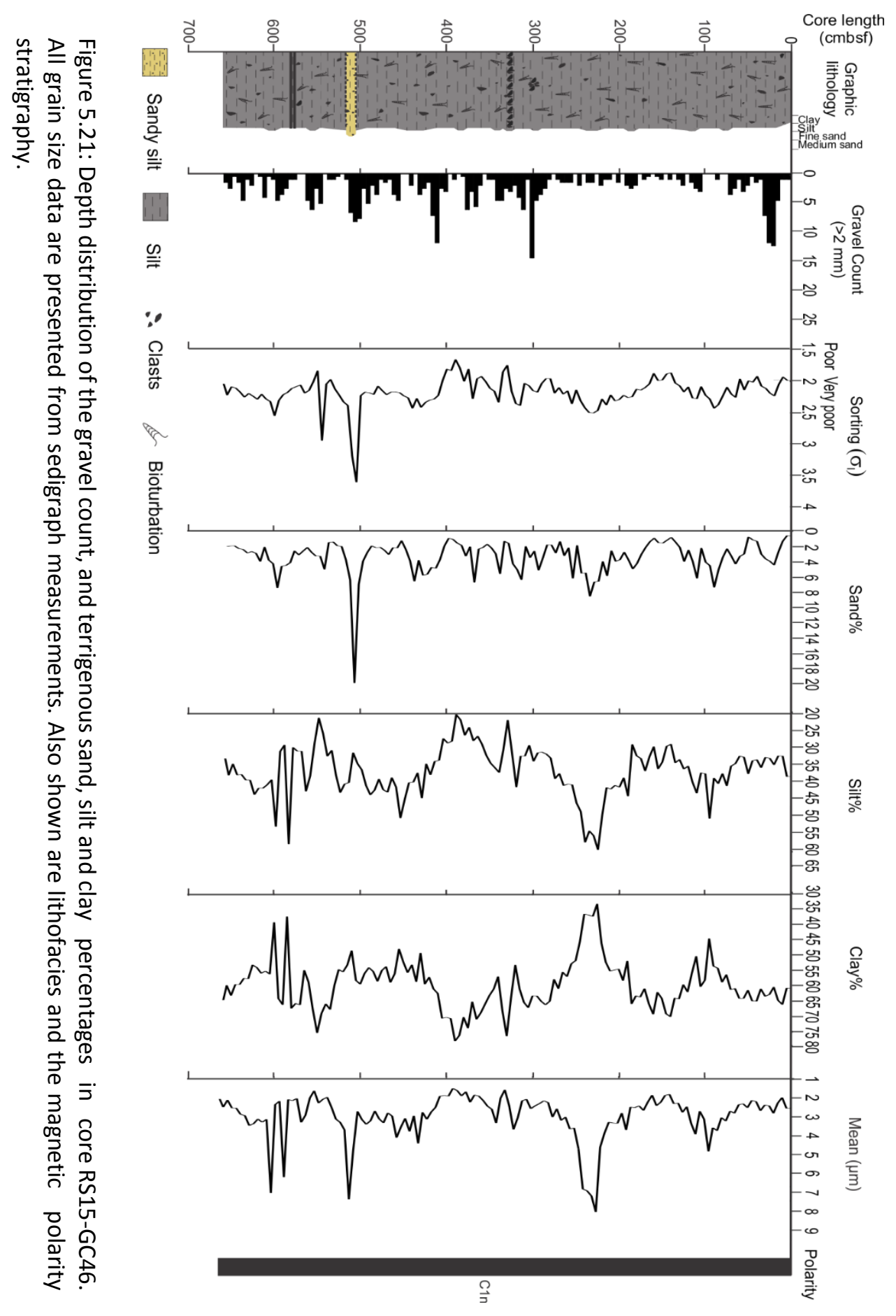



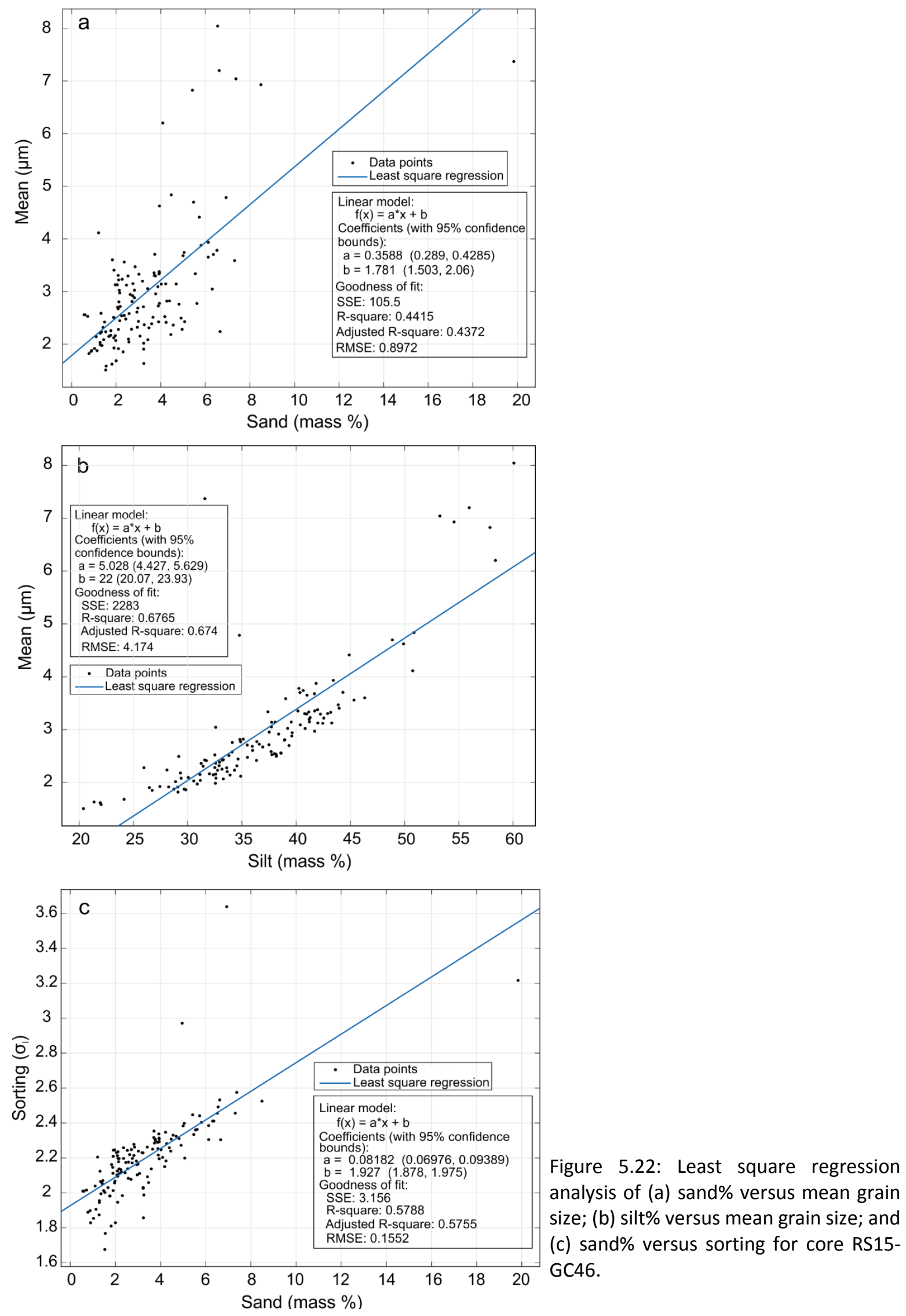


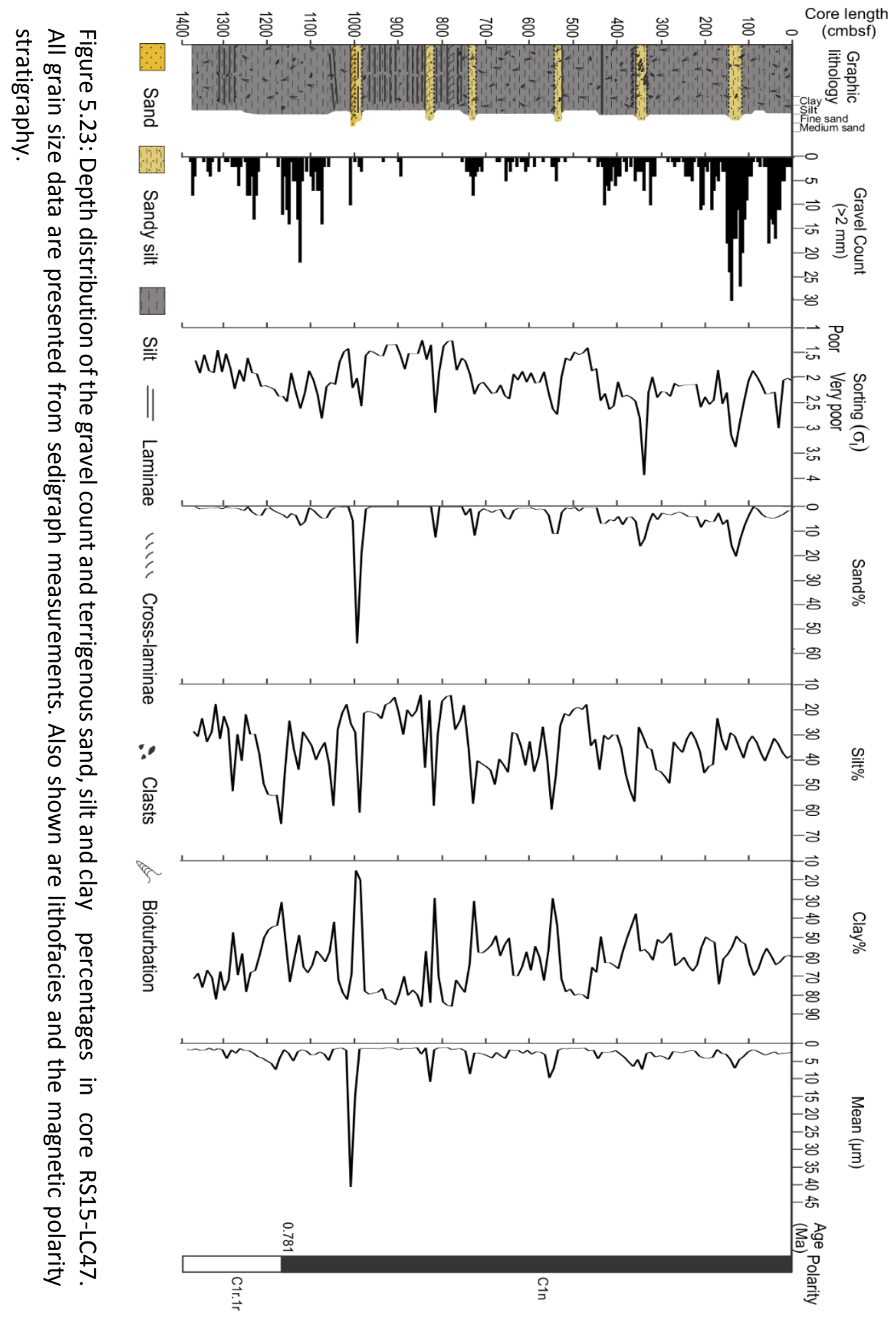



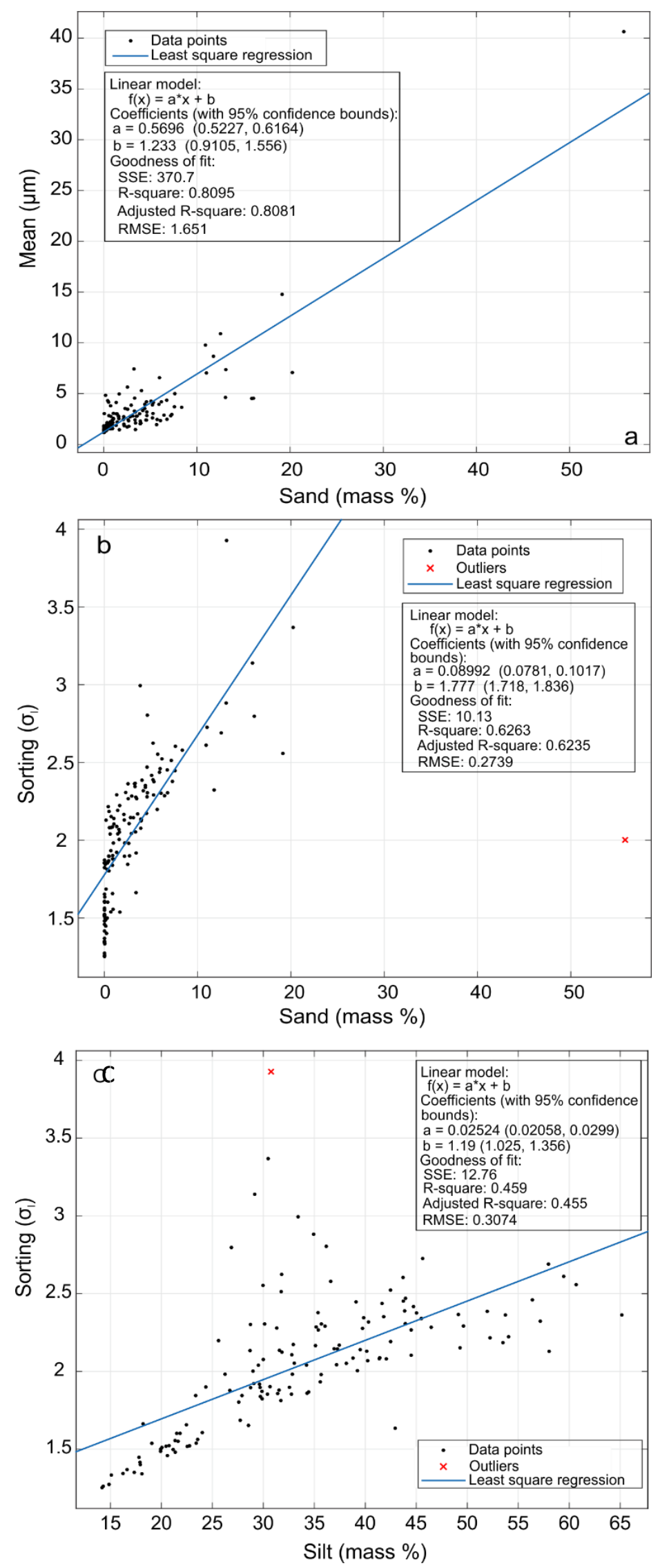

Figure 5.24: Least square regression analysis of (a) sand\% versus mean grain size; (b) sand\% versus sorting; and (c) silt\% versus sorting for core RS15-LC47. 


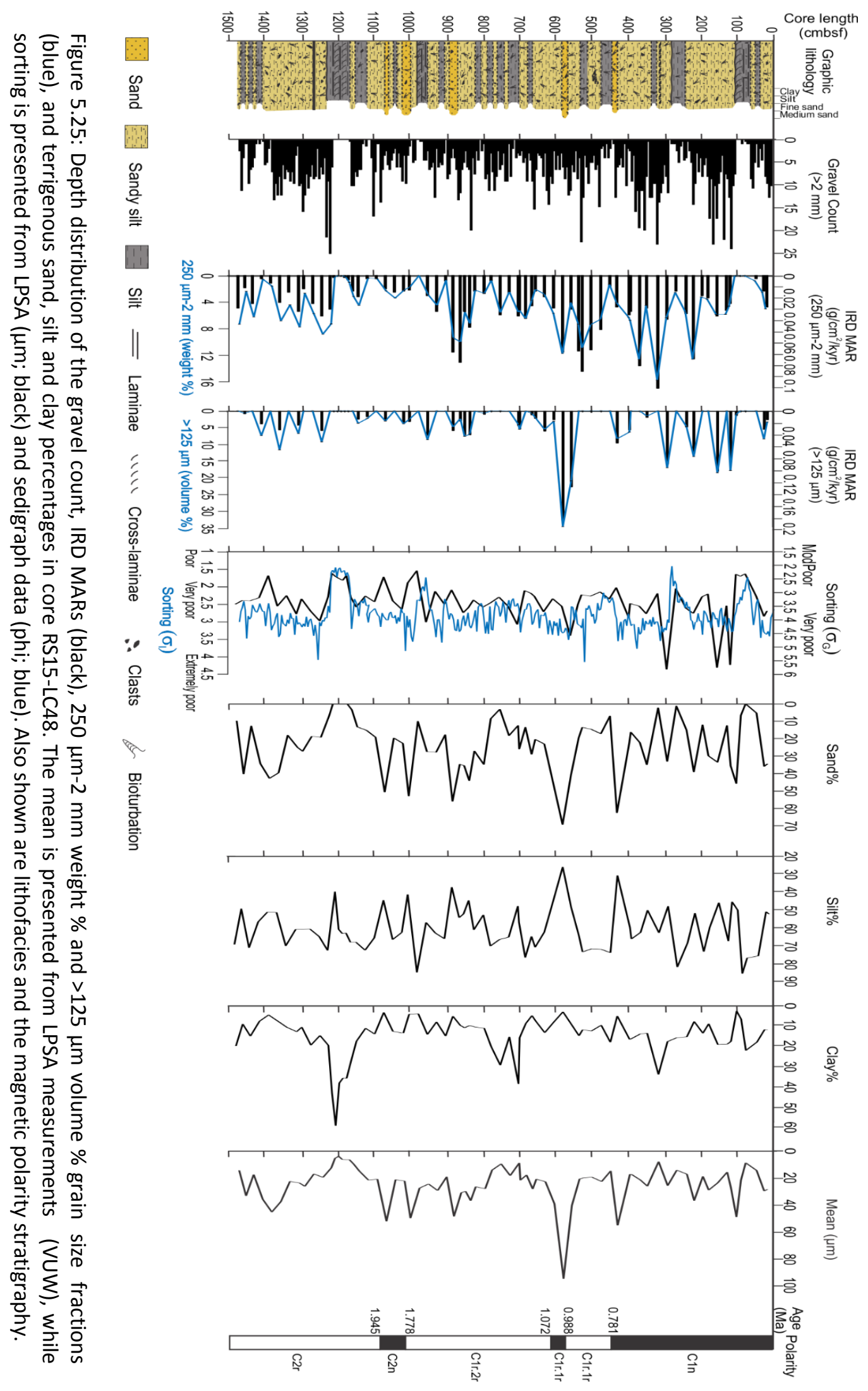



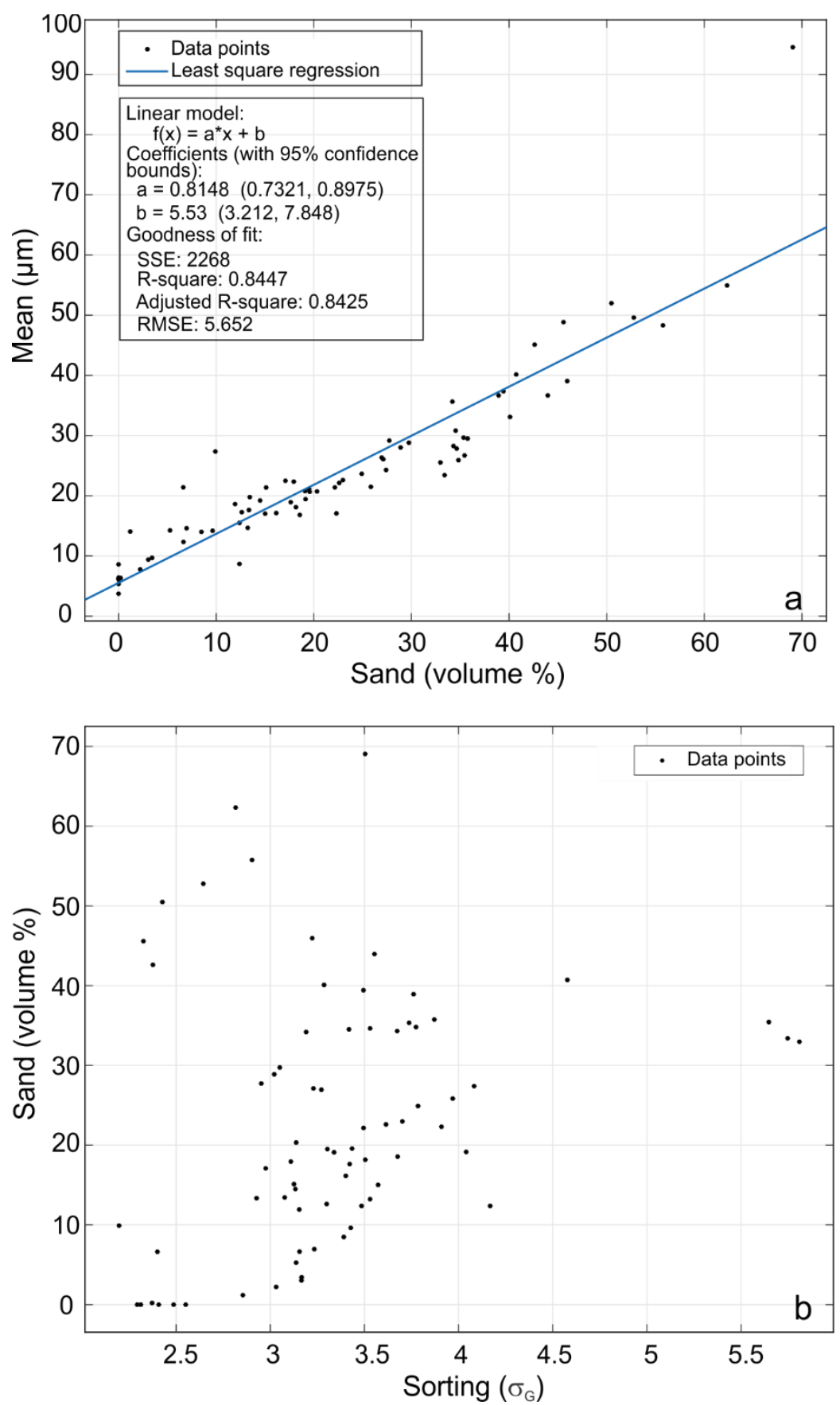

Figure 5.26: RS15-LC48 least square regression analysis (a) Least square regression analysis of sand\% versus mean grain size shows a very strong correlation with an $\mathrm{R}^{2}$ value of 0.84 . (b) Sorting versus sand\% shows no relationship.

\subsection{Ice-rafted debris}

Three separate laboratory techniques were used in this study to determine the "coarse-grained" content for cores RS15-LC42 and RS15-LC48, while only one method (gravel counts in xradiographs) was carried out on cores RS15-GC46, RS15-LC47, RS15-GC107 and RS15-LC108 (see 4.2 and 4.3). Previous studies have determined different grain size cut-offs and utilised different 
methods to determine changes in the coarse fraction that may represent an IRD component. In this section, the differences between these methods are quantified by comparing downcore variation for the $125 \mu \mathrm{m}$ (volume \% using LPSA), $250 \mu \mathrm{m}-2 \mathrm{~mm}$ (weight \% by sieving) and $>2 \mathrm{~mm}$ (clast counts in $x$-ray images) fractions. Figures 5.19, 5.21, 5.23 and 5.25 show the IRD component determined using the methods described above.

Grain size data highlight that decreases in IRD MARs and gravel counts coincide with increases in silt\% in cores RS15-LC42 (Figure 5.19) and RS15-LC48 (Figure 5.25) and increases in clay\% in cores RS15-GC46 (Figure 5.21) and RS15-LC47 (Figure 5.23), while increases in IRD MARs and gravel counts are associated with increased sand\% in all cores. In general, peaks in gravel counts coincide with poorly to very poorly sorted sediments in all cores, aside from one moderately sorted, IRDrich interval between 0 and $10 \mathrm{cmbsf}$ in core RS15-LC42. Least square regression analysis of gravel counts and sorting (gravel count and sorting data were picked for the same depth intervals) for cores RS15-LC42, RS15-LC47 and RS15-LC48 displays weak correlations with $\mathrm{R}^{2}$ values of 0.10 , $0.20,0.15$, respectively, while no correlation is observed in core RS15-GC46 (Figure 5.27). IRD MAR peaks determined from LPSA and sieve measurements for cores RS15-LC42 and RS15-LC48 show no correlation with sorting (Figure 5.28), with the exception of LPSA measurements for core RS15-LC48, which demonstrate a weak to moderate relationship with sorting, with an $R^{2}$ value of 0.33 . 


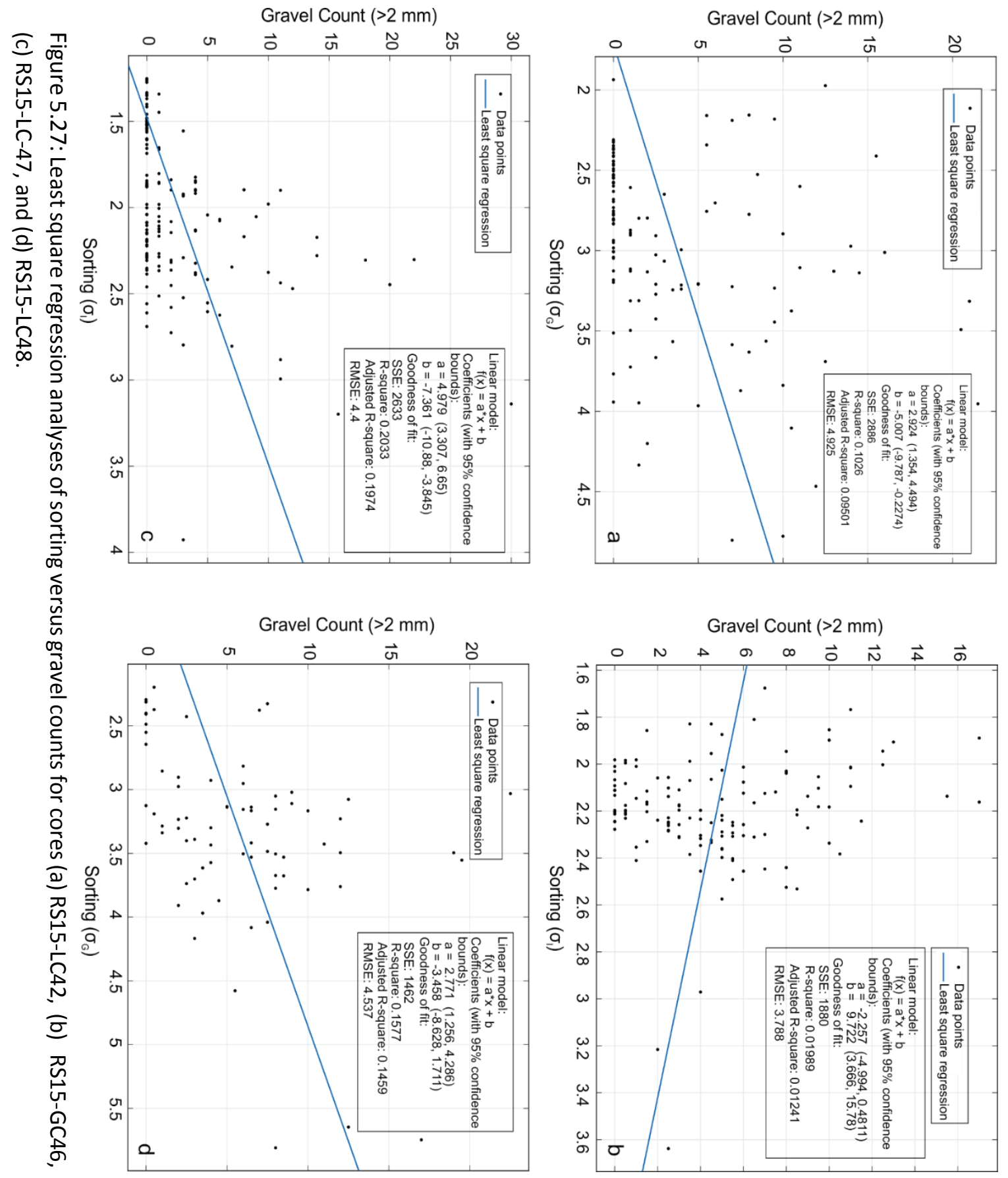




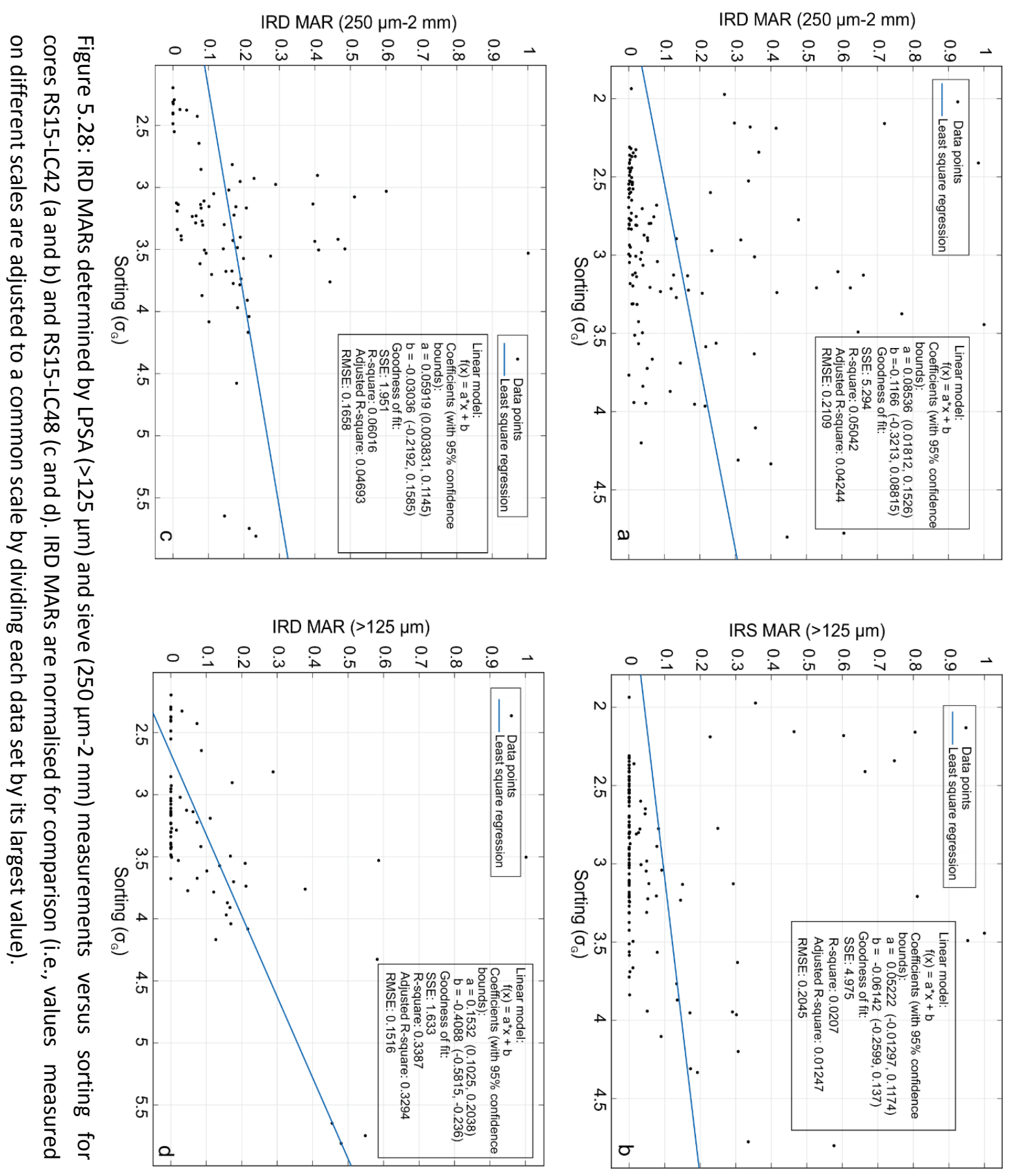


To assess the correlation between the three methods, the results were normalised for each method (i.e., values measured on different scales were adjusted to a common scale by dividing each data set by its largest value) and cross correlated. X-ray gravel counts were selected for the same depth interval as the samples analysed by sieve and LPSA analyses. A linear regression model was applied to each cross plot (Figures 5.29 and 5.30). For both cores, the gravel counts display a stronger correlation with the IRD MARs obtained by sieve rather than LPSA analyses, with $R^{2}$ values of 0.42 and 0.46 compared to $R^{2}$ values of 0.22 and 0.04 for RS15-LC42 and RS15LC48, respectively. The LPSA fails to register a significant volume of sediment in the $>125 \mu \mathrm{m}$ fraction, where $x$-ray counting and sieve analysis identify a significant IRD component. This circumstance is observed between 645 and 685 and 720 and $760 \mathrm{cmbsf}$ in core RS15-LC42, and again between 315-395 and 500-535 cmbsf in core RS15-LC48 (Figure 5.19). Substantial volumes of sediment in the $>125 \mu \mathrm{m}$ fraction are also recorded where both sieve analysis and $\mathrm{x}$-ray counting show a significantly smaller or completely absent IRD component. This is observed between 880-890, 1040-1045 and 1100-1110 cmbsf in core RS15-LC42, and between 555-580 cmbsf in core RS15-LC48 (Figure 5.25). The correlation between sieve and LPSA measurements is significantly higher for core RS15-LC42 than for core RS15-LC48, with an $\mathrm{R}^{2}$ value of 0.52 compared to 0.08 . 

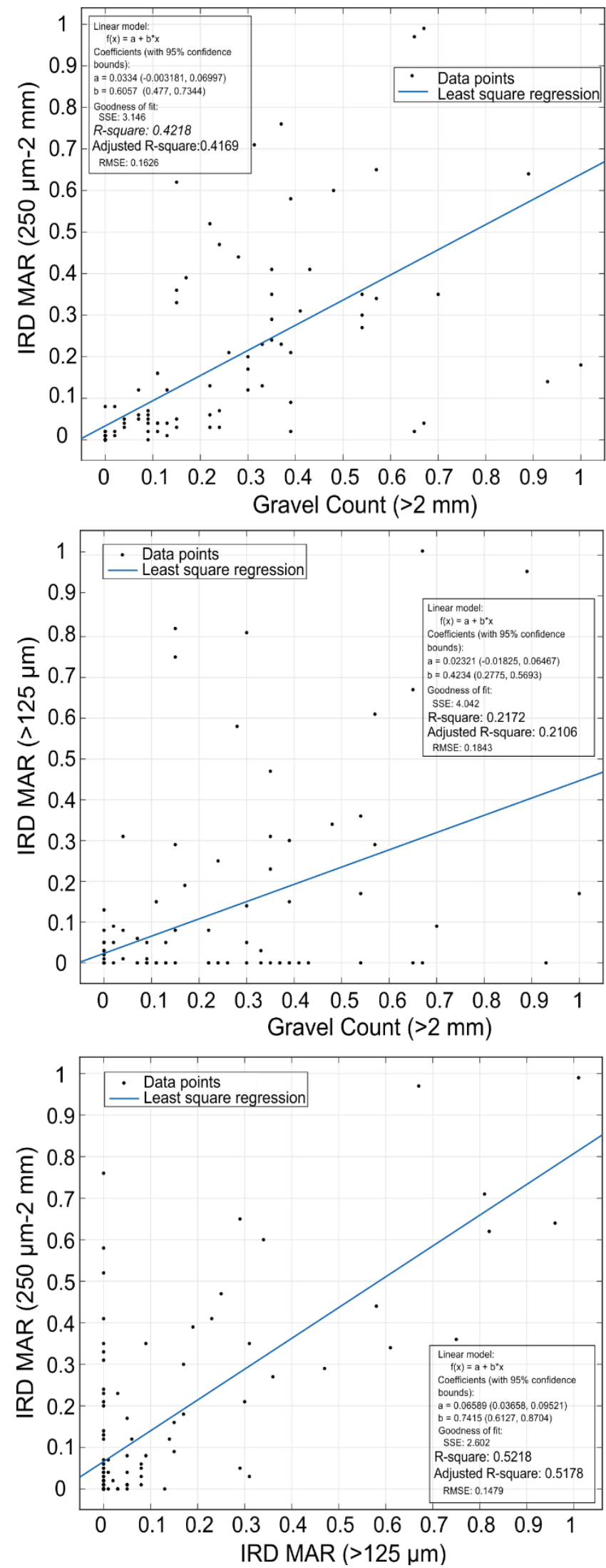

(a)

(b)

Figure 5.29: Cross correlation plots with the least square regression model for core RS15LC42 of (a) IRD MARs estimated from weight \% of the $250 \mu \mathrm{m}-2 \mu \mathrm{mm}$ vs gravel count; (b) IRD MARs estimated from volume $\%$ of $>125 \mu \mathrm{m}$ grains measured on the LPSA vs gravel count; and (c) IRD MARs estimated from weight $\%$ of the $250 \mu \mathrm{m}-2 \mathrm{~mm}$ vs IRD MAR estimated from (c) volume $\%$ of $>125 \mu \mathrm{m}$ grains measured on the LPSA. 

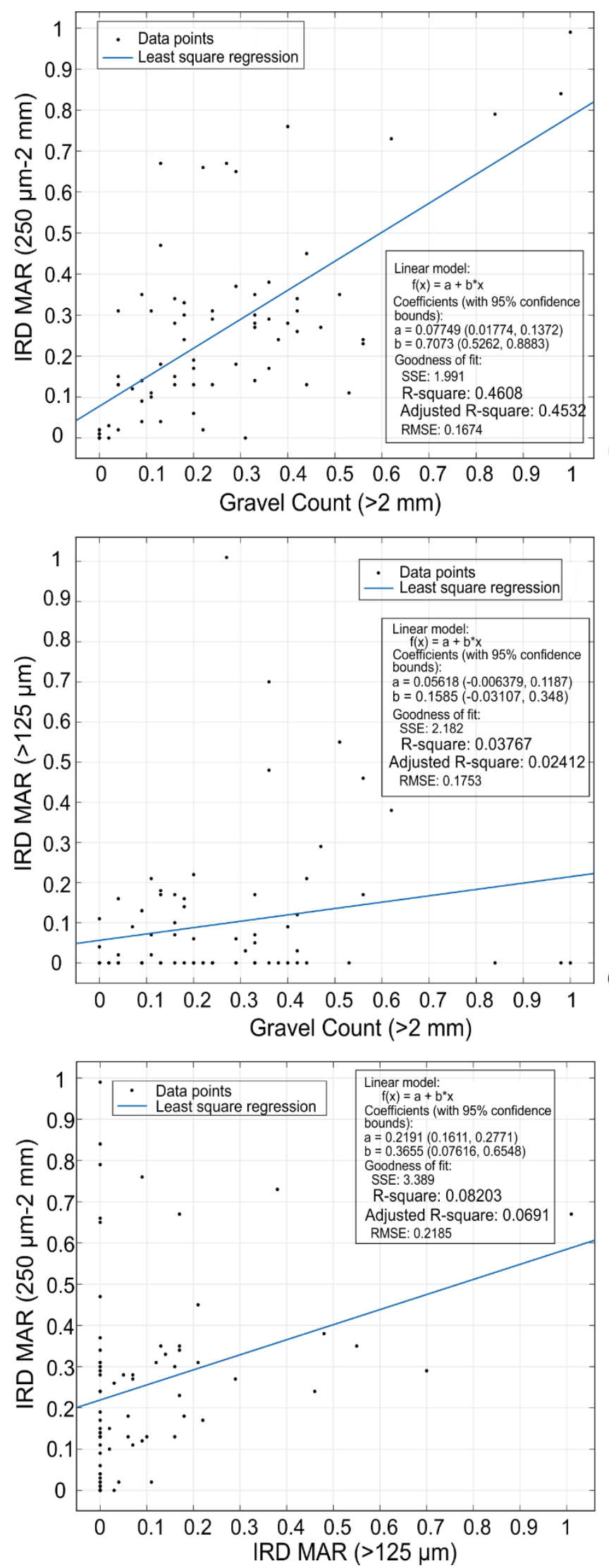

(a)

Figure 5.30: Cross correlation plots with the least square regression model for core RS15LC48 of (a) IRD MAR estimated from weight \% of the $250 \mu \mathrm{m}-2 \mathrm{~mm}$ vs gravel count; (b) IRD MAR estimated from volume $\%$ of $>125 \mu \mathrm{m}$ grains measured on the LPSA vs gravel count; and (c) IRD MAR estimated from weight \% of the $250 \mu \mathrm{m}-2 \mathrm{~mm}$ vs IRD MAR estimated from

(c) volume $\%$ of $>125 \mu \mathrm{m}$ grains measured on the LPSA. 


\subsection{Lithofacies analysis}

Two primary lithofacies are assigned in this study; Lithofacies 1) laminated muds (Figure 5.32) and Lithofacies 2) bioturbated muds, sands and diamictites with clasts (Figures 5.33 and 5.34). Grain size data collected in this study for cores RS15-LC42 and RS15-LC48 and grain size data provided by KOPRI for cores RS15-GC46 and RS15-LC47 confirm the initial sediment texture and lithological descriptions. Ternary grain size diagrams for cores RS15-LC42, RS15-GC46, RS15-LC47 and RS15LC48 show the non-gravel component of facies 1 having a silty clay to silt texture and facies 2 displaying a clayey silt, sandy silt and silty sand texture (Figure 5.31). Notably, the grain size populations for cores RS15-LC42 and RS15-LC48 do not fall into distinct clusters, but represent a continuum of gradational coarsening from Facies 1 into Facies 2. Cores RS15-GC46 and RS15-LC47 are finer-grained in texture and are predominately silty clay, with some samples coarsening into the clayey silt texture range. The interbedding of facies 1 (laminated) and facies 2 (bioturbated) forms repetitive lithological cycles at $\mathrm{cm}$ - to $\mathrm{m}$-scale. 


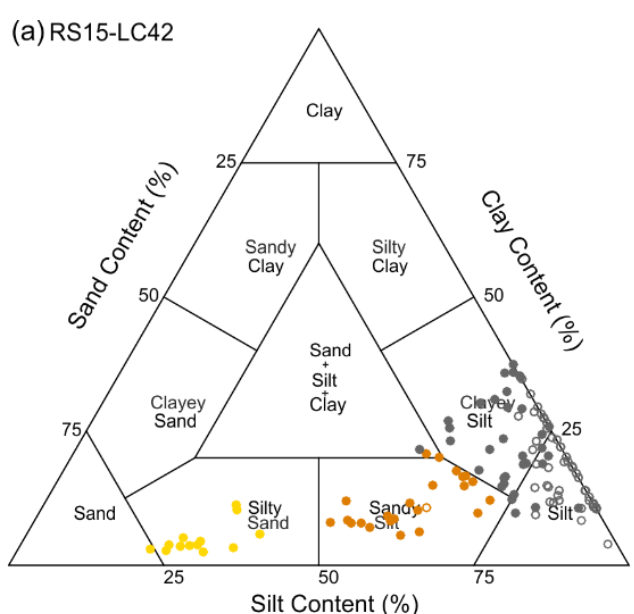

(c) RS15-LC47

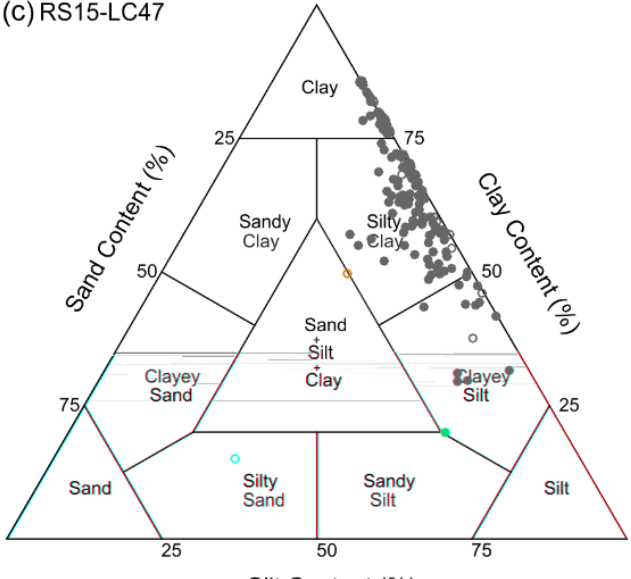

Silt Content (\%)

Bioturbated sand

Laminated sand
Bioturbated sandy silt

Laminated sandy silt (b) RS15-GC46

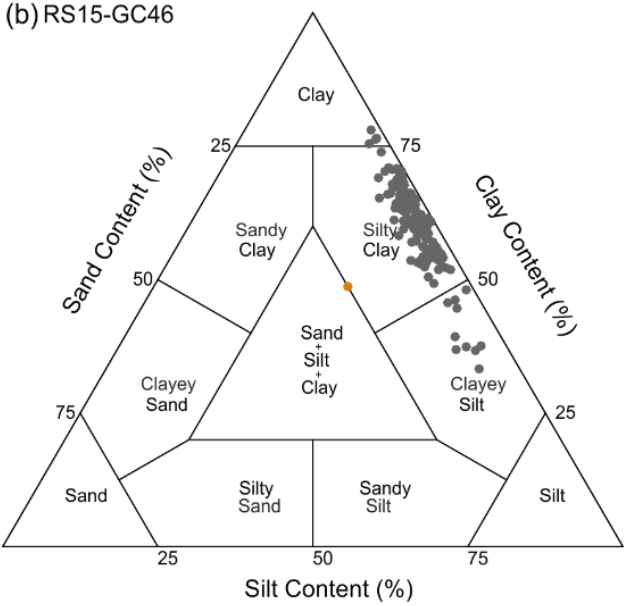

(d) RS15-LC48

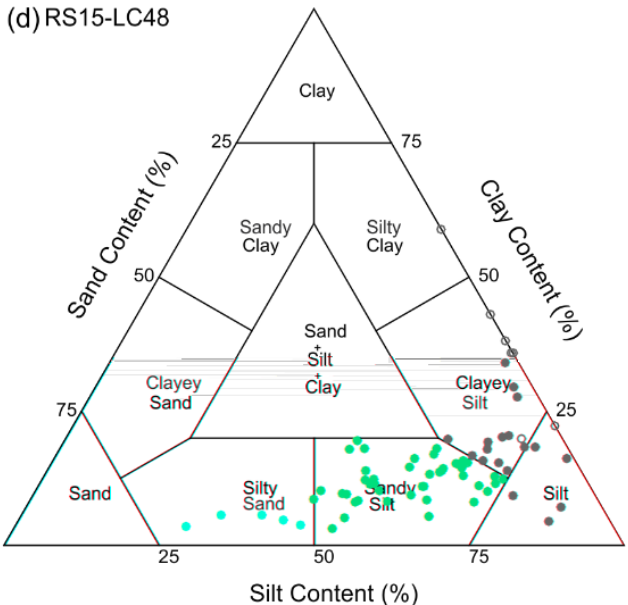

Figure 5.31: Ternary diagrams for (a) RS15-LC42, (b) RS15-GC46, (c) RS15-LC47 and (d) RS15LC48 displaying textural variability between bioturbated and laminated lithofacies.

\subsubsection{Lithofacies descriptions and preliminary interpretations}

Lithofacies 1 (laminated)

Description

The laminated lithofacies consists predominantly of silty clays and clayey silts (Figure 5.31 and 5.32), although in core RS15-LC47 there is an interval of weakly bioturbated sand with welldefined mm-scale planar- and cross-laminae between 1000 and $1010 \mathrm{cmbsf}$. This facies is characterised by absent to uncommon bioturbation and absent to sparse IRD. In all cores, laminae range from $0.5 \mathrm{~mm}$ to $1.15 \mathrm{~cm}$ in thickness, although the mean thickness is $\sim 1.5 \mathrm{~mm}$ and those exceeding $1 \mathrm{~cm}$ in thickness are rare (i.e., bed rather than lamina), except for an interval in RS15LC42 between 340 and $370 \mathrm{cmbsf}$. Thicker laminae are generally observed within the middle interval of a laminated package, rather than at the top or base of the package. Laminae and beds 
are generally well-defined, parallel, continuous, internally massive and have sharp upper and lower contacts. Although IRD is sparse, it does occur within laminated intervals, and occasionally cross-cuts laminae. Diatom content is relatively poor throughout ( $<25 \%$ diatom content in smear slides from lithological descriptions for RS15-LC42 and RS15-LC48).

Interpretation

Well-defined laminae with sharp upper and lower contacts that are rhythmic in nature, continuous, lack grading, lack bioturbation, contain low biogenic content, and contain occasional IRD or pebbly layers point towards a traction current influenced environment (e.g., bottom currents), rather than relatively fast deposition from sediment gravity flows (e.g., turbidity currents; Stow and Piper, 1984; Lucchi et al., 2002; Lucchi and Rebesco, 2007). This interpretation is consistent with both the texture and structure of previously described silty to sandy clastic contourites (c.f. Rebesco et al., 2014). Well-defined laminations with little bioturbation suggest the presence of energetic tractive currents and/or oxygen-reduced bottom waters, both of which result in suppressed benthic activity on the sea floor (Stow and Piper, 1984; Caburlotto et al., 2010). The presence of scattered, rather than abundant IRD, may be associated with several depositional processes including: reduced iceberg discharge; icebergs calving off large ice shelves lacking basal debris (e.g., RIS where subglacial debris melts out prior to iceberg calving); or higher local sedimentation rates which would reduce the magnitude of IRD events (Anderson, 1999; Patterson et al., 2014). 


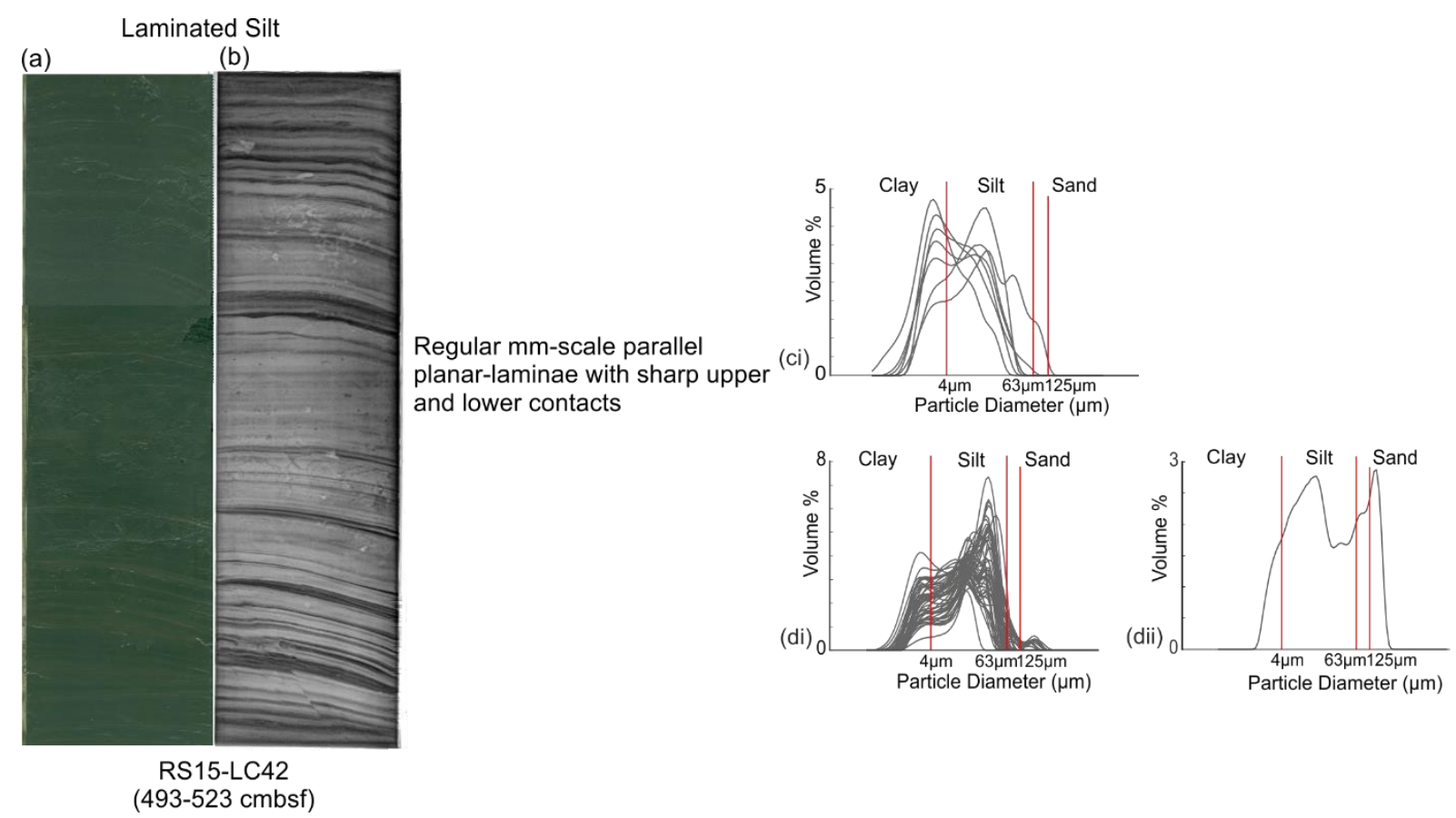

Figure 5.32: (a) Representative photograph and (b) x-ray image highlighting sediment characteristics of laminated lithofacies. (ci) Grain size frequency for RS15-LC48 of silt. (di) and (dii) Grain size frequencies for RS15-LC42 of silt and sandy silt, respectively.

\section{Lithofacies 2 (bioturbated)}

\section{Description}

The bioturbated lithofacies consists of gradational variation of muds and sands with clasts, and diamictites (Figures 5.31, 5.33 and 5.34). This facies is moderately to strongly bioturbated, which obscures any primary sedimentary structures, and contains $<25 \% \mathrm{BiSi}(<25 \%$ diatom content in smear slides from lithological descriptions for RS15-LC42 and RS15-LC48), with the exception of rare beds in RS15-LC42 that were observed to have $20-30 \%$ diatom content. Weak to very weak mm-scale planar laminations are common in silts and sandy silts, which often appear as discontinuous, parallel-aligned silt mottles and lenses, rather than continuous laminae. Laminae are rare in muddy and sandy diamictites. IRD is common to abundant throughout.

Interpretation

The presence of faint laminae, gradational contacts between interbeds, pervasive bioturbation, common to abundant IRD and the continuum of coarsening observed from facies 1 to facies 2 (i.e., facies 2 represents a winnowed end-member of facies 1 ) indicate deposition under lowenergy tractive currents (Stow and Piper, 1984; Busetti et al., 2003). Furthermore, the presence of medium-to-coarse sands/gravel layers (i.e., lag surfaces) suggests that tractive currents acted 
to remobilise fine-grained sediment. Thus, the texture and structure of these intervals is not compatible with rapid sedimentary depositional processes such as turbidity and/or debris flows (Stow and Piper, 1984). Common to abundant bioturbation may be attributed to well-oxygenated bottom water conditions (e.g., Busetti et al., 2003) or reduced local sedimentation rates (Rebesco et al., 2014). The increase in IRD relative to facies 1 may be associated with current winnowing, a reduction in background (i.e., non-IRD) sedimentation rate, enhanced iceberg calving off inland glaciers, rather than calving off ice shelves lacking basal debris (e.g., RIS), and hence reduced ice shelf coverage (Anderson, 1999; Patterson et al., 2014).

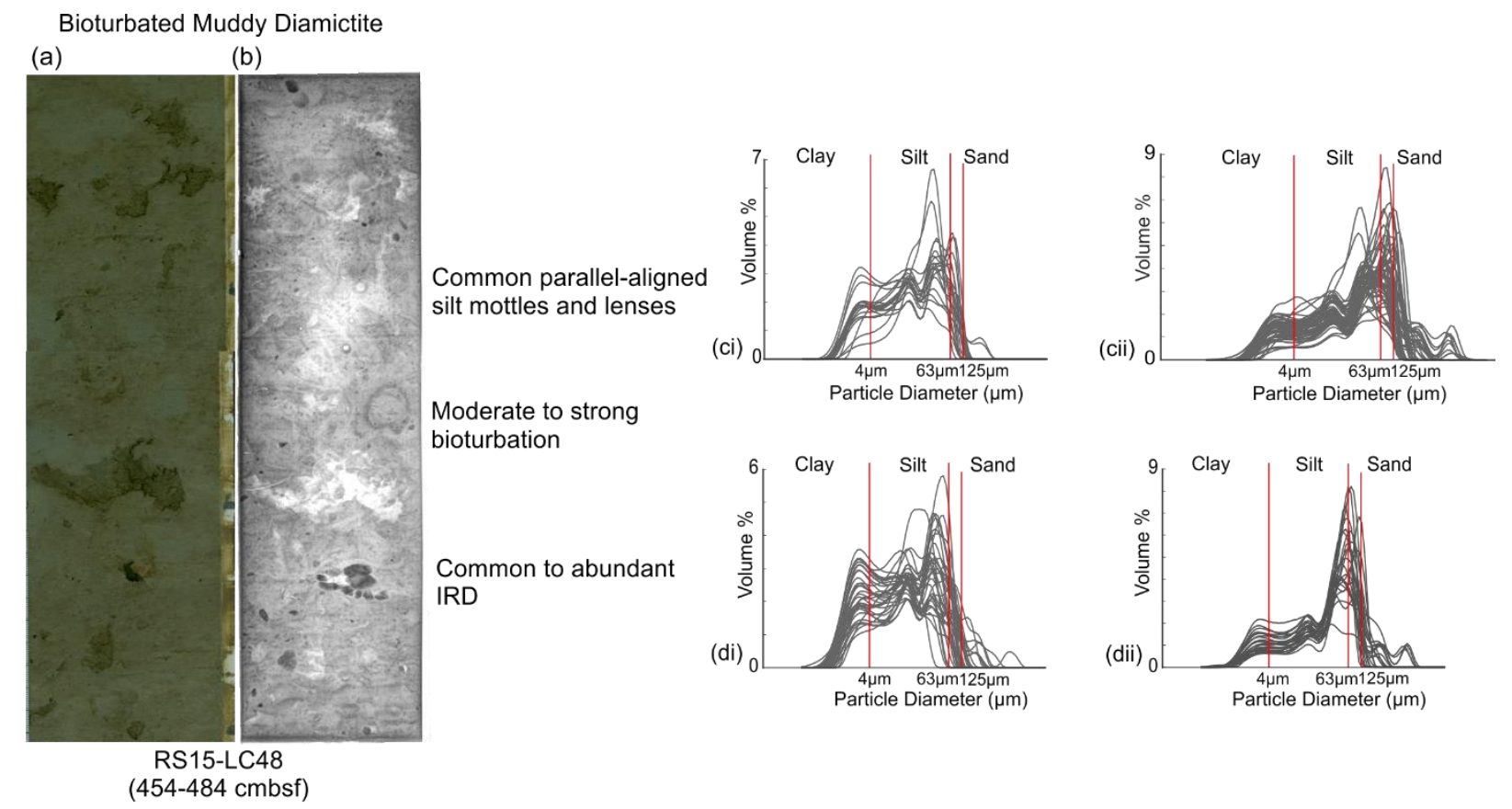

Figure 5.33: (a) Representative photograph and (b) x-ray image highlighting sediment characteristics of the bioturbated lithofacies. (ci) and (cii) Grain size frequencies for RS15-LC48 of silt and sandy silt, respectively. (di) and (dii) Grain size frequencies for RS15-LC42 of silt and sandy silt, respectively. 


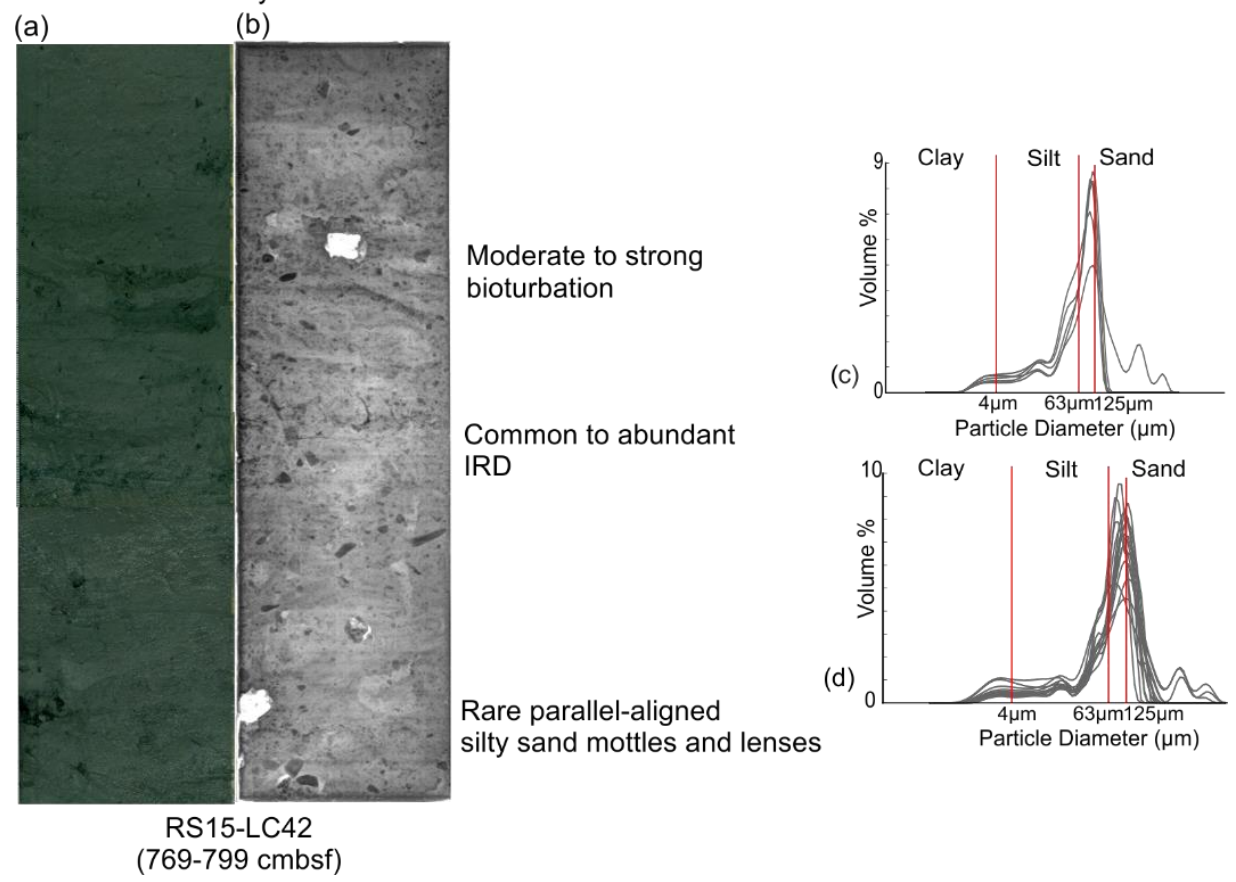

Figure 5.34: (a) Representative photograph and (b) x-ray image highlighting distinct sediment characteristics of bioturbated lithofacies. (c) and (d) Grain size frequencies of silty sand for RS15-LC48 and RS15-LC42, respectively.

Table 5.1: Summary of the identified lithofacies, their sedimentary structures and preliminary interpretations.

\begin{tabular}{|c|l|l|c|}
\hline Lithofacies & \multicolumn{1}{|c|}{ Sedimentary Structures } & Preliminary Interpretation & $\begin{array}{l}\text { Facies } \\
\text { Code }\end{array}$ \\
\hline $\begin{array}{c}\text { Laminated } \\
\text { Silt } \\
\text { Sand }\end{array}$ & $\begin{array}{l}\text { Well-defined planar- and cross- } \\
\text { laminae/beds with sparse IRD. }\end{array}$ & $\begin{array}{l}\text { Bottom current origin - } \\
\text { anoxic bottom water } \\
\text { conditions with reduced ice } \\
\text { rafting. }\end{array}$ & 1a \\
\hline $\begin{array}{c}\text { Bioturbated } \\
\text { Silt }\end{array}$ & $\begin{array}{l}\text { Primary sedimentary structures } \\
\text { are largely absent, although } \\
\text { weakly defined laminae occur in } \\
\text { places. IRD common. }\end{array}$ & $\begin{array}{l}\text { Bottom current origin - } \\
\text { oxygenated bottom water } \\
\text { conditions with increased ice } \\
\text { rafting. }\end{array}$ & $2 \mathrm{2a}$ \\
Sandy diamictite & 2b diamictite & 2c \\
\hline
\end{tabular}

\subsection{Stable isotope analysis}

The planktonic foraminifer N. pachyderma was present in sufficient numbers in some intervals of cores RS15-LC42 and RS15-LC48 to measure oxygen $\left(\delta^{18} \mathrm{O}\right)$ and carbon $\left(\delta^{13} \mathrm{C}\right)$ isotopic values. Specimens for analysis were picked from the $>250 \mu \mathrm{m}$ size fraction to minimise the effects of size dependent isotope fractionation (Elderfield et al., 2002). The benthic foraminifer Cibicides spp. 
was chosen for analysis of deep-sea oxygen $\left(\delta^{18} \mathrm{O}\right)$ and carbon $\left(\delta^{13} \mathrm{C}\right)$ isotopic values. These were much less abundant than $N$. pachyderma, and consequently form a less continuous time series.

\subsubsection{Oxygen isotopes}

The $\delta^{18} \mathrm{O}$ of $N$. pachyderma (s.) varies between 4.12 and $5.45 \%$ o with a mean of $4.95 \%$ o $( \pm 0.05 \%$ o) in core RS15-LC42 and between 4.34 and $5.03 \%$ with a mean of $4.80( \pm 0.10 \%$ ) in core RS15-LC48 (Table 5). Two excursions to isotopically lighter values (smaller $\delta^{18} \mathrm{O}$ values) compared with the mean are observed at 574 (4.12\%o) and 1040 (4.43\%o) cmbsf in core RS15-LC42, and one excursion at $603\left(4.34 \%\right.$ ) $\mathrm{cmbsf}$ in core RS15-LC48. The $\delta^{18} \mathrm{O}$ of Cibicides spp. varies between 3.99 and $4.56 \%$ with a mean of $4.28( \pm 0.29 \%$ ) in core RS15-LC42 (note Cibicides spp. were only recovered at 720 and $1140 \mathrm{cmbsf}$ ) and between 4.07 and $4.55 \%$ with a mean of $4.39( \pm 0.07 \%$ ) in core RS15LC48 (Table 5.2). A deviation to isotopically lighter $\delta^{18} \mathrm{O}$ of Cibicides spp. in core RS15-LC48 is also observed at $603(4.071 \%)$ cmbsf.

N. pachyderma (s.) and Cibicides spp. are both known to precipitate calcite systematically out of equilibrium with the $\delta^{18} \mathrm{O}$ of surrounding sea water due to the vital effects in the uptake of $\delta^{18} \mathrm{O}$ into the species tests (i.e., biological fractionation of carbon and oxygen that occurs during precipitation of carbonate) (Bostock and Neil, 2015). Following the consistent offsets between calcite tests and the equilibrium $\delta^{18} \mathrm{O}$ of ambient surface seawater described in the literature, corrections of $+0.40 \%$ and $+0.64 \%$ are applied to the $\delta^{18} \mathrm{O}$ values of $N$. pachyderma (s.) and Cibicides spp., respectively (Shackleton and Hall, 1997; Jonkers et al., 2013). Table 5.2 shows the corrected values of $\delta^{18} \mathrm{O}$ for RS15-LC42 and RS15-LC48.

\subsubsection{Carbon isotopes}

The $\delta^{13} \mathrm{C}$ of $N$. pachyderma (s.) varies between -0.90 and $0.08 \%$ o with a mean of -0.47 ( $\pm 0.04 \%$ o) in core RS15-LC42 and between -0.48 and $0.33 \%$ with a mean of $-0.09 \%$ ( \pm 0.13 ) in core RS1LC48. $\delta^{13} \mathrm{C}$ of Cibicides spp. varies between -1.39 and $-0.71 \%$ with a mean of $-1.05( \pm 0.34 \%$ ) in core RS15-LC42, and between -0.55 and $0.29 \%$ with a mean of $4.39( \pm 0.07 \%$ ) in core RS15-LC48 (Table 5.2). $\delta^{13} \mathrm{C}$ of $N$. pachyderma (s.) do not fluctuate significantly in core RS15-LC42, with the exception of a positive excursion in $\delta^{13} \mathrm{C}$ to $0.08 \%$ o coinciding with $\delta^{18} \mathrm{O}$ excursion to lighter isotopic values at $574 \mathrm{cmbsf}$. In contrast, $\delta^{13} \mathrm{C}$ of $N$. pachyderma (s.) in core RS15-LC48 show an increasing trend from 0.18 to $0.33 \%$ o between $16-24.5 \mathrm{cmbsf}$, and decreased $\delta^{13} \mathrm{C}$ values of $0.08 \%$ o between $117-127 \mathrm{cmbsf}$, which decrease further downcore to $-0.48 \%$ ond $-0.40 \%$ at 347 and $603 \mathrm{cmbsf}$, respectively. The positive excursions in $\delta^{18} \mathrm{O}$ at 347 and $603 \mathrm{cmbsf}$ are 
accompanied by negative excursions in $\delta^{13} \mathrm{C}$ values. The $\delta^{13} \mathrm{C}$ of Cibicides spp. mirror the changes in $\delta^{13} \mathrm{C}$ of $N$. pachyderma (s.) (Figure 6.5).

Previous studies of N. pachyderma (s.) have determined a systematic disequilibrium offset of $-1 \%$ o for carbon between their tests and the dissolved inorganic carbon (DIC) pool of the ambient sea water (Charles et al., 1990; Kohfeld et al., 2000). Corrected $\delta^{13} \mathrm{C}$ values are summarised in Table 5.2. A previous stable isotopic study by Grossman et al. (1987) showed that Cibicides spp. precipitate their tests at or near equilibrium with bottom waters. 
Table 5.2: N. pachyderma (s.) and Cibicides spp. $\delta^{18} \mathrm{O}$ and $\delta^{13} \mathrm{C}$ results for cores RS15-LC42 and RS15-LC48.

\begin{tabular}{|c|c|c|c|c|c|c|c|c|c|}
\hline \multicolumn{7}{|c|}{ N. pachyderma (s.) } & \multicolumn{3}{|c|}{ Cibicides spp. } \\
\hline $\begin{array}{l}\text { RS15-LC2 } \\
\text { Sample }\end{array}$ & $\begin{array}{l}\text { Depth interval } \\
\qquad(\mathrm{cm})\end{array}$ & $\delta^{18} \mathrm{O}_{\mathrm{PDB}}$ & Corrected & $\delta^{13} \mathrm{C}_{\mathrm{PDB}}$ & Corrected & $\begin{array}{c}\mathrm{T}^{\circ} \mathrm{C} \\
\text { (Shackleton, 1974) }\end{array}$ & $\delta^{18} \mathrm{O}_{\mathrm{PDB}}$ & Corrected & $\delta^{13} \mathrm{C}_{\mathrm{PDB}}$ \\
\hline $42-1-10-12$ & $10-12$ & 5.452 & 5.852 & -0.541 & 0.459 & -7.13 & & & \\
\hline $42-1-90-92$ & $90-92$ & 5.061 & 5.461 & 0.017 & 1.017 & -5.91 & & & \\
\hline $42-3-110-112$ & $358-360$ & 5.211 & 5.611 & -0.392 & 0.608 & -6.38 & & & \\
\hline $42-3-150-152$ & $398-400$ & 5.143 & 5.543 & -0.506 & 0.494 & -6.17 & & & \\
\hline $42-4-0-2$ & $403-405$ & 4.975 & 5.375 & -0.286 & 0.714 & -5.64 & & & \\
\hline $42-4-10-12$ & $413-415$ & 5.026 & 5.426 & -0.004 & 0.996 & -5.80 & & & \\
\hline $42-4-20-22$ & $423-425$ & 5.091 & 5.491 & -0.357 & 0.643 & -6.00 & & & \\
\hline $42-4-30-32$ & $433-435$ & 5.062 & 5.462 & -0.369 & 0.631 & -5.91 & & & \\
\hline $42-4-60-62$ & $463-465$ & 5.082 & 5.482 & -0.326 & 0.674 & -5.98 & & & \\
\hline $42-4-90-92$ & $493-495$ & 5.263 & 5.663 & -0.361 & 0.639 & -6.55 & & & \\
\hline $42-4-130-132$ & $533-535$ & 4.992 & 5.392 & -0.498 & 0.502 & -5.69 & & & \\
\hline $42-5-10-12$ & $563-565$ & 4.647 & 5.047 & -0.544 & 0.456 & -4.58 & & & \\
\hline $42-5-20-22$ & $573-575$ & 4.121 & 4.521 & 0.076 & 1.076 & -2.84 & & & \\
\hline $42-5-90-92$ & $643-645$ & 5.002 & 5.402 & -0.509 & 0.491 & -5.72 & & & \\
\hline $42-5-110-112$ & $663-665$ & 4.872 & 5.272 & -0.427 & 0.573 & -5.31 & & & \\
\hline $42-5-130-132$ & $683-685$ & 4.867 & 5.267 & -0.497 & 0.503 & -5.29 & & & \\
\hline $42-5-150-152$ & $703-705$ & 5.033 & 5.433 & -0.438 & 0.562 & -5.82 & & & \\
\hline $42-6-10-12$ & $719-721$ & 5.057 & 5.457 & -0.440 & 0.560 & -5.90 & 4.564 & 5.204 & -0.709 \\
\hline $42-6-60-62$ & $769-771$ & 4.847 & 5.247 & -0.348 & 0.652 & -5.23 & & & \\
\hline $42-7-50-52$ & $909-911$ & 4.874 & 5.274 & -0.650 & 0.350 & -5.31 & & & \\
\hline $42-7-80-82$ & $939-941$ & 4.919 & 5.319 & -0.641 & 0.359 & -5.46 & & & \\
\hline $42-7-100-102$ & $959-961$ & 5.015 & 5.415 & -0.703 & 0.297 & -5.76 & & & \\
\hline $42-7-110-112$ & $969-971$ & 4.952 & 5.352 & -0.676 & 0.324 & -5.56 & & & \\
\hline $42-7-120-122$ & $979-981$ & 5.081 & 5.481 & -0.769 & 0.231 & -5.97 & & & \\
\hline $42-8-10-12$ & $1009-1011$ & 4.827 & 5.227 & -0.809 & 0.191 & -5.16 & & & \\
\hline $42-8-30-32$ & $1029-1031$ & 4.929 & 5.329 & -0.551 & 0.449 & -5.49 & & & \\
\hline $42-8-40-42$ & $1039-1041$ & 4.430 & 4.830 & -0.634 & 0.366 & -3.87 & & & \\
\hline $42-8-140-142$ & $1139-1141$ & & & & & & 3.990 & 4.630 & -1.386 \\
\hline $42-9-0-2$ & $1146-1148$ & 4.751 & 5.151 & -0.901 & 0.099 & -4.66 & & & \\
\hline \multicolumn{10}{|l|}{ RS15-LC48 } \\
\hline \multicolumn{10}{|l|}{ Sample } \\
\hline $48-1-15-17$ & $15-17$ & 5.028 & 5.428 & 0.182 & 1.182 & -5.81 & 4.547 & 5.187 & 0.232 \\
\hline $48-1-24-25$ & $24-25$ & 4.968 & 5.368 & 0.327 & 1.327 & -5.61 & 4.322 & 4.962 & 0.290 \\
\hline $48-2-26-28$ & $116-118$ & 4.884 & 5.284 & -0.079 & 0.921 & -5.35 & 4.466 & 5.106 & -0.190 \\
\hline $48-2-36-38$ & $126-128$ & 4.898 & 5.298 & -0.077 & 0.923 & -5.39 & 4.543 & 5.183 & -0.219 \\
\hline $48-3-106-108$ & $346-348$ & 4.682 & 5.082 & -0.484 & 0.516 & -4.70 & 4.366 & 5.006 & -0.378 \\
\hline $48-5-58-60$ & $602-604$ & 4.336 & 4.736 & -0.402 & 0.598 & -3.56 & 4.071 & 4.711 & -0.553 \\
\hline
\end{tabular}




\subsection{Spectral analysis}

Spectral analyses are conducted on the gravel count (number of clasts at $5 \mathrm{~cm}$ intervals) and magnetic susceptibility (1 cm sample intervals) data series. Magnetic susceptibility is utilised instead of individual grain size parameters (e.g., weight \% sand) as it closely reflects the variations in the mean grain size and has a much higher sampling resolution (Figure 6.3). Spectral analysis is not performed on core RS15-GC46 as preliminary interpretations indicate the record spans a short interval during the Late Pleistocene, and is therefore of inadequate length for orbital signal detection.

The results of MTM power spectrum for the gravel count and magnetic susceptibility data series for cores RS15-LC42, RS15-LC47, RS15-LC48, RS15-GC107 and RS15-GC108 indicate that most of the power is concentrated at frequencies $\leq 10$ cycles $/ \mathrm{m}$. The EHA results of the gravel count and magnetic susceptibility data for all cores indicate several persistent, high amplitude frequencies. However, it is acknowledged that in all cores the majority of spatial frequencies identified by EHA display instability, which may be associated with variation in sedimentation rates, or hiatuses. Individual MTM and EHA results are summarised below.

\subsubsection{RS15-LC42}

Three frequencies (labelled 1-3 in Figure 5.35b) are identified as significant in the MTM analysis of the gravel count data, while four frequencies (labelled 1-4 in Figure 5.35b) are identified as significant in the magnetic susceptibility data. Assuming a time-averaged sedimentation rate of $10.6 \mathrm{~m} / \mathrm{myr}$, as constrained by the Brunhes-Matuyama chron boundary ( $0.781 \mathrm{Ma})$ at $8.26 \mathrm{mbsf}$, these frequencies correspond to eccentricity, obliquity and precession (Figure 5.35d). The EHA results show a high amplitude, low frequency band corresponding to eccentricity spanning the entirety of both records. In the magnetic susceptibility record medium-to-high amplitude, high frequency bands corresponding to precession and obliquity become significant from 5.10 and 7 mbsf, respectively, and are significant between 0-3 and 9-12 mbsf in the gravel count record (Figure 5.35c). 


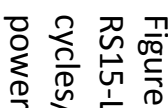

ज行

品

产 畏

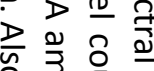

ปั

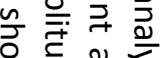

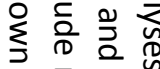

ज. $\overline{0}$

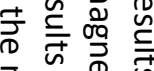

उ.

骂 䆛 $u$

음.

교용

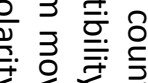

品熍

过蛋

긍 员 节

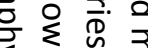

으므 묵

공

흥

응 त

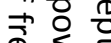

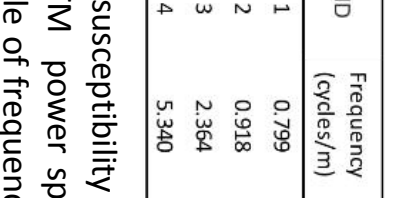

贾. 等

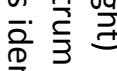

吾

离 흥

金 的

กิ

$\stackrel{n}{\circ} \Rightarrow$

를 웅

बิ่ 0

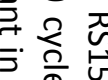

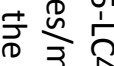

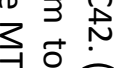

灵市

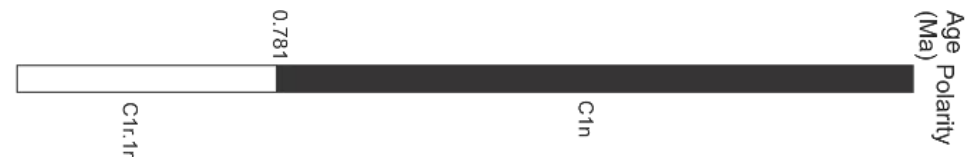

Depth (mbsf)
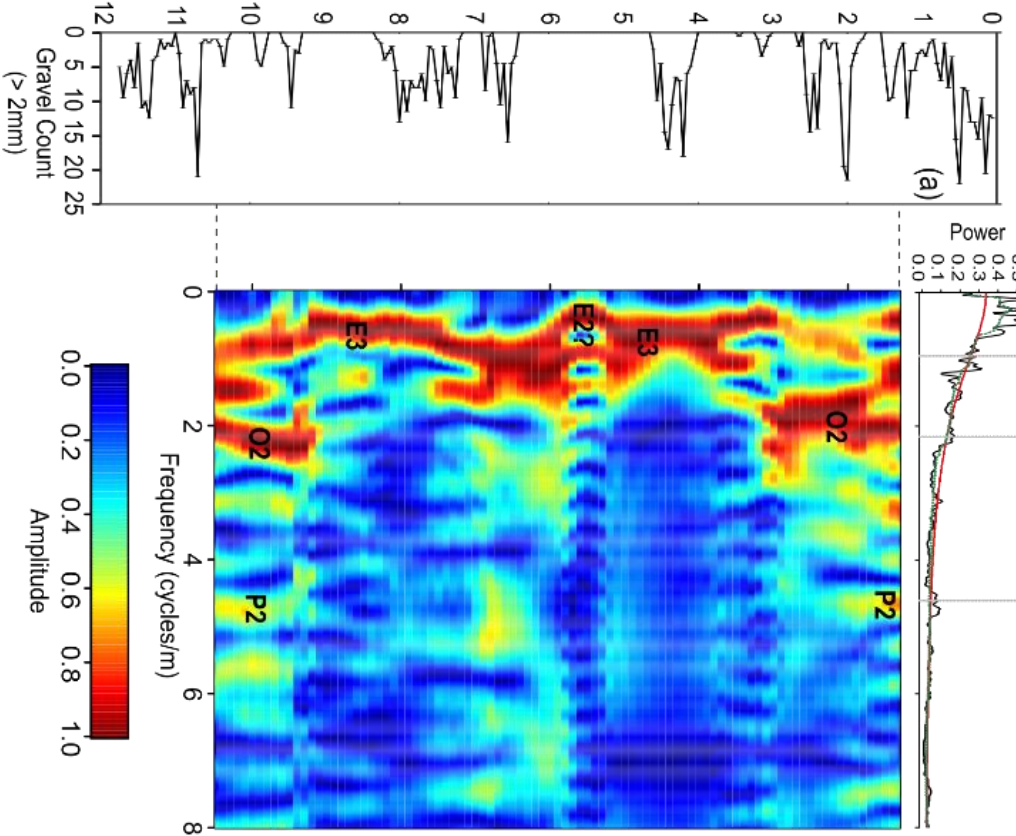

$\widehat{\Omega}$

Depth (mbsf)
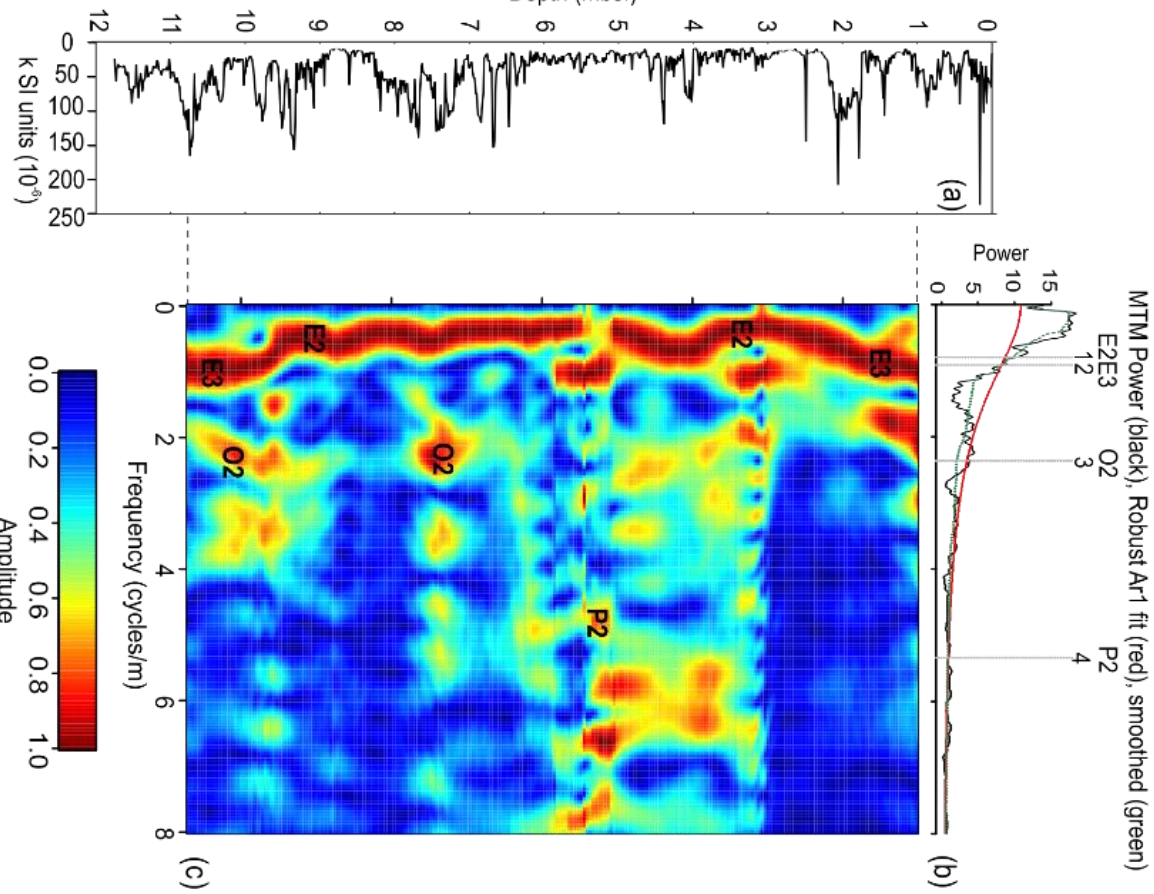


\subsubsection{RS15-LC47}

Five frequencies (labelled 1-5 in Figure 5.36b) and two frequencies (labelled 1-2 in Figure 5.36b) are identified as significant in the MTM analyses of the gravel count and magnetic susceptibility data series, respectively. Assuming a time-averaged sedimentation rate of $14.9 \mathrm{~m} / \mathrm{myr}$, as constrained by the Brunhes-Matuyama chron (0.781 Ma) at $11.65 \mathrm{mbsf}$, cycles identified in the gravel count record at frequencies (cycles/m) of 1.366, 2.147, 3.459 and 3.576 may relate to obliquity and precession signals (Figure 5.36d). A similar 1.201 frequency is noted in the magnetic susceptibility and may also relate to obliquity, but this is obscured by a very large red noise signal with a period of $5.733 \mathrm{~m}$, possibly due to the influence of the $400 \mathrm{kyr}$ eccentricity cycles - although the length of the time series is too short to assess if this is a real paleoclimate signal (Figure 5.36d). The EHA results identify persistent, high amplitude low frequencies in both records, which are representative of eccentricity and a $\sim 70 \mathrm{kyr}$ cycle, while low frequencies corresponding to precession and obliquity only gain significant amplitude beginning at $7.5 \mathrm{mbsf}$ (Figure 5.36c). The $70 \mathrm{kyr}$ cycle is a common signal noted in paleoclimate time series of the Quaternary, and is attributed to non-linear spectral interactions between eccentricity and obliquity bands (Huybers and Wunsch, 2004). 

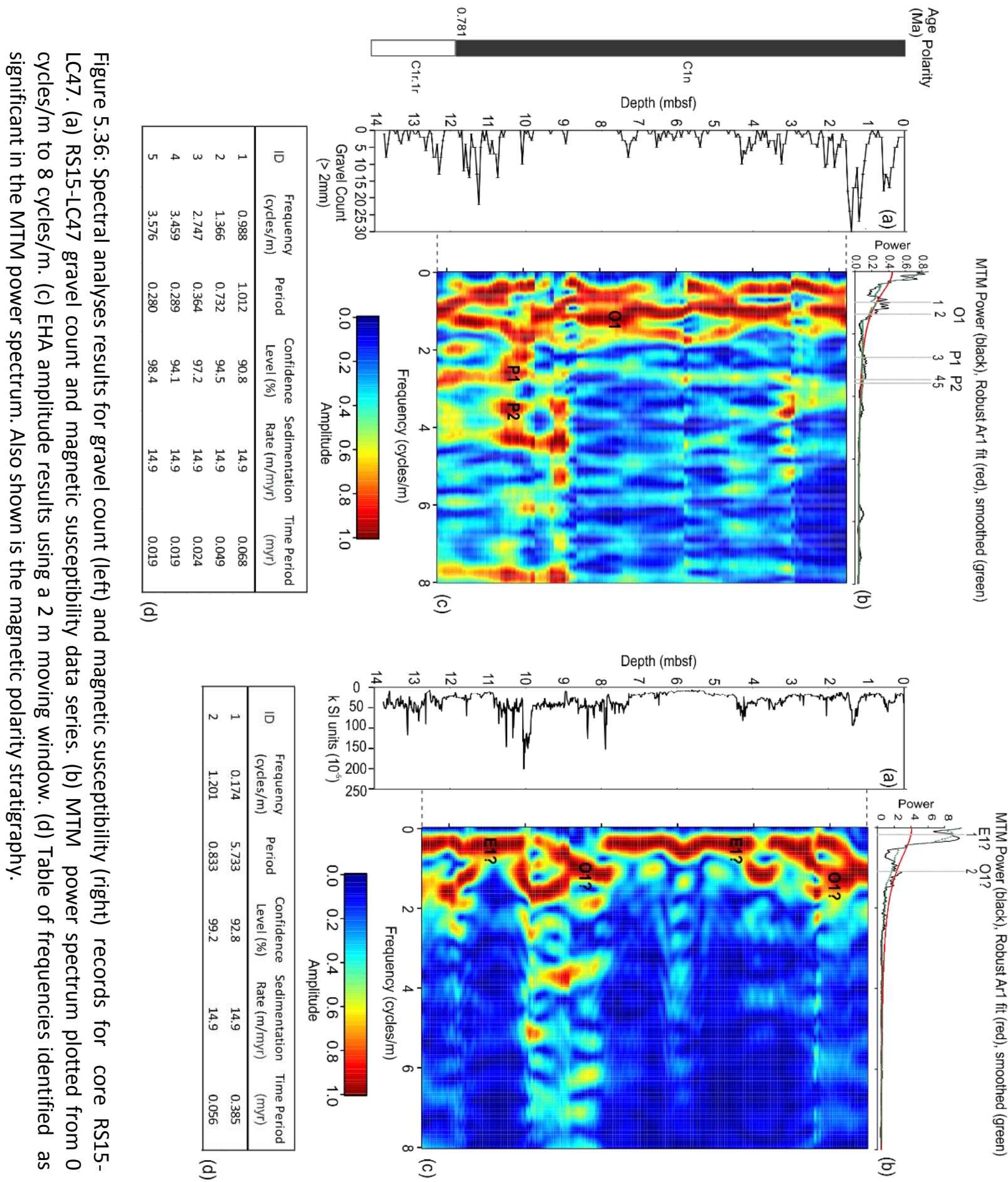


\subsubsection{RS15-LC48}

The MTM analyses of the gravel count data identify six frequencies (labelled 1-6 in Figure 5.37b) as significant, while MTM results of the magnetic susceptibility data show four significant frequencies (labelled 1-4 in Figure 5.37b). Assuming a time-averaged constant sedimentation rate of $5.5 \mathrm{~m} / \mathrm{myr}$ eccentricity, obliquity and precession are identified in both datasets (Figure 5.37d). The EHA results show that persistent high amplitude, low frequencies corresponding to eccentricity bands are dominant throughout both records, while medium-to-high amplitude frequencies corresponding to obliquity and precession, as well as a $\sim 30 \mathrm{kyr}$ cycle, become significant between 4.3 and 10.2 mbsf, below the Brunhes-Matuyama boundary (5.37c). 


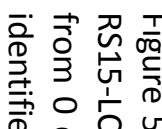

要余市

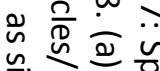

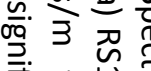

율 屶

北它官

$\Xi \stackrel{\infty}{\infty}$

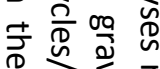

了

츨 읗

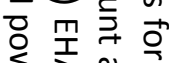

$\sum^{\frac{1}{D}} \stackrel{0}{\frac{0}{2}}$

임

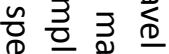

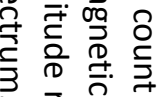

离总岕

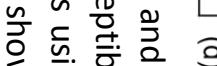

结宗 的

ज唫察

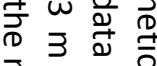

उై

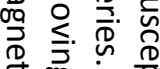

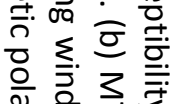

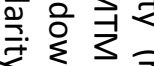

势

票 $\rightarrow$

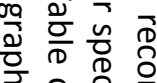

우 辛 웅

$\overrightarrow{\vec{D}} \frac{1}{3}$

윧응

음

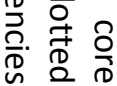
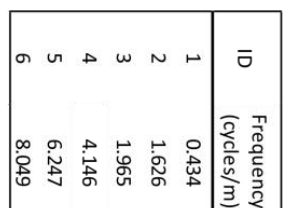

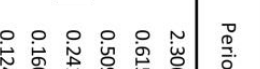
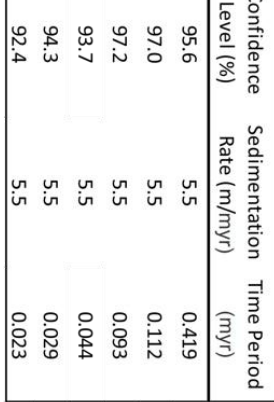

a
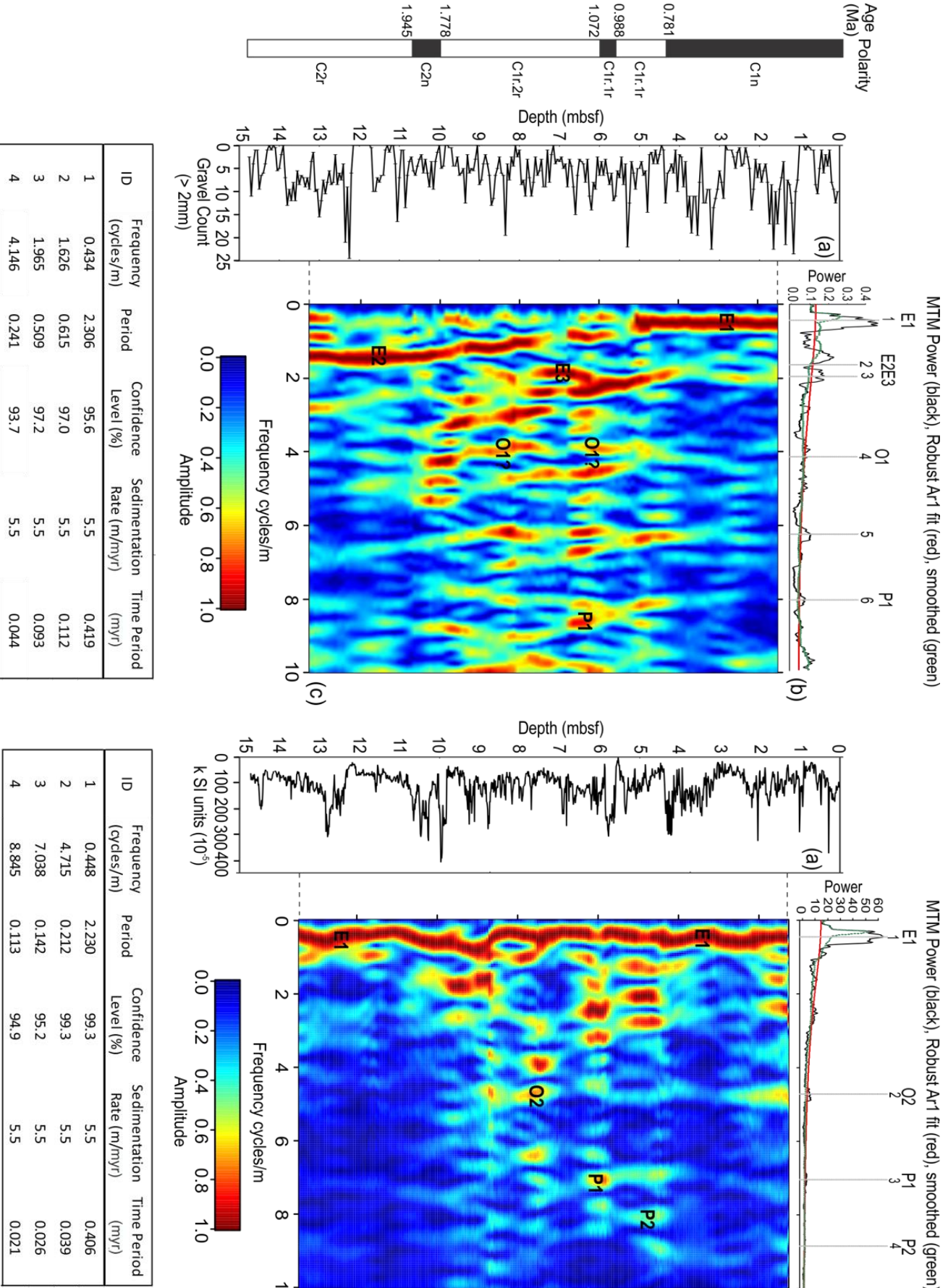

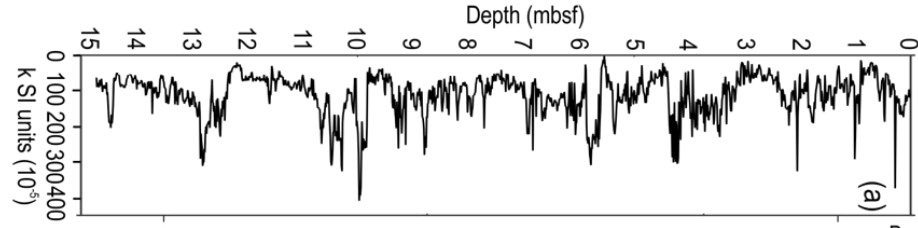

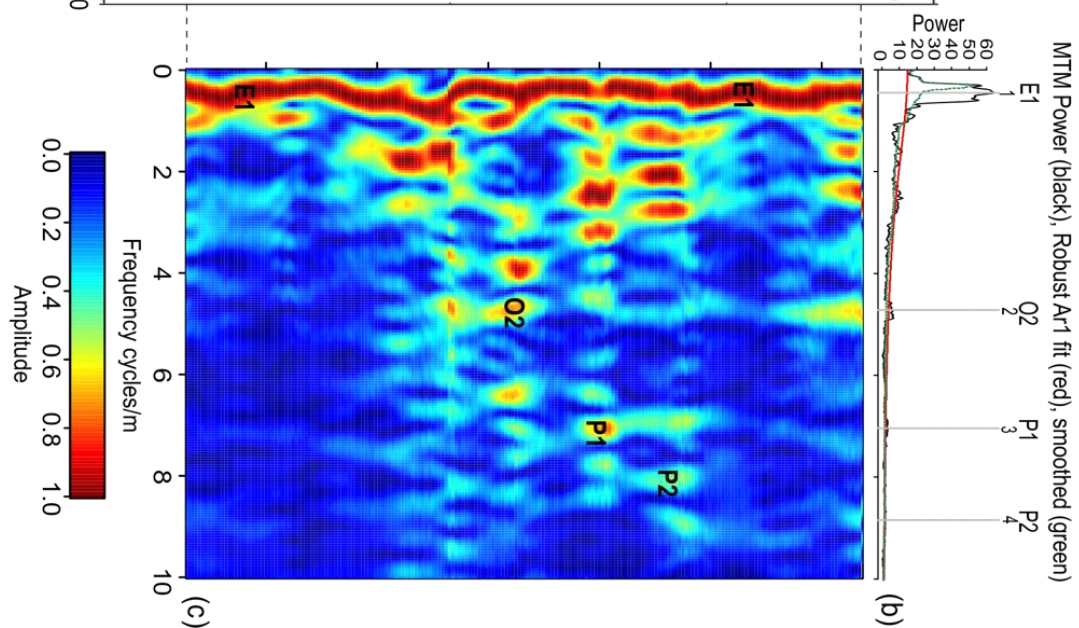




\subsubsection{RS15-GC107}

MTM analyses identify four frequencies (labelled 1-4 in Figure 5.38b) and three frequencies (labelled 1-2 in Figure 5.38b) as significant in the gravel count and magnetic susceptibility data series, respectively. No paleomagnetic age constraints are currently available. An assumed timeaveraged constant sedimentation rate of $7.2 \mathrm{~m} / \mathrm{myr}$, as constrained by correlation of the magnetic susceptibility record to those with an established age model, would mean frequencies 3 and 4 in the gravel count record correspond to obliquity (41 kyr) and precession (23 kyr), respectively, while frequency 1 in the magnetic susceptibility data series is likely representative of a 124 kyr eccentricity cycle (Figure 5.38d). Furthermore, an additional phase in the magnetic susceptibility record that is not identified as significant in the MTM harmonic F-test exhibits increased amplitude and is above the noise level, and could correspond to a $400 \mathrm{kyr}$ eccentricity signal, although the length of the time series is too short to statistically demonstrate this (Figure 4.39b).

EHA of the gravel count data show that the high amplitude, high frequencies corresponding to obliquity and precession, as well as a 70 kyr cycle also observed in RS15-LC42 that may relate to the same non-linear spectral interaction noted in core RS15-LC47, become significant beginning at 3.5 mbsf (Figure 5.38c). A weaker signal with a frequency of 2.536 may relate to a harmonic of eccentricity, or the consequence of an abrupt shift in sedimentation rate. EHA analyses show a shift in the frequency bands occurs below $\sim 4.5$ mbsf. Meanwhile high amplitude frequencies corresponding to eccentricity are significant throughout the entire magnetic susceptibility data series, but with spectral instability below $4.5 \mathrm{mbsf}$, where there is increasing medium-to-high amplitude frequencies corresponding to a 70 kyr cycle (Figure 5.38c).

ASM analysis was performed on the data series in order to evaluate the potential astronomical signals independent of the sedimentation rate that was arbitrarily applied to fit the spectral peaks to known Milankovitch bands. This analysis was performed across 100 sedimentation rates spanning 0.1 and $5 \mathrm{~cm} / \mathrm{kyr}$ to obtain an optimal constant sedimentation rate. Using the Laskar04/Laskar11 astronomical models (Laskar et al., 2004; Laskar et al., 2011), optimal sedimentation rates of $0.736 \mathrm{~cm} / \mathrm{kyr}\left(\mathrm{H}_{0}=0.061 \%\right)$ and $0.852 \mathrm{~cm} / \mathrm{kyr}\left(\mathrm{H}_{0}=0.017 \%\right)$ are identified for the gravel count and magnetic susceptibility records, respectively. Using the calculated sedimentation rates, the eccentricity, obliquity and precession components are fitted to the data (Figure 5.39). The ASM results of the two records are relatively consistent, considering the different sampling spacing, and that the Late Pleistocene is characterised by a non-linear response 
to orbital cycles (Hays et al., 1976). The identified sedimentation rates reject the null hypothesis, which states that the observed spectral signatures are not caused by orbital frequencies, with all $\mathrm{H}_{0}$ significance levels substantially below the required threshold of $0.5 \%$. Furthermore, the sedimentation rates determined by ASM analyses are consistent with paleomagnetic orbital frequencies in both datasets. 


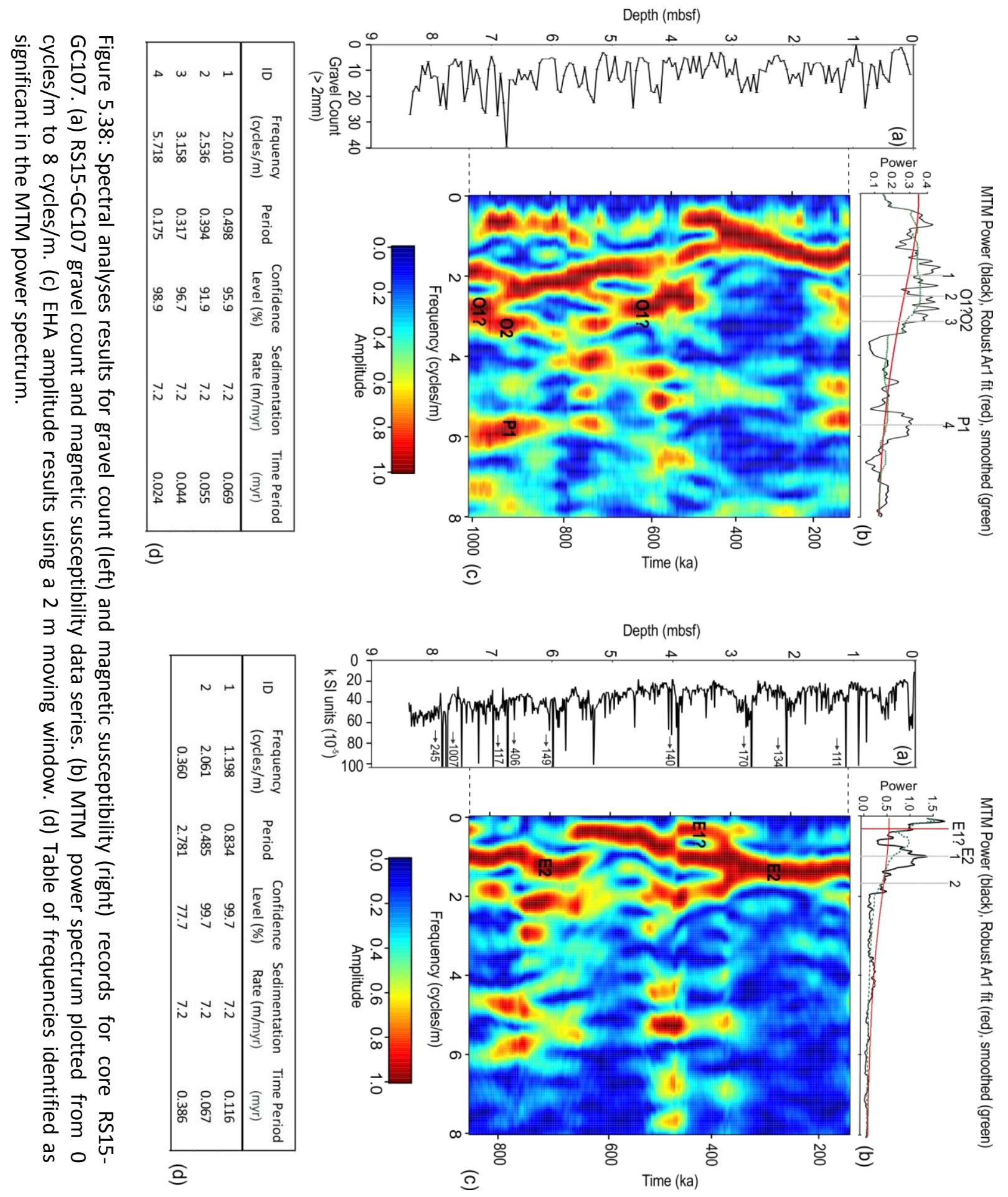


(I) Average Spectral Misfit

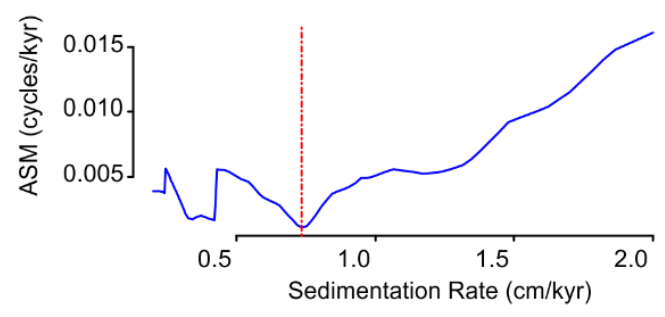

(iii) Null Hypothesis Significance Level

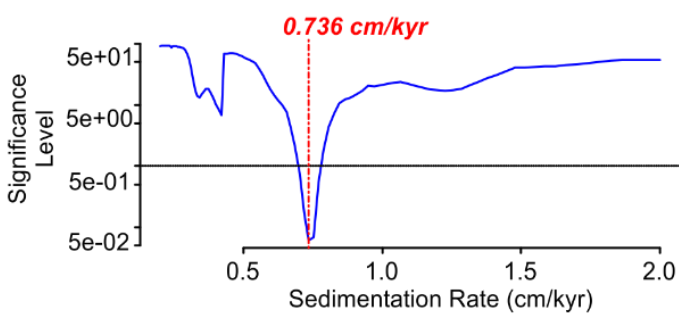

(I) Average Spectral Misfit

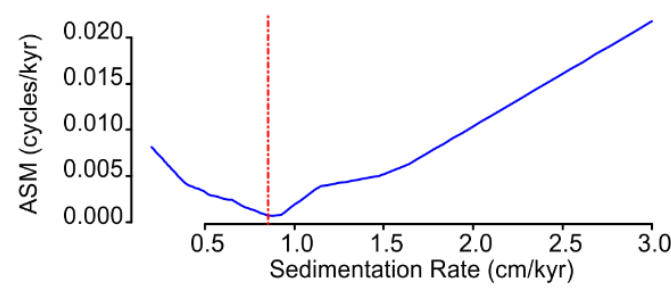

(iii) Null Hypothesis Significance Level

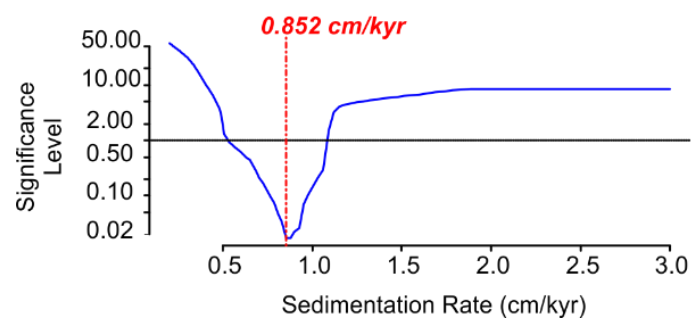

(ii) Number of Terms Evaluated

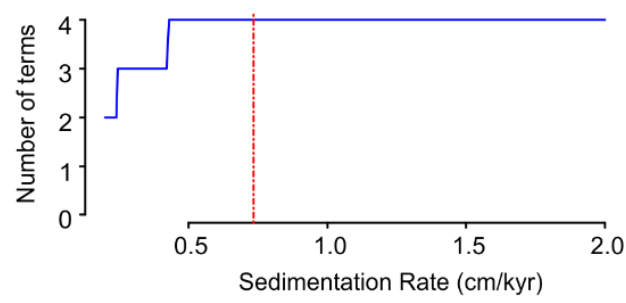

(iv) Data (black) vs. Target (red)

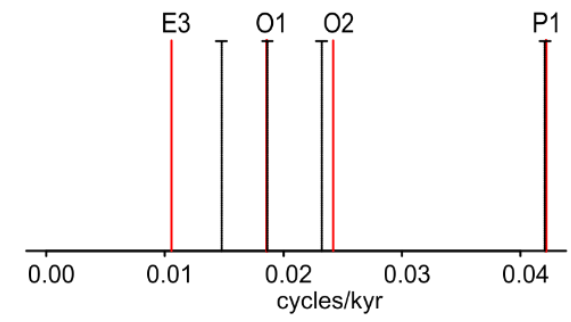

(a)

(ii) Number of Terms Evaluated

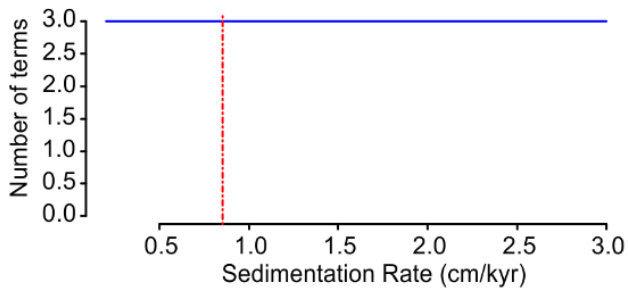

(iv) Data (black) vs. Target (red)

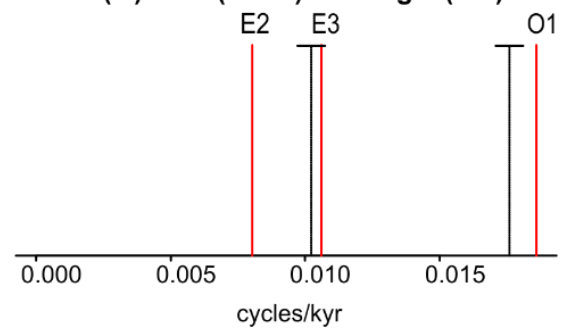

(b)

Figure 5.39: ASM results for the gravel count (a) and magnetic susceptibility (b) data series for core RS15-GC107 using Laskar04/Laskar11 tuning solutions. In each result (I) is the average spectral misfit with the optimal fit denoted by the red dashed line; (ii) number of orbital periods evaluated with the sedimentation rate denoted by the red dashed line; (iii) the null hypothesis significance level denoted by the black line for the sole sedimentation rate (red dashed line) that rejects the null hypothesis; (iv) frequencies identified in the data (black solid lines) compared against the orbital tuning targets (red solid lines). 


\subsubsection{RS15-LC108}

The MTM results identify 9 frequencies (labelled 1-9 in Figure 5.40b) as significant in the gravel count record, meanwhile 6 frequencies (labelled 1-6 in Figure 5.40b) are identified as significant in the magnetic susceptibility data. No paleomagnetic age constraints are currently available, but applying a constant sedimentation rate of $7.4 \mathrm{~m} / \mathrm{myr}$, as constrained by correlating the magnetic susceptibility record to those with an established age model, would allow cycles identified at frequencies of $1.041,1.030,1.228$, and 1.347 to approximate eccentricity signals, cycles with periods of 3.404 and 3.068 to approximate obliquity, and cycles with periods of 5.345 and 5.796 to approximate precession in both data sets, as well as other known periods (e.g., $30 \mathrm{kyr}$ ) identified in Quaternary paleoclimate archives (Figure 4.41d; Huybers and Wunsch, 2004; Lisiecki and Raymo, 2005).

The EHA results show that high amplitude, low frequencies corresponding to eccentricity are consistent throughout both records, while medium-to-high amplitude, high frequencies corresponding to obliquity, as well as a 30 kyr cycle, become significant beginning at 5.5 mbsf (Figure 5.40c). As with RS15-GC107, ASM analysis is used to statistically verify sedimentation rates determined from the magnetic susceptibility-derived age model. The potential astronomical signals across 100 sedimentation rates spanning 0.1 and $5 \mathrm{~cm} / \mathrm{kyr}$ were assessed. Using the Laskar04/Laskar11 astronomical models, optimal constant sedimentation rates of $0.776 \mathrm{~cm} / \mathrm{kyr}$ $\left(\mathrm{H}_{0}=0.001 \%\right)$ and $0.726 \mathrm{~cm} / \mathrm{kyr}\left(\mathrm{H}_{0}=0.001 \%\right)$ are identified for the gravel count and magnetic susceptibility records, respectively. Using these sedimentation rates, the ASM analyses show the expected eccentricity, obliquity and precession components (Figure 5.41). The sedimentation rates determined by ASM analysis are very consistent between datasets and with the existing age model sedimentation rate. Thus, MTM and ASM analyses indicate that orbital frequencies are present in both data sets, and suggest that RS15-LC108 likely contains a high fidelity orbitally paced paleoclimate record. The calculated sedimentation rates using ASM analysis will be tested by paleomagnetic analysis on the U-channelled cores, which is currently being undertaken at the University of Otago by Dr. Christian Ohneiser. 


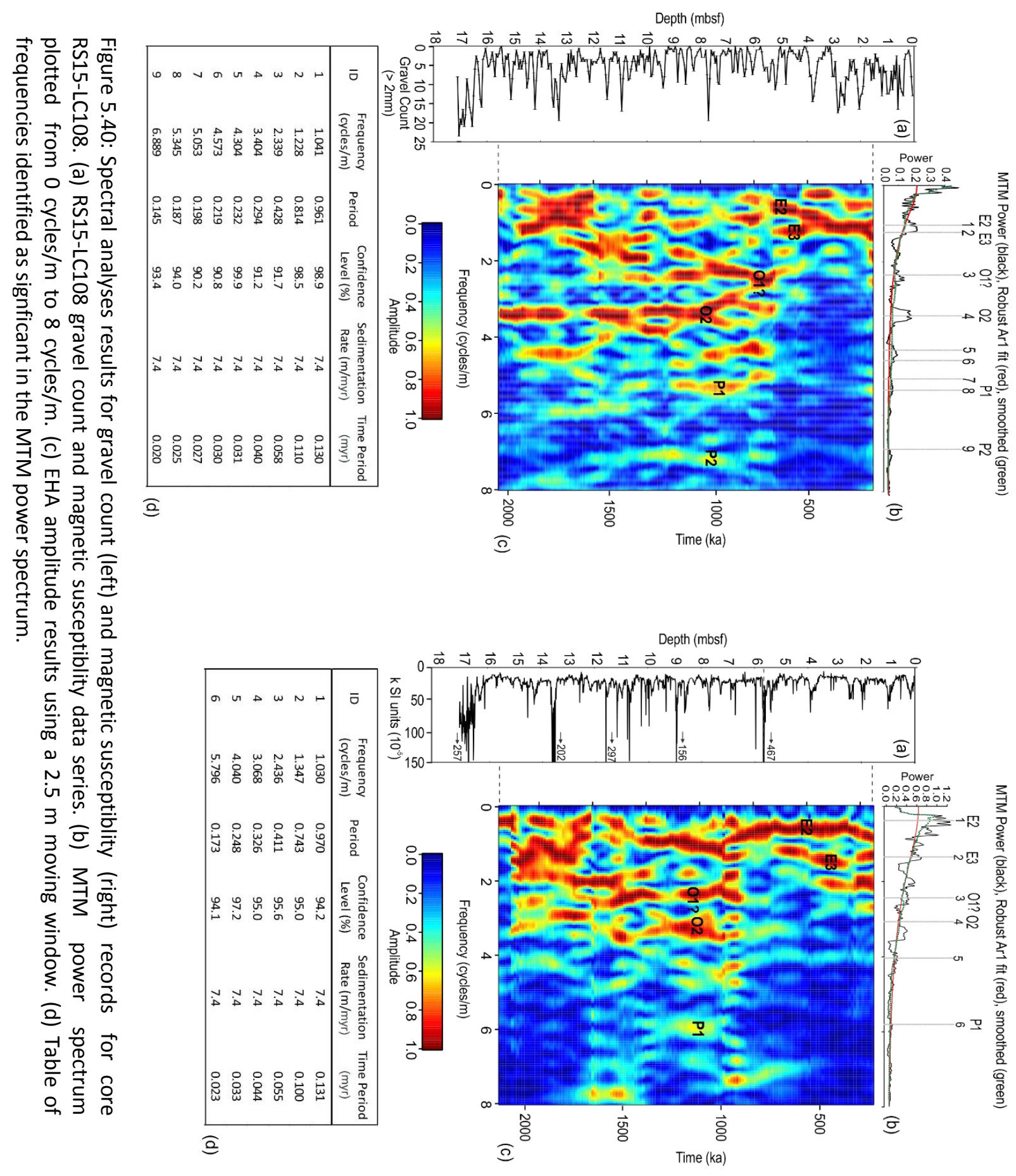


(I) Average Spectral Misfit

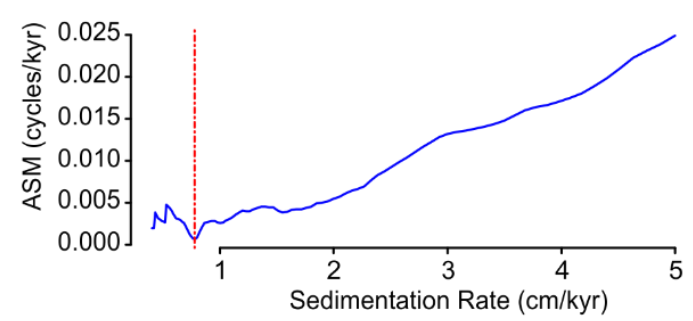

(iii) Null Hypothesis Significance Level

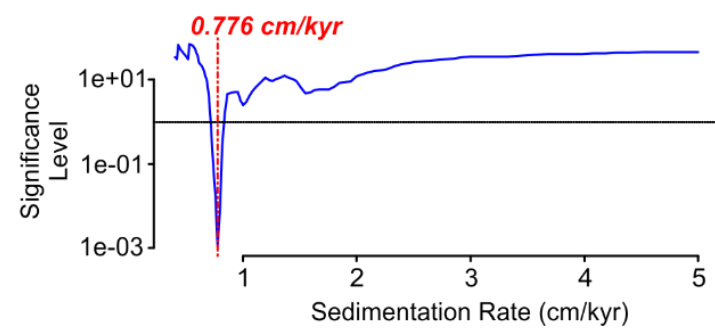

(I) Average Spectral Misfit

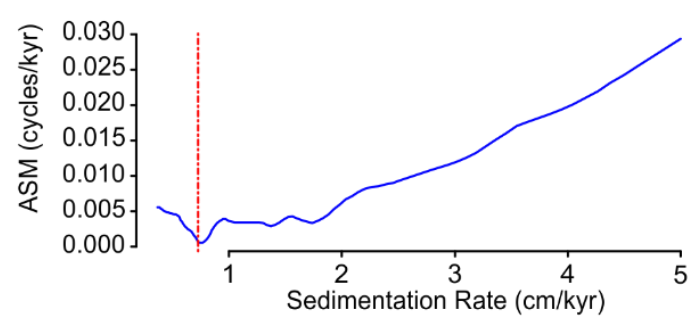

(iii) Null Hypothesis Significance Level

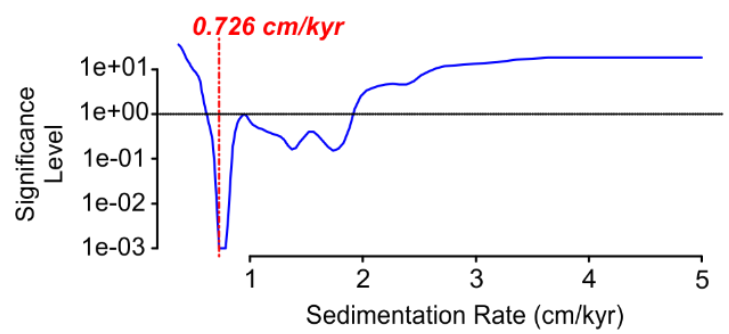

(ii) Number of Terms Evaluated

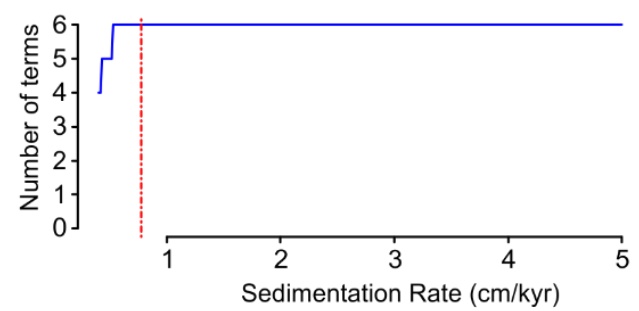

(iv) Data (black) vs. Target (red)

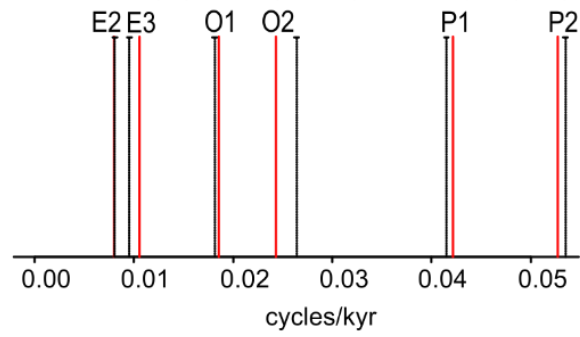

(a)

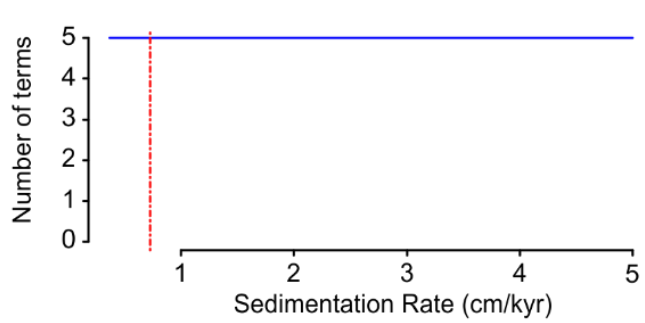

(iv) Data (black) vs. Target (red)

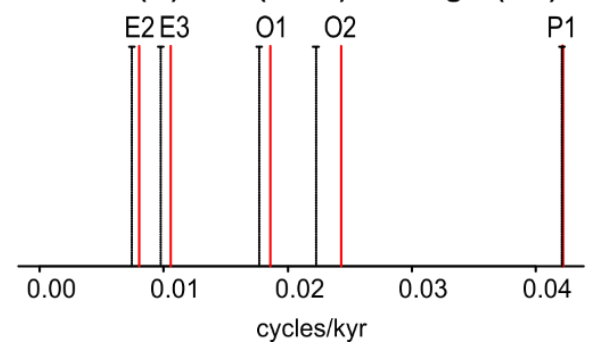

Figure 5.41: ASM results for the gravel count (a) and magnetic susceptibility (b) data series for core RS15-GC107 using Laskar04/Laskar11 tuning solutions. In each result (I) is the average spectral misfit with the optimal fit denoted by the red dashed line; (ii) number of orbital periods evaluated with the sedimentation rate denoted by the red dashed line; (iii) the null hypothesis significance level denoted by the black line for the sole sedimentation rate (red dashed line) that rejects the null hypothesis; (iv) frequencies identified in the data (black solid lines) compared against the orbital tuning targets (red solid lines). 


\section{CHAPTER 6: DISCUSSION}

This chapter discusses the physical and geochemical proxies of the cores, and then provides a preliminary interpretation of the depositional environments. The primary aim of this chapter is to identify long-term shifts in sedimentation and glacial-interglacial variability through core-to-core correlation of core physical properties and facies. Changes in the dynamics of the WAIS throughout the Pleistocene Epoch, as recorded by sediments on the continental rise, are illustrated through preliminary sedimentation models, which are subject to refinement with the addition of future proxy datasets that will aid in understanding the past depositional environments.

\subsection{Ice-rafted debris}

\subsubsection{Defining ice-rafted debris}

In ice proximal environments on the continental rise to abyssal plain, grain sizes of $>150,>250 \mu \mathrm{m}$ or $>2 \mathrm{~mm}$ have been used to define the IRD fraction, although this is subject to mass transport processes relating to continental margin sedimentary processes (e.g., Kanfoush et al., 2002; Murphy et al., 2002; Krissek, 1995; Patterson et al., 2014; Weber et al., 2014; also see 2.4). Transport by sea ice is generally restricted to the 63-150 $\mu \mathrm{m}$ fraction, with most sand-size sediment restricted to coastal fast ice $<5 \mathrm{~km}$ offshore (Chewings et al., 2013), while wind and resuspension by bottom currents is generally restricted to the $<63 \mu \mathrm{m}$ fraction (Andrews, 2000). Grain size, shape, and texture have been used to resolve these different processes. Specifically, sub-angular to angular clasts, and a high abundance of fractures and striations/gouges on the clasts have been used as indicators of an iceberg-rafted, rather than sea ice-rafted, origin of these clasts (St John et al., 2015). A caveat of this approach is that a glacial erosion signature is likely to be pervasive on the Antarctic margin and re-deposition, via the above processes, is likely to contain grains where the original subglacial and glacimarine grain shape/surface textures are likely to be preserved.

A lack of correlation between results from some of the methods presented in Chapter 5 indicates the need to establish a consistent methodology for quantifying the IRD content of sediments. Patterson et al. (2014) chose the $250 \mu \mathrm{m}-2 \mathrm{~mm}$ grain size interval as the indicator of IRD delivered by icebergs for overbank levee turbidite deposits on the lowermost continental rise/abyssal plain of Wilkes Land, East Antarctica. However, later studies used a cut-off of $>125 \mu \mathrm{m}$ for IRD for similar depositional settings in East Antarctica (Passchier, 2011; Hansen et al., 2015). These studies show 
similar trends, but conflicting results in regards to orbital pacing of the EAIS growth dynamics. Patterson et al. (2014) demonstrated a high-fidelity response to obliquity prior to $3.6 \mathrm{Ma}$ on the lowermost continental shelf, while Hansen et al. (2015) produced a noisier wavelet analysis dataset suggesting a reduced response to obliquity from the same levee system, but in shallower water where the levee relief was much higher. This difference could relate to grain size methodology, or that some depositional settings with variable sedimentation rates on the continental margin of Antarctica are less suitable for resolving orbital scale processes.

The results of this study indicate a moderate-to-strong correlation between IRD MARs determined by sieve analysis (weight \% of the $250 \mu \mathrm{m}-2 \mathrm{~mm}$ grain size fraction) and visual clast counts using image $\mathrm{x}$-ray analysis, compared to a weak relationship between IRD MARs from LPSA analysis (volume $\%>125 \mu \mathrm{m}$ ) and visual clast counts (see 5.2.3). Furthermore, the $250 \mu \mathrm{m}-2 \mathrm{~mm}$ versus $>125 \mu \mathrm{m}$ IRD MARs show a very weak correlation in core RS15-LC48, which has a consistently high IRD content throughout. The $>125 \mu \mathrm{m}$ IRD MARs show consistently higher values than the 250 $\mu \mathrm{m}-2 \mathrm{~mm}$ IRD MARs, and record spurious peaks where the $250 \mu \mathrm{m}-2 \mathrm{~mm}$ IRD MARs and visual clast counts do not capture a significant IRD component. It also fails to detect any IRD components in intervals where the other two methods show sustained peaks. The grain size distributions (see 5.2.1; Figure 5.18) show that the $>125 \mu \mathrm{m}$ cut-off captures the coarse-grained shoulder of welldefined modes in sandy silts and silty sands. As IRD is unlikely to be represented by this welldefined mode, it is apparent that at these sites, the $>125 \mu \mathrm{m}$ LPSA method is overestimating the IRD component of sediments and will consequently result in a noisier IRD signal.

An additional consideration is that the IRD component may be amplified as the LPSA results appear to underestimate the fine fraction component $(<63 \mu \mathrm{m})$ of the sediment relative to the sedigraph data (Figure 4.10; Table 6.1). Applying a cut-off of $>250 \mu \mathrm{m}$ to LPSA measurements does reduce the spurious peaks associated with the shoulder of the sandy silts and silty sand modes (Table 6.2). Nevertheless, the IRD MARs determined by LPSA remain substantially higher than the IRD MARs calculated from the sieved $250 \mu \mathrm{m}-2 \mathrm{~mm}$ grain size fraction, with the exception of one sample in core RS15-LC48. In addition to the underestimation of the mud\% discussed above, this is also the possible result of the small sampling size $(<0.15 \mathrm{~g})$ required for LPSA, where the volume of few single very coarse sand grains (e.g., $1-2 \mathrm{~mm}$ ) in a $<0.15 \mathrm{~g}$ sample have the potential to greatly skew the final measurement towards the coarser end of the spectrum, while a relative lack of very coarse sands within IRD-rich grain size populations would bias the results towards the 
finer end of the spectrum. Ideally, it is necessary to examine individual grain size frequency curves to assess the influences of these potential biases.

Following the methodology of previous high latitude studies using the $250 \mu \mathrm{m}-2 \mathrm{~mm}$ grain size interval as an indicator of IRD (Krissek, 1995; St John and Krissek, 2002; Patterson et al., 2014), $10-20 \mathrm{~cm}^{3}$ of dry sample was used to determine the IRD component (see 4.3 ). This method is much more consistent with the visual clast count records from x-ray analysis, and is therefore considered a less noisy representation of the IRD component than the LPSA >125 $\mu$ m method.

Table 6.1: Sand\% vs mud\% as measured by the LPSA vs sedigraph for depth intervals showing LPSA underestimation of fine fractions /overestimation of sands.

\begin{tabular}{|lccccc|}
\hline \multirow{2}{*}{ Core Site } & $\begin{array}{c}\text { Depth Interval } \\
\text { (cmbsf) }\end{array}$ & \multicolumn{2}{c}{ LPSA } & \multicolumn{2}{c|}{ Sedigraph } \\
\hline \multirow{2}{*}{ RS15-LC42 } & $1039-1041$ & 29.52 & 70.48 & 8.03 & 91.97 \\
& $1109-1111$ & 28.80 & 71.21 & 13.25 & 86.75 \\
\hline \multirow{2}{*}{ RS15-LC48 } & $554-556$ & 37.96 & 45.84 & 10.41 & 89.56 \\
& $577-579$ & 65.92 & 27.74 & 40.47 & 59.53 \\
\hline
\end{tabular}

Table 6.2: Comparison of IRD MARs for depth intervals showing significantly smaller IRD MARs calculated from sieve analysis. The choice of a higher threshold of $>250 \mu \mathrm{m}$ results in significantly smaller discrepancy between IRD MARs.

\begin{tabular}{|lcccc|}
\hline Core Site & $\begin{array}{c}\text { Depth Interval } \\
\text { (cmbsf) }\end{array}$ & $\begin{array}{c}\text { IRD MAR }\left(\mathrm{g} / \mathrm{cm}^{2} / \mathrm{kyr}\right) \\
(250 \mu \mathrm{m}-2 \mathrm{~mm} \\
\text { weight } \%)\end{array}$ & $\begin{array}{c}\text { IRD MAR } \\
\left(\mathrm{g} / \mathrm{cm}^{2} / \mathrm{kyr}\right)(>125 \\
\mu \mathrm{m} \text { volume } \%)\end{array}$ & $\begin{array}{c}\text { IRD MAR (g/cm } / \mathrm{kyr}) \\
(>250 \mu \mathrm{m} \text { volume } \%)\end{array}$ \\
\hline \multirow{2}{*}{ RS15-LC42 } & $1039-1041$ & 0.009 & 0.136 & 0.072 \\
& $1109-1111$ & 0.012 & 0.129 & 0.062 \\
\hline \multirow{2}{*}{ RS15-LC48 } & $554-556$ & 0.029 & 0.125 & 0.042 \\
& $577-579$ & 0.067 & 0.181 & 0.051 \\
\hline
\end{tabular}

\subsubsection{Ice-rafted debris as a proxy}

Sediment archives on the lower continental rise of the Antarctic margin record a more distal and less direct signal of AIS behaviour than those on the continental shelf. However, they provide an opportunity to study more continuous records, and thus have some advantages over continental shelf sediment sequences, which are often hindered by hiatuses as a result of repeated ice sheet grounding events throughout the Neogene and Quaternary Periods. One of the few direct measures of shifting ice sheet dynamics is the presence of IRD. Continuous, well-dated, records of IRD allow examination of interactions between ice sheet dynamics, temperature, and the water 
masses of the Southern Ocean (e.g., Weber et al., 2014). However, caution is warranted when interpreting IRD records as calving events can occur during glacial and interglacial maximums (e.g., Williams et al., 2010), and are also influenced by the glacial regime, as well as differential melt-out rates of glacial debris in an iceberg related to local climatic conditions such as sea ice, SSTs and ocean currents (see 2.4.3).

At present, icebergs passing over the core sites are sourced from the Amundsen Sea embayment and the Ross Sea region (Figure 3.1), and are subsequently entrained in the westward flowing Antarctic Coastal Current (Stuart and Long, 2011). Previous studies have demonstrated that the westward flowing Antarctic Coastal Current and its associated ASF persist even under greatly reduced EAIS scenarios due to the bathymetric and geostrophic constraints (DeConto et al., 2007). However, during glacials much of the western Ross Sea is covered by an expanded marine-based WAIS and EAIS (Barrett, 2009). Thus, the IRD records presented in this thesis are interpreted to represent iceberg calving events from ice sheets that occupied the Ross and Amundsen Seas during past interglacials and glacial cycles, and transported over the sites by the southern limb of the Ross Sea gyre (Figure 3.3).

Previous work has shown that IRD concentrations in the northernmost Southern Ocean are higher during glacial periods, as colder SSTs allow icebergs to travel further north before melting (Carter et al., 2002; Cook et al., 2014). Conversely, IRD peaks in Antarctic proximal records have been related to major deglaciation events (e.g., Williams et al., 2010; Patterson et al., 2014). The core sites are proximal enough to record such deglaciation events with only seasonal winter sea ice conditions at present, although the more proximal sites (RS15-LC42, RS15-GC46, RS15-LC47 and RS15-LC48) may be subject to a prolonged period of summer sea ice cover, which would act to buffer the icebergs against a significant increase in melt rate resulting from warmer SSTs. In the present interglacial, all SSTs at these sites are $<0^{\circ} \mathrm{C}$ (Figure 3.7), suggesting it is unlikely that glacialinterglacial SSTs are playing a significant role in iceberg melt-out rates at the core sites - unless there were significantly warmer interglacials than present during the Pleistocene. SSTs do warm significantly (by $\sim 2^{\circ} \mathrm{C}$ ) near the southern boundary front of the ACC, which lies $\sim 600 \mathrm{~km}$ north of site RS15-LC108. This front is associated with greatly enhanced productivity (Diekmann and Kuhn, 2002), and thus productivity spikes at this most productive site (Figure 3.7) may provide an approximation for a rapid increase in SSTs. The north-to-south core transect approach also provides an opportunity to assess the potential influence of changes in local frontal strength or 
position, as the SST is likely to be more of an influence on the IRD signal at the northernmost sites (RS15-GC107, RS15-LC108) relative to sites closer the continental shelf edge.

Previous studies have demonstrated an orbital pacing component in IRD records along the EAIS margin (Escutia et al., 2009; Passchier, 2011; Patterson et al., 2014). The IRD records in this study have also been shown to contain statistically significant signals at orbital periodicities, and for the first time across multiple cores in a single region (see 5.6), suggesting that iceberg calving is not a random process, and is paced by orbital forcing.

\subsubsection{Ice-rafted debris mass accumulation rates versus lag deposits}

Previous studies have used the sorting parameter (spread of the sizes around the mean; Folk and Ward, 1957) of the terrigenous fraction (i.e., biogenic and organic components removed) alongside the IRD MARs in order to differentiate enrichments in the CS\% caused by actual peaks in IRD abundance versus current winnowing of the fine fraction (Passchier, 2011; Patterson et al., 2014). It is suggested that a peak in the IRD MAR that coincides with well-sorted terrigenous material is likely the result of a coarse sand fraction caused by winnowing of fine-grained material by high energy bottom currents.

Following this methodology, Figures 6.1 and 6.2 demonstrate a lack of well-sorted sediments in both RS15-LC42 and RS15-LC48. Lack of well-sorted terrigenous material at the site indicates that the bottom currents likely didn't reach speeds over $20 \mathrm{cms}^{-1}$ required for erosional winnowing of the fine fraction (McCave and Hall, 2006). All IRD MAR peaks coincide with poorly to very poorly sorted sediments, which on the criteria set by Passchier (2011), suggest that enrichments in the CS\% are actual IRD events, and are not the result of lag deposits. Furthermore, lack of well-sorted terrigenous material supports an assumption of no major hiatuses related to current winnowing between the chronostratigraphic tiepoints (Patterson et al., 2014). 
RS15-LC48

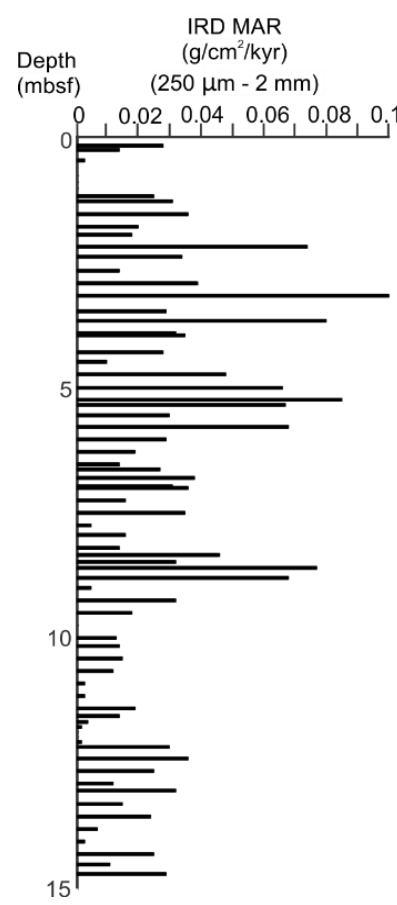

RS15-LC42

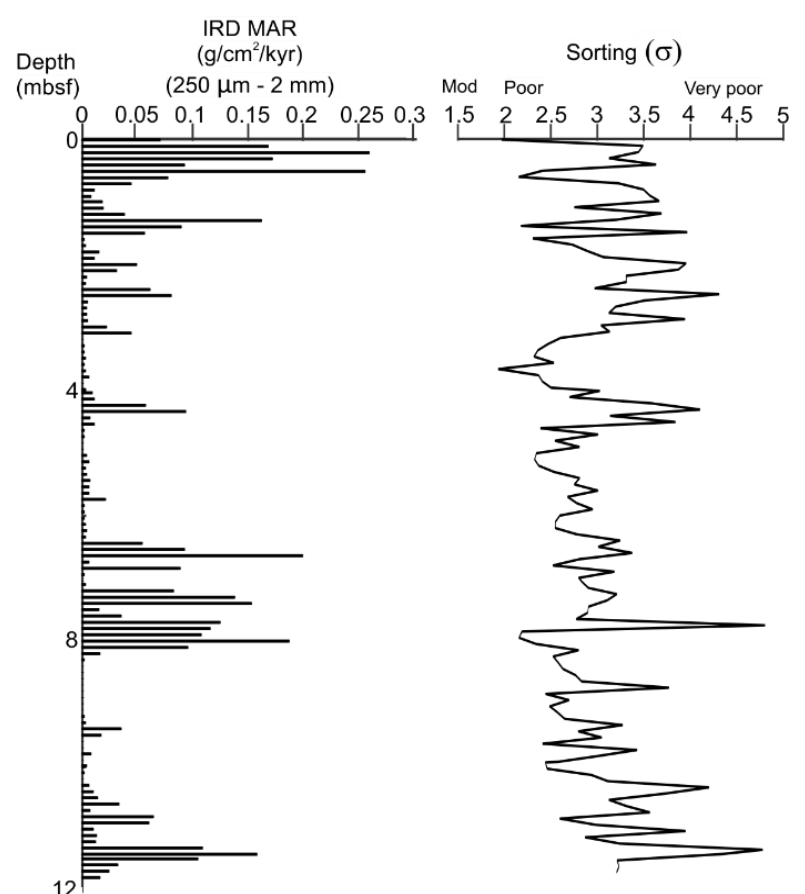

Figure 6.1: RS15-LC48 and RS15-LC42 IRD MAR (250 $\mu \mathrm{m}-2 \mathrm{~mm})$ compared to bulk sorting of terrigenous material. Sorting measurements follow parameters defined by Folk and Ward (1957). All samples for RS15LC48 are classified as poorly (2-4 $\sigma)$ and very poorly (4-6 $\sigma)$ sorted. Two samples in RS15-LC42 (0.01 and $0.369 \mathrm{mbsf}$ ) are moderately sorted (1.62-2 $\sigma)$, while the rest are classified as poorly and very poorly sorted. 


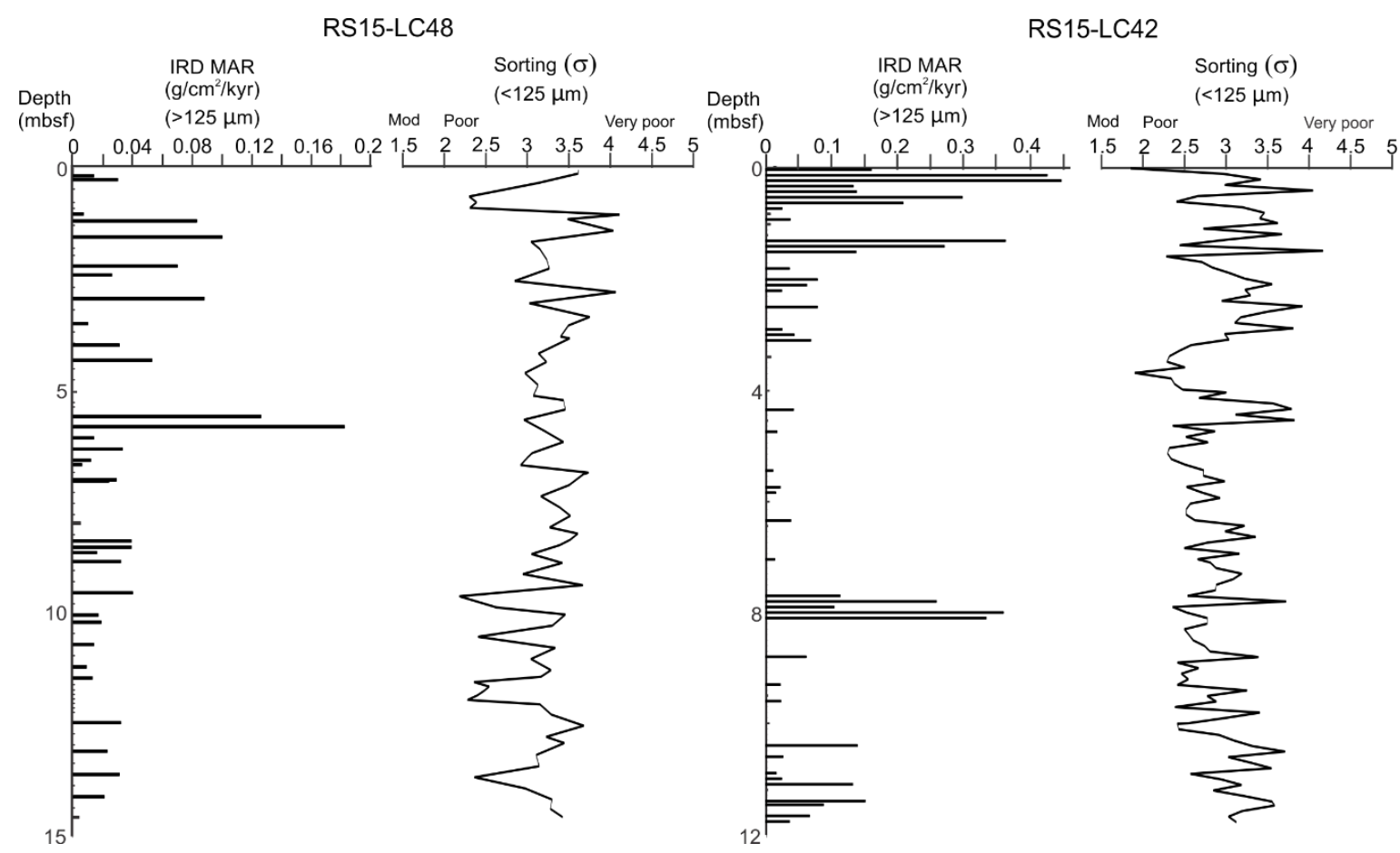

Figure 6.2: RS15-LC48 and RS15-LC42 IRD MAR (>125 $\mu \mathrm{m})$ compared to sorting of the $<125 \mu \mathrm{m}$ grain size fraction. Sorting measurements follow parameters defined by Folk and Ward (1957). All samples for RS15-LC48 are classified as poorly (2-4 $\sigma$ ) and very poorly (4-5 $\sigma)$ sorted. Two samples in RS15-LC42 $(0.01$ and $0.369 \mathrm{mbsf})$ are moderately sorted $(1.62-2 \sigma)$, while the rest are classified as poorly and very poorly sorted.

However, previous grain size studies have demonstrated that a comparison of the source and the resultant sediment deposit must be made in order to identify the sedimentary transport process (e.g., winnowing), and thus it is not possible to identify the depositional environment from a single grain size distribution (McLaren, 1981). Furthermore, the relative trends in several grain size parameters including, the mean grain size, sorting and skewness (spread to one side of the mean), must be assessed between the source sediment and its deposit to provide a thorough understanding of the transport and depositional processes (McLaren, 1981). For example, if a source sediment is extremely poorly sorted and is subject to erosional winnowing, the lag remaining after erosion, although better sorted, may still be poorly sorted. However, the skewness will be more positive as winnowing leads to an increase in the mean grain size, and therefore decreases the amount of fines that can be removed from the grain size population. The above example highlights the importance of comparing the source sediment and its deposit, as well as the changes in sediment grain size characteristics from source to deposit.

Additionally, sedimentary structures of the deposit must be considered in combination with the grain size characteristics because they reflect environmental conditions at the time of deposition, and therefore serve as tools for interpreting aspects of sedimentary environments, such as 
sediment transport mechanisms and relative current velocity (Boggs, 2006). The presence of cross-laminae and scour features in silt and sandy silt beds in both RS15-LC42 and RS15-LC48 (see 5.1.1 and 5.1.4), indicates that current velocities reached at least $23 \mathrm{cms}^{-1}$ required for movement of silt (McCave and Hall, 2006), and current-induced erosion has had some influence at both sites. A single cross-laminated sand bed is present in RS15-LC47 (Figure 5.9), suggesting current velocities reached above $30 \mathrm{cms}^{-1}$, and extensive winnowing of the fine fraction has likely occurred (McCave and Hall, 2006). Furthermore, the localised effects of the rough bottom topography and the narrow channels on the steepening margin likely aided to enhance the bottom current flows during episodes of increased bottom current activity, thereby increasing seafloor erosion (Howe et al., 1997; 2001). For example, Gordon et al. (2004) recorded rapid descent of dense shelf water cascading through the Drygalski Trough and down the continental slope at speeds up to $100 \mathrm{cms}^{-1}$.

Although the cross-laminated intervals are largely free of IRD, and IRD-rich intervals do not show any preserved primary sedimentary structures, erosional winnowing cannot be ruled out completely as an influence. Gravel lags, suggested to be indicative of vigorous bottom current activity in contourites (Stow et al., 1998b), are present in both proximal and distal sites (see 5.1). The gravel lag deposits are therefore interpreted as a product of direct iceberg rafting and the removal of the fine-grained fraction by strong bottom currents. These lags were subsequently buried within the contourite sequences during a later phase of reduced current activity. The presence of gravel lags within the contourite sequences also represents some loss of sediment thickness through erosion, indicating a possible hiatus within that part of the sequence (Howe et al., 2001).

In summary, caution should be exercised when applying a single method (e.g., sorting) to assess the influence of deep-water seabed erosion on continental margin sedimentary sequences, particularly in regions of complex, steep bathymetry on bottom current flows influenced by intense dense water production and geostrophic currents. It highlights the need to consider the entire grain size distributions through the core, and detailed observation of sedimentary structures indicative of bottom current erosion.

\subsection{Core correlation}

Physical properties of the sediments (magnetic susceptibility), facies and chronostratigraphic tiepoints are used to correlate the cores and establish 11 intervals with common trends and 
patterns (1-11 in Figure 6.3). These intervals are interpreted to represent depositional environments under glacial-interglacial regimes. The paleomagnetic tie points served as a first order correlation method. The depth estimations for Brunhes-Matuyama, Jaramillo and Olduvai Subchron boundaries for cores RS15-GC107 and RS15-LC108 are consistent with the ASM results and the assumption of near-continuous linear sedimentation rates, providing further confidence in the preliminary age models. Low frequency magnetic susceptibility intervals provided a secondary approach to correlation and were used to identify the interval boundaries. The identified intervals display similar trends in the physical and geochemical properties of sediments (Figure 6.3). Because magnetic susceptibility reveals zones of common patterns across all sites, the depositional processes are inferred to primarily respond to changes in sediment delivery relating to long-term shifts in ice sheet dynamics and ocean circulation in response to changes in global climate. High frequency fluctuations in magnetic susceptibility within the established intervals enabled the identification of individual glacial-interglacial cycles, and thus provided a third order approach to correlation. In general, peaks in magnetic susceptibility are hypothesised to represent glacial maxima, as they typically coincide with low $\mathrm{Ba} / \mathrm{Al}(\mathrm{Ti})$ ratios (indicative of low biological productivity), as is the case with the Amundsen Sea core PS58/254 (Hillenbrand et al., 2009). The magnetic susceptibility record of core RS15-LC48 and the Amundsen Sea core PS8/254 show strong similarities (Figure 6.4; also see Appendix F), and therefore peaks in the magnetic susceptibility records of the cores analysed in this work are inferred to represent glacial periods. However, this pattern is complicated and should be treated as a working hypothesis until further proxies of productivity and SSTs are available. The correlated glacial-interglacial cycles prior to the Jaramillo reversal (1.072 Ma) are established at a lower confidence, and further proxy data is needed to provide additional age constraints.

Based on the paleomagnetic tiepoints, the apparent long-term linear sedimentation and the strong orbital relationship observed in the frequency spectra of the IRD and magnetic susceptibility records (see 5.6), a one-to-one correlation is established between cycles expressed in the IRD and magnetic susceptibility data series and the orbitally paced global benthic $\delta^{18} \mathrm{O}$ stack (Lisiecki and Raymo, 2005; Figure 6.4). It is acknowledged that the correlative relationships, although constrained by paleomagnetic reversals at three study sites, do not provide a unique solution, but the orbital frequencies identified in the magnetic susceptibility and IRD records appear to be consistent with the orbital variability. The depositional environments and their interpreted relationship to global climate are discussed in section 6.4. 


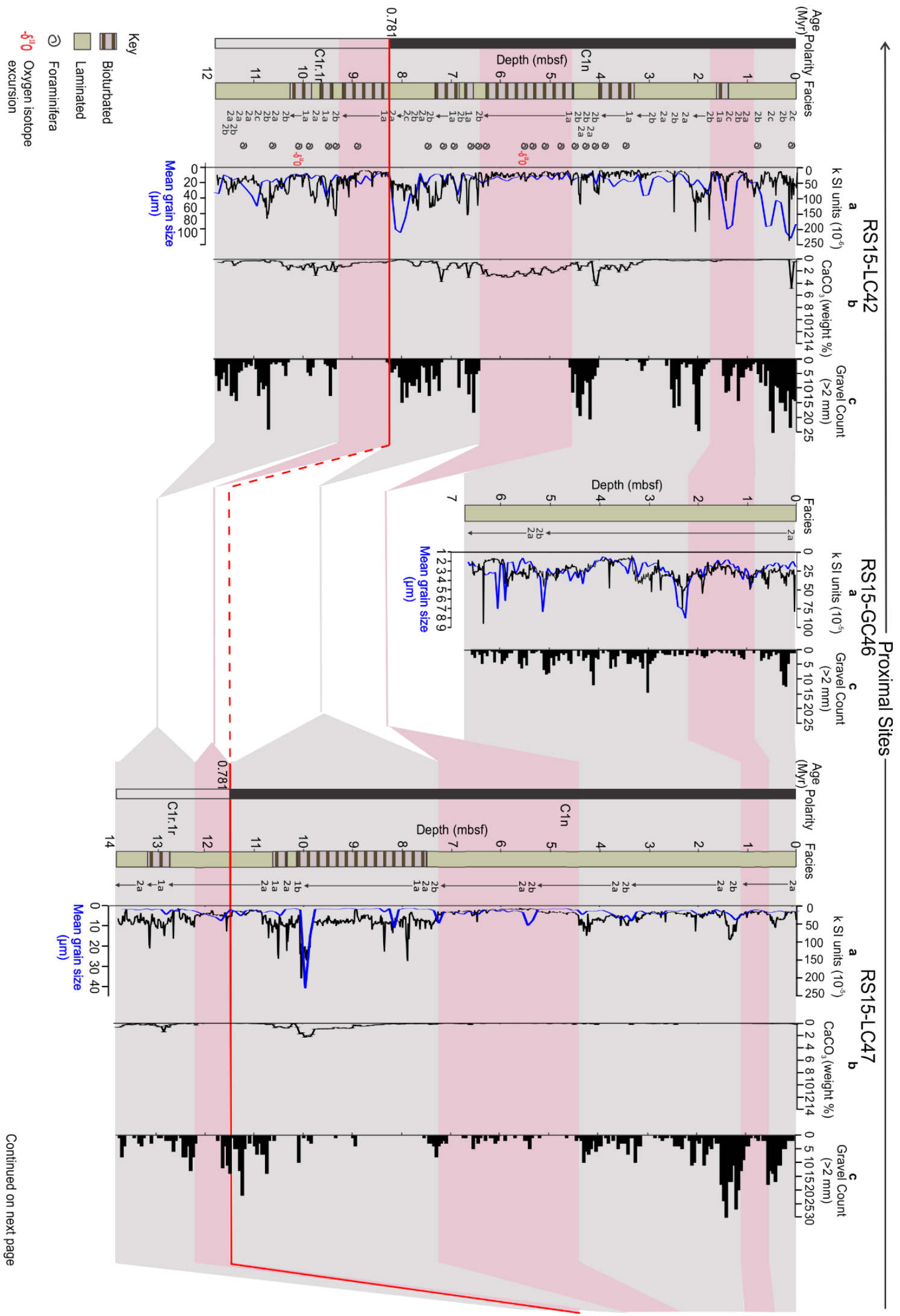




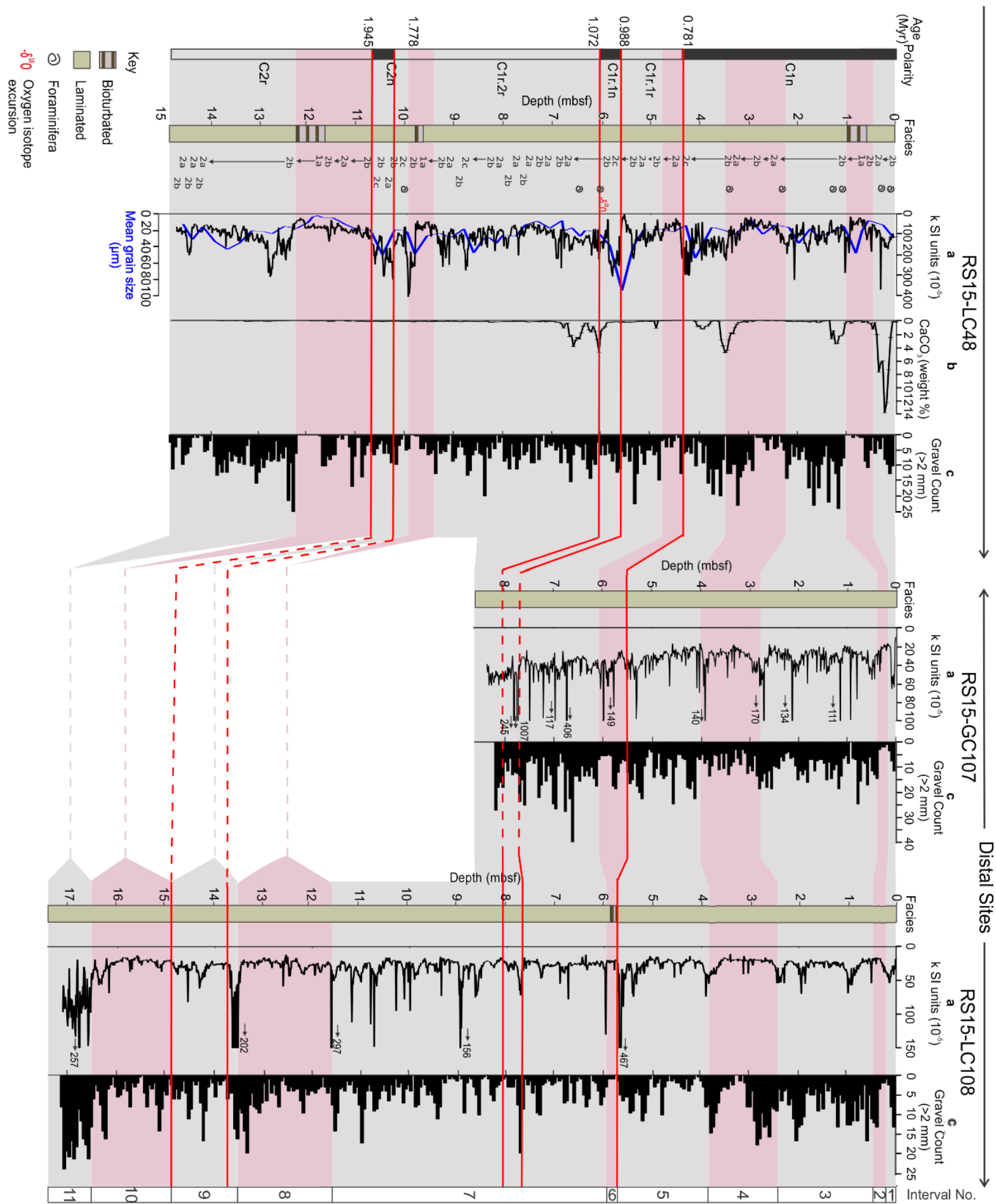

Figure 6.3: Core-to-core correlation of (a) magnetic susceptibility and mean grain size, (b) $\mathrm{CaCO}_{3}$ content, and (c) gravel content of sediments. Also shown are lithofacies and depths of foraminifera preservation (labelled in key). Identified intervals are shaded in pink and grey. Red lines denote paleomagnetic tiepoints. 
a RS15-LC48

Time Period (kyr)
(myr)

(cycles/m) b RS15-LC108

c LR04 $\delta^{18} 0$ stack

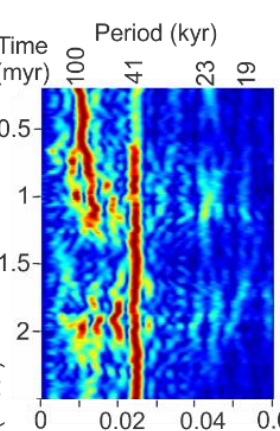

$0.02 \quad 0.04$
0

Frequency
(cycles/kyr)

d LA04 ETP

e PS58/254
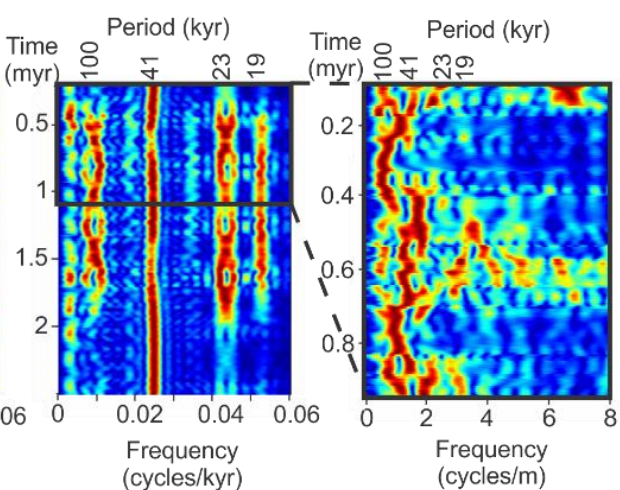

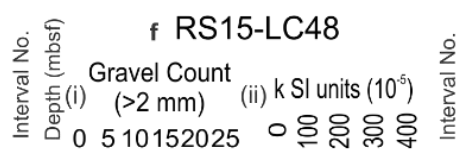

g RS15-LC108

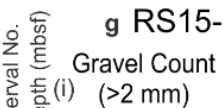

(ii) $\mathrm{kSI}$ units $\left(10^{-5}\right)$

PS58/254

h PS

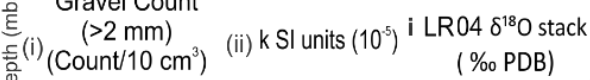
50100150

$\begin{array}{lllllllllllll}0 & 0 & 5 & 10 & 15 & 10 & 30 & 50 & 70 & 5 & 4.54 & 3.5 & 3\end{array} \begin{aligned} & \text { ATS } \\ & \text { (myr) }\end{aligned}$

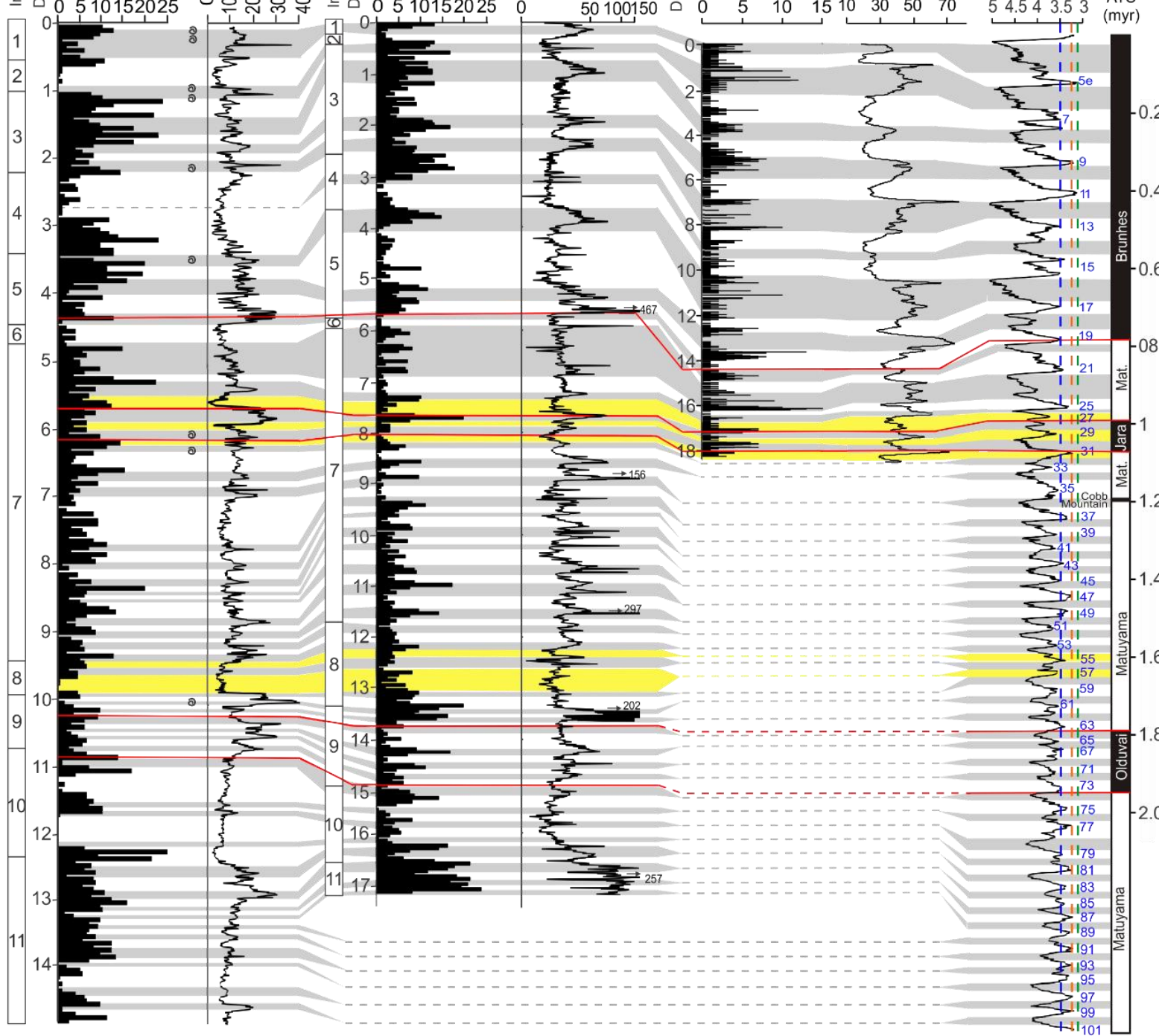

- - - West Antarctica and

as inferred from AND-1B

- Present-day ice volume Fully glaciated
(LGM eqv.) 
Figure 6.4: Spectral analyses and depth-time series developed for cores RS15-LC48 and RS15-LC108 from the Ross Sea, and PS58/254 from the Amundsen Sea (Hillenbrand et al., 2009). EHA amplitude results are presented for (a) RS15-LC48, (b) RS15-LC108, (c) LR04 $\delta^{18} \mathrm{O}$ stack (Lisiecki and Raymo, 2005), (d) the eccentricity-tilt-precession (ETP) solution (Laskar et al., 2004), and (e) PS58/254. The (i) gravel count and (ii) magnetic susceptibility series of cores (f) RS15-LC48 (with the age constrained by the magnetic polarity time series), (g) RS15-LC108 (with the age constrained by the preliminary chronostratigraphic tiepoints) and (h) PS58/254 are correlated with the (i) LR04 $\delta^{18} \mathrm{O}$ stack. Also shown are the established intervals and the Astronomical Time Scale (ATS). Red lines denote paleomagnetic tiepoints.

\subsection{Environmental interpretation of stable isotopes}

Both planktonic and benthic $\delta^{18} \mathrm{O}$ in RS15-LC42 and RS15-LC48 cores show minor fluctuations around baseline values of $4.9 \%$ and $4.4 \%$, respectively, with notable $\sim 0.5 \%$ oxcursions to isotopically lighter values recorded at each site (Figure 6.5). The pattern of $\delta^{18} \mathrm{O}$ variability is therefore not representative of full glacial-interglacial cycles. In the Southern Ocean, glacialinterglacial variability typically displays a saw-tooth profile with an amplitude on the order of $\sim 2 \%$ (e.g., Hodell et al., 2000; 2006; Kanfoush et al., 2016). Thus, the foraminifera preserved in cores RS15-LC42 and RS15-LC48 appear to provide a discontinuous isotopic record.

In determining what part of a glacial-interglacial cycle is represented by the $\delta^{18} \mathrm{O}$, two major factors need to be considered; 1 ) when are foraminifera most likely to be present in waters overlying the cores sites and; 2 ) is there preferential preservation of foraminifera during some parts of the geological record (e.g., glacial vs interglacial).

1) Foraminifera production through glacial-interglacial cycles

Planktonic foraminifera are dependent on photosynthesis-based primary production for survival, which is in turn dependent on the exposure to sunlight (Arrigo et al., 1998). Although, primary production occurs both within and under sea ice (e.g., Dieckmann et al., 1991; Arrigo et al., 1998), the highest productivity occurs in open ocean conditions during the summer and in polynyas (Arrigo and van Dijken, 2004; Thatje et al., 2008). Thus, foraminifera production on the Antarctic continental margin is greatest during interglacial conditions (Thatje et al., 2008). Whilst permanent sea ice cover during glacial periods would have restricted the habitat of planktonic foraminifera, opening of polynyas as a result of upwelling of warm, nutrient-rich deep water would have promoted primary production, vertical mixing and oxygenation in the uppermost part of the water column, and thus re-establishment of a planktonic foraminiferal habitat (Thatje et al, 2008). 
2) Preservation of foraminifera over glacial-interglacial cycles

Interglacial sediments on the Antarctic continental margin are often carbonate-poor even though water column productivity is enhanced during these periods (Grobe and Mackensen, 1992; Bonaccorsi et al., 2007). This is because the high flux of organic matter generated in surface waters during interglacial conditions increases the $\mathrm{CO}_{2}$ content of deep waters through bacterial respiration as sinking organic material is consumed. This in turn reduces $\mathrm{CO}_{3}{ }^{2-}$ concentrations and raises the Carbonate Compensation Depth (CCD; depth below which $\mathrm{CaCO}_{3}$ dissolution exceeds $\mathrm{CaCO} 3$ preservation), thereby reducing carbonate preservation. In contrast, surface productivity is suppressed during glacial periods, causing the CCD to deepen, facilitating deep-sea carbonate accumulation (Grobe and Mackensen, 1992; Bonaccorsi et al., 2007). Furthermore, rapid burial rates due to increased background sedimentation as a result of increased transport of sediment to the shelf edge during glacial maxima, or increased IRD flux due to rapid disintegration of an ice sheet during glacial terminations, may enhance carbonate preservation in bottom sediments (Bonaccorsi et al., 2007).

Thus, preservation of planktonic and benthic foraminifera at the study sites in this thesis is assumed to be indicative of glacial conditions, or represent a deglaciation phase. This is supported by the one-to-one correlation of the IRD and magnetic susceptibility records with the global benthic $\delta^{18} \mathrm{O}$ stack (Figure 6.4). 


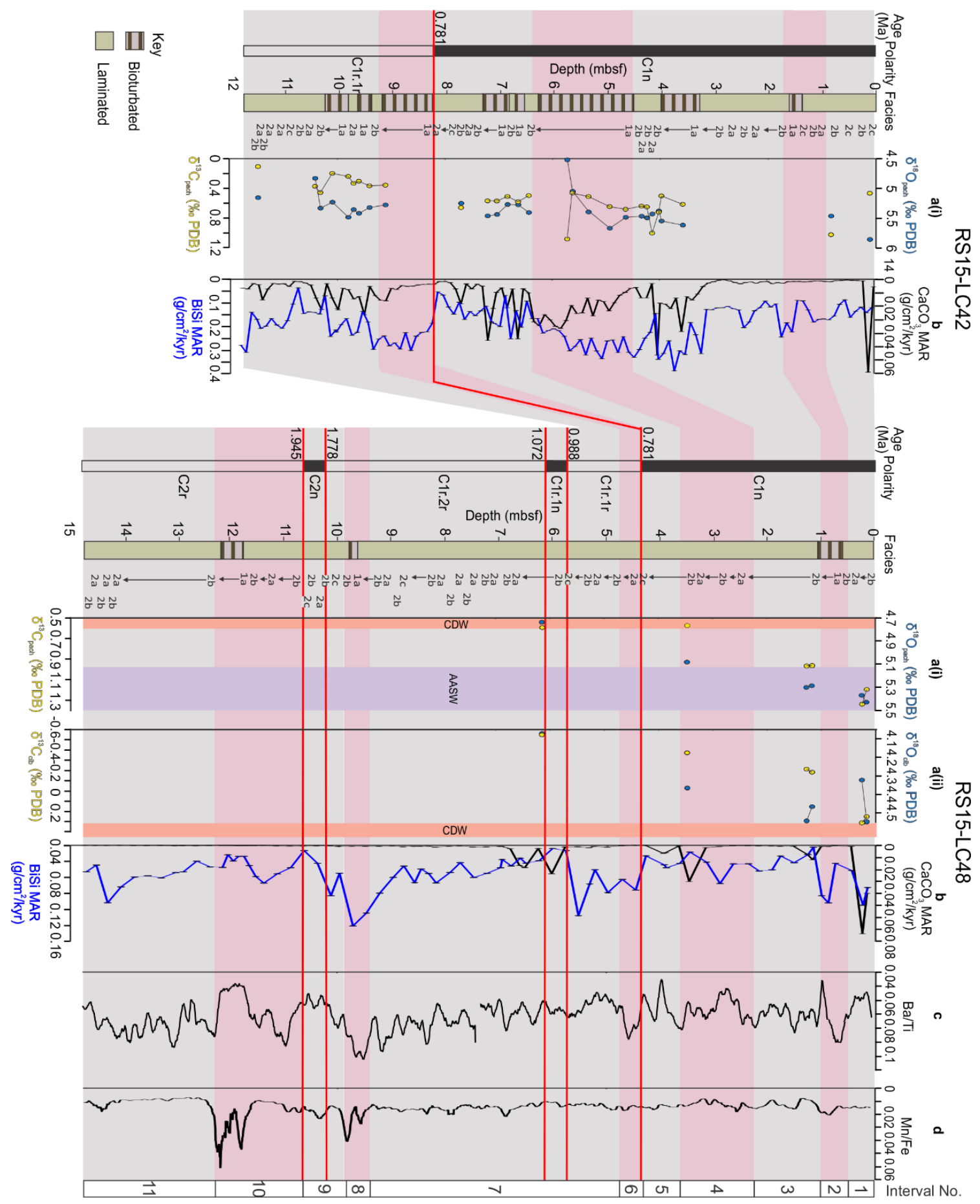

Figure 6.5: Stable isotope results and paleoproductivity proxies for cores RS15-LC42 and RS15LC48. $\delta^{18} \mathrm{O}$ and $\delta^{13} \mathrm{C}$ results are presented for (a(i)) N. Pachyderma (s.) and (a(ii)) Cibicides spp. (b) $\mathrm{CaCO}_{3}$ and BiSi MARs are shown for RS15-LC42 and RS15-LC48, and (c) Ba/Ti and (d) Mn/Fe ratios are also presented for RS15-LC48. Also shown are lithofacies (labelled in key). Identified intervals are shaded in pink and grey. Light red and light blue shading denote stable isotope values representative of CDW and AASW, respectively (Mackensen et al., 2001; 2012; Hodell et al., 2003). Red lines denote paleomagnetic tiepoints. 


\subsubsection{Foraminifera $\delta^{18} \mathrm{O}$ and paleotemperature estimates}

The $\delta^{18} \mathrm{O}$ of foraminifera is dependent on the temperature of calcification and the isotopic composition of the ocean in which they lived (Ravelo and Hillaire-Marcel, 2007). To constrain one variable as an independent measure a justifiable estimate of the other is required. A key aspect of ice sheet stability is ocean temperature (Shepherd et al., 2004; Pollard and DeConto, 2009; Pritchard et al., 2012; also see 2.1.4), and therefore it was deemed worthwhile examining the $\delta^{18} \mathrm{O}$ data from a paleotemperature perspective.

Previous work in the northern North Atlantic Ocean has demonstrated that the $\delta^{18} \mathrm{O}$ of $\mathrm{N}$. Pachyderma (s.) in sediment trap samples track monthly SST changes (Jonkers et al., 2013). Provided the $\delta^{18} \mathrm{O}$ of sea water can be estimated or determined, sea surface paleotemperatures can be calculated using the equation of Shackleton (1974) (modified after Epstein et al., 1953). This equation provides better constraints in the low temperature domain $\left(<10^{\circ} \mathrm{C}\right)$ compared to the original equation proposed by Epstein et al. (1953).

$\mathrm{T}=16.9-4.38\left(\delta_{\mathrm{c}}-\mathrm{A}\right)+0.10\left(\delta_{\mathrm{c}}-\mathrm{A}\right)^{2}$

(Shackleton, 1974)

$A=\delta_{w}-0.27 \%$

Where $T$ represents the temperature $\left(\right.$ in $\left.{ }^{\circ} \mathrm{C}\right), \delta_{c}$ and $\delta_{w}$ represent the isotopic composition in $\delta$ units (i.e., \%o deviation of ${ }^{18} \mathrm{O} /{ }^{16} \mathrm{O}$ ratio vs standard value) of calcite (measured against VPDB) and ambient seawater (measured against VSMOW), respectively. $\delta^{18} \mathrm{O}$ seawater is $-0.31 \%$, the present-day $\delta^{18} \mathrm{O}$ of surface waters in the Ross Sea (Jacobs et al., 1985). $\delta^{18} \mathrm{O}$ of seawater is converted from VSMOW to VPDB by subtracting $0.27 \%$ (Hut, 1987).

The applicability of this paleotemperature equation relies on several assumptions: 1) Foraminifera were not subject to diagenetic alteration (partial dissolution, precipitation of secondary calcite or recrystallization; 2) N. Pachyderma (s.) secrete their tests systematically at $-0.40 \%$ from oxygen isotopic equilibrium; 3) $\delta^{18} \mathrm{O}$ of seawater is a constant value of $-0.31 \%$. The calculated paleotemperatures are listed in Table 6.3.

For Plio-Pleistocene $\delta^{18} \mathrm{O}$ records it is not possible to separate the influence of global ice volume changes from changes in temperature without an independent measure of the temperature component (e.g., from $\mathrm{Mg} / \mathrm{Ca}$ from foraminifera) of foraminiferal $\delta^{18} \mathrm{O}$ (Theissen et al., 2003). Additional influences of local surface water changes in salinity, which display a positive correlation to $\delta^{18} \mathrm{O}$, as well $\mathrm{CO}_{3}{ }^{2-}$ concentrations, whereby increasing the concentration of $\mathrm{CO}_{3}{ }^{2-}$ reduces the $\delta^{18} \mathrm{O}$ of foraminifera shells, make it difficult to assess paleotemperature conditions based entirely 
on stable isotopes, as the influence of the these various factors on N. Pachyderma (s.) in the Ross Sea is unknown (Duplessy et al., 1992; Spero et al., 1997; Ravelo and Hillaire-Marcel, 2007).

Table 6.3: N. Pachyderma (s.) $\delta^{18} \mathrm{O}$ and paleotemperature estimates using the equation of Shackleton (1974).

\begin{tabular}{|c|c|c|c|c|}
\hline \multicolumn{5}{|c|}{ N. Pachyderma (s.) } \\
\hline $\begin{array}{l}\text { RS15-LC2 } \\
\text { Sample }\end{array}$ & $\begin{array}{l}\text { Depth interval } \\
\text { (cm) }\end{array}$ & $\delta^{18} \mathrm{O}_{\mathrm{PDB}}$ & Corrected & $\begin{array}{c}\mathrm{T}^{\circ} \mathrm{C} \\
\text { (Shackleton, 1974) }\end{array}$ \\
\hline $42-1-10-12$ & $10-12$ & 5.452 & 5.852 & -7.13 \\
\hline $42-1-90-92$ & $90-92$ & 5.061 & 5.461 & -5.91 \\
\hline $42-3-110-112$ & $358-360$ & 5.211 & 5.611 & -6.38 \\
\hline $42-3-150-152$ & $398-400$ & 5.143 & 5.543 & -6.17 \\
\hline $42-4-0-2$ & $403-405$ & 4.975 & 5.375 & -5.64 \\
\hline $42-4-10-12$ & $413-415$ & 5.026 & 5.426 & -5.80 \\
\hline $42-4-20-22$ & $423-425$ & 5.091 & 5.491 & -6.00 \\
\hline $42-4-30-32$ & $433-435$ & 5.062 & 5.462 & -5.91 \\
\hline $42-4-60-62$ & $463-465$ & 5.082 & 5.482 & -5.98 \\
\hline $42-4-90-92$ & 493-495 & 5.263 & 5.663 & -6.55 \\
\hline $42-4-130-132$ & $533-535$ & 4.992 & 5.392 & -5.69 \\
\hline $42-5-10-12$ & $563-565$ & 4.647 & 5.047 & -4.58 \\
\hline $42-5-20-22$ & $573-575$ & 4.121 & 4.521 & -2.84 \\
\hline $42-5-90-92$ & $643-645$ & 5.002 & 5.402 & -5.72 \\
\hline $42-5-110-112$ & $663-665$ & 4.872 & 5.272 & -5.31 \\
\hline $42-5-130-132$ & $683-685$ & 4.867 & 5.267 & -5.29 \\
\hline $42-5-150-152$ & 703-705 & 5.033 & 5.433 & -5.82 \\
\hline $42-6-10-12$ & $719-721$ & 5.057 & 5.457 & -5.90 \\
\hline $42-6-60-62$ & $769-771$ & 4.847 & 5.247 & -5.23 \\
\hline $42-7-50-52$ & $909-911$ & 4.874 & 5.274 & -5.31 \\
\hline $42-7-80-82$ & $939-941$ & 4.919 & 5.319 & -5.46 \\
\hline $42-7-100-102$ & $959-961$ & 5.015 & 5.415 & -5.76 \\
\hline $42-7-110-112$ & $969-971$ & 4.952 & 5.352 & -5.56 \\
\hline $42-7-120-122$ & $979-981$ & 5.081 & 5.481 & -5.97 \\
\hline $42-8-10-12$ & $1009-1011$ & 4.827 & 5.227 & -5.16 \\
\hline $42-8-30-32$ & 1029-1031 & 4.929 & 5.329 & -5.49 \\
\hline $42-8-40-42$ & 1039-1041 & 4.430 & 4.830 & -3.87 \\
\hline $42-8-140-142$ & 1139-1141 & & & \\
\hline $42-9-0-2$ & $1146-1148$ & 4.751 & 5.151 & -4.66 \\
\hline \multicolumn{5}{|l|}{ RS15-LC48 } \\
\hline \multicolumn{5}{|l|}{ Sample } \\
\hline $48-1-15-17$ & $15-17$ & 5.028 & 5.428 & -5.81 \\
\hline $48-1-24-25$ & $24-25$ & 4.968 & 5.368 & -5.61 \\
\hline $48-2-26-28$ & $116-118$ & 4.884 & 5.284 & -5.35 \\
\hline $48-2-36-38$ & $126-128$ & 4.898 & 5.298 & -5.39 \\
\hline $48-3-106-108$ & $346-348$ & 4.682 & 5.082 & -4.70 \\
\hline $48-5-58-60$ & $602-604$ & 4.336 & 4.736 & -3.56 \\
\hline
\end{tabular}


The calculated temperature ranges of -7.1 to $-2.8^{\circ} \mathrm{C}$ for core RS15-LC42 and -5.8 to $-3.6^{\circ} \mathrm{C}$ for core RS15-LC48 presented in Table 6.3 are unrealistically low since the coldest ocean waters cannot exceed $\sim-1.8^{\circ} \mathrm{C}$ and the modern (interglacial) Ross Sea varies between -1.8 to $0^{\circ} \mathrm{C}$ (Locarnini et al., 2013). This may be the result of post-depositional alteration of the original $\delta^{18} \mathrm{O}$ as minor dissolution effects are observed under SEM around the primary organic membrane of the chamber walls (see 4.5), which would cause foraminifera to yield artificially heavy $\delta^{18} \mathrm{O}$ values and thus underestimate SST (Edgar et al., 2015). However, well-preserved Holocene N. Pachyderma (s.) from Prydz Bay with $\delta^{18} \mathrm{O}$ ranges of 3.50 to $4.20 \%$ also yield unrealistically low minimum SSTs using a paleotemperature equation of Craig (1965) (Rathburn et al., 1997), while Pleistocene $N$. Pachyderma (s.) from Prydz Bay also show glacial isotopic values up to 5.40\%o (Theissen et al., 2003), which would result in unreasonable SSTs estimates using Shackleton's equation. Given that foraminifera that precipitate their tests in colder waters are isotopically heavier (Jouzel et al., 1994), and the annual SST range of the Ross Sea $\left(-1.8\right.$ to $\left.0^{\circ} \mathrm{C}\right)$ is colder compared to Prydz Bay (1.8 to $1^{\circ} \mathrm{C}$ ) (Locarnini et al., 2013), the corrected $\delta^{18} \mathrm{O}$ values of $N$. Pachyderma (s.) from core sites RS15-LC42 and RS15-LC48 appear reasonable. The most likely explanation for the erroneously low SST estimates resides in the calibration of Shackleton's paleotemperature equation. Shackleton (1974) proposed the $\delta^{18} \mathrm{O}-\mathrm{T}^{\circ} \mathrm{C}$ relationship based on low-temperature (0.8 to $7^{\circ} \mathrm{C}$ ) calibration with benthic Uvigerina spp. Because the paleotemperature equation is not calibrated using temperatures below $0^{\circ} \mathrm{C}$, which are typical SSTs of the Ross Sea, the $\delta^{18} \mathrm{O}-\mathrm{T}^{\circ} \mathrm{C}$ relationship does not hold true for heavy $\delta^{18} \mathrm{O}$ values representative of temperatures below $0^{\circ} \mathrm{C}$. Thus, without independent ice volume measurements, the $\delta^{18} \mathrm{O}$ of $\mathrm{N}$. Pachyderma is not sufficiently constrained to provide accurate estimates of past SSTs. Future work using an organic biomarker proxy, the long chain diol index (LDI; Rampen et al., 2012) established by the extraction of long chain diols from eustigmatophyte algae, will help to constrain SSTs, and thus the magnitude of temperature change between baseline $\delta^{18} \mathrm{O}$ values and excursions to isotopically lighter $\delta^{18} \mathrm{O}$ values.

However, because planktonic and benthic foraminifera from the same core depth record the changes in $\delta^{18} \mathrm{O}$ caused by global ice volume changes equally, the difference between their $\delta^{18} \mathrm{O}$ values can be solely attributed to temperature (Berger et al., 1978). This characteristic has been used to monitor the magnitude and synchronicity of changes between surface and deep water temperatures over time (Theissen et al., 2003). Two intervals between 24.5 and 16 cmbsf ( 45$27 \mathrm{ka}$; interpolated ages constrained by magnetostratigraphy) and 117 and $127 \mathrm{cmbsf}$ ( 227-208 ka) in core RS15-LC48 show uniform changes between planktonic and benthic $\delta^{18} \mathrm{O}$ values. The difference of the offset-corrected $\delta^{18} \mathrm{O}$ (see 5.5 ) values ranges between 0.24 and $0.41 \%$ for the 
interval between $16-24.5 \mathrm{cmbsf}$ and between 0.18 and $0.12 \%$ for the interval between $117-127$ cmbsf. Using the temperature-oxygen isotope relationship of $0.23 \% \circ /{ }^{\circ} \mathrm{C}$ established by Chappell and Shackleton (1986), these differences indicate $0.8^{\circ} \mathrm{C}$ and $0.3^{\circ} \mathrm{C}$ temperature change between surface and deep waters from 16-24.5 and 117-127 cmbsf, respectively. The uniform changes between planktonic and benthic $\delta^{18} \mathrm{O}$ values suggests synchronous changes in surface and deep water temperatures during the two recorded periods of the Pleistocene, with up to $0.8^{\circ} \mathrm{C}$ temperature change between surface and deep water masses.

\subsubsection{Foraminifera $\delta^{13} \mathrm{C}$ and paleoproductivity proxies}

Foraminifera $\delta^{13} \mathrm{C}$ records reflect changes in the isotopic composition of dissolved inorganic carbon (DIC) in surface and deep waters, which are influenced by water mass circulation, primary production, air-sea gas exchange, as well as species specific vital effects and $\mathrm{CO}_{3}{ }^{2-}$ concentration effects (Broecker et al., 1982; Charles and Fairbanks, 1990). $\delta^{13} \mathrm{C}$ signatures of $N$. Pachyderma (s.) provide an integrated depth signal for their depth habitat $(0-200 \mathrm{~m})$, which is strongly impacted by surface and intermediate water mass characteristics, biological productivity and air-sea gas exchange (Carstens and Wefer, 1992; Bauch et al., 1997). $\delta^{13} \mathrm{C}$ signatures of Cibicides spp. have been interpreted to reflect a signal of individual deep water masses (e.g., NADW) (McCorkle and Keigwin, 1994; Eichler et al., 2007). However, the dominant control on foraminifera $\delta^{13} \mathrm{C}$ is the effect on $\delta^{13} \mathrm{C}$ of the DIC pool resulting from changes in biological productivity (Bostock and Neil, 2015). Phytoplankton production in surface waters preferentially removes the lighter ${ }^{12} \mathrm{C}$ isotope, thus enriching the surface water DIC in ${ }^{13} \mathrm{C}$. The ${ }^{12} \mathrm{C}$-enhanced organic carbon is remineralised via bacterial respiration as it sinks through the water column, enriching the intermediate and deep waters in ${ }^{12} \mathrm{C}$ and creating a negative $\delta^{13} \mathrm{C}$ gradient between surface and deep waters (Bostock and Neil, 2015).

Positive excursions in planktonic $\delta^{13} \mathrm{C}$ values in RS15-LC42, the most proximal site to the continental shelf, correspond with the highest BiSi MARs (Figure 6.5), and are therefore interpreted to be productivity-induced. In contrast, planktonic $\delta^{13} \mathrm{C}$ values in RS15-LC48, the more distal site on the lower continental rise, correspond to relatively low BiSi MARs (Figure 6.5). In addition, the barium/titanium (Ba/Ti) elemental ratio, a proxy for paleoproductivity in Antarctic continental margin sediments (Bonn et al., 1998), falls well below 0.1 for the majority of the record (Figure 6.5). Such values are indicative of low productivity, as modern day Ba/Ti within the Ross Sea polynya is 1.5 (McManus et al., 2002), with the caveat that the provenance of lithogenic sediment is assumed to be the same at site RS15-LC48 as in the Ross Sea polynya. Evidence for 
low primary production at site RS15-LC48, suggests that surface biological productivity may not have been a dominant control, and $\delta^{13} \mathrm{C}$ planktonic values may thus reflect changes in water mass characteristics and/or sea ice cover.

Previous work has shown that sea ice cover leads to reduced planktonic $\delta^{13} \mathrm{C}$ by restricting air-sea gas exchange (Charles and Fairbanks, 1990; Mackensen, 2012). The ocean surface water $\delta^{13} \mathrm{C}$ is influenced by temperature dependent fractionation of ${ }^{12} \mathrm{C} /{ }^{13} \mathrm{C}$ during the exchange of atmospheric $\mathrm{CO}_{2}$ with surface water DIC, whereby $\delta^{13} \mathrm{C}$ of surface waters increases by $0.1 \%$ per degree of cooling (Mook et al., 1974). Gas exchange rates are also facilitated by wind-driven mixing with stronger winds enhancing the ${ }^{13} \mathrm{C}$ of seawater (Charles and Fairbanks, 1990). However, the lightest planktonic $\delta^{13} \mathrm{C}$ values in RS15-LC48 also occur alongside the lightest $\delta^{18} \mathrm{O}$ values, which are indicative of warmer SSTs, and hence reduced sea ice cover. Assuming foraminifera resided in lower productivity waters (e.g., open waters during a deglaciation phase), rather than in high productivity waters of a glacial polynya, it is possible that the planktonic $\delta^{13} \mathrm{C}$ reflect changes in water mass characteristics, where $\delta^{13} \mathrm{C}$ values between $0.4-0.6 \%$ ond $1-4.3 \%$ o are representative of CDW and AASW inflows, respectively (Mackensen et al., 2012). Meanwhile, benthic $\delta^{13} C$ values between 0.3-0.6\% are thought to reflect CDW (Mackensen et al., 2001; Hodell et al., 2003), and negative benthic $\delta^{13} \mathrm{C}$ excursions are interpreted to represent poorly ventilated bottom waters (e.g., enhanced surface water stratification, reduced vertical mixing across the thermocline; Hodell and Venz-Curtis, 2006).

\subsection{Depositional patterns and associated climate changes during the Quaternary}

\subsubsection{Pre-Mid Pleistocene Transition (2.5-1.2 Ma)}

The Early Pleistocene is recovered in cores RS15-LC48 and RS15-LC108 and characterised by lower-amplitude, higher frequency IRD flux dominated by obliquity and eccentricity forcing, alongside non-linear spectral interactions of 30 and 70 kyr cycles (Figure 6.4). While Naish et al. (2009) inferred obliquity-paced Late Pliocene WAIS oscillations from the AND-1B record, the highly discontinuous nature of that core in the Early Pleistocene $(<2.5 \mathrm{Ma})$ made this interpretation equivocal during this time. Conversely, Patterson et al. (2014) describe a variance in the eccentricity and precession bands between 3.5 and $2.5 \mathrm{Ma}$, with minimal influence of obliquity, which they infer to reflect a threshold response of Southern Ocean sea ice to reduced summer duration (i.e., melt season) under a colder climate regime, which acted to restrict upwelling of warmer masses that are thought to influence marine ice sheet collapse events. A reduction in the duration of summer biases the melt season toward peak summer insolation 
(which is precession-modulated) rather than mean annual insolation (which is obliquity dominated) (Huybers, 2006). Patterson et al. (2014) also noted a reappearance of obliquity variance, occurring alongside eccentricity and precession, between 2.5 and $2.0 \mathrm{Ma}$, which is consistent with the variance of IRD for RS15-LC48 and RS15-LC108 in this study.

The persistent, relatively lower amplitude IRD flux throughout the Early Pleistocene appears to reflect a relatively linear response of marine-based ice sheets to orbital pacing compared to later times, with the orbital solution (LA04 ETP) showing high power in eccentricity, obliquity and precession between 1.8 and $0.8 \mathrm{Ma}$ (Figure 6.4d).

Anomalous laminated intervals in RS15-LC48 occur between 1185-1215 and 960-985 cmbsf, where there is a sustained lull in IRD deposition and lows in magnetic susceptibility. This is mirrored by similar intervals of reduced IRD in RS15-LC108 between 1520-1540 cmbsf and 1290$1310 \mathrm{mbsf}$, respectively, indicating it is not related to site specific processes. With caveat that the one-to-one correlations presented in Figure 6.4 are not unique solutions, the preferred correlation based on the assumption of relatively linear sedimentation rate is that the older IRDpoor interval occurred during MIS 82-78. This period is characterised by two of the strongest glacial cycles occurring prior to the Olduvai Subchron (>1.945 Ma) in the benthic $\delta^{18} \mathrm{O}$ stack, and appears to immediately precede the increase in variance in all orbital bands.

The laminated interval between $1185-1215$ cmbsf in RS-15 LC48 is associated with reduced Ba/Ti ratios, and the biggest $\mathrm{Mn} / \mathrm{Fe}$ excursion of the record (Figure 6.5). Enrichments in $\mathrm{Mn}$ are commonly explained by redox fronts during which there is a shift from oxic (well ventilated) to suboxic (poorly ventilated) environments, which could result from changing bottom water conditions (Marsh et al., 2007). Mn/Fe excursions are therefore interpreted to represent periods of poorly ventilated water bathing the site, which may explain the lack of bioturbation in this interval. This interval is also clay rich (up to $60 \%$ ), but contains sand laminae that exhibit scour features at their base, while the top of the underlying unit has a clear gravel lag surface (see 5.1.4). This indicates deposition under periods of erosive, high-energy bottom currents (Howe et al., 2001). The presence of pervasive cross-cutting reverse faults may represent a compressional zone at the toe of a slump, which would be expected during a phase of sediment remobilization by contour currents. The lack of coarse clasts and IRD argues against a large-scale mass flow event which would rework pre-existing IRD rich sediment that is otherwise pervasive in this core (Figure 5.13). This interval appears to correspond to the coldest glacials of the Early Pleistocene, and it is inferred that enhanced sea ice cover over the core site is likely responsible for the reduction of 
biological activity and reduced ventilation of bottom waters. Fringing ice shelves at the continental shelf edge may have resulted in the calving of debris-free icebergs (as is the case with the modern RIS).

A thinner laminated interval between $960-985 \mathrm{cmbsf}$ also lacks IRD and shows a similar Mn/Fe peak indicating a shift in redox conditions. However, it is characterised by enhanced $\mathrm{Ba} / \mathrm{Ti}$ ratios and high biogenic opal, implying higher surface water productivity, lacks faulting, and contains vertical burrows, indicating the presence of lower-energy, non-erosive bottom currents and slightly more ventilated water masses (Figures 6.5 and 5.25). It is unclear if this laminated interval represents interglacial or glacial conditions, and further proxies (diatom assemblages, SSTs estimates) are required to determine this.

\subsubsection{The Mid-Pleistocene Transition (1.2-0.8 Ma)}

In the Ross Sea, the MPT is characterised by high frequency, low amplitude IRD peaks operating at several orbital frequencies (Figure 6.4). As with the Early Pleistocene, the IRD records from both, the Ross and Amundsen Seas, continue to show the non-linear spectral interaction (70 and $30 \mathrm{kyr}$ cylces) alongside eccentricity, obliquity and precession cycles that began after $1.8 \mathrm{Ma}$. This is also evident in the LRO4 benthic $\delta^{18} \mathrm{O}$ stack (Figure 6.4). Globally, the MPT corresponds to a major climate transition in benthic $\delta^{18} \mathrm{O}$ records from $\sim 41 \mathrm{kyr}$ symmetric pacing of glacialinterglacial cycles to higher amplitude, asymmetric $\sim 100 \mathrm{kyr}$ glacial-interglacial cycles with increased ice volume variations (Mudelsee and Schulz, 1997; Lisiecki and Raymo, 2005). This shift is thought to have occurred in the absence of a substantial change in orbital forcing. Although, the climate system mechanisms responsible for the change in the AIS response to orbital variations remain uncertain, several hypotheses have been proposed, including non-linear ice sheet dynamics (Clark and Pisias, 2000; Elderfield et al., 2012), cooling of the deep ocean and rapid variations in sea ice cover (Gildor and Tziperman, 2003), and large-scale changes in the thermohaline circulation (Pena and Goldstein, 2014).

The MPT is characterised by bioturbated facies in the deeper water sites RS15-LC48, RS15-GC107 and RS15-LC108, and by predominantly laminated facies in the more proximal sites RS15-LC42 and RS15-LC47. Lack of bioturbation at the proximal sites could be attributed to an enhanced extent and duration of sea ice cover restricting productivity and ventilation, which would result in less oxygenated bottom waters feeding the sites. Alternatively, these depositional patterns could be the consequence of increased sediment supply to the proximal sites resulting from enhanced production of bottom water cascading downslope during this period of cooling (Hall et 
al., 2001). An assessment of diatom and radiolarian assemblages in these cores would help to distil which of these processes may have occurred. The increase in carbonate preservation at sites RS15-LC42 and RS15-LC48 is tentatively attributed to enhanced ice sheet expansion on the continental shelf, as foraminifera are noted to be better preserved during the Last Glacial Maximum and last termination than during the peak of the Holocene interglacial (Bonaccorsi et al., 2007; Weber et al., 2011; also see 6.3).

Foraminifera are preserved at the base of the Jaramillo Subchron (1.072 Ma) in RS15-LC48 and are characterised by excursions to isotopically light $\delta^{18} \mathrm{O}$ values indicating warmer conditions, planktonic $\delta^{13} \mathrm{C}$ values typical of $\mathrm{CDW}$, and negative benthic $\delta^{13} \mathrm{C}$ excursions suggesting diminished ventilation of bottom waters. Planktonic foraminifera prior to the Brunhes-Matuyama Subchron (0.781 Ma) in RS15-LC42 are characterised by relatively stable values of $\delta^{18} \mathrm{O}$ and $\delta^{13} \mathrm{C}$, with one excursion to isotopically light $\delta^{18} \mathrm{O}$ values. These excursions may represent transient melting events occurring during a phase of enhanced upwelling of CDW. In core LC48, the values consistent with CDW at 1.072 Ma coincide with MIS 31, a warm interglacial during which the WAIS is suspected to have collapsed (Scherer et al., 2008; McKay et al., 2012b). However, the IRD records from the Ross and Amundsen Seas do not exhibit a significantly higher influx than at any other stage of the Early Pleistocene, suggesting that while IRD fluxes are identifying glacial to interglacial cycles, they may not be a reliable indicator of the relative volume of ice sheet loss or growth across the MPT.

\subsubsection{The Late Pleistocene (0.8-0.01 Ma)}

The Ross Sea IRD records throughout the Late Pleistocene are characterised by higher amplitude, lower frequency fluctuations, matching the observed trends in the Amundsen Sea record (Figure 6.4; Hillenbrand et al, 2009), that appear to respond to eccentricity forcing that becomes dominant between 600-400 ka. At sites RS15-LC42 and RS15-LC47, the pre-400 kyr record is characterised by laminated intervals completely devoid of (or very minimal) IRD. The IRD records in the Ross Sea can be explained by a cooler, more ice-influenced setting, where proximal sites had reduced bioturbation resulting from reduced bottom water oxygenation. McKay et al. (2012b) infer a cooling of the glacial regime in the Ross Embayment at $\sim 800 \mathrm{ka}$, and highlight that while there is evidence of ice sheet grounding migration for each of the past 8 glacial cycles, the cycles between $\sim 800-400$ ka were dominated by subglacial or grounding line proximal sediment. Reduced bioturbation could therefore be a result of enhanced sea ice cover, or greater ice sheet cover on the Ross Sea continental shelf. The latter would act to reduce the formation of well- 
ventilated (i.e., polynya-mixed) high-salinity shelf water of the continental shelf, as a polynya system would be greatly reduced in size. Restricted IRD deposition at these proximal sites may result from floating ice shelves at the mouth of Joides Trough, and thus calving of relatively clean, debris-free ice.

However, the laminated packages in RS15-LC42 and RS15-L47 also show current-induced scour features and pervasive faulting, pointing to episodic action of high energy bottom currents (Figures 5.3 and 5.9). Overall, carbonate preservation is highest between $~ 800-400$ kyr (Figures 6.5). Given the colder global climate regime of the Late Pleistocene, it is possible that the proximal sites were subject to increased extent and duration of sea ice cover. However, preservation of foraminifera indicates at least episodic opening of a polynya system during glacial periods (Thatje et al., 2008; also see 6.3). Intuitively, the expansion of a grounded ice sheet must result in a shift of the formation regions of AABW. At the LGM, it has been inferred that polynya systems developed at the ice sheet margin near the continental shelf edge in the Amundsen (Lu et al., 2016) and Weddell Seas (Weber et al., 2011; Sprenk et al., 2014). The evidence of productivity and current-induced structures noted above in RS15-LC42 during glacial conditions suggests this was also likely the case in the Ross Sea.

McKay et al. (2012b) infer a shift towards more extensive ice shelf development (i.e., grounding line distal deposits) occurring in the interglacials after $400 \mathrm{kyr}$, suggesting smaller ice sheets characterised the interglacials after $400 \mathrm{ka}$, which is consistent with the noted increase in the amplitude of interglacial periods after $400 \mathrm{kyr}$ (Jouzel et al., 2007). For glacial periods, it is inferred that the marine margins of the EAIS in Prydz Bay were less extensive during the last $400 \mathrm{kyr}$, whereby the glacial advances did not reach the continental shelf (Domack et al., 1999; O'Brien et al., 2007). Thus, it is suggested that increased bioturbation following $\sim 400 \mathrm{kyr}$ at sites RS15-LC42 and RS15-LC47 may be indicative of less extensive grounded ice on the Ross Sea continental shelf allowing the formation of well-ventilated water masses. However, to test this hypothesis, a direct drill core record is required from the outer continental shelf.

Hillenbrand et al. (2009) noted a depositional anomaly in the Amundsen Sea during MIS 15-MIS 13 , which they attribute to relatively warm conditions on the West Antarctic continental margin during the muted glacial MIS 14. Hillenbrand et al. (2009) hypothesised that even though there is no direct evidence for a collapse event, it was the duration, rather than the strength, of interglacial conditions that was the critical factor for disintegration of the WAIS. This depositional anomaly is also noted in the Ross Sea, with a notable prolonged low in magnetic susceptibility 
apparent in all sites during interval 4, which appears to correspond to MIS 15-MIS 13 (Figures 6.3 and 6.4). However, it remains enigmatic if this was indeed a prolonged interglacial as a lack of bioturbation at the ice proximal site RS15-LC42 suggests an oxygen starved environment. Thus, it may be that this proximal site is actually experiencing enhanced sediment delivery due to an increased bottom current cascading downslope through Joides Trough resulting from enhanced dense water formation on the continental shelf. The reduced IRD influx at RS15-LC42 and RS15LC47, could therefore be a consequence of rapid sediment emplacement. An increase in sediment flux is supported by the core-to-core correlations to the deeper water sites (RS15-LC48, RS15LC107, RS15-LC108), whereby core RS15-LC42 appears to have greater variation in sedimentation rates (Figure 6.3). There is some evidence in support of warmer than usual conditions at this time with isotopically lighter planktonic $\delta^{18} \mathrm{O}$ and $\delta^{13} \mathrm{C}$ values, indicative of warmer SSTs/reduced ice volume and upwelling of CDW, respectively, and consistently high BiSi MARs at RS15-LC42 suggesting increased biological productivity of surface waters (Figure 6.5). However, more proxy data such as independent estimates of SSTs using organic biomarkers (e.g., LDI and TEX ${ }_{86}$ ) is required to further test this hypothesis.

Similarly, laminated and IRD-poor packages are observed in RS15-LC42 and RS15-LC48 in interval 2 (Figure 6.3), and are tentatively correlated to MIS 5 (Figure 6.4). These sediments are characterised by increases in BiSi MARs, and significantly increased $\mathrm{Ba} / \mathrm{Ti}$ ratios and a small excursion in Mn/Fe ratios in RS15-LC48, as observed between 960-985 cmbsf (Figure 6.5). The occurrence of gravel lags at both sites (Figures 5.3 and 5.13) points to the presence of high energy bottom currents, and thus enhanced dense water formation and sediment delivery through Joides and Drygalski Troughs on the continental shelf to the core sites. A shift to slightly less ventilated bottom waters may be a result of increased meltwater contributing to stratification of the uppermost part of the water column (Smith et al., 2012a; 2012b). Future work with the LDI SST proxy and diatom/radiolarian assemblages will add to the understanding of sea surface conditions during this period.

\subsection{Future work to resolve sedimentation models}

It is clear from the sediment texture and structures, and facies assemblages that most of the deposits in this study have formed primarily under the influence of bottom currents, most likely from changing dense AABW formation (i.e., downslope) through glacial-interglacial cycles, although geostrophic (i.e., alongslope) currents are also likely to have had an influence (Figure 6.6). However, the sedimentary patterns described above could have multiple (and contradictory) 
interpretations. Pleistocene contourite sequences from the proximal western Ross Sea reveal that facies appear to have lasted for extended glacial-interglacial periods. Laminated facies alongside reduced IRD flux and reduced productivity are interpreted to represent enhanced ice sheet and sea ice conditions during glacial conditions, while laminated facies alongside reduced IRD flux and increased productivity are inferred to represent reduction of ice shelf and sea ice cover resulting in enhanced AABW formation and sediment delivery. In general, it is interpreted that bioturbated facies in combination with enhanced productivity are common during interglacial conditions, with peaks in IRD associated with ice sheet retreat events. IRD fluxes appear to be clearly identifying the orbital pacing of glacial-interglacial cycles, but are equivocal in identifying the relative magnitude of ice sheet loss or growth through glacial-interglacial cycles.

Despite these uncertainties, clear sedimentary patterns in the facies and IRD records can be identified in a proximal continental rise to abyssal transect of cores in the Ross Sea, which are interpreted to represent broad changes in deposition relating to ice sheet and oceanic processes, rather than site specific processes. To test the hypotheses outlined above, additional proxies such as continuous estimates of SSTs using the LDI organic biomarker proxy, and surface water stratification/mixing from diatom and radiolarian census counts are required. 
b) Glacial

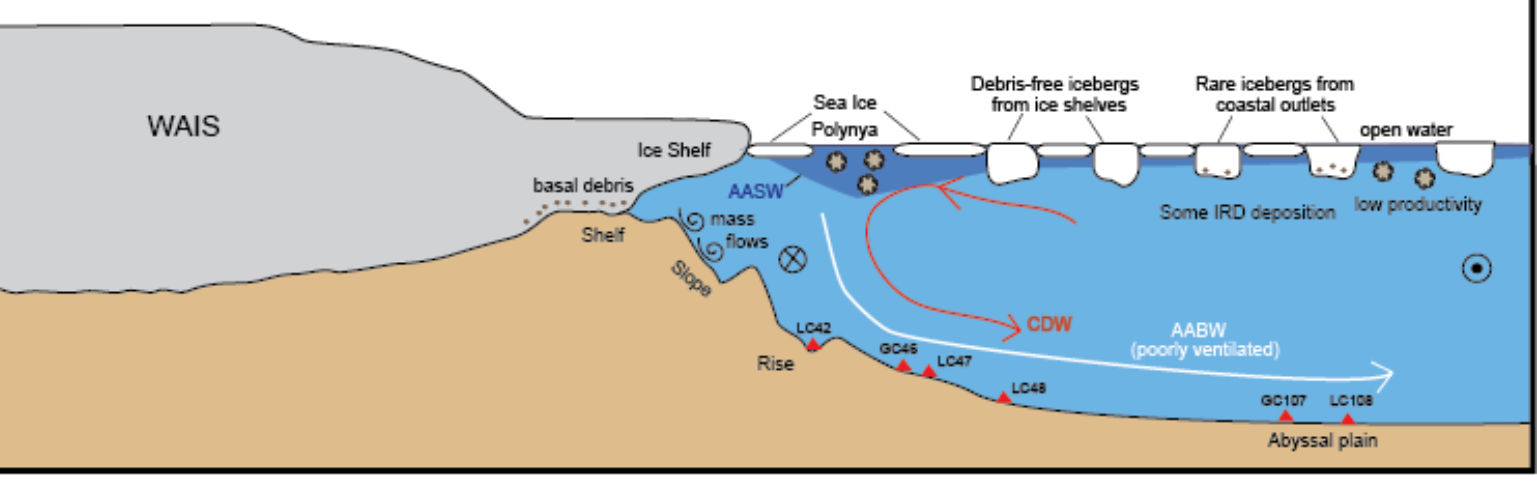

a) Interglacial

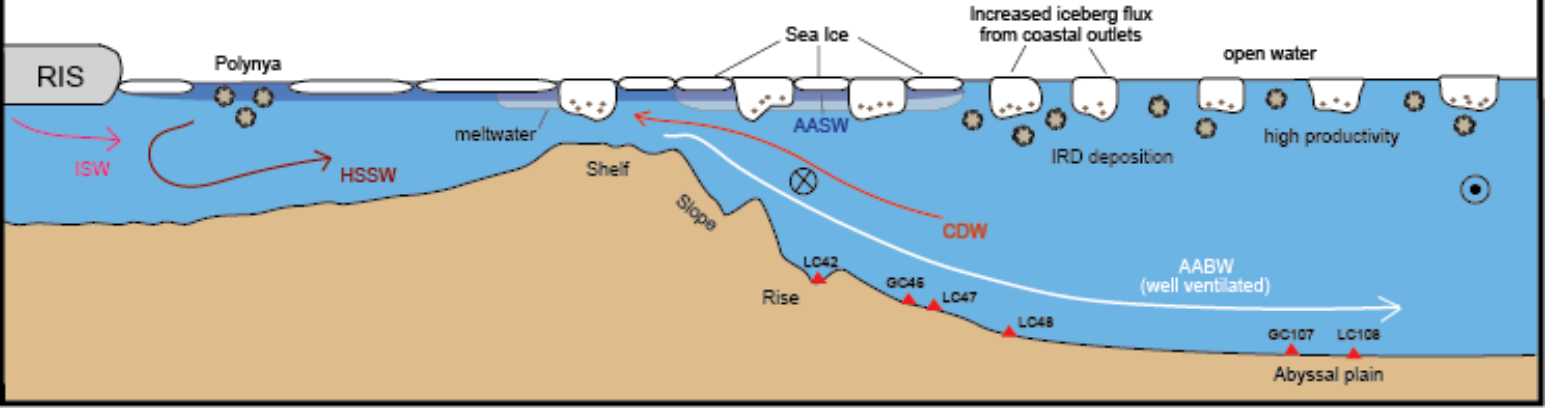

Figure 6.6: Schematic diagram illustrating the interpreted (a) interglacial and (b) glacial climate stages influence on sedimentation at core sites RS15-LC42, RS15-GC46, RS15-LC47, RS15-LC48, RS15-GC107 and RS15-LC108. The Antarctic Coastal Current is denoted by a circle with a black cross with the flow direction into the diagram, and the ACC is represented by a circle with a black dot with the flow direction coming out of the diagram. 


\section{CHAPTER 7: CONCLUSIONS AND FUTURE WORK}

\subsection{Conclusions}

This study examined the glacimarine sedimentary processes operating on the continental margin of the western Ross Sea through glacial-interglacial cycles of the Pleistocene ( $2.5 \mathrm{Ma}$ ). This was achieved through analysis of six sedimentary cores retrieved from the continental rise and abyssal plain. The main findings of this work are summarised below:

- An assessment of the IRD content was undertaken using the following three methodologies: 1) sieved (>250 $\mu \mathrm{m}-2 \mathrm{~mm}$ ) weight percentage, 2) LPSA volume estimates of the >125 $\mu \mathrm{m}$ fraction; and 3) visual counts of clasts exceeding $2 \mathrm{~mm}$ in size identified in $\mathrm{x}$-ray images. The sieve analysis and $\mathrm{x}$-ray clast counts show a moderate-to-strong correspondence, while LPSA analysis and $\mathrm{x}$-ray clast counts display only a weak correspondence. Comparison of the sieve and LPSA IRD data down core reveals a very weak relationship in core RS15-LC48, which has a consistently high IRD content throughout, and a moderate relationship in core RS15-LC42, which has thick packages of IRD-free sediment. The weak correlation between IRD content determined by LPSA and other methods suggests this method is both, less precise and less accurate with respect to measuring the volume of medium (and coarser) sand. The primary reason for this is the very small sample size ( $0.15 \mathrm{~g})$ used for the LPSA. The small sample size is required for correct obscuration of the laser. However, a consequence of the small sample size is that the coarse 'tail' of the grain size distribution of a poorly sorted sandy mud is represented by only relatively few grains, leading to lack of precision and accuracy. Using a lower grain size limit (rather than $125 \mu \mathrm{m}$ ) may improve the signal to noise ratio in LPSA data, but at the risk of including sediment deposited by non-IRD processes. Thus, IRD determination by sieve analysis is considered a less noisy representation of the IRD component than the LPSA >125 $\mu$ m method.

- Assessment of grain size parameters in combination with sedimentary structures also indicates that caution should be exercised when using a single method (e.g., sorting) to assess the influence of deep-water seabed erosion on continental margin sedimentary sequences (e.g., the relative influence of IRD flux and background sedimentation).

- The cores all contain contourite sequences that are largely consistent with previous studies from around the Antarctic margin and globally. They consist of two dominant lithofacies (laminated and bioturbated muds), but alternations between these facies 
generally occur on timescales longer than individual glacial-interglacial cycles (i.e., >100 kyr). Although, there are some site-specific considerations, the north-to-south transect of cores from the continental rise to the abyssal plain of the Ross Sea shows systematic changes in sedimentary facies, magnetic susceptibility and IRD records over time, which are interpreted to represent large scale changes in deposition relating to ice sheet and oceanic processes in the Ross Sea.

- Laminated facies containing little IRD alongside reduced productivity are interpreted to represent more extensive ice sheet, ice shelf and sea ice conditions during glacial periods. Laminated sediments with little IRD but increased productivity are associated with warmer SSTs and reduced ice volume implied by $\delta^{18} \mathrm{O}$ data. These sediments are inferred to represent a reduction of ice shelf and sea ice cover resulting in enhanced AABW formation and sediment delivery. In general, bioturbated facies in combination with enhanced productivity are common during interglacial conditions, with peaks in IRD probably associated with ice sheet retreat events during glacial terminations. IRD fluxes appear to be clearly identifying the orbital pacing of glacial-interglacial cycles, but are equivocal in identifying the relative magnitude of ice sheet loss or growth through glacialinterglacial cycles.

- The occurrence of foraminifera is discontinuous in both RS15-LC42 and RS15-LC48, and ranges from common to abundant where present. The sole planktonic species recovered, N. pachyderma (s.), is much more abundant than the most common benthic foraminifera Cibicides spp., and consequently form a more continuous time series. Foraminifera preservation is interpreted to be greatest during glacial maxima, within high productivity waters of a polynya, or during a deglaciation phase when carbonate preservation on the sea floor was enhanced due to rapid burial rates (Bonaccorsi et al., 2007; Thatje et al., 2008).

- Time series spectral analysis of the magnetic susceptibility (a proxy for mean grain size variation) and IRD data series of cores RS15-LC42, RS15-LC47, RS15-LC48, RS15-GC107 and RS15-LC108 reveals frequencies that correspond with the orbital signals of precession, obliquity and eccentricity, although not all periodicities of the orbital parameters are present. The ASM results of RS15-GC107 and RS15-LC108 are consistent with the preliminary age models, providing confidence in the established chronostratigraphic tiepoints in these cores. Thus, the depositional environments, although relatively sediment starved, are characterised by sedimentation rates adequate for orbital signal detection. 
- Spectral analysis reveals three clear shifts in the pattern of sedimentation on the western Ross Sea continental margin.

- The Early Pleistocene (2.5-1.2 Ma) is characterised by lower-amplitude, higher frequency IRD flux dominated by both obliquity and eccentricity forcing, consistent with the results of Patterson et al. (2014) who also noted an appearance of obliquity variance occurring alongside eccentricity and precession between 2.5 and 2.0 Ma for a sediment record offshore Wilkes Land.

- The Mid-Pleistocene Transition (1.2-0.8 Ma) is characterised by IRD records that show increased non-linear spectral interaction (70 and 30 kyr cycles) occurring alongside eccentricity, obliquity and precession periodicity that begins after $\sim 1.8$ $\mathrm{Ma}$ and lasts until $0.8 \mathrm{Ma}$. This corresponds to a long maxima in eccentricity, obliquity and precession in the orbital solutions, suggesting that iceberg calving events from marine ice sheets in the Ross Sea were forced in a relatively linear manner by changes in Earth's orbital configuration.

- The IRD records throughout the Late Pleistocene show higher amplitude, lower frequency fluctuations, consistent with the observed trends in the Amundsen Sea record (Hillenbrand et al, 2009). This change is likely in response to eccentricity forcing that becomes dominant between 600-400 ka. Sites proximal to the continental shelf are characterised by laminated facies suggesting greater ice cover at this time. Higher amplitude IRD variance and bioturbated facies are more pronounced during the Late Pleistocene suggesting there was reduced ice cover during the interglacials of the past $400 \mathrm{kyr}$, which is consistent with a previous interpretation from the AND-1B drillcore on the Ross Sea continental shelf (McKay et al., 2012b)

\subsection{Future work}

Future work is currently being undertaken by other research teams and will focus on refining the preliminary age models presented in this thesis using biostratigraphy and paleomagnetic analysis for cores RS15-GC46, RS15-GC107 and RS15-LC108. The depositional models presented can be tested by lipid biomarker analysis (including LDI and TEX ${ }_{86}$ ), in combination with diatom and radiolarian assemblages, which will assist in evaluating glacial-interglacial SST variability and water column stratification at the study sites. 


\section{References}

Ackley, S., \& Sullivan, C. (1994). Physical controls on the development and characteristics of Antarctic sea ice biological communities-a review and synthesis. Deep Sea Research Part I: Oceanographic Research Papers, 41(10), 1583-1604.

Alley, R. B., Anandakrishnan, S., Christianson, K., Horgan, H. J., Muto, A., Parizek, B. R., . . Walker, R. T. (2015). Oceanic forcing of ice-sheet retreat: West Antarctica and more. Annual Review of Earth and Planetary Sciences, 43, 207-231.

Allis, R. G., Barrett, P. J., \& Christoffel, D. A. (1975). A paleomagnetic stratigraphy for Oligocene and early Miocene marine glacial sediments at Site 270, Ross Sea, Antarctica. Hayes, DE, et al., Initial reports of the Deep Sea Drilling Project, 28, 879-884.

Alonso, B., Anderson, J. B., Díaz, J. I., \& Bartek, L. R. (1992). Pliocene-Pleistocene Seismic Stratigraphy of the Ross Sea: Evidence for Multiple Ice Sheet Grounding Episodes. Contributions to Antarctic Research III, 93-103.

Anderson, J. B. (1999). Antarctic marine geology: Cambridge University Press.

Anderson, J. B., Brake, C. F., \& Myers, N. C. (1984). Sedimentation on the Ross Sea continental shelf, Antarctica. Marine Geology, 57(1-4), 295-333.

Anderson, J. B., Conway, H., Bart, P. J., Witus, A. E., Greenwood, S. L., McKay, R. M., . . Jakobsson, M. (2014). Ross Sea paleo-ice sheet drainage and deglacial history during and since the LGM. Quaternary Science Reviews, 100, 31-54.

Anderson, J. B., Kurtz, D., Domack, E., \& Balshaw, K. (1980). Glacial and glacial marine sediments of the Antarctic continental shelf. The Journal of Geology, 399-414.

Andrews, J. T. (2000). Icebergs and iceberg rafted detritus (IRD) in the North Atlantic: facts and assumptions. OCEANOGRAPHY-WASHINGTON DC-OCEANOGRAPHY SOCIETY-, 13(3), $100-$ 108.

Andrews, J. T., Erlenkeuser, H., Tedesco, K., Aksu, A. E., \& Jull, A. T. (1994). Late Quaternary (stage 2 and 3) meltwater and Heinrich events, northwest Labrador Sea. Quaternary research, 41(1), 26-34.

Arrigo, K. R., DiTullio, G. R., Dunbar, R. B., Robinson, D. H., VanWoert, M., Worthen, D. L., \& Lizotte, M. P. (2000). Phytoplankton taxonomic variability in nutrient utilization and primary production in the Ross Sea. Journal of Geophysical Research: Oceans, 105(C4), 8827-8846.

Arrigo, K. R., \& van Dijken, G. L. (2004). Annual changes in sea-ice, chlorophyll a, and primary production in the Ross Sea, Antarctica. Deep Sea Research Part II: Topical Studies in Oceanography, 51(1), 117-138.

Arrigo, K. R., van Dijken, G. L., \& Bushinsky, S. (2008). Primary production in the Southern Ocean, 1997-2006. Journal of Geophysical Research: Oceans, 113(C8).

Arrigo, K. R., Weiss, A. M., \& Smith, W. O. (1998). Physical forcing of phytoplankton dynamics in the southwestern Ross Sea. Journal of Geophysical Research: Oceans, 103(C1), 10071021.

Arrigo, K. R., Worthen, D. L., \& Robinson, D. H. (2003). A coupled ocean-ecosystem model of the Ross Sea: 2 . Iron regulation of phytoplankton taxonomic variability and primary production. Journal of Geophysical Research: Oceans, 108(C7).

Barker, P. F. (1992). The sedimentary record of Antarctic climate change. Philosophical Transactions of the Royal Society B: Biological Sciences, 338(1285), 259-267.

Barrett, P. (1999). Antarctic climate history over the last 100 million years. Terra Antarctica Reports, 3, 53-72. 
Barrett, P. (2009). Cenozoic climate and sea level history from glacimarine strata off the Victoria Land coast, Cape Roberts Project, Antarctica. Glacial sedimentary processes and products: International Association of Sedimentologists Special Publication, 39, 259-287.

Barrett, P. (2013). Resolving views on Antarctic Neogene glacial history-the Sirius debate. Earth and Environmental Science Transactions of the Royal Society of Edinburgh, 104(01), 3153.

Barrett, P. J. (1989). Antarctic Cenozoic history from the CIROS-1 drillhole, McMurdo Sound: DRIS Publishing.

Bassis, J., \& Jacobs, S. (2013). Diverse calving patterns linked to glacier geometry. Nature Geoscience, 6(10), 833-836.

Bauch, D., Darling, K., Simstich, J., Bauch, H. A., Erlenkeuser, H., \& Kroon, D. (2003). Palaeoceanographic implications of genetic variation in living North Atlantic Neogloboquadrina pachyderma. Nature, 424(6946), 299-302.

Bianchi, G., Hall, I. R., McCave, I., \& Joseph, L. (1999). Measurement of the sortable silt current speed proxy using the Sedigraph 5100 and Coulter Multisizer lle: Precision and accuracy. Sedimentology, 46(6), 1001-1014.

Blott, S. J., \& Pye, K. (2001). GRADISTAT: a grain size distribution and statistics package for the analysis of unconsolidated sediments. Earth surface processes and Landforms, 26(11), 1237-1248.

Boggs, S. (2006). Principles of sedimentology and stratigraphy. Pearson Education, Inc. New Jersey.

Bonaccorsi, R., Quaia, T., Burckle, L., Anderson, R., Melis, R., \& Brambati, A. (2007). C-14 age control of pre-and post-LGM events using N. pachyderma preserved in deep-sea sediments (Ross Sea, Antarctica). Paper presented at the Antarctica: A Keystone in a Changing World-Online Proceedings of the 10th ISAES X, edited by AK Cooper and CR Raymond et al., USGS Open-File Report.

Bond, G., Heinrich, H., Broecker, W., Labeyrie, L., McManus, J., Andrews, J., . . Simet, C. (1992). Evidence for massive discharges of icebergs into the North Atlantic ocean during the last glacial period.

Bostock, H. a. Neil., H. (2015). Using stable isotopes of oxygen and carbon for paleoceanography. GNS, Wellington.

Bouma, A. H. (1962). Sedimentology of some flysch deposits: a graphic approach to facies interpretation: Elsevier Pub. Co.

Bracegirdle, T. J., \& Stephenson, D. B. (2012). Higher precision estimates of regional polar warming by ensemble regression of climate model projections. Climate dynamics, 39(12), 2805-2821.

Brancolini, G., Cooper, A. K., \& Coren, F. (1995). Seismic facies and glacial history in the western Ross Sea (Antarctica). Geology and Seismic Stratigraphy of the Antarctic Margin, 209233.

Busetti, M., Caburlotto, A., Armand, L., Damiani, D., Giorgetti, G., Lucchi, R., . . Villa, G. (2003). Plio-Quaternary sedimentation on the Wilkes Land continental rise: preliminary results. Deep Sea Research Part II: Topical Studies in Oceanography, 50(8), 1529-1562.

Caburlotto, A., Lucchi, R., De Santis, L., Macrì, P., \& Tolotti, R. (2010). Sedimentary processes on the Wilkes Land continental rise reflect changes in glacial dynamic and bottom water flow. International Journal of Earth Sciences, 99(4), 909-926.

Camerlenghi, A., Domack, E., Rebesco, M., Gilbert, R., Ishman, S., Leventer, A., . . Drake, A. (2001). Glacial morphology and post-glacial contourites in northern Prince Gustav Channel (NW Weddell Sea, Antarctica). Marine Geophysical Researches, 22(5-6), 417443. 
Carter, L., Neil, H. L., \& Northcote, L. (2002). Late Quaternary ice-rafting events in the SW Pacific Ocean, off eastern New Zealand. Marine Geology, 191(1-2), 19-35.

Chappell, J., \& Shackleton, N. J. (1986). Oxygen isotopes and sea level. Nature, 324, 137-140.

Charles, C., \& Fairbanks, R. (1990). Glacial to interglacial changes in the isotopic gradients of Southern Ocean surface water Geological History of the Polar Oceans: Arctic Versus Antarctic (pp. 519-538): Springer.

Chewings, J. M. (2013). Sedimentology and numerical modelling of aeolian sediment dispersal, McMurdo Sound, southwest Ross Sea, Antarctica. Unpublished MSc Thesis, Victoria University of Wellington.

Chriss, T., \& Frakes, L. (1972). Glacial marine sedimentation in the Ross Sea Antarctic Geology and Geophysics (pp. 747-762): Universitetsforlaget Oslo.

Clark, P. U., \& Pisias, N. G. (2000). Interpreting iceberg deposits in the deep sea. Science, 290(5489), 51-52.

Cofaigh, C. Ó. (2012). Ice sheets viewed from the ocean: the contribution of marine science to understanding modern and past ice sheets. Philosophical Transactions of the Royal Society of London A: Mathematical, Physical and Engineering Sciences, 370(1980), 55125539.

Cofaigh, C. O., Dowdeswell, J. A., \& Pudsey, C. J. (2001). Late Quaternary iceberg rafting along the Antarctic Peninsula continental rise and in the Weddell and Scotia Seas. Quaternary research, 56(3), 308-321.

Cofaigh, C. Ó., Taylor, J., Dowdeswell, J. A., \& Pudsey, C. J. (2003). Palaeo-ice streams, trough mouth fans and high-latitude continental slope sedimentation. Boreas, 32(1), 37-55.

Comiso, J. C., Kwok, R., Martin, S., \& Gordon, A. L. (2011). Variability and trends in sea ice extent and ice production in the Ross Sea. Journal of Geophysical Research: Oceans, 116(C4).

Cook, C., Hill, D., Flierdt, T., Williams, T., Hemming, S., Dolan, A., . . Cortese, G. (2014). Sea surface temperature control on the distribution of far-traveled Southern Ocean icerafted detritus during the Pliocene. Paleoceanography, 29(6), 533-548.

Cook, C. P., van de Flierdt, T., Williams, T., Hemming, S. R., Iwai, M., Kobayashi, M., . . Khim, B.K. (2013). Dynamic behaviour of the East Antarctic ice sheet during Pliocene warmth. Nature Geoscience, 6(9), 765-769.

Cowan, E. A., Hillenbrand, C.-D., Hassler, L. E., \& Ake, M. T. (2008). Coarse-grained terrigenous sediment deposition on continental rise drifts: A record of Plio-Pleistocene glaciation on the Antarctic Peninsula. Palaeogeography, Palaeoclimatology, Palaeoecology, 265(3), 275-291.

Coxall, H. K., Wilson, P. A., Pälike, H., Lear, C. H., \& Backman, J. (2005). Rapid stepwise onset of Antarctic glaciation and deeper calcite compensation in the Pacific Ocean. Nature, 433(7021), 53-57.

Craig, H. (1965). The measurement of oxygen isotope paleotemperatures. Stable isotopes in oceanographic studies and paleotemperatures, 23.

Cramer, B., Miller, K., Barrett, P., \& Wright, J. (2011). Late Cretaceous-Neogene trends in deep ocean temperature and continental ice volume: Reconciling records of benthic foraminiferal geochemistry $(\delta 180$ and $\mathrm{Mg} / \mathrm{Ca}$ ) with sea level history. Journal of Geophysical Research: Oceans, 116(C12).

Dadey, K. A., Janecek, T., and Klaus, A. (1992). Dry-bulk density: its use and determination. . Taylor, B., Fujioka, K., et al., Proc. ODP, Sci. Results, College Station, TX (Ocean Drilling Program), 126, 551-554.

Davey, F. (2004). Ross Sea Bathymetry, 1: 2,000,000, Version 1.0, Institute of Geological \& Nuclear Sciences Geophysical Map 16. Institute of Geological \& Nuclear Sciences Limited, Lower Hutt, New Zealand. 
Davey, F., \& Jacobs, S. (2007). Influence of submarine morphology on bottom water flow across the western Ross Sea continental margin. (No. 2007-1047-SRP-067). US Geological Survey.

De Santis, L., Prato, S., Brancolini, G., Lovo, M., \& Torelli, L. (1999). The Eastern Ross Sea continental shelf during the Cenozoic: implications for the West Antarctic ice sheet development. Global and Planetary Change, 23(1), 173-196.

Death, R., Siegert, M. J., Bigg, G. R., \& Wadley, M. R. (2006). Modelling iceberg trajectories, sedimentation rates and meltwater input to the ocean from the Eurasian Ice Sheet at the Last Glacial Maximum. Palaeogeography, Palaeoclimatology, Palaeoecology, 236(1), 135-150.

DeConto, R., Pollard, D., \& Harwood, D. (2007). Sea ice feedback and Cenozoic evolution of Antarctic climate and ice sheets. Paleoceanography, 22(3).

DeConto, R. M., \& Pollard, D. (2003). Rapid Cenozoic glaciation of Antarctica induced by declining atmospheric CO2. Nature, 421(6920), 245-249.

DeConto, R. M., \& Pollard, D. (2016). Contribution of Antarctica to past and future sea-level rise. Nature, 531(7596), 591-597.

DeConto, R. M., Pollard, D., \& Kowalewski, D. (2012). Reprint of: Modeling Antarctic ice sheet and climate variations during Marine Isotope Stage 31. Global and Planetary Change, 96, 181-188.

DeConto, R. M., Pollard, D., Wilson, P. A., Pälike, H., Lear, C. H., \& Pagani, M. (2008). Thresholds for Cenozoic bipolar glaciation. Nature, 455(7213), 652-656.

DeMaster, D. J., Dunbar, R. B., Gordon, L. I., Leventer, A. R., Morrison, J. M., Nelson, D. M., . . Smith Jr, W. O. (1992). Cycling and accumulation of biogenic silica and organic matter in high-latitude environments: the Ross Sea. Oceanography, 5(3), 146-153.

Denton, G. H., Anderson, R. F., Toggweiler, J. R., Edwards, R. L., Schaefer, J. M., \& Putnam, A. E. (2010). The last glacial termination. Science, 328(5986), 1652-1656.

Depoorter, M., Bamber, J., Griggs, J., Lenaerts, J., Ligtenberg, S., van den Broeke, M., \& Moholdt, G. (2013). Calving fluxes and basal melt rates of Antarctic ice shelves. Nature, 502(7469), 89-92.

Dieckmann, G., Spindler, M., Lange, M. A., Ackley, S. F., \& Eicken, H. (1991). Antarctic sea ice: a habitat for the foraminifer Neogloboquadrina pachyderma. Journal of Foraminiferal Research, 21(2), 182-189.

Diekmann, B., \& Kuhn, G. (2002). Sedimentary record of the mid-Pleistocene climate transition in the southeastern South Atlantic (ODP Site 1090). Palaeogeography, Palaeoclimatology, Palaeoecology, 182(3), 241-258.

Domack, E. W., Jacobson, E. A., Shipp, S., \& Anderson, J. B. (1999). Late Pleistocene-Holocene retreat of the West Antarctic Ice-Sheet system in the Ross Sea: Part 2-sedimentologic and stratigraphic signature. Geological Society of America Bulletin, 111(10), 1517-1536.

Donda, F., Brancolini, G., O'Brien, P., De Santis, L., \& Escutia, C. (2007). Sedimentary processes in the Wilkes Land margin: a record of the Cenozoic East Antarctic Ice Sheet evolution. Journal of the Geological Society, 164(1), 243-256.

Droxler, A. W., Alley, R. B., Howard, W. R., Poore, R. Z., \& Burckle, L. H. (2003). Unique and exceptionally long interglacial Marine Isotope Stage 11: window into Earth warm future climate. Earth's Climate and Orbital Eccentricity: The Marine Isotope Stage 11 Question, 1-14.

Dunbar, R. B., Anderson, J. B., Domack, E. W., \& Jacobs, S. S. (1985). Oceanographic influences on sedimentation along the Antarctic continental shelf. Oceanology of the Antarctic Continental Shelf, 291-312. 
Dutrieux, P., De Rydt, J., Jenkins, A., Holland, P. R., Ha, H. K., Lee, S. H., . . Schröder, M. (2014). Strong sensitivity of Pine Island ice-shelf melting to climatic variability. Science, 343(6167), 174-178.

Elderfield, H., Ferretti, P., Greaves, M., Crowhurst, S., McCave, I., Hodell, D., \& Piotrowski, A. (2012). Evolution of ocean temperature and ice volume through the mid-Pleistocene climate transition. Science, 337(6095), 704-709.

Elderfield, H., Vautravers, M., \& Cooper, M. (2002). The relationship between shell size and $\mathrm{Mg} / \mathrm{Ca}, \mathrm{Sr} / \mathrm{Ca}, \delta 180$, and $\delta 13 \mathrm{C}$ of species of planktonic foraminifera. Geochemistry, Geophysics, Geosystems, 3(8), 1-13.

Emiliani, C. (1966). Paleotemperature analysis of Caribbean cores P6304-8 and P6304-9 and a generalized temperature curve for the past 425,000 years. The Journal of Geology, 109124.

Escutia, C., Bárcena, M., Lucchi, R., Romero, O., Ballegeer, A., Gonzalez, J., \& Harwood, D. (2009). Circum-Antarctic warming events between 4 and 3.5 Ma recorded in marine sediments from the Prydz Bay (ODP Leg 188) and the Antarctic Peninsula (ODP Leg 178) margins. Global and Planetary Change, 69(3), 170-184.

Escutia, C., Brinkhuis, H., \& Klaus, A. (2011). IODP Expedition 318: From Greenhouse to Icehouse at the Wilkes Land Antarctic Margin. Scientific Drilling, 12, 15-23.

Escutia, C., De Santis, L., Donda, F., Dunbar, R., Cooper, A., Brancolini, G., \& Eittreim, S. (2005). Cenozoic ice sheet history from East Antarctic Wilkes Land continental margin sediments. Global and Planetary Change, 45(1), 51-81.

Escutia, C., Nelson, C., Acton, G., Eittreim, S., Cooper, A., Warnke, D., \& Jaramillo, J. (2002). Current controlled deposition on the Wilkes Land continental rise, Antarctica. Geological Society, London, Memoirs, 22(1), 373-384.

Escutia, C., Warnke, D., Acton, G., Barcena, A., Burckle, L., Canals, M., \& Frazee, C. (2003). Sediment distribution and sedimentary processes across the Antarctic Wilkes Land margin during the Quaternary. Deep Sea Research Part II: Topical Studies in Oceanography, 50(8), 1481-1508.

Evans, J., \& Pudsey, C. (2002). Sedimentation associated with Antarctic Peninsula ice shelves: implications for palaeoenvironmental reconstructions of glacimarine sediments. Journal of the Geological Society, 159(3), 233-237.

Faugèers, J.-C., Gonthier, E., \& Stow, D. A. (1984). Contourite drift molded by deep Mediterranean outflow. Geology, 12(5), 296-300.

Faugeres, J.-C., \& Mulder, T. (2011). Contour currents and contourite drifts. Deep-sea sediments, $63,149-214$.

Flückiger, J., Knutti, R., \& White, J. W. (2006). Oceanic processes as potential trigger and amplifying mechanisms for Heinrich events. Paleoceanography, 21(2).

Folk, R. L., \& Ward, W. C. (1957). Brazos River bar: a study in the significance of grain size parameters. Journal of Sedimentary Research, 27(1).

Galeotti, S., DeConto, R., Naish, T., Stocchi, P., Florindo, F., Pagani, M., . . Pollard, D. (2016). Antarctic Ice Sheet variability across the Eocene-Oligocene boundary climate transition. Science, 352(6281), 76-80.

Gersonde, R., \& Zielinski, U. (2000). The reconstruction of late Quaternary Antarctic sea-ice distribution - the use of diatoms as a proxy for sea-ice. Palaeogeography, Palaeoclimatology, Palaeoecology, 162(3), 263-286.

Ghil, M., Allen, M., Dettinger, M., Ide, K., Kondrashov, D., Mann, M., ... Varadi, F. (2002). Advanced spectral methods for climatic time series. Reviews of Geophysics, 40(1).

Gilbert, I. M., Pudsey, C. J., \& Murray, J. W. (1998). A sediment record of cyclic bottom-current variability from the northwest Weddell Sea. Sedimentary geology, 115(1), 185-214. 
Gilbert, R. (1990). Rafting in glacimarine environments. Geological Society, London, Special Publications, 53(1), 105-120.

Gloersen, P., Campbell, W., Cavalieri, D., Comiso, J., Parkinson, C., \& Zwally, H. (1992). Arctic and Antarctic sea ice, 1978-1987. National Aeronautics and Space Administration, Washington, DC NASA SP-551, 290.

Golledge, N. R., Fogwill, C. J., Mackintosh, A. N., \& Buckley, K. M. (2012). Dynamics of the last glacial maximum Antarctic ice-sheet and its response to ocean forcing. Proceedings of the National Academy of Sciences, 109(40), 16052-16056.

Golledge, N. R., Kowalewski, D. E., Naish, T. R., Levy, R. H., Fogwill, C. J., \& Gasson, E. G. (2015). The multi-millennial Antarctic commitment to future sea-level rise. Nature, 526(7573), 421-425.

Gonthier, E., Faugères, J.-C., \& Stow, D. (1984). Contourite facies of the Faro drift, Gulf of Cadiz. Geological Society, London, Special Publications, 15(1), 275-292.

Gordon, A. L., Orsi, A. H., Muench, R., Huber, B. A., Zambianchi, E., \& Visbeck, M. (2009). Western Ross Sea continental slope gravity currents. Deep Sea Research Part II: Topical Studies in Oceanography, 56(13), 796-817.

Gordon, A. L., Zambianchi, E., Orsi, A., Visbeck, M., Giulivi, C. F., Whitworth, T., \& Spezie, G. (2004). Energetic plumes over the western Ross Sea continental slope. Geophysical Research Letters, 31(21).

Grobe, H. (1987). A simple method for the determination of ice-rafted debris in sediment cores. Polarforschung, 57(3), 123-126.

Grobe, H., \& Mackensen, A. (1992). Late Quaternary climatic cycles as recorded in sediments from the Antarctic continental margin. The Antarctic Paleoenvironment: A Perspective on Global Change: Part One, 349-376.

Grossman, E. L. (1987). Stable isotopes in modern benthic foraminifera; a study of vital effect. The Journal of Foraminiferal Research, 17(1), 48-61.

Grützner, J., Hillenbrand, C.-D., \& Rebesco, M. (2005). Terrigenous flux and biogenic silica deposition at the Antarctic continental rise during the late Miocene to early Pliocene: implications for ice sheet stability and sea ice coverage. Global and Planetary Change, 45(1), 131-149.

Hambrey, M. J., Ehrmann, W., \& Larsen, B. (1991). Cenozoic glacial record of the Prydz Bay continental shelf, East Antarctica. In: Barron, J; Larsen, B, et al.(eds.), Proc. ODP, Sci. Results, College Station, TX.(Ocean Drilling Program), 119, 77-132, 119, 77-132.

Hansen, M. A., Passchier, S., Khim, B. K., Song, B., \& Williams, T. (2015). Threshold behavior of a marine-based sector of the East Antarctic Ice Sheet in response to early Pliocene ocean warming. Paleoceanography, 30(6), 789-801.

Hayes, D., \& Davey, F. (1975). A geophysical study of the Ross Sea, Antarctica. Initial reports of the deep sea drilling project, 28, 887-907.

Hays, J. D., Imbrie, J., \& Shackleton, N. J. (1976). Variations in the Earth's orbit: pacemaker of the ice ages. Science, 194, 1121-1132.

Heath, G., Moore, T., \& Dauphin, J. (1977). Organic carbon in deep-sea sediments. The fate of fossil fuel CO, 2, 605-625.

Heinrich, H. (1988). Origin and consequences of cyclic ice rafting in the northeast Atlantic Ocean during the past 130,000 years. Quaternary research, 29(2), 142-152.

Hepp, D. A., Mörz, T., \& Grützner, J. (2006). Pliocene glacial cyclicity in a deep-sea sediment drift (Antarctic Peninsula Pacific Margin). Palaeogeography, Palaeoclimatology, Palaeoecology, 231(1), 181-198. 
Hesse, R., Khodabakhsh, S., Klaucke, I., \& Ryan, W. B. (1997). Asymmetrical turbid surface-plume deposition near ice-outlets of the Pleistocene Laurentide ice sheet in the Labrador Sea. Geo-Marine Letters, 17(3), 179-187.

Hillenbrand, C.-D., Kuhn, G., \& Frederichs, T. (2009). Record of a Mid-Pleistocene depositional anomaly in West Antarctic continental margin sediments: an indicator for ice-sheet collapse? Quaternary Science Reviews, 28(13), 1147-1159.

Hodell, D. A., Charles, C. D., \& Ninnemann, U. S. (2000). Comparison of interglacial stages in the South Atlantic sector of the southern ocean for the past $450 \mathrm{kyr}$ : implifications for Marine Isotope Stage (MIS) 11. Global and Planetary Change, 24(1), 7-26.

Hodell, D. A., \& Venz-Curtis, K. A. (2006). Late Neogene history of deepwater ventilation in the Southern Ocean. Geochemistry, Geophysics, Geosystems, 7(9).

Howe, J. A., Pudsey, C. J., \& Cunningham, A. P. (1997). Pliocene-Holocene contourite deposition under the Antarctic Circumpolar Current, western Falkland Trough, South Atlantic Ocean. Marine Geology, 138(1), 27-50.

Howe, J. A., Stoker, M. S., \& Woolfe, K. J. (2001). Deep-marine seabed erosion and gravel lags in the northwestern Rockall Trough, North Atlantic Ocean. Journal of the Geological Society, 158(3), 427-438.

Hulbe, C. L., MacAyeal, D. R., Denton, G. H., Kleman, J., \& Lowell, T. V. (2004). Catastrophic ice shelf breakup as the source of Heinrich event icebergs. Paleoceanography, 19(1).

Hüneke, H., \& Stow, D. (2008). Identification of ancient contourites: problems and palaeoceanographic significance. Developments in Sedimentology, 60, 323-344.

Huybers, P. (2006). Early Pleistocene glacial cycles and the integrated summer insolation forcing. Science, 313(5786), 508-511.

Huybers, P., \& Wunsch, C. (2004). A depth-derived Pleistocene age model: Uncertainty estimates, sedimentation variability, and nonlinear climate change. Paleoceanography, 19(1).

IPCC, (2013). Climate Change 2013: Observations: Cryosphere. In: Climate Change 2013: The Physical Science Basis. Contribution of Working Group I to the Fifth Assessment Report of the Intergovernmental Panel on Climate Change [Stocker, T.F., D. Qin, G.-K. Plattner, M. Tignor, S.K. Allen, J. Boschung, A. Nauels, Y. Xia, V. Bex and P.M. Midgley (eds.)]. Cambridge University Press, Cambridge, United Kingdom and New York, NY, USA.

Jaccard, S., Hayes, C. T., Martínez-García, A., Hodell, D., Anderson, R. F., Sigman, D., \& Haug, G. (2013). Two modes of change in Southern Ocean productivity over the past million years. Science, 339(6126), 1419-1423.

Jacobs, S., Giulivi, C., \& Mele, P. (2002). Freshening of the Ross Sea during the late 20th century. Science, 297(5580), 386-389.

Jacobs, S. S. (2004). Bottom water production and its links with the thermohaline circulation. Antarctic Science, 16(04), 427-437.

Jacobs, S. S., \& Giulivi, C. F. (2010). Large multidecadal salinity trends near the Pacific-Antarctic continental margin. Journal of Climate, 23(17), 4508-4524.

Jacobs, S. S., Jenkins, A., Giulivi, C. F., \& Dutrieux, P. (2011). Stronger ocean circulation and increased melting under Pine Island Glacier ice shelf. Nature Geoscience, 4(8), 519-523.

Jansen, E., Fronval, T., Rack, F., \& Channell, J. E. (2000). Pliocene-Pleistocene ice rafting history and cyclicity in the Nordic Seas during the last 3.5 Myr. Paleoceanography, 15(6), 709721.

Jonkers, L., Jiménez-Amat, P., Mortyn, P. G., \& Brummer, G.-J. A. (2013). Seasonal Mg/Ca variability of $\mathrm{N}$. pachyderma (s) and $\mathrm{G}$. bulloides: Implications for seawater temperature reconstruction. Earth and Planetary Science Letters, 376, 137-144. 
Joughin, I., Alley, R. B., \& Holland, D. M. (2012). Ice-sheet response to oceanic forcing. Science, 338(6111), 1172-1176.

Joughin, I., Smith, B. E., \& Medley, B. (2014). Marine ice sheet collapse potentially under way for the Thwaites Glacier Basin, West Antarctica. Science, 344(6185), 735-738.

Kanfoush, S. L. (2016). A pulse in the delivery of ice-rafted debris at site 704 in the southeast Atlantic during glacial Termination V. Marine Geophysical Research, 37(1), 37-48.

Kanfoush, S. L., Hodell, D. A., Charles, C. D., Guilderson, T. P., Mortyn, P. G., \& Ninnemann, U. S. (2000). Millennial-scale instability of the Antarctic ice sheet during the last glaciation. Science, 288(5472), 1815-1819.

Kanfoush, S. L., Hodell, D. A., Charles, C. D., Janecek, T. R., \& Rack, F. R. (2002). Comparison of ice-rafted debris and physical properties in ODP Site 1094 (South Atlantic) with the Vostok ice core over the last four climatic cycles. Palaeogeography, Palaeoclimatology, Palaeoecology, 182(3), 329-349.

Kemp, A., Grigorov, I., Pearce, R. B., \& Garabato, A. N. (2010). Migration of the Antarctic Polar Front through the mid-Pleistocene transition: evidence and climatic implications. Quaternary Science Reviews, 29(17), 1993-2009.

Kennett, J. P., \& Barker, P. F. (1990). Latest Cretaceous to Cenozoic climate and oceanographic developments in the Weddell Sea, Antarctica: an ocean-drilling perspective. Paper presented at the Proceedings of the Ocean Drilling Program, Scientific Results.

Kleiven, H. F., Jansen, E., Fronval, T., \& Smith, T. (2002). Intensification of Northern Hemisphere glaciations in the circum Atlantic region (3.5-2.4 Ma)-ice-rafted detritus evidence. Palaeogeography, Palaeoclimatology, Palaeoecology, 184(3), 213-223.

Kohfeld, K., Anderson, R., \& Lynch-Stieglitz, J. (2000). Carbon isotopic disequilibrium in polar planktonic foraminifera and its impact on modern and Last Glacial Maximum reconstructions. Paleoceanography, 15(1), 53-64.

Konert, M., \& Vandenberghe, J. (1997). Comparison of laser grain size analysis with pipette and sieve analysis: a solution for the underestimation of the clay fraction. Sedimentology, 44(3), 523-535.

Krissek, L. (1995). Late Cenozoic ice-rafting records from Leg 145 sites in the North Pacific: Late Miocene onset, late Pliocene intensification, and Pliocene-Pleistocene events, in Proc. Ocean Drill. Proj. Sci. Results, 145, 3-19.

Krissek, L., Browne, G., Carter, L., Cowan, E., Dunbar, G., McKay, R., . . Wilch, T. (2007). Sedimentology and stratigraphy of the AND-1B Core, ANDRILL McMurdo Ice Shelf Project, Antarctica.

Laskar, J., Fienga, A., Gastineau, M., \& Manche, H. (2011). La2010: a new orbital solution for the long-term motion of the Earth. Astronomy \& Astrophysics, 532, A89.

Laskar, J., Robutel, P., Joutel, F., Gastineau, M., Correia, A., \& Levrard, B. (2004). A long-term numerical solution for the insolation quantities of the Earth. Astronomy \& Astrophysics, 428(1), 261-285.

Lear, C. H., Billups, K., Rickaby, R. E., Diester-Haass, L., Mawbey, E. M., \& Sosdian, S. M. (2016). Breathing more deeply: Deep ocean carbon storage during the mid-Pleistocene climate transition. Geology, 44(12), 1035-1038.

Ledford-Hoffman, P. A., DeMaster, D., \& Nittrouer, C. (1986). Biogenic-silica accumulation in the Ross Sea and the importance of Antarctic continental-shelf deposits in the marine silica budget. Geochimica et Cosmochimica Acta, 50(9), 2099-2110.

Levy, R., Harwood, D., Florindo, F., Sangiorgi, F., Tripati, R., von Eynatten, H., . . . DeConto, R. (2016). Antarctic ice sheet sensitivity to atmospheric $\mathrm{CO} 2$ variations in the early to midMiocene. Proceedings of the National Academy of Sciences, 201516030. 
Lewis, D. W., \& McConchie, D. (1994). Analytical sedimentology. Champan \& Hall, New York, $272 p$.

Li, G., \& Piper, D. J. (2015). The influence of meltwater on the Labrador Current in Heinrich event 1 and the Younger Dryas. Quaternary Science Reviews, 107, 129-137.

Lisiecki, L. E., \& Raymo, M. E. (2005). A Pliocene-Pleistocene stack of 57 globally distributed benthic $\delta 180$ records. Paleoceanography, 20(1).

Liu, Z., Pagani, M., Zinniker, D., DeConto, R., Huber, M., Brinkhuis, H., . . Pearson, A. (2009). Global cooling during the Eocene-Oligocene climate transition. Science, 323(5918), 11871190.

Llave, E., Schönfeld, J., Hernández-Molina, F., Mulder, T., Somoza, L., Del Rio, V. D., \& SánchezAlmazo, I. (2006). High-resolution stratigraphy of the Mediterranean outflow contourite system in the Gulf of Cadiz during the late Pleistocene: the impact of Heinrich events. Marine Geology, 227(3), 241-262.

Locarnini, R., Mishonov, A., Antonov, J., Boyer, T., Garcia, H., Baranova, O., . . J Johnson, D. (2013). World Ocean Atlas 2013, vol. 1: A. Mishonov Technical Ed.

Lowe, D. R. (1982). Sediment gravity flows: II Depositional models with special reference to the deposits of high-density turbidity currents. Journal of Sedimentary Research, 52(1).

Lu, Z., Hoogakker, B. A., Hillenbrand, C.-D., Zhou, X., Thomas, E., Gutchess, K. M., . . Rickaby, R. E. (2016). Oxygen depletion recorded in upper waters of the glacial Southern Ocean. Nature communications, 7.

Lucchi, R., Rebesco, M., Camerlenghi, A., Busetti, M., Tomadin, L., Villa, G., . . Giorgetti, G. (2002). Mid-late Pleistocene glacimarine sedimentary processes of a high-latitude, deepsea sediment drift (Antarctic Peninsula Pacific margin). Marine Geology, 189(3), 343-370.

Lucchi, R. G., \& Rebesco, M. (2007). Glacial contourites on the Antarctic Peninsula margin: insight for palaeoenvironmental and palaeoclimatic conditions. Geological Society, London, Special Publications, 276(1), 111-127.

Maiorano, P., Marino, M., \& Flores, J.-A. (2009). The warm interglacial Marine Isotope Stage 31: Evidences from the calcareous nannofossil assemblages at Site 1090 (Southern Ocean). Marine Micropaleontology, 71(3), 166-175.

Mann, M. E., \& Lees, J. M. (1996). Robust estimation of background noise and signal detection in climatic time series. Climatic change, 33(3), 409-445.

Marcott, S. A., Clark, P. U., Padman, L., Klinkhammer, G. P., Springer, S. R., Liu, Z., . . Padman, J. (2011). Ice-shelf collapse from subsurface warming as a trigger for Heinrich events. Proceedings of the National Academy of Sciences, 108(33), 13415-13419.

Marshall, J., \& Speer, K. (2012). Closure of the meridional overturning circulation through Southern Ocean upwelling. Nature Geoscience, 5(3), 171-180.

Martin, J. H. (1990). Glacial-interglacial CO2 change: The Iron Hypothesis. Paleoceanography, 5(1), 1-13. doi: 10.1029/PA005i001p00001

Martin, J. H., Fitzwater, S. E., \& Gordon, R. M. (1990). Iron deficiency limits phytoplankton growth in Antarctic waters. Global Biogeochemical Cycles, 4(1), 5-12. doi: 10.1029/GB004i001p00005

Martin, S., Drucker, R. S., \& Kwok, R. (2007). The areas and ice production of the western and central Ross Sea polynyas, 1992-2002, and their relation to the B-15 and C-19 iceberg events of 2000 and 2002. Journal of Marine Systems, 68(1), 201-214.

Martínez-Garcia, A., Rosell-Melé, A., Jaccard, S. L., Geibert, W., Sigman, D. M., \& Haug, G. H. (2011). Southern Ocean dust-climate coupling over the past four million years. Nature, 476(7360), 312-315. 
Mazzullo, J., Meyer, A. and Kidd, R. (1988) New sediment classification scheme for the Ocean Drilling Program. In: Handbook for Shipboard

Sedimentologists (Eds J.Mazzullo and A.G.Graham) Texas A\&M University, Ocean Drilling Program, Technical Note, 8, 45-67.

McCave, I., \& Hall, I. R. (2006). Size sorting in marine muds: Processes, pitfalls, and prospects for paleoflow-speed proxies. Geochemistry, Geophysics, Geosystems, 7(10).

McCave, I., Manighetti, B., \& Robinson, S. (1995). Sortable silt and fine sediment size composition slicing-parameters for paleocurrent speed and paleoceanography. Paleoceanography, 10(3), 593-610.

McKay, R., De Santis L., Bart, P., Shevenell, A., Williams, T., Levy, R., Bartek, L., Sjunneskog, Orsi, A., Warny, S., Deconto, R., Pollard, D., Suganuma, Y., Hong, J. (2016b). Ocean-ice sheet interactions and West Antarctic Ice Sheet vulnerability: clues from the Neogene and Quaternary record of the outer Ross Sea continental margin. IODP Proposal.

McKay, R., Barrett, P., Levy, R., Naish, T., Golledge, N., \& Pyne, A. (2016a). Antarctic Cenozoic climate history from sedimentary records: ANDRILL and beyond. Phil. Trans. R. Soc. A, 374(2059), 20140301.

McKay, R., Browne, G., Carter, L., Cowan, E., Dunbar, G., Krissek, L., .. T Talarico, F. (2009). The stratigraphic signature of the late Cenozoic Antarctic Ice Sheets in the Ross Embayment. Geological Society of America Bulletin, 121(11-12), 1537-1561.

McKay, R., Dunbar, G., Naish, T., Barrett, P., Carter, L., \& Harper, M. (2008). Retreat history of the Ross Ice Sheet (Shelf) since the Last Glacial Maximum from deep-basin sediment cores around Ross Island. Palaeogeography, Palaeoclimatology, Palaeoecology, 260(1), 245-261.

McKay, R., Naish, T., Powell, R., Barrett, P., Scherer, R., Talarico, F., . . Jackolski, C. (2012b). Pleistocene variability of Antarctic ice sheet extent in the Ross embayment. Quaternary Science Reviews, 34, 93-112.

McLaren, P. (1981). An interpretation of trends in grain size measures. Journal of Sedimentary Research, 51(2).

McManus, J. F., Anderson, R. F., Broecker, W. S., Fleisher, M. Q., \& Higgins, S. M. (1998). Radiometrically determined sedimentary fluxes in the sub-polar North Atlantic during the last 140,000 years. Earth and Planetary Science Letters, 155(1), 29-43.

Mercer, J. H. (1978). West Antarctic ice sheet and CO 2 greenhouse effect- A threat of disaster. Nature, 271(5643), 321-325.

Meyers, S. R. (2014). Astrochron: An R package for Astrochronology. Available at c ran. rproject. org/web/packages/astrochron/index. html.

Meyers, S. R., Sageman, B. B., \& Arthur, M. A. (2012). Obliquity forcing of organic matter accumulation during Oceanic Anoxic Event 2. Paleoceanography, 27(3).

Michels, K. H., Rogenhagen, J., \& Kuhn, G. (2001). Recognition of contour-current influence in mixed contourite-turbidite sequences of the western Weddell Sea, Antarctica. Marine Geophysical Researches, 22(5-6), 465-485.

Middleton, G. V. (1993). Sediment deposition from turbidity currents. Annual Review of Earth and Planetary Sciences, 21, 89-114.

Middleton, G. V., \& Hampton, M. A. (1973). Part I. Sediment gravity flows: mechanics of flow and deposition. In: Turbidity and Deep Water Sedimentation (Eds G.V. Middleton and A.H. Bouma), SEPM, Pacific Section, Short Course Lecture Notes, 1-38.

Milankovitch, M. (1941). Kanon der Erdebestrahlung und seine Anwendung auf das Eiszeitenproblem: Königlich Serbische Akademie. 
Miller, K. G., Kominz, M. A., Browning, J. V., Wright, J. D., Mountain, G. S., Katz, M. E., . . Pekar, S. F. (2005). The Phanerozoic record of global sea-level change. Science, 310(5752), 1293-1298.

Miller, K. G., Wright, J. D., Browning, J. V., Kulpecz, A., Kominz, M., Naish, T. R., . . Sosdian, S. (2012). High tide of the warm Pliocene: Implications of global sea level for Antarctic deglaciation. Geology, 40(5), 407-410.

Moncrieff, A. (1989). Classification of poorly-sorted sedimentary rocks. Sedimentary geology, 65(1-2), 191-194.

Mortlock, R. A., \& Froelich, P. N. (1989). A simple method for the rapid determination of biogenic opal in pelagic marine sediments. Deep Sea Research Part A. Oceanographic Research Papers, 36(9), 1415-1426.

Mudelsee, M., Bickert, T., Lear, C. H., \& Lohmann, G. (2014). Cenozoic climate changes: A review based on time series analysis of marine benthic $\delta 180$ records. Reviews of Geophysics, 52(3), 333-374.

Mudelsee, M., \& Schulz, M. (1997). The Mid-Pleistocene climate transition: onset of $100 \mathrm{ka}$ cycle lags ice volume build-up by $280 \mathrm{ka}$. Earth and Planetary Science Letters, 151(1), 117-123.

Muench, R., Padman, L., Gordon, A., \& Orsi, A. (2009). A dense water outflow from the Ross Sea, Antarctica: Mixing and the contribution of tides. Journal of Marine Systems, 77(4), 369387.

Murphy, L., Warnke, D., Andersson, C., Channell, J., \& Stoner, J. (2002). History of ice rafting at South Atlantic ODP Site 177-1092 during the Gauss and late Gilbert Chrons. Palaeogeography, Palaeoclimatology, Palaeoecology, 182(3), 183-196.

Naish, T., Levy, R., Powell, R., and MIS Science and Operations Team Members. (2008). Scientific Logistics Implementation Plan for the ANDRILL McMurdo Ice Shelf Project. ANDRILL Program.

Naish, T., Powell, R., Levy, R., Wilson, G., Scherer, R., Talarico, F., ... Wilson, T. (2009). Obliquitypaced Pliocene West Antarctic ice sheet oscillations. Nature, 458 (7236), 322-328.

Naish, T. R., Woolfe, K. J., Barrett, P. J., Wilson, G. S., Atkins, C., Bohaty, S. M., ... Dunbar, G. B. (2001). Orbitally induced oscillations in the East Antarctic ice sheet at the Oligocene/Miocene boundary. Nature, 413(6857), 719-723.

Orsi, A., Johnson, G., \& Bullister, J. (1999). Circulation, mixing, and production of Antarctic Bottom Water. Progress in Oceanography, 43(1), 55-109.

Orsi, A. H., Jacobs, S. S., Gordon, A. L., \& Visbeck, M. (2001). Cooling and ventilating the abyssal ocean. Geophysical Research Letters, 28(15), 2923-2926.

Orsi, A. H., Smethie, W. M., \& Bullister, J. L. (2002). On the total input of Antarctic waters to the deep ocean: A preliminary estimate from chlorofluorocarbon measurements. Journal of Geophysical Research: Oceans, 107(C8).

Orsi, A. H., \& Wiederwohl, C. L. (2009). A recount of Ross Sea waters. Deep Sea Research Part II: Topical Studies in Oceanography, 56(13), 778-795.

$\varnothing v$ reb $\varnothing$, L. K., Haughton, P. D., \& Shannon, P. M. (2006). A record of fluctuating bottom currents on the slopes west of the Porcupine Bank, offshore Ireland-implications for Late Quaternary climate forcing. Marine Geology, 225(1), 279-309.

Padman, L., Howard, S. L., Orsi, A. H., \& Muench, R. D. (2009). Tides of the northwestern Ross Sea and their impact on dense outflows of Antarctic Bottom Water. Deep Sea Research Part II: Topical Studies in Oceanography, 56(13), 818-834.

Pälike, H., Norris, R. D., Herrle, J. O., Wilson, P. A., Coxall, H. K., Lear, C. H., ... Wade, B. S. (2006). The heartbeat of the Oligocene climate system. Science, 314(5807), 1894-1898.

Paolo, F. S., Fricker, H. A., \& Padman, L. (2015). Volume loss from Antarctic ice shelves is accelerating. Science, 348(6232), 327-331. 
Passchier, S. (2011). Linkages between East Antarctic Ice Sheet extent and Southern Ocean temperatures based on a Pliocene high-resolution record of ice-rafted debris off Prydz Bay, East Antarctica. Paleoceanography, 26(4).

Patterson, M., McKay, R., Naish, T., Escutia, C., Jimenez-Espejo, F., Raymo, M., . . Expedition, I. (2014). Orbital forcing of the East Antarctic ice sheet during the Pliocene and Early Pleistocene. Nature Geoscience, 7(11), 841-847.

Payne, A. J., Vieli, A., Shepherd, A. P., Wingham, D. J., \& Rignot, E. (2004). Recent dramatic thinning of largest West Antarctic ice stream triggered by oceans. Geophysical Research Letters, 31(23).

Pezza, A. B., Rashid, H. A., \& Simmonds, I. (2012). Climate links and recent extremes in Antarctic sea ice, high-latitude cyclones, Southern Annular Mode and ENSO. Climate dynamics, 38(1-2), 57-73.

Pollard, D., \& DeConto, R. M. (2009). Modelling West Antarctic ice sheet growth and collapse through the past five million years. Nature, 458(7236), 329-332.

Powell, R., \& Domack, E. (1995). Modern glaciomarine environments. Glacial environments, 1, 445-486.

Prézelin, B. B., Hofmann, E. E., Mengelt, C., \& Klinck, J. M. (2000). The linkage between Upper Circumpolar Deep Water (UCDW) and phytoplankton assemblages on the west Antarctic Peninsula continental shelf. Journal of Marine Research, 58(2), 165-202.

Pritchard, H., Ligtenberg, S., Fricker, H., Vaughan, D., Van den Broeke, M., \& Padman, L. (2012). Antarctic ice-sheet loss driven by basal melting of ice shelves. Nature, 484(7395), 502505.

Pritchard, H. D., Arthern, R. J., Vaughan, D. G., \& Edwards, L. A. (2009). Extensive dynamic thinning on the margins of the Greenland and Antarctic ice sheets. Nature, 461(7266), 971-975.

Pudsey, C. (2000). Sedimentation on the continental rise west of the Antarctic Peninsula over the last three glacial cycles. Marine Geology, 167(3), 313-338.

Pudsey, C. J., \& Camerlenghi, A. (1998). Glacial-interglacial deposition on a sediment drift on the Pacific margin of the Antarctic Peninsula. Antarctic Science, 10(03), 286-308.

Rashid, H., Saint-Ange, F., Barber, D. C., Smith, M., \& Devalia, N. (2012). Fine scale sediment structure and geochemical signature between eastern and western North Atlantic during Heinrich events 1 and 2. Quaternary Science Reviews, 46, 136-150.

Rebesco, M., Pudsey, C., Canals, M., Camerlenghi, A., Barker, P., Estrada, F., \& Giorgetti, A. (2002). Sediment drifts and deep-sea channel systems, Antarctic Peninsula Pacific Margin. Geological Society, London, Memoirs, 22(1), 353-371.

Rebesco, M., Hernández-Molina, F. J., Van Rooij, D., \& Wåhlin, A. (2014). Contourites and associated sediments controlled by deep-water circulation processes: state-of-the-art and future considerations. Marine Geology, 352, 111-154.

Rignot, E., Mouginot, J., Morlighem, M., Seroussi, H., \& Scheuchl, B. (2014). Widespread, rapid grounding line retreat of Pine Island, Thwaites, Smith, and Kohler glaciers, West Antarctica, from 1992 to 2011. Geophysical Research Letters, 41(10), 3502-3509.

Rintoul, S. R. (1998). On the origin and influence of Adélie Land Bottom Water. Ocean, ice, and atmosphere: interactions at the Antarctic continental margin, 151-171.

Rintoul, S. R. (2007). Rapid freshening of Antarctic Bottom Water formed in the Indian and Pacific oceans. Geophysical Research Letters, 34(6).

Rohling, E., Foster, G. L., Grant, K., Marino, G., Roberts, A., Tamisiea, M. E., \& Williams, F. (2014). Sea-level and deep-sea-temperature variability over the past 5.3 million years. Nature, 508(7497), 477-482.

Ruddiman, W, F. (2001). Earth's Climate: Past and Future: Macmillan. 
Russell, J. L., Dixon, K. W., Gnanadesikan, A., Stouffer, R. J., \& Toggweiler, J. (2006). The Southern Hemisphere westerlies in a warming world: Propping open the door to the deep ocean. Journal of Climate, 19(24), 6382-6390.

Ryves, D., Juggins, S., Fritz, S. C., \& Battarbee, R. (2001). Experimental diatom dissolution and the quantification of microfossil preservation in sediments. Palaeogeography, Palaeoclimatology, Palaeoecology, 172(1), 99-113.

Sarmiento, J., \& Toggweiler, J. (1984). A new model for the role of the oceans in determining atmospheric pCO 2. Nature, 308(5960), 621-624.

Scambos, T. A., Hulbe, C., Fahnestock, M., \& Bohlander, J. (2000). The link between climate warming and break-up of ice shelves in the Antarctic Peninsula. Journal of Glaciology, 46(154), 516-530.

Scherer, R., Bohaty, S., Dunbar, R. B., Esper, O., Flores, J. A., Gersonde, R., . . Taviani, M. (2008). Antarctic records of precession-paced insolation-driven warming during early Pleistocene Marine Isotope Stage 31. Geophysical Research Letters, 35(3).

Scherer, R. P., Aldahan, A., Tulaczyk, S., Possnert, G., Engelhardt, H., \& Kamb, B. (1998). Pleistocene collapse of the West Antarctic ice sheet. Science, 281(5373), 82-85.

Shackleton, N. (1974). Attainment of isotopic equilibrium between ocean water and the benthonic foraminifera genus Uvigerina: isotopic changes in the ocean during the last glacial. Cent. Natl. Rech. Sci. Colloq. Int. (1974), pp. 203-209, No. 219.

Shackleton, N., \& Hall, M. (1997). The late Miocene stable isotope record, site 926. Proceedings of the ODP, Scientific Results, vol. 154, Ocean Drilling Program, College Station, TX (1997), pp. 367-373.

Shackleton, N. J., \& Kennett, J. P. (1975). Paleotemperature history of the Cenozoic and the initiation of Antarctic glaciation: oxygen and carbon isotope analyses in DSDP Sites 277, 279, and 281. Initial reports of the deep sea drilling project, 29, 743-755.

Shanmugam, G. (1997). The Bouma sequence and the turbidite mind set. Earth-Science Reviews, 42(4), 201-229.

Shanmugam, G. (2008). Deep-water bottom currents and their deposits. Developments in Sedimentology, 60, 59-81.

Shanmugam, G. (2012). New perspectives on deep-water sandstones: Origin, recognition, initiation, and reservoir quality (Vol. 9): Elsevier.

Shepherd, A., Wingham, D., \& Rignot, E. (2004). Warm ocean is eroding West Antarctic ice sheet. Geophysical Research Letters, 31(23).

Sigman, D. M., Hain, M. P., \& Haug, G. H. (2010). The polar ocean and glacial cycles in atmospheric $\mathrm{CO} 2$ concentration. Nature, 466(7302), 47-55.

Smith Jr, W. O., Sedwick, P. N., Arrigo, K. R., Ainley, D. G., \& Orsi, A. H. (2012a). The Ross Sea in a sea of change. Oceanography, 25, 90-103.

Smith, W. O., Ainley, D. G., Cattaneo-Vietti, R., \& Hofmann, E. E. (2012b). The Ross Sea continental shelf: regional biogeochemical cycles, trophic interactions, and potential future changes. Antarctic ecosystems: an extreme environment in a changing world, 213242.

Somoza, L., Hernández-Molina, F., De Andrés, J., \& Rey, J. (1997). Continental shelf architecture and sea-level cycles: Late Quaternary high-resolution stratigraphy of the Gulf of Cádiz, Spain. Geo-Marine Letters, 17(2), 133-139.

Sorlien, C. C., Luyendyk, B. P., Wilson, D. S., Decesari, R. C., Bartek, L. R., \& Diebold, J. B. (2007). Oligocene development of the West Antarctic Ice Sheet recorded in eastern Ross Sea strata. Geology, 35(5), 467-470. 
Spero, H. J., Bijma, J., Lea, D. W., \& Bemis, B. E. (1997). Effect of seawater carbonate concentration on foraminiferal carbon and oxygen isotopes. Nature, 390(6659), 497500.

Sprenk, D., Weber, M., Kuhn, G., Wennrich, V., Hartmann, T., \& Seelos, K. (2014). Seasonal changes in glacial polynya activity inferred from Weddell Sea varves. Climate of the Past, 10(3), 1239-1251.

St John, K. (2008). Cenozoic ice-rafting history of the central Arctic Ocean: Terrigenous sands on the Lomonosov Ridge. Paleoceanography, 23(1).

St John, K. E., \& Krissek, L. A. (1999). Regional patterns of Pleistocene ice-rafted debris flux in the North Pacific. Paleoceanography, 14(5), 653-662.

Steig, E. J., Ding, Q., Battisti, D., \& Jenkins, A. (2012). Tropical forcing of Circumpolar Deep Water inflow and outlet glacier thinning in the Amundsen Sea Embayment, West Antarctica. Annals of Glaciology, 53(60), 19-28.

Stephens, B. B., \& Keeling, R. F. (2000). The influence of Antarctic sea ice on glacial-interglacial CO 2 variations. Nature, 404(6774), 171-174.

Stow, D. (1985). Deep-sea clastics: where are we and where are we going? Geological Society, London, Special Publications, 18(1), 67-93.

Stow, D., \& Faugères, J.-C. (2008). Contourite facies and the facies model. Developments in Sedimentology, 60, 223-256.

Stow, D., Hernández-Molina, F., Llave, E., Bruno, M., García, M., del Rio, V. D., . . Brackenridge, R. (2013). The Cadiz Contourite Channel: Sandy contourites, bedforms and dynamic current interaction. Marine Geology, 343, 99-114.

Stow, D., \& Piper, D. (1984). Deep-water fine-grained sediments: facies models. Geological Society, London, Special Publications, 15(1), 611-646.

Stow, D. A., Faugères, J.-C., Howe, J. A., Pudsey, C. J., \& Viana, A. R. (2002). Bottom currents, contourites and deep-sea sediment drifts: current state-of-the-art. Geological Society, London, Memoirs, 22(1), 7-20.

Stow, D. A., Faugères, J.-C., Viana, A., \& Gonthier, E. (1998b). Fossil contourites: a critical review. Sedimentary geology, 115(1), 3-31.

Stow, D. A., \& Tabrez, A. R. (1998a). Hemipelagites: processes, facies and model. Geological Society, London, Special Publications, 129(1), 317-337.

Stuart, K., \& Long, D. (2011). Tracking large tabular icebergs using the SeaWinds Ku-band microwave scatterometer. Deep Sea Research Part II: Topical Studies in Oceanography, 58(11), 1285-1300.

Sugden, D. E., Marchant, D. R., \& Denton, G. H. (1993). The case for a stable East Antarctic ice sheet: the background. Geografiska Annaler. Series A. Physical Geography, 151-154.

Teitler, L., Warnke, D. A., Venz, K. A., Hodell, D. A., Becquey, S., Gersonde, R., \& Teitler, W. (2010). Determination of Antarctic Ice Sheet stability over the last 500 ka through a study of iceberg-rafted debris. Paleoceanography, 25(1).

Theissen, K. M., Dunbar, R. B., Cooper, A. K., Mucciarone, D. A., \& Hoffmann, D. (2003). The Pleistocene evolution of the East Antarctic Ice Sheet in the Prydz Bay region: stable isotopic evidence from ODP Site 1167. Global and Planetary Change, 39(3), 227-256.

Thomas, R. H., \& Bentley, C. R. (1978). A model for Holocene retreat of the West Antarctic Ice Sheet. Quaternary research, 10(2), 150-170.

Thompson, D. W., \& Solomon, S. (2002). Interpretation of recent Southern Hemisphere climate change. Science, 296(5569), 895-899.

Toggweiler, J. (1999). Variation of atmospheric CO2 by ventilation of the ocean's deepest water. Paleoceanography, 14(5), 571-588. 
Tripati, A. K., Eagle, R. A., Morton, A., Dowdeswell, J. A., Atkinson, K. L., Bahé, Y., . . Shorttle, O. (2008). Evidence for glaciation in the Northern Hemisphere back to $44 \mathrm{Ma}$ from ice-rafted debris in the Greenland Sea. Earth and Planetary Science Letters, 265(1), 112-122.

Tulaczyk, S., Kamb, B., Scherer, R. P., \& Engelhardt, H. F. (1998). Sedimentary processes at the base of a West Antarctic ice stream: constraints from textural and compositional properties of subglacial debris. Journal of Sedimentary Research, 68(3).

Udden, J. A. (1914). Mechanical composition of clastic sediments. Geological Society of America Bulletin, 25(1), 655-744.

Vanney, J., Falconer, R., \& Johnson, G. (1981). Geomorphology of the Ross Sea and adjacent oceanic provinces. Marine Geology, 41(1), 73-102.

Vaughan, D. G., Marshall, G. J., Connolley, W. M., Parkinson, C., Mulvaney, R., Hodgson, D. A., . . . Turner, J. (2003). Recent rapid regional climate warming on the Antarctic Peninsula. Climatic change, 60(3), 243-274.

Vautravers, M., \& Hillenbrand, C. (2008). Deposition of planktonic forminifera on the Pacific margin of the Antarctic Peninsula (ODP Site 1101) during the last 1 Myr. Paper presented at the Geophysical Research Abstracts.

Viana, A., \& Faugères, J.-C. (1998). Upper slope sand deposits: the example of Campos Basin, a latest Pleistocene-Holocene record of the interaction between alongslope and downslope currents. Geological Society, London, Special Publications, 129(1), 287-316.

Villa, G., Lupi, C., Cobianchi, M., Florindo, F., \& Pekar, S. (2008). A Pleistocene warming event at 1 Ma in Prydz Bay, East Antarctica: evidence from ODP site 1165. Palaeogeography, Palaeoclimatology, Palaeoecology, 260(1), 230-244.

Wåhlin, A., Kalén, O., Arneborg, L., Björk, G., Carvajal, G., Ha, H. K., . . . Stranne, C. (2013). Variability of warm deep water inflow in a submarine trough on the Amundsen Sea shelf. Journal of Physical Oceanography, 43(10), 2054-2070.

Warner, N. R., \& Domack, E. W. (2002). Millennial-to decadal-scale paleoenvironmental change during the Holocene in the Palmer Deep, Antarctica, as recorded by particle size analysis. Paleoceanography, 17(3).

Webb, P., Harwood, D., McKelvey, B., Mercer, J., \& Stott, L. D. (1984). Cenozoic marine sedimentation and ice-volume variation on the East Antarctic craton. Geology, 12(5), 287291.

Weber, M., Clark, P., Kuhn, G., Timmermann, A., Sprenk, D., Gladstone, R., . . Chikamoto, M. (2014). Millennial-scale variability in Antarctic ice-sheet discharge during the last deglaciation. Nature, 510(7503), 134-138.

Weber, M. E., Clark, P. U., Ricken, W., Mitrovica, J. X., Hostetler, S. W., \& Kuhn, G. (2011). Interhemispheric ice-sheet synchronicity during the Last Glacial Maximum. Science, 334(6060), 1265-1269.

Weedon, G. P. (2003). Time-series analysis and cyclostratigraphy: examining stratigraphic records of environmental cycles: Cambridge University Press.

Weltje, G. J., \& Tjallingii, R. (2008). Calibration of XRF core scanners for quantitative geochemical logging of sediment cores: theory and application. Earth and Planetary Science Letters, 274(3), 423-438.

Wentworth, C. K. (1922). A scale of grade and class terms for clastic sediments. The Journal of Geology, 30(5), 377-392.

Whitworth, T., \& Orsi, A. (2006). Antarctic Bottom Water production and export by tides in the Ross Sea. Geophysical Research Letters, 33(12).

Whitworth, T., Orsi, A., Kim, S. J., Nowlin, W., \& Locarnini, R. (1998). Water masses and mixing near the Antarctic Slope Front. Ocean, ice, and atmosphere: interactions at the Antarctic continental margin, 1-27. 
Williams, T., \& Handwerger, D. (2005). A high-resolution record of early Miocene Antarctic glacial history from ODP Site 1165, Prydz Bay. Paleoceanography, 20(2).

Williams, T., van de Flierdt, T., Hemming, S. R., Chung, E., Roy, M., \& Goldstein, S. L. (2010). Evidence for iceberg armadas from East Antarctica in the Southern Ocean during the late Miocene and early Pliocene. Earth and Planetary Science Letters, 290(3), 351-361.

Wise, S. W. (2000). The Antarctic Ice Sheet: Rise and Demise? Journal of Land Use \& Environmental Law, 15(2), 383-422.

Woodard, S. C., Rosenthal, Y., Miller, K. G., Wright, J. D., Chiu, B. K., \& Lawrence, K. T. (2014). Antarctic role in Northern Hemisphere glaciation. Science, 346(6211), 847-851.

Zachos, J., Pagani, M., Sloan, L., Thomas, E., \& Billups, K. (2001). Trends, rhythms, and aberrations in global climate $65 \mathrm{Ma}$ to present. Science, 292(5517), 686-693.

Zachos, J. C., Dickens, G. R., \& Zeebe, R. E. (2008). An early Cenozoic perspective on greenhouse warming and carbon-cycle dynamics. Nature, 451(7176), 279-283.

Zhang, Y. G., Pagani, M., Liu, Z., Bohaty, S. M., \& DeConto, R. (2013). A 40-million-year history of atmospheric CO2. Phil. Trans. R. Soc. A, 371(2001), 20130096. 


\section{Appendices}

Appendix A: High-resolution stratigraphic logs with lithological descriptions

RS15-LC42 166

RS15-GC46 167

RS15-LC47 168

RS15-LC48 170

The following appendices are attached on Disc 1:

Appendix B: IRD counts of $x$-ray images.

Appendix C: Grain size data and statistics.

Appendix D: Paleomagnetic age models.

Appendix $\mathrm{E}:$ IRD, $\mathrm{CaCO}_{3}$ and $\mathrm{BiSi}$ MAR calculations.

Appendix F: Correlation of RS15-LC42 and PS58/254 magnetic susceptibility records. 


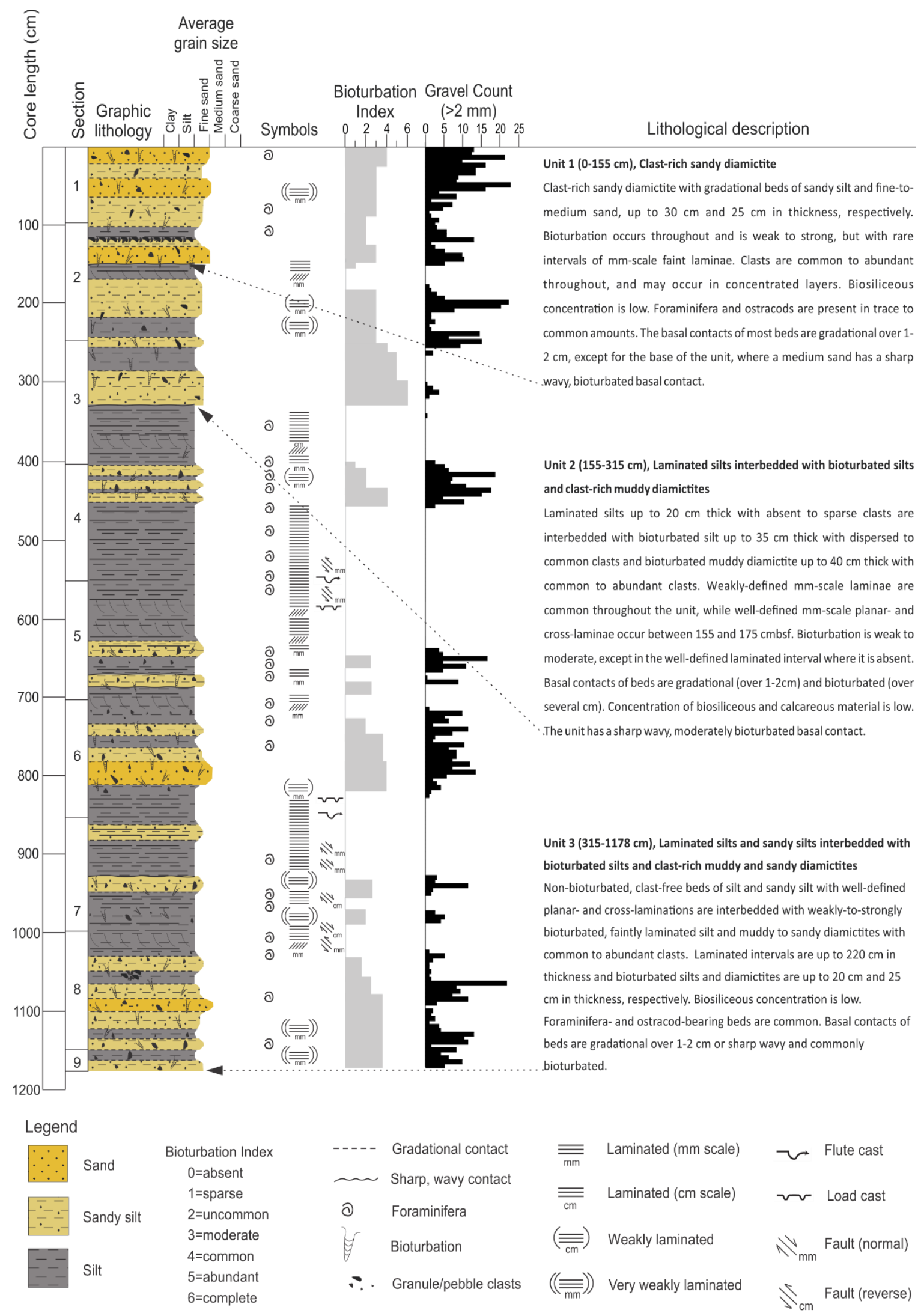




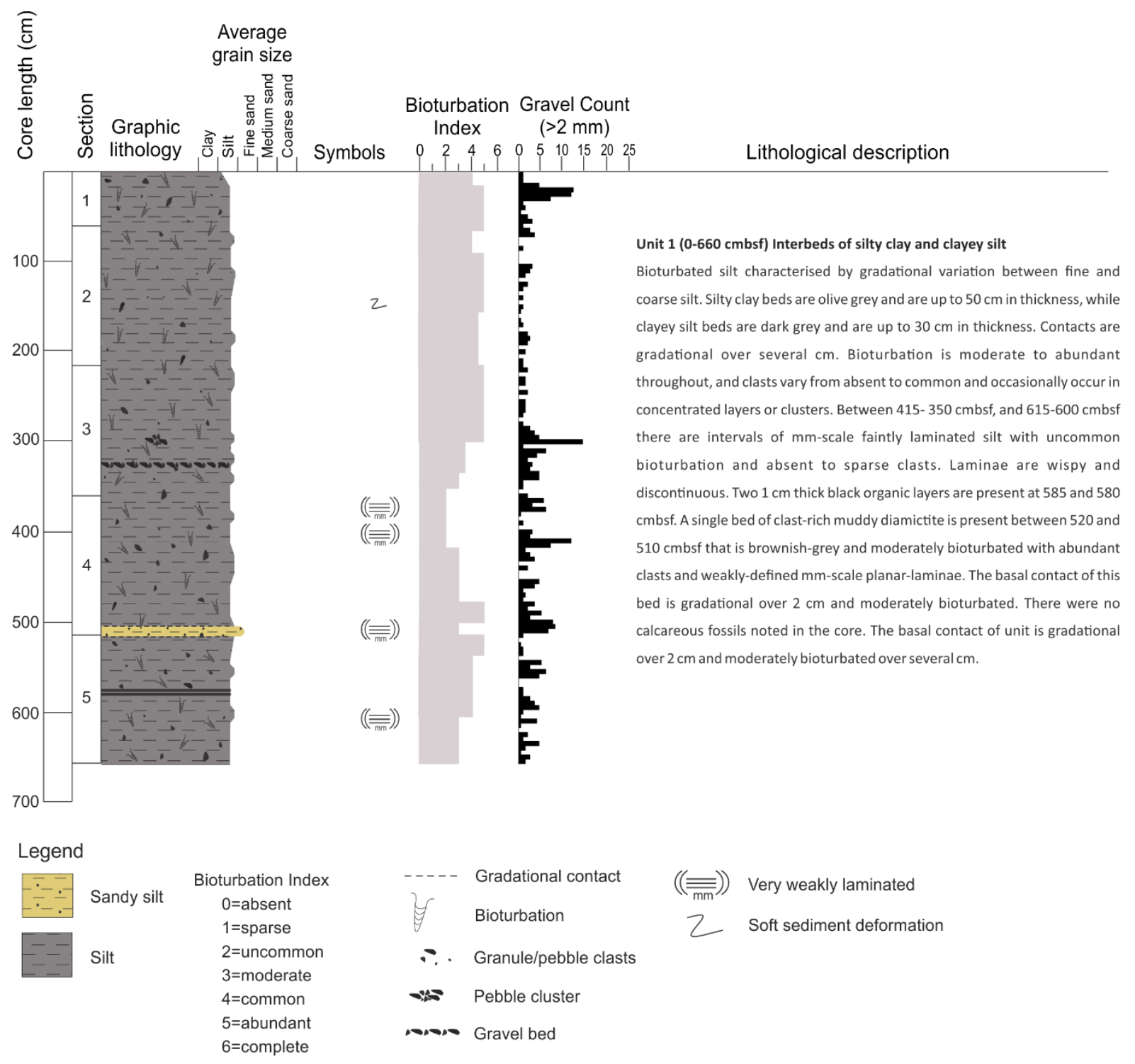




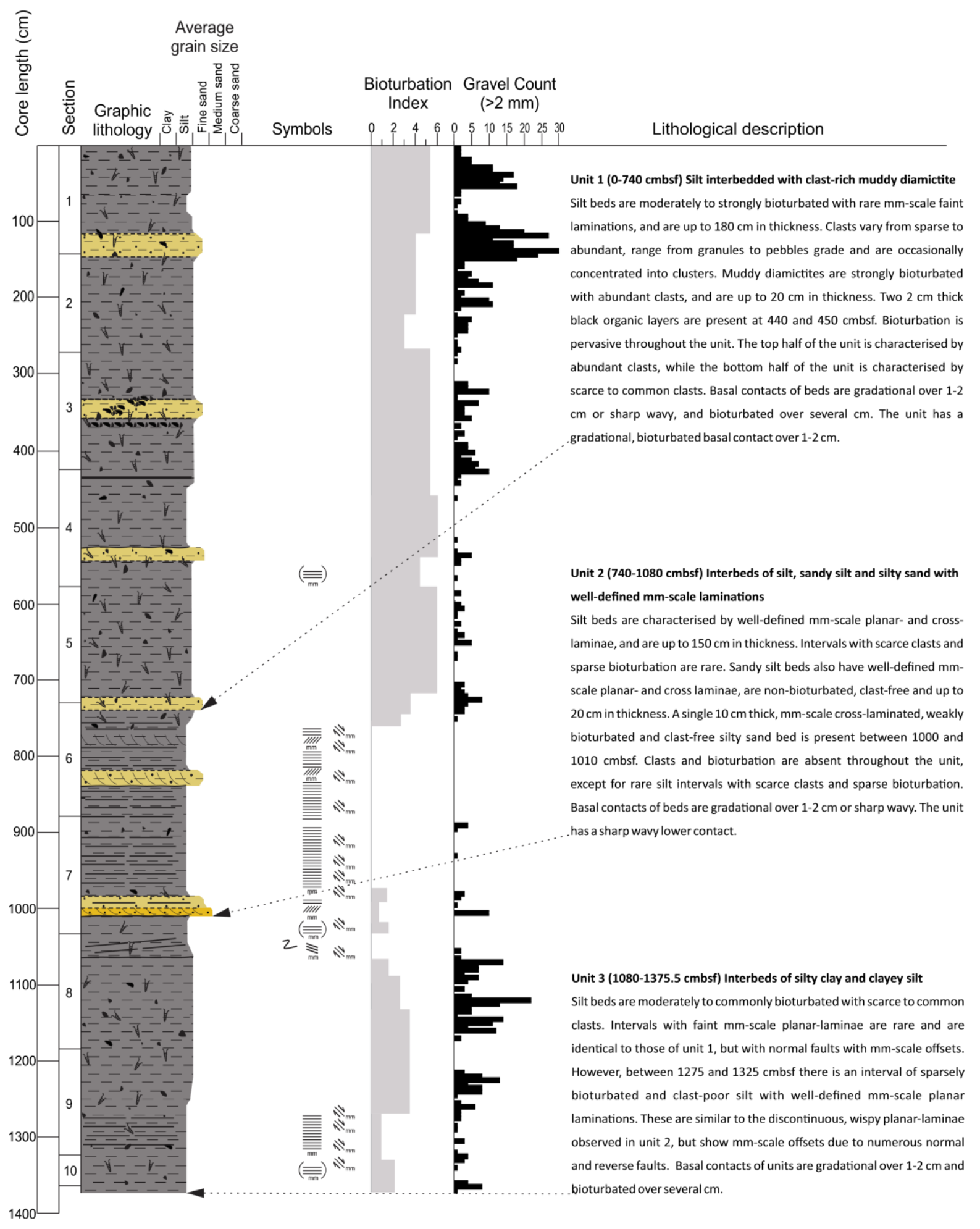




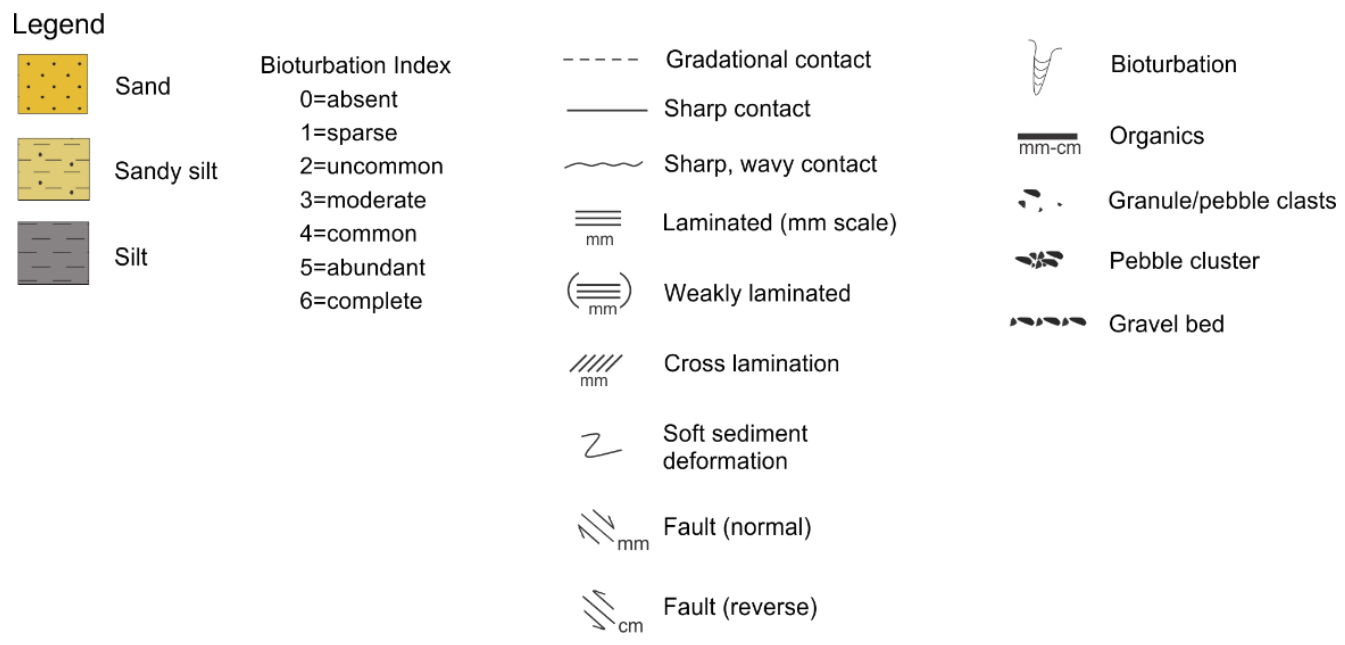




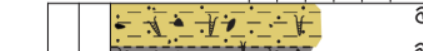

100

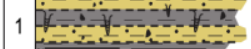

1.

2 $1-\div=$

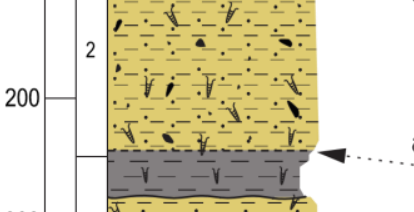

3
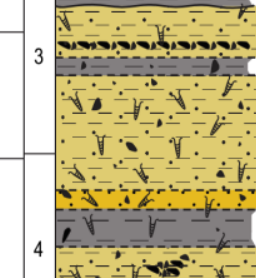

$30-10$
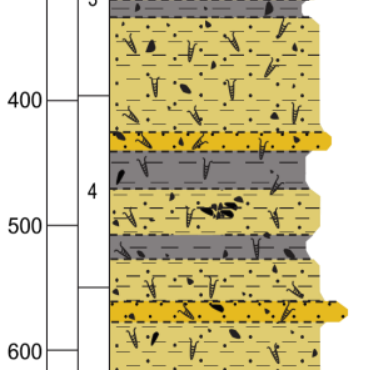

6

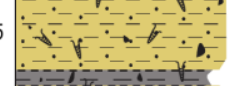

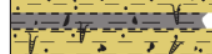

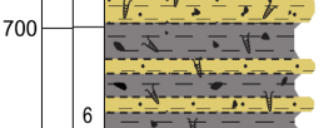

$800 \square+2$

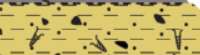
$\therefore \forall-1$

$900+7$

$-t^{2}-1=0$

$2-2.2 .5$

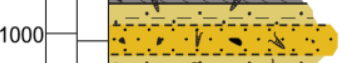

$=-5 x=$

1.:-

8 -

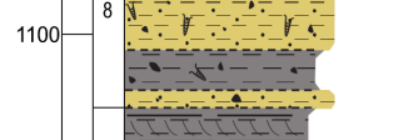

12

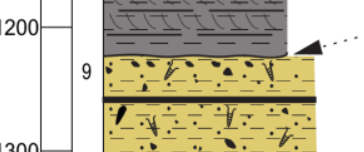

1300 $\sqrt{-0} \div$ 1400 $\therefore=i$. and $x=c$ $11 \div 2=$
(輀)

$((\equiv))$
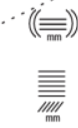

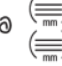

$2 \overline{\overline{\text { IIII }}} \cdot \sqrt{\mathrm{m}} \cdot$

v

$((\overline{\overline{(\bar{m}}}))$

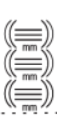

Symbols $\quad 0 \quad \begin{array}{lllllllll}0 & 4 & 6 & 0 & 5 & 10 & 15 & 20 & 25\end{array}$

Lithological description

Unit $1(0-240 \mathrm{~cm})$, Clast-rich muddy diamictites interbedded with silt

Clast-rich muddy diamictites with moderate to abundant bioturbation are up to $100 \mathrm{~cm}$ in thickness, and are interbedded with silt beds up to $40 \mathrm{~cm}$ in thickness, which are either moderately bioturbated with common to abundant clasts, or faintly laminated with absent to sparse clasts. Between 90 and $100 \mathrm{cmbsf}$, there is a silt bed with very sparse bioturbation and welldefined mm-scale planar- and cross-laminae. Biosiliceous content is low. Foraminifera and ostracods are common. Basal contacts of units are gradational and bioturbated over several $\mathrm{cm}$ or sharp wavy. The lower contact of the unit is gradational and bioturbated over several $\mathrm{cm}$.

Unit 2 (240-944 cm), Weakly laminated silt interbedded with clast-rich muddy and sandy diamictites

Silt beds with moderate to abundant bioturbation, faint $\mathrm{mm}$-scale laminations and common to abundant clasts are up to $30 \mathrm{~cm}$ in thickness. These are interbedded with clast-rich muddy and sandy diamictites with moderate to abundant bioturbation that are up to $80 \mathrm{~cm}$ and $20 \mathrm{~cm}$ in thickness, respectively. Clasts are abundant throughout the unit and range from granules to pebbles grade, and occasionally occur in concentrated clusters or layers. Bioturbation is pervasive through the entire unit. Calcareous and biosiliceous content is low. Basal contacts of beds are gradational and bioturbated over several $\mathrm{cm}$, with the exception of a sharp wavy, bioturbated contact at $285 \mathrm{cmbsf}$. Lower contact of the unit is gradational and bioturbated over several $\mathrm{cm}$.

Unit $3(944-1220 \mathrm{~cm})$, Laminated silt interbedded with clast-rich muddy and sandy diamictites

Silt beds with well-defined mm-scale laminations and absent to scarce clasts are up to $55 \mathrm{~cm}$ in thickness and are interbedded with clast-rich, moderately bioturbated muddy and sandy diamictites up to 50 and $15 \mathrm{~cm}$ in thickness, respectively. Bioturbation is absent in the laminated silt beds and is sparse to moderate in the muddy and sandy diamictites, which contain rare intervals of $\mathrm{mm}$-scale faint laminae. Calcareous and biosiliceous content is low. Basal contacts of beds are gradational and bioturbated over several $\mathrm{cm}$, with the exception of a sharp weakly bioturbated contact at $985 \mathrm{cmbsf}$. Lower contact of unit is sharp wavy.

Unit 4 (1220-1472 cm), Clast-rich muddy diamictites interbedded with weakly laminated silt

Clast-rich, moderately to strongly bioturbated muddy diamictites are interbedded with weakly laminated silt with common to abundant clasts. Muddy diamictites are up to $180 \mathrm{~cm}$ in thickness and are identical to those described in units 1,2 and 3 , with rare $\mathrm{mm}$-scale faint laminations and a 2 $\mathrm{cm}$ thick black organic layer at $1260 \mathrm{cmbsf}$. Silt beds are up to $20 \mathrm{~cm}$ in thickness and are identical to those described in unit 2. Bioturbation is moderate to strong and clasts are common to abundant throughout the unit. Biosiliceous and calcareous content is low. Basal contacts of beds are gradational and bioturbated over several $\mathrm{cm}$. 
Legend

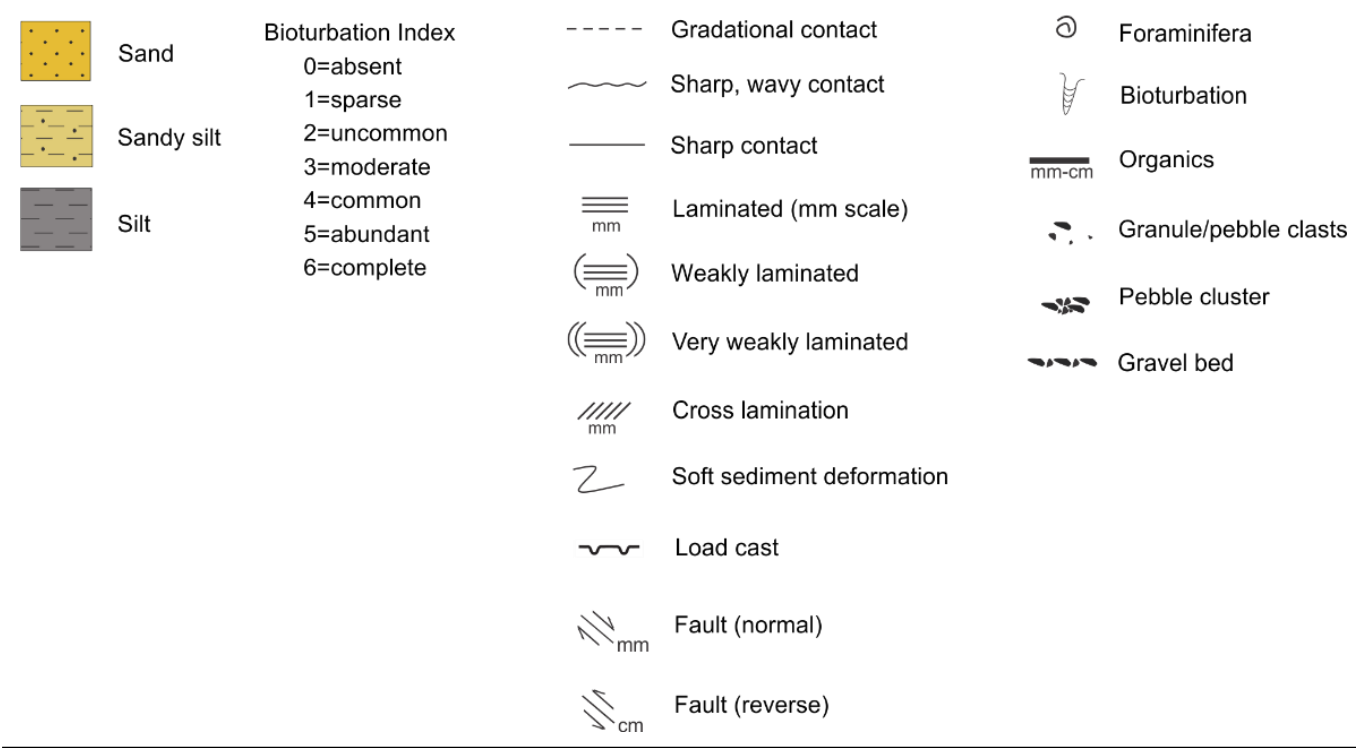

